\title{
Velocity Modelling and
}

\section{Earthquake Relocation in}

\author{
the Rotorua and Kawerau
}

Geothermal Areas,

\section{Taupo Volcanic Zone,}

New Zealand

Daniel Clarke

A thesis submitted to

Victoria University of Wellington

in partial fulfilment of the

requirements for the degree of

Master of Science

in Geophysics.

Victoria University of Wellington

2008 



\begin{abstract}
We analyse catalogued phase arrival times and seismograms from two sets of earthquakes that occurred in and around the Rotorua and Kawerau geothermal systems in the Taupo Volcanic Zone, New Zealand. These data sets contain 504 and 1875 shallow ( $\leq 20 \mathrm{~km}$ deep) earthquakes, respectively, and span the 21 year period between the beginning of 1984 and the end of 2004 .

We use arrival time data from these earthquakes to calculate reliable 1-D P- and S-wave seismic velocity models and accompanying station correction terms for Rotorua and Kawerau. These models are well constrained at depths of 4 to $15 \mathrm{~km}$ and are consistent with models obtained in seismic refraction studies for the same region.

Using a combination of precise cross-correlation-derived and cataloguebased arrival times, we calculate accurate hypocentres for 155 and 400 earthquakes in Rotorua and Kawerau, respectively. These hypocentres are far less scattered than those in the earthquake catalogue. In Rotorua, the earthquakes cluster near the geothermally active parts of Rotorua City and also beneath the Mount Ngongotaha rhyolite dome. In Kawerau, the earthquakes align along northeast-trending lineations, consistent with the predominant alignment of faults within the region. Earthquakes in Okataina caldera to the southwest of Kawerau are tightly clustered, particularly beneath Puhipuhi Hill.
\end{abstract}


We use cross-correlation to identify clusters of earthquakes in Rotorua and Kawerau based on the similarity of their recorded seismograms. Apart from two clusters in the northern part of Rotorua City, these are generally indicative of relatively short-lived bursts of activity within these regions. We compute composite focal mechanisms for four of these clusters, all of which indicate rupture on normal faults, consistent with the extensional tectonic regime of the Taupo Volcanic Zone. 


\section{Acknowledgements}

First, I wish to gratefully acknowledge my supervisors: John Townend and Martha Savage, who have guided me throughout the course of this study. I humbly thank them for sharing their competence, patience and enthusiasm with me, and for showing me that geophysics is a relevant and exciting field of science. I am also grateful to Stephen Bannister and Steven Sherburn who have selflessly shared their experience and expertise during numerous discussions throughout this study.

Sincere thanks to the researchers at GNS Science who have willingly offered support and advice at various stages of this investigation. Specifically, I am grateful for the help of Tony Hurst, Ken Gledhill, Mark Chadwick and Russell Robinson, who have generously shared their time and expert perspectives with me. Special thanks also to many of the staff and students at Victoria university of Wellington who have contributed to this study. I particularly thank Todd Nicholson and Wanda Stratford for their constructive thoughts and suggestions. Thanks also to Mighty River Power for their kind hospitality and for providing me with useful information to help me with this project.

I gratefully acknowledge the New Zealand GeoNet project and its spon- 
sors EQC, GNS Science and FRST, for providing the earthquake data used in this study. I am particularly grateful for the kind service provided by Kevin Fenaughty who promptly extracted earthquake arrival time data and seismograms at my request. Thanks also to the EQC Research Foundation who provided funding for this project (grant UNI/508, "Seismicity in Taupo Volcanic Zone geothermal systems").

Special thanks to those authors whose software has been freely available for use in this study. These packages include GMT (Paul Wessel and Walter Smith), Velest (Edi Kissling), hypoDD (Felix Waldhauser and William Ellsworth), BCSeis (Wayne Du and Cliff Thurber), HaSh (Jeanne Hardebeck and Peter Shearer), and Focmec (Arthur Snoke). Thanks, too, to Ralph Wahrlich for maintaining the computers on which these programs were run.

Sincere and heartfelt thanks to those who have shared an office with me during the course of this study. Special thanks to Suzannah Toulmin and Anya Seward for always being supportive and helpful. Thanks also to Louise Christie, Bronwyn O'Keefe, Nastasja Scholz and Jonathan Crook who have always been available to offer advice and who have made my time as a postgraduate student an enjoyable one. 


\section{Contents}

Abstract

Acknowledgements iv

1 Introduction 1

1.1 Motivation . . . . . . . . . . . . . . . . 1

1.2 Tectonic setting . . . . . . . . . . . . . . . 4

1.3 Seismicity in the $\mathrm{TVZ} \ldots \ldots \ldots \ldots$

1.4 Rotorua . . . . . . . . . . . . . . . . . 8

1.5 Kawerau . . . . . . . . . . . . . . . . . . . . 10

1.6 Goals . . . . . . . . . . . . . . . . . . . . . 12

2 Data and analysis $\quad 15$

2.1 Method overview . . . . . . . . . . . . . . 15

2.2 Data ........................... 16

2.2.1 Seismograph networks . . . . . . . . . . 16

2.2.2 Rotorua earthquakes . . . . . . . . . . . . . . 19

2.2.3 Kawerau earthquakes . . . . . . . . . . . . . 19

2.3 Methods of analysis . . . . . . . . . . . . . . 24 
2.3.1 1-D velocity model estimation . . . . . . . . . . 24

2.3.2 Waveform cross-correlation . . . . . . . . . . 26

2.3.3 Double-difference earthquake relocation . . . . . . . . . 29

2.3.4 Earthquake clustering and focal mechanism determi-

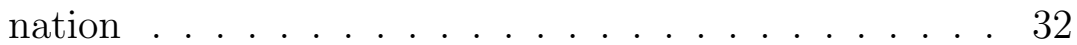

3 1-D velocity model estimation 35

3.1 Introduction . . . . . . . . . . . . . . . . 35

3.2 Earthquake selection . . . . . . . . . . . . . . 36

3.3 Outline of procedure . . . . . . . . . . . . . . 38

3.4 P-wave velocity model . . . . . . . . . . . . . . . . 41

3.4.1 Initial velocity models . . . . . . . . . . . . . . 41

3.4.2 Control parameters ............... 43

3.4 .3 Results..................... . . 44

3.4.4 Alternative models . . . . . . . . . . . . . . 52

$3.5 \mathrm{P}-$ and S-wave velocity model . . . . . . . . . . . . . 59

3.5.1 Earthquake selection . . . . . . . . . . . 59

3.5.2 Initial velocity models . . . . . . . . . . . . . 59

3.5.3 Control parameters . . . . . . . . . . . . 62

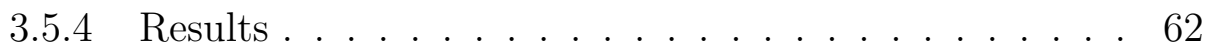

3.5.5 Discussion . . . . . . . . . . . . . . . 72

3.6 Summary . . . . . . . . . . . . . . . 76

4 Double-difference relocation $\quad 79$

4.1 Introduction . . . . . . . . . . . . . . . . . 79

4.2 Waveform cross-correlation . . . . . . . . . . . . . 80 
4.2.1 Cross-correlation method . . . . . . . . . . . 80

4.2 .2 Data . . . . . . . . . . . . . . 82

4.2.3 Tests of control parameters . . . . . . . . . . 83

4.2.4 Cross-correlation results . . . . . . . . . . . . 92

4.3 Double-difference earthquake relocation . . . . . . . . . . . . . 95

4.3.1 Double-difference location method . . . . . . . . . . 95

4.3.2 Data selection . . . . . . . . . . . . . . 95

4.3.3 Velocity models . . . . . . . . . . . . . . . . 96

4.3.4 Data weighting . . . . . . . . . . . 97

4.3.5 Inversion method and earthquake linkage . . . . . . . 106

4.3.6 Final locations . . . . . . . . . . . . . . . . . 114

4.4 Summary . . . . . . . . . . . . . . . . . . . . 118

$\begin{array}{llr}5 & \text { Spatiotemporal analysis } & 121\end{array}$

5.1 Introduction . . . . . . . . . . . . . . . . . . 121

5.2 Earthquake clustering . . . . . . . . . . . . . . . . . . 121

5.2.1 Earthquake clustering method . . . . . . . . . . . . 122

5.2.2 Rotorua earthquake clusters . . . . . . . . . . . 126

5.2.3 Kawerau earthquake clusters . . . . . . . . . . . . . 131

5.2 .4 Summary . . . . . . . . . . . . . . . . . 138

5.3 Focal mechanism determination . . . . . . . . . . . . . . 140

5.3.1 Focal mechanism method . . . . . . . . . . . . . . 141

5.3.2 Focal mechanism results . . . . . . . . . . . . . . 143

5.4 Summary . . . . . . . . . . . . . . . . . 146 
6 Discussion and conclusions 147

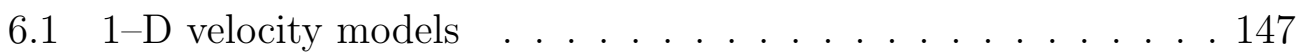

6.2 Double-difference relocation . . . . . . . . . . . . . 150

6.2.1 Waveform cross-correlation . . . . . . . . . . 150

6.2.2 Double-difference earthquake relocation . . . . . . . . 151

6.3 Spatiotemporal analysis . . . . . . . . . . . . . 153

6.3.1 Earthquake clustering . . . . . . . . . 153

6.3.2 Focal mechanism determination . . . . . . . . 155

6.4 Conclusions . . . . . . . . . . . . . . . 157

$\begin{array}{ll}\text { Appendices } & 173\end{array}$

A 1-D velocity model estimation 173

B Double-difference relocation $\quad 181$ 


\section{List of Figures}

1.1 The Taupo Volcanic Zone . . . . . . . . . . . . . . . . . . 6

1.2 Rotorua . . . . . . . . . . . . . . . . . . 9

1.3 Kawerau . . . . . . . . . . . . . . . . . . . . . . 11

2.1 Seismograph networks . . . . . . . . . . . . . . . . 18

2.2 Seismograph availability . . . . . . . . . . . . . 20

2.3 Rotorua earthquake catalogue . . . . . . . . . . . . . . . 21

2.4 Kawerau earthquake catalogue . . . . . . . . . . . . . . . . 23

2.5 How cross-correlation finds delay times . . . . . . . . . . . . 28

2.6 Similar ray paths from nearby earthquakes . . . . . . . . . 31

3.1 The Rotorua P-wave modelling earthquake set . . . . . . . . . 39

3.2 The Kawerau P-wave modelling earthquake set . . . . . . . . . 40

3.3 Random P-wave models . . . . . . . . . . . . . . . . . . . . . 42

3.4 Velocity histograms for Rotorua . . . . . . . . . . . . 46

3.5 Velocity histograms for Kawerau . . . . . . . . . . . . . 47

3.6 RMS coloured velocity models for Rotorua . . . . . . . . . . . 48

3.7 RMS coloured velocity models for Kawerau . . . . . . . . . . . 49 
3.8 Velest locations for the Rotorua P-wave modelling earthquake

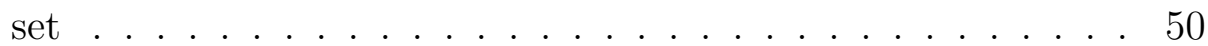

3.9 Velest locations for the Kawerau P-wave modelling earthquake

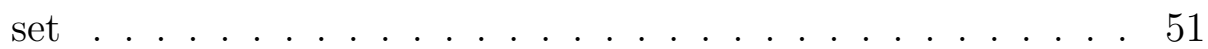

3.10 P-wave station corrections for Rotorua . . . . . . . . . . 53

3.11 P-wave station corrections for Kawerau . . . . . . . . . . . . 54

3.12 Earthquake selection test results for Rotorua . . . . . . . . . 57

3.13 Earthquake selection test results for Kawerau . . . . . . . . . 58

3.14 Initial locations for the Rotorua P- and S-wave velocity modelling earthquake set . . . . . . . . . . . . 6 60

3.15 Initial locations for the Kawerau P- and S-wave velocity modelling earthquake set . . . . . . . . . . . . . 61

3.16 Random P- and S-wave models . . . . . . . . . . . . 63

3.17 P- and S-wave velocity histograms for Rotorua . . . . . . . . 65

3.18 P- and S-wave velocity histograms for Kawerau . . . . . . 66

3.19 RMS coloured P- and S-wave velocity models for Rotorua . . . 67

3.20 RMS coloured P- and S-wave velocity models for Kawerau . . 68

3.21 Velest locations for the Rotorua P- and S-wave velocity modelling earthquake set . . . . . . . . . . . 70

3.22 Velest locations for the Kawerau P- and S-wave velocity modelling earthquake set . . . . . . . . . . . 71

3.23 S-wave station corrections for Rotorua . . . . . . . . . . 73

3.24 S-wave station corrections for Kawerau . . . . . . . . . . . 74

3.25 Seismic refraction and reflection profile for the TVZ . . . . 76 
4.1 Cross-correlation time windows . . . . . . . . . . . . 81

4.2 Earthquake test subsets . . . . . . . . . . . . . 84

4.3 Lower frequency limit test . . . . . . . . . . . . . . 85

4.4 Lower frequency limit test results . . . . . . . . . . . . 86

4.5 Upper frequency limit test . . . . . . . . . . . . . 87

4.6 Upper frequency limit test results . . . . . . . . . . . . . 88

4.7 Coefficient matrices for the Rotorua test set . . . . . . . . . . 91

4.8 Seismograms realigned using cross-correlation . . . . . . . . . 92

4.9 Cross-correlation summary . . . . . . . . . . . . . . . . 94

4.10 Cross-correlation double-difference residual distributions . . . 103

4.11 Catalogue double-difference residual distributions . . . . . . . 104

4.12 Cross-correlation double-difference residuals versus distance . . 107

4.13 Catalogue double-difference residuals versus distance . . . . . 108

4.14 Distance weighting functions for hypoDD . . . . . . . . . . 109

4.15 Cross-correlation linkage for relocatable Rotorua earthquakes . 111

4.16 Cross-correlation linkage for relocatable Kawerau earthquakes 112

4.17 Damping parameters for hypoDD . . . . . . . . . . 113

4.18 HypoDD locations for Rotorua . . . . . . . . . . . . . . . 115

4.19 HypoDD locations for Kawerau . . . . . . . . . . . . . . 116

4.20 Earthquake locations found using different inversion methods . 117

4.21 Earthquake occurrence versus time . . . . . . . . . . . . . 119

5.1 Tests of clustering thresholds for Rotorua and Kawerau . . . . 125

5.2 Clustered Rotorua epicentres . . . . . . . . . . . . . . . . . 128

5.3 Seismograms for clustered Rotorua earthquakes . . . . . . . . 129 
5.4 The largest Rotorua cluster . . . . . . . . . . . . . . . . 132

5.5 The second largest Rotorua cluster . . . . . . . . . . . . 133

5.6 The Mount Ngongotaha cluster . . . . . . . . . . . . . . . 134

5.7 Clustered Kawerau epicentres . . . . . . . . . . . . . . . 135

5.8 Seismograms for clustered Kawerau earthquakes . . . . . . . . 136

5.9 The southern Okataina cluster . . . . . . . . . . . . . 137

5.10 The Kawerau cluster . . . . . . . . . . . . . . . . . . . . . 138

5.11 The northern Okataina cluster . . . . . . . . . . . . . . . 139

5.12 Focal mechanism solutions . . . . . . . . . . . . . . . . . . 144

5.13 Map of focal mechanism solutions . . . . . . . . . . . . 145

A.1 Earthquake quality indicators for Rotorua . . . . . . . . . . . 174

A.2 Earthquake quality indicators for Kawerau . . . . . . . . . 175

A.3 Model resolution and covariance for Rotorua . . . . . . . . . . 176

A.4 Model resolution and covariance for Kawerau . . . . . . . . . . 177

A.5 Velocity models with low velocity layers allowed . . . . . . . 178

A.6 Constant starting models for Rotorua . . . . . . . . . . . . . 179

A.7 Constant starting models for Kawerau . . . . . . . . . . . . . 180

B.1 Wadati diagram for Rotorua . . . . . . . . . . . . . . . 182

B.2 Wadati diagram for Kawerau . . . . . . . . . . . . . . 183 


\section{List of Tables}

2.1 Phase pick qualities for Rotorua and Kawerau . . . . . . . . . 22

3.1 Earthquake selection criteria for P-wave velocity inversions . . 38

3.2 GeoNet qualities and Velest weights . . . . . . . . . . . 44

3.3 Earthquake selection criteria tested for Rotorua and Kawerau 55

3.4 Final 1-D P- and S-wave velocity models for Rotorua . . . . . 69

3.5 Final 1-D P- and S-wave velocity models for Kawerau . . . . . 69

4.1 Distribution of S- minus P-wave arrival times . . . . . . . . . 89

4.2 Differential travel time data for hypoDD . . . . . . . . . 96

4.3 Velocity models used by hypoDD . . . . . . . . . . . . 98

4.4 GeoNet qualities and weights for hypoDD . . . . . . . . . . 99

4.5 A priori weights for hypoDD . . . . . . . . . . . . . . 100

5.1 Location scatter in the largest Rotorua earthquake cluster . . 131

5.2 Focal Mechanism summary and final solutions . . . . . . . . . 143 


\section{Chapter 1}

\section{Introduction}

\subsection{Motivation}

Geothermal systems are excellent natural laboratories for the investigation of fault slip and seismicity in shallow crustal environments: fluctuations in temperature and fluid pressure are able to act as earthquake triggers within geothermal systems (Sibson and Rowland, 2003). As a result, the analysis of seismicity within geothermal fields can provide insight into subsurface structure and seismogenic processes in these environments.

The amount of shear stress required for a fault to rupture is directly proportional to the normal stress it is subjected to. This relationship can be expressed as follows:

$$
\tau=\mu\left(\sigma_{n}-P_{f}\right)
$$

Here, $\tau$ is the amount of shear stress required for failure to occur, $\sigma_{n}$ is the tectonic stress (positive for compression) perpendicularly incident on the 
fault, $P_{f}$ is the pore fluid pressure and $\mu$ is the coefficient of friction (Hubbert and Rubey, 1959). The two terms in parentheses constitute the total normal stress acting on the fault at any time. In cases where the shear stress is close to, but does not exceed $\tau$, the fault is said to be "critically stressed", and failure occurs when either the tectonic shear stress increases or the total normal stress on the fault decreases. Critically stressed faults are common in continental crust at seismogenic depths (Townend and Zoback, 2000). If the pore fluid pressure $P_{f}$ is increased in a critically stressed fault, the total normal stress decreases and an earthquake can be triggered. Moreover, the failure of a fault may temporarily increase its permeability (Sibson and Rowland, 2003), encouraging fluids to propagate along it, triggering more earthquakes along the way. This results in a sequence of seismicity whose spatial and temporal evolution can delineate zones of relatively high permeability along which fluids can propagate.

Human activity influences fluid pressure in geothermal systems. For example, hot fluids from the geothermal system at Rotorua have been used for domestic and recreational purposes for much of the last century (Scott et al., 2005). This resulted in a loss of fluid pressure followed by an increase in pressure after restrictions to the amount of fluid being removed were imposed in the 1980s (Scott et al., 2005). The geothermal system at Kawerau has been exploited for electricity production since the mid 1950s. As a result, a drawdown in fluid pressure of $\sim 0.1 \mathrm{MPa}$ has been observed. In addition, waste-fluids used for electricity production have been reinjected into the geothermal system since 1991 (Bignall and Harvey, 2005).

The correlation between induced changes in fluid pressure and increased 
levels of seismicity is well documented and usually involves the injection of fluids generating overpressures of the order of several MPa at depth (e.g. Allis et al., 1985; Stark, 1990; Evans et al., 2005). Such changes in pressure are much greater than the static stress changes of the order of $0.1 \mathrm{MPa}$ which trigger earthquakes along faults during mainshock-aftershock sequences of seismicity (Harris, 1998).

Several studies of seismicity have illuminated structure and hydrothermal processes within geothermal systems. Prejean et al. (2002) relocated $\sim 45,000$ earthquakes in the Long Valley caldera region, California using the same relative relocation technique (Waldhauser and Ellsworth, 2000) we apply in this study. The accurate hypocentres obtained by Prejean et al. (2002) delineate a number of faults that were previously indiscernible in routinely calculated and archived earthquake locations. By comparing the alignment of relocated hypocentres with the nodal planes of focal mechanisms for the largest of these earthquakes, Prejean et al. (2002) were able to distinguish the fault planes on which these earthquakes ruptured, and found that the manner in which they slipped was controlled primarily by the tectonics of the region rather than local geothermal processes. Prejean et al. (2002) were also able to trace the propagation of a high pressure transient (magmatically derived fluids) by analysing the diffusion-like migration of triggered earthquakes within the Caldera.

Lippitsch et al. (2005) undertook a similar investigation of small earthquakes in the Torfajökul volcanic system in Iceland. Using probabilistic relocation techniques (NonLinLoc, Lomax et al., 2000), relative relocation techniques and a $1-\mathrm{D}$ velocity model determined in a way similar to that 
described in Chapter 3, Lippitsch et al. (2005) were able to determine accurate hypocentres for $\sim 100$ earthquakes in the region, and found that these earthquakes occurred almost exclusively within the geothermal system.

Rowe et al. (2004) relocated $\sim 4000$ earthquakes near the Soufriere Hills volcano, Montserrat and found that the hypocentres for these events were confined to a volume 100 times smaller than indicated by the original locations. The challenges confronted by Rowe et al. (2004) are similar to those we expect to face for our Rotorua and Kawerau earthquake sets as their earthquakes were recorded on a small network of mainly vertical-component seismographs.

\section{$1.2 \quad$ Tectonic setting}

The New Zealand region forms part of the boundary between the Australia and Pacific tectonic plates. Within New Zealand, this boundary is manifest as three distinct tectonic environments. In the southwestern part of the South Island, the Australia plate subducts beneath the Pacific plate, forming the steeply eastward-dipping Puysegur subduction zone (e.g., Lamarche and Lebrun, 2000). North of this, the transpressive Alpine fault runs $900 \mathrm{~km}$ (e.g., Sutherland et al., 2006) along the western side of the South Island. Further north is the obliquely-westward dipping Hikurangi subduction zone, which lies to the east of the North Island. Here the Pacific plate subducts beneath the overriding Australia plate at $43 \mathrm{~mm} / \mathrm{yr}$ (Beavan et al., 2002).

The Central Volcanic Region is situated in the central part of the North Island (Figure 1.1). It is a backarc environment associated with the Hikurangi 
subduction zone (Figure 1.1) and is subject to northwest-southeast extension (Darby and Meertens, 1995) caused by the rotation of much of the North Island (Wallace et al., 2004). This may be due to variations in coupling along the strike of the Hikurangi margin (Reyners, 1998; Wallace et al., 2004). The Taupo Volcanic Zone (TVZ) occupies the southern and eastern boundaries of the broader wedge-shaped Central Volcanic Region, and is defined by the loci of the most recent two million years of active volcanism therein (Wilson et al., 1995). Consequently, The TVZ is characterised by a thinned crust (Stratford and Stern, 2006), very high heat flow $\left(700 \mathrm{~mW} / \mathrm{m}^{2}\right.$, Bibby et al., 1995), and extensive volcanism and geothermal activity (Wilson et al., 1995).

Volcanism within the Taupo Volcanic Zone is generally andesitic in nature near its northern and southern extremities (Wilson et al., 1995). The central part of the TVZ, however, is predominantly rhyolitic, erupting an average of $0.28 \mathrm{~m}^{3}$ of rhyolite per second over the past $0.34 \mathrm{Myr}$ (Wilson et al., 1995), chiefly via catastrophic eruptions as evidenced by several collapse calderas and associated ignimbrite sheets. Interspersed throughout these calderas are at least 20 distinct geothermal systems (Bibby et al., 1995). These are delineated by surficial hydrothermal features such as geysers and hot springs, and also by electrical resistivity mapping (Bibby et al., 1995). Although some geothermal fields seem to be associated with collapse calderas, such a relationship is not always the case and any apparent correlation between the distributions of the two types of features may be coincidental (Bibby et al., 1995). 


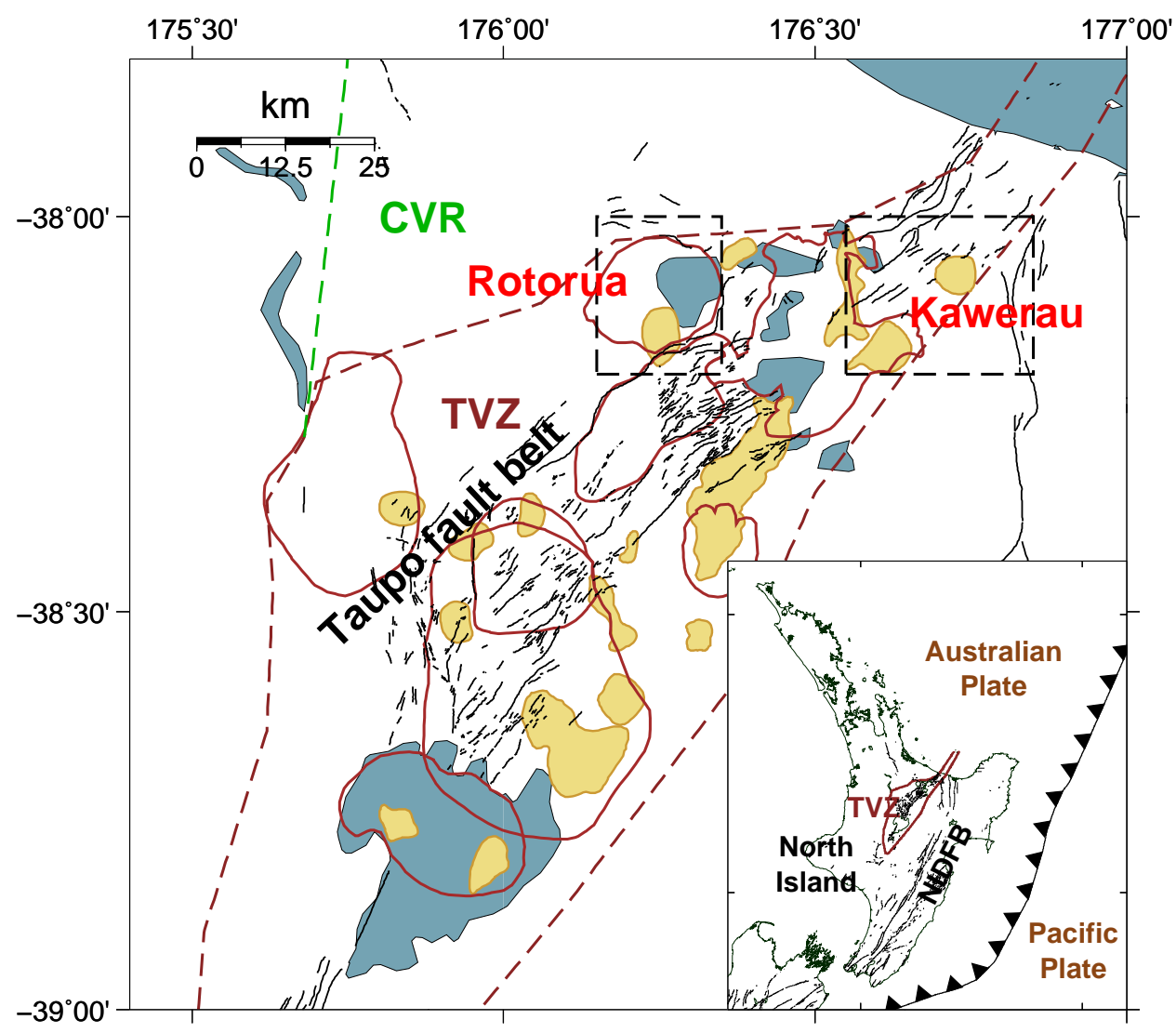

Figure 1.1: The central Taupo Volcanic Zone (TVZ, dashed brown lines). The dashed green line marks the western boundary of the Central Volcanic Region (CVR). Thermal areas are coloured yellow. Black lines are faults. Solid brown lines border calderas. Dashed black boxes surround Rotorua and Kawerau. The inset shows the location of the TVZ in the North Island and the convergent boundary (ticked line) between the Australian and Pacific tectonic plates. Black lines mark faults. NIDFB is the North Island Dextral Fault Belt. 


\subsection{Seismicity in the Taupo Volcanic Zone}

There are two primary loci of seismicity beneath the TVZ. The first of these is the subducting oceanic crust of the Pacific plate. Deep earthquakes beneath the TVZ delineate the deep westward-dipping structure of the slab as it subducts beneath the Australia plate under the central North Island. In addition, numerous shallow crustal earthquakes also occur in the TVZ. These earthquakes tend to occur in spatiotemporally distinct swarms (Sherburn, 1992) along the central axis and the eastern side of the region (Bryan et al., 1999). Focal depths for these earthquakes rarely exceed 10 km (Bryan et al., 1999), indicating the depth to the transition between brittle and ductile deformation is relatively shallow. This transition has been interpreted to coincide with the maximum depth to which convective cells of circulating hydrothermal fluids penetrate beneath the TVZ (Bibby et al., 1995).

The focal mechanisms that have been determined for shallow earthquakes in the TVZ tend to be normal with a small dextral strike-slip component, assuming they occur on the predominantly northeast trending faults of the Taupo fault belt (e.g. Richardson, 1989; Robinson, 1989; Hurst et al., 2002). These focal mechanisms are consistent with the extensional tectonic regime of the central North Island inferred from geodetic measurements (Darby and Meertens, 1995; Wallace et al., 2004). These focal mechanisms, however, exhibit various directions of strike, indicating the faults on which earthquakes rupture in the TVZ are not restricted to the predominant northeastsouthwest trend of the Taupo fault belt (Hurst et al., 2002).

The most significant earthquake to occur during the past few decades 
in the TVZ is the Edgecumbe earthquake of 1987. This event had a local magnitude of 6.3 and ruptured near the coast of the Bay of Plenty, just north of Kawerau (Anderson et al., 1990). More than 100 aftershocks were recorded for this event, with hypocentres aligning in a broad, $65 \mathrm{~km}$-long northeast-trending zone (Robinson, 1989). Focal mechanisms for the Edgecumbe earthquake and its subsequent aftershocks are also normal (Anderson et al., 1990), consistent with the extensional tectonic regime of the central North Island (Wallace et al., 2004).

\subsection{Rotorua}

The Rotorua geothermal system (Figure 1.1, 1.2) is an elongate northwardstriking feature that occupies $18-28 \mathrm{~km}^{2}$ (Allis and Lumb, 1992) of the northwestern part of the Taupo Volcanic Zone. With an estimated natural heat flow of around $430 \mathrm{MW}$ (Allis and Lumb, 1992) it is one of the more powerful geothermal systems in the region (Bibby et al., 1995). The Rotorua geothermal system lies astride the southern boundary of Rotorua Caldera, a roughly circular, $20 \mathrm{~km}$ wide structure that collapsed following the $140 \mathrm{ka}$ eruption of Mamaku ignimbrite (Wood, 1992). This caldera hosts another smaller geothermal system in the eastern part of Lake Rotorua (Bibby et al., 1992).

Attempts to investigate the subsurface structure of the Rotorua area have achieved varying levels of success. Most faults are buried and their locations are generally inferred from the loci of surficial hydrothermal features or shallow drilled ignimbrite offsets in the geothermal field (Wood, 1992). Lamarche 


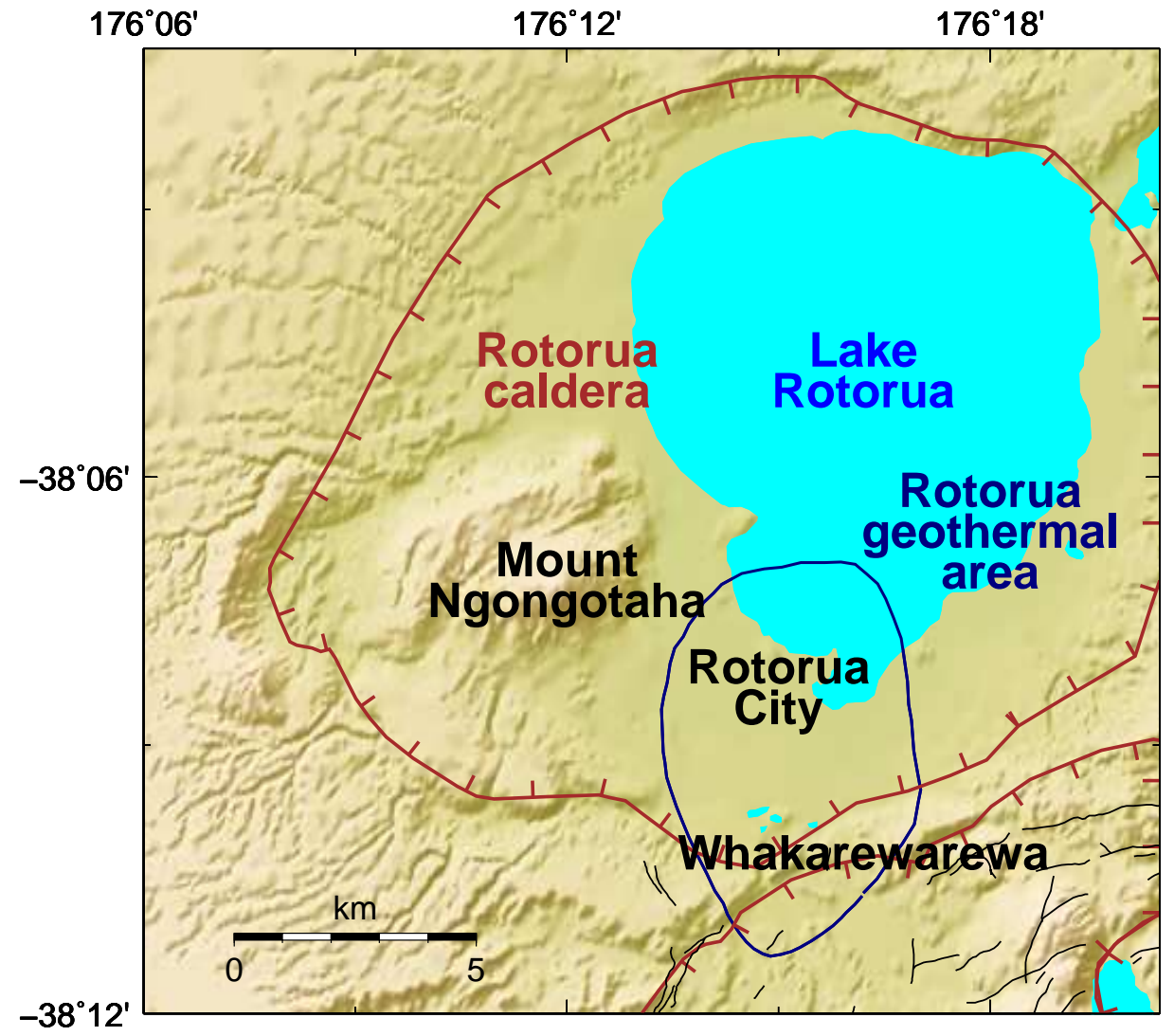

Figure 1.2: The Rotorua geothermal field (dark blue line) and its environs. The brown hachured line borders Rotorua caldera. Thin black lines are faults.

(1992) used seismic reflection data to image the subsurface structure of the geothermal field to a depth of $500 \mathrm{~m}$. Despite their results being complicated by the effects of reverberations and cultural and environmental noise, Lamarche (1992) was able to image a series of faults at the southern boundary of Rotorua caldera. Hunt (1992) used gravity surveying methods to determine the density structure of Rotorua caldera and found that anomalously high density features exist below Rotorua City. Based on drillhole data in this area, these are interpreted to be two buried rhyolite domes aligned north 
to south beneath Rotorua City.

With increased exploitation of thermal waters in the Rotorua geothermal field between the 1920s and the 1980s, fluid pressures were observed to decrease within the area and the discharge of hydrothermal water from vents at the surface waned and in some cases ceased altogether (Allis and Lumb, 1992). To preserve the economic and cultural value of the geothermal field, restrictions were imposed to limit the amount of water being removed from the system in 1986 (Scott et al., 2005). Since then fluid pressures have gradually risen and the discharge of fluids from vents at the surface has increased and in many cases recommenced (Scott et al., 2005). Puzzlingly, despite this recovery, the Rotorua area has subsided at a rate of up to $13 \mathrm{~mm} / \mathrm{yr}$ in the southern part of the field between 1996 and 2000 (Hole et al., 2005).

\subsection{Kawerau}

The Kawerau geothermal field (Figure 1.3) is situated in the more seismically active and younger eastern side of the TVZ (Wilson et al., 1995). This geothermal field is roughly circular and covers an area of $19-35 \mathrm{~km}^{2}$, although its surficial manifestations span an area of only about half this size (Allis, 1997). Unlike the Rotorua geothermal field, the Kawerau geothermal field is not located in or on any calderas, with the nearest being the Okataina caldera around $10 \mathrm{~km}$ to the southwest. The hydrothermal features of the Kawerau geothermal field are not as spectacular as those in the Rotorua area, with a much smaller energy output of only 100 MW (Bibby et al., 1995).

The Kawerau geothermal field is located at the eastern boundary of the 


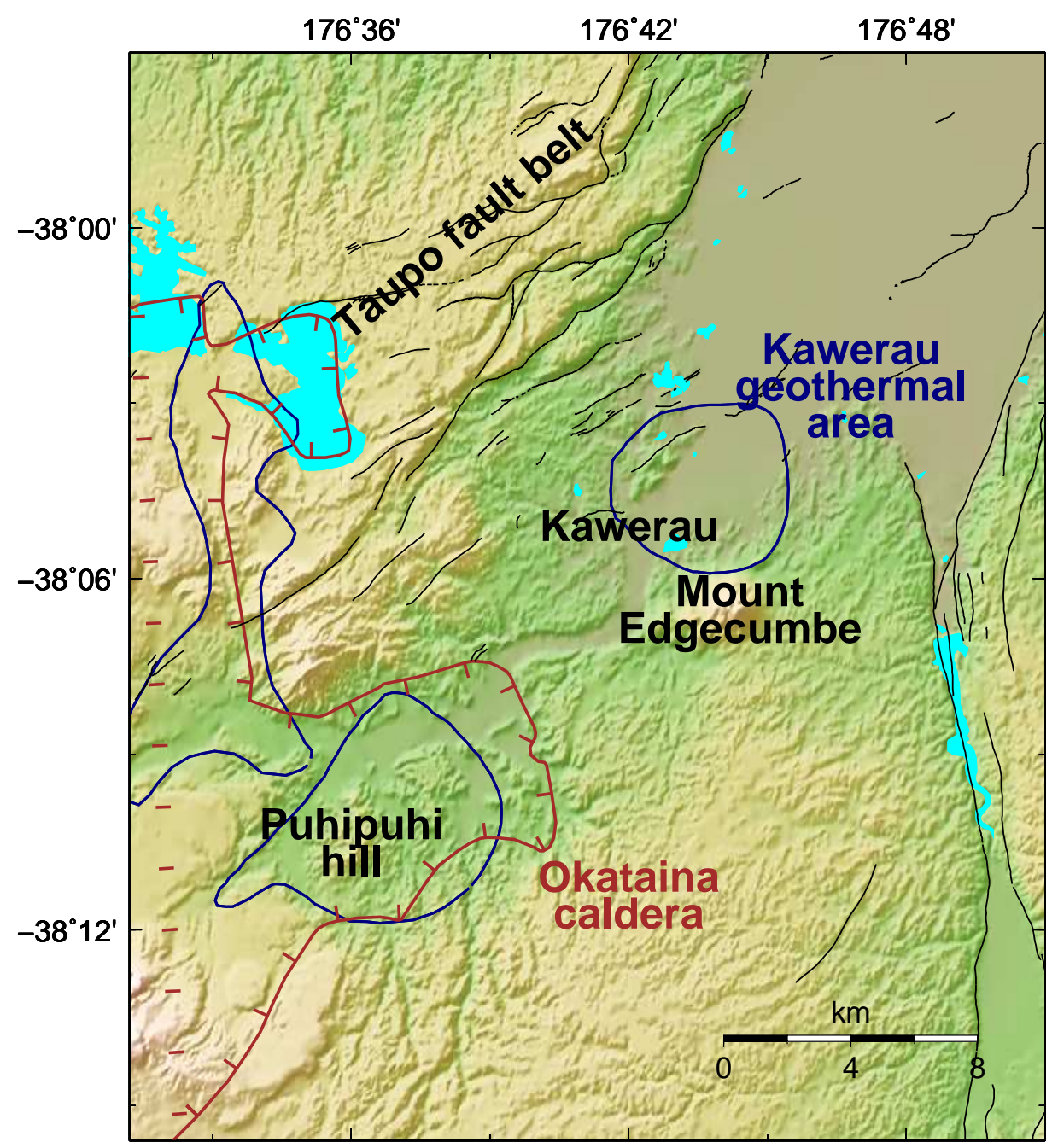

Figure 1.3: The Kawerau geothermal field and its environs. Dark blue lines surround thermal areas. The brown hachured line borders Okataina caldera. Thin black lines are faults. 
TVZ, between the normal northeast-trending faults of the Taupo fault belt to the west (Villamor and Berryman, 2001) and the northward striking strikeslip faults of the North Island dextral fault belt to the east. Within the Kawerau geothermal field, the basement is buried by volcanic material and sediments to a depth of around $1 \mathrm{~km}$ (Wood et al., 2001) and slopes downward from south to north. Attempts have been made to determine the faulting geometry in these basement rocks based on contoured drillhole data, but their orientation is the subject of ongoing controversy (Wood et al., 2001; Bignall and Harvey, 2005).

Steam from the Kawerau geothermal field has been exploited since 1957 for the production of power for a nearby paper mill and, more recently, for large scale electricity production. As in Rotorua, fluid pressures represented by the elevation of flowing hot springs have declined, resulting in surface deformation in the region with up to $30 \mathrm{~mm} / \mathrm{yr}$ of subsidence centred in a $10 \mathrm{~km}^{2}$ area in the northern part of the field (Allis, 1997).

\subsection{Goals}

In this study we aim to calculate accurate hypocentres for earthquakes that have occurred in the Rotorua and Kawerau geothermal fields. This is achieved through the use of seismic velocity profiles we obtain using earthquake arrival time data, and a relative relocation procedure that utilises the precise travel times we measure using waveform cross-correlation of earthquake seismograms.

We also aim to examine the spatial and temporal distribution of earth- 
quakes in Rotorua and Kawerau. Specifically, we determine clusters of similar earthquakes based on the similarity of their P-wave seismograms and attempt to calculate composite focal mechanisms for them. We attempt to interpret the distribution of clustered earthquake hypocentres and focal mechanisms in the context of known faults and stress orientations in the region. By examining the timing and comparing the alignment of relocated earthquake hypocentres with faults and geological structures in Rotorua and Kawerau, we aim to gain insight into the processes that cause earthquakes in these two active geothermal regions. 


\section{Chapter 2}

\section{Data and analysis}

\subsection{Method overview}

This section provides an overview of the steps we take to obtain reliable earthquake location and source parameters for events that occurred in and around the Rotorua and Kawerau geothermal areas.

The first goal of this study is to calculate accurate hypocentres for well recorded earthquakes in each region. To do this, we focus on techniques that minimise the influence that two major sources of uncertainty have on our resolved images of seismicity: uncertainty in phase arrival time data and unmodelled velocity structure.

To address the the effects of poorly known velocity structure, we produce one dimensional (1-D) seismic velocity models for each region (Chapter 3) using the joint hypocentre-velocity model inversion algorithm Velest (Kissling et al., 1994). In Chapter 4, the effects of unmodelled velocity structure are further accounted for through the application of the relative earthquake 
location procedure HypoDD (Waldhauser and Ellsworth, 2000).

Waveform cross-correlation is used to reduce the amount of error in our P- and S-wave arrival time catalogues. Precise travel time differences are estimated by finding where the cross-correlation function is maximised between pairs of seismograms (Chapter 4).

Having calculated reliable locations for earthquakes in Rotorua and Kawerau, our focus shifts to characterizing their occurrence in space and time, and determining the nature of their sources (Chapter 5).

Each set of earthquakes are split into clusters of events with similar locations and source mechanisms. Cross-correlation provides a measure of similarity between pairs of earthquakes, so we apply hierarchical clustering to the correlation results. Families of similar events are defined using an empirically determined correlation threshold above which events are grouped together and below which they are not.

We analyse the spatial and temporal occurrence of the relocated and clustered events. Our analysis is aided by the focal mechanisms we obtain by grouping together first motion polarity observations within clusters of earthquakes.

\subsection{Data}

\subsubsection{Seismograph networks}

The earthquakes that are archived in the GeoNet catalogue have been recorded on a growing network of seismograph stations located throughout the New 
Zealand region (Figure 2.1). In the Taupo Volcanic Zone (TVZ), shortperiod National Network seismometers (red squares) are accompanied by local networks of short-period vertical-component instruments (green triangles). These networks are centred around regions of seismological and volcanological interest such as Mount Ruapehu and the Rotorua area in the central Taupo Volcanic Zone (dark green triangles). Earthquake arrival time and velocity seismogram data used in this study were primarily recorded on Rotorua Network and National Network seismograms (large symbols).

Figure 2.2 shows the number of seismograph stations in operation versus time near the Rotorua and Kawerau geothermal areas. Only stations that appear in the earthquake data set described in Sections 2.2.2 and 2.2.3 are shown. The colour of each line indicates the distance from each station to the Rotorua or Kawerau geothermal areas (whichever is nearest). A histogram of shallow ( $\leq 20 \mathrm{~km}$ deep) earthquake occurrence in these regions is also plotted. These plots show that the growth in the number of seismograph stations in operation is accompanied by an increase in the rate of seismicity that is recorded in Rotorua and Kawerau. This trend is particularly evident in the latter half of 1993, when a small increase in the number of close (less than 10 $\mathrm{km})$ stations is accompanied by a significant increase in the rate of seismicity that is recorded. The deployment of dense arrays of temporary seismographs (white triangles in Figure 2.1) in 1995 and 2001 are coincident with notable increases in the number of earthquakes that are recorded. The most striking feature of Figure 2.2 is the large burst of seismicity observed during the first half of 1987. These earthquakes are likely to be associated with the $\mathrm{M}_{L} 6.3$ Edgecumbe earthquake that ruptured in the Bay of Plenty in March that year 


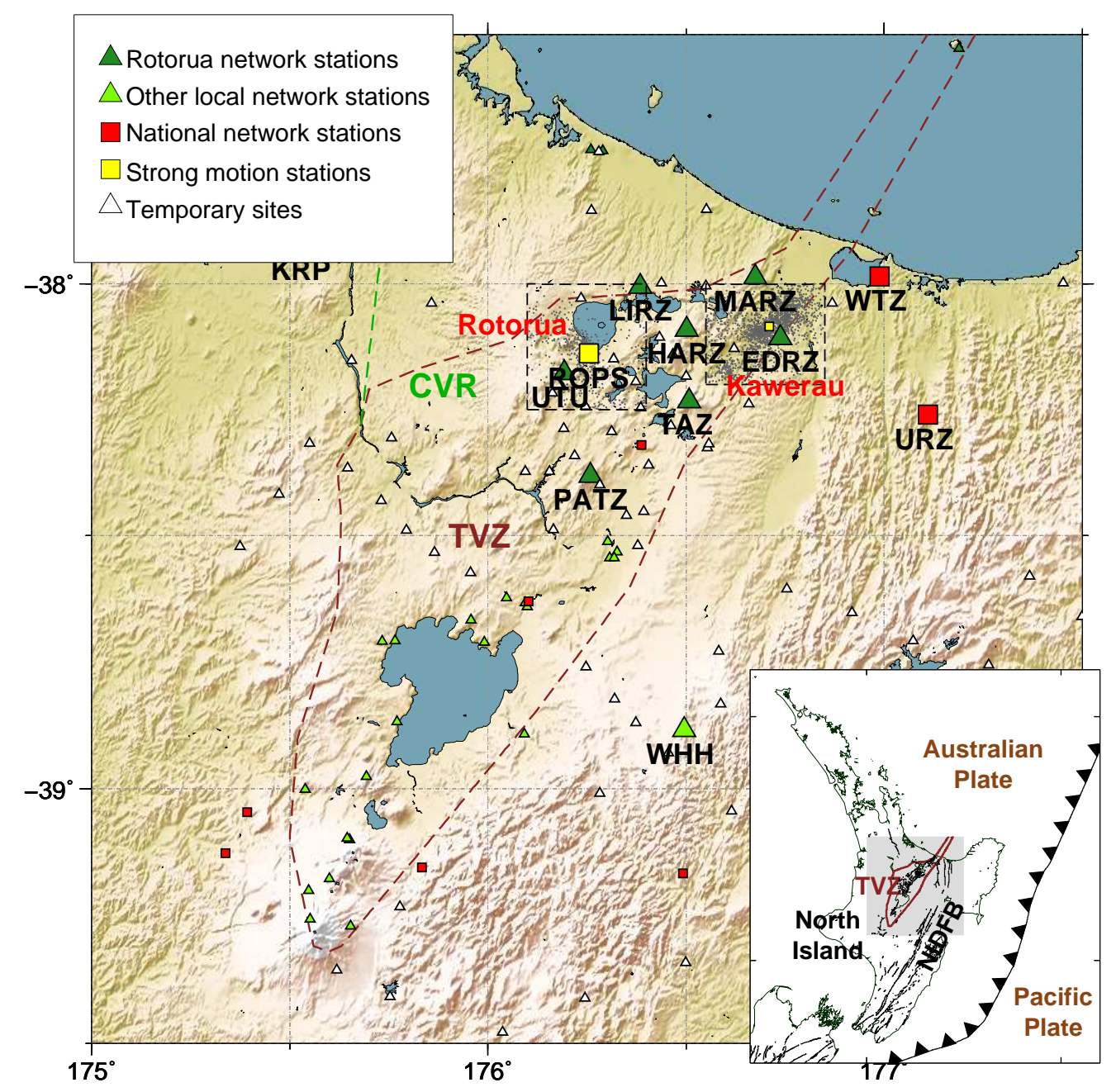

Figure 2.1: Map showing the location of seismograph sites around Rotorua and Kawerau. Large, named symbols mark stations with more than 200 observations from the two earthquake sets. TVZ is the Taupo Volcanic Zone and CVR the Central Volcanic Region. The inset shows the location of the TVZ in the North Island and its proximity to the convergent boundary (ticked line) between the Australian and Pacific tectonic plates. Black lines mark faults. NIDFB is the North Island Dextral Fault Belt. 
(Robinson, 1989). The Kawerau area is included in the northeast-trending zone delineated by the aftershocks that followed that event (Robinson, 1989).

\subsubsection{Rotorua earthquakes}

The first set of earthquakes we consider occurred beneath the Rotorua geothermal area and its environs. Using the Quake Search facility of the GeoNet earthquake catalogue, we select earthquakes with archived latitudes between $-38.20^{\circ}$ and $-38.00^{\circ}$, longitudes between $176.15^{\circ}$ and $176.35^{\circ}$ and focal depths of $20 \mathrm{~km}$ or less. We restrict our search to earthquakes that ruptured between 1984 and 2004 inclusive. The resulting earthquake set (Figure 2.3) consists of 504 events, with local magnitudes ranging between 1.4 and 4.7. Many of these earthquakes had their depths fixed at 2, 5 or $12 \mathrm{~km}$ depths during the routine location process. This is why there appear to be streaks of seismicity in the profiles in Figure 2.3 at these depths.

We obtain phase arrival time data for these earthquakes from the GeoNet archive. These data sets consist of 4167 arrival time picks, 1411 (34\%) of which are S-wave arrival times. We also obtain 6411 archived velocity seismograms for these earthquakes.

\subsubsection{Kawerau earthquakes}

The second set of earthquakes we consider ruptured in and around the Kawerau geothermal area. Again we only consider earthquakes that occurred between 1984 and 2004. This time, earthquakes with archived latitudes between $-38.20^{\circ}$ and $-38.00^{\circ}$, longitudes between $176.55^{\circ}$ and $176.85^{\circ}$ and focal 

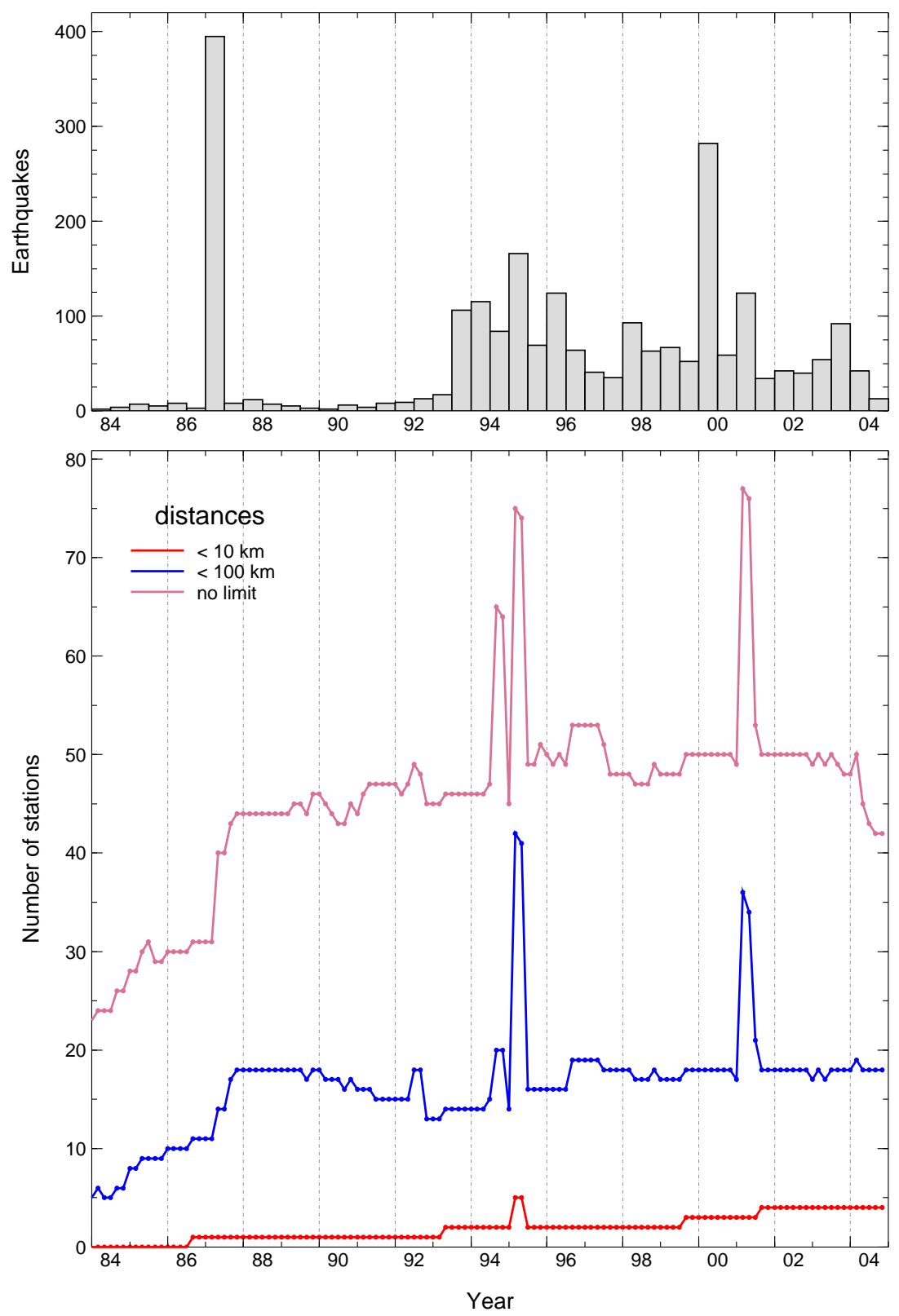

Figure 2.2: Number of seismograph stations recording earthquakes in Kawerau and Rotorua versus time. The bottom panel shows when the 173 stations in the Rotorua and Kawerau phase catalogues were operating between 1984 and 2004. Colours are (red) stations within $10 \mathrm{~km}$ of Rotorua or Kawerau, (blue) stations within $100 \mathrm{~km}$ of Rotorua or Kawerau, and (salmon) all stations. The top panel is a histogram of observed earthquake occurrence in Rotorua and Kawerau during the same period. The spike in the first half of 1987 coincides with the $M_{L} 6.3$ Edgecumbe earthquake (Robinson, 1989). 


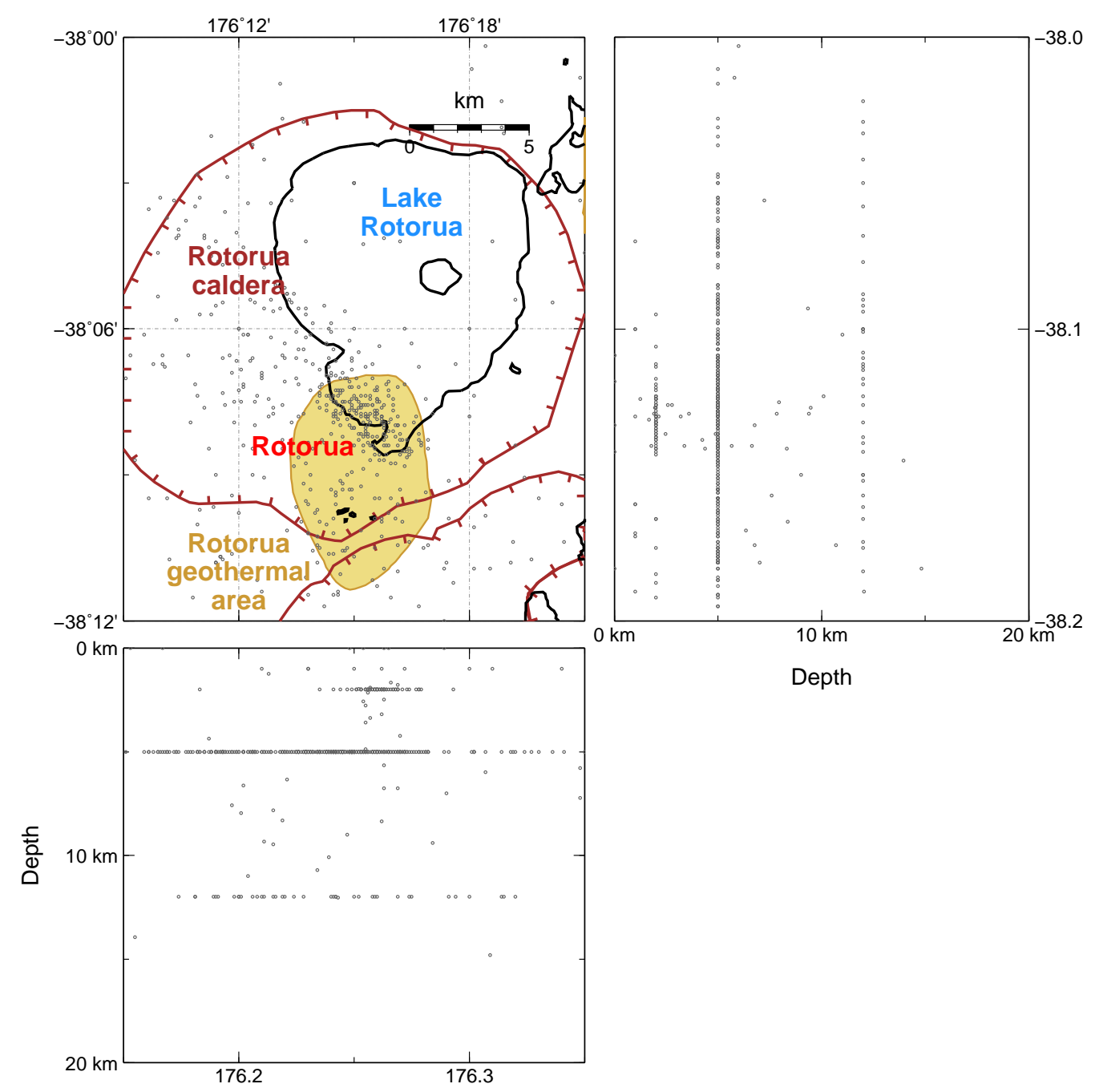

Figure 2.3: 504 catalogue locations for Rotorua earthquakes. The two depth sections are $\mathrm{E}-\mathrm{W}$ and $\mathrm{N}-\mathrm{S}$ profiles onto which all the seismicity has been projected. The yellow area is the Rotorua geothermal system. Rotorua caldera is bordered by the brown hachured line. Black lines mark lake boundaries. Note that the focal depths recorded in the catalogue are generally fixed during the hypocentre calculation at 2,5 or $12 \mathrm{~km}$. 
depths of $20 \mathrm{~km}$ or less (Figure 2.4) are selected. Using these criteria we find 1875 earthquakes in the catalogue, with local magnitudes between 0.4 and 5.0 .

The phase arrival time data obtained from the GeoNet archive for these earthquakes consist of 14463 arrival time picks, 4886 (34\%) of which are S-wave arrival times. We obtain 18644 seismograms for the Kawerau earthquake set.

When phase arrival times are routinely estimated, an analyst assigns a quality to each arrival time pick. These qualities range between zero for the most certain picks to four for more emergent and uncertain phase onsets. The amount of arrival times in the Rotorua and Kawerau data sets with each assigned quality are listed in table 2.1. Most of the arrival time picks in the Rotorua and Kawerau earthquake sets have assigned qualities of two or better, indicating that the majority of the phase data are of high quality.

\begin{tabular}{|c|c|c|}
\hline \multirow{2}{*}{ Quality } & \multicolumn{2}{|c|}{ Frequency (\%) } \\
\cline { 2 - 3 } & Rotorua & Kawerau \\
\hline 0 & 22 & 18 \\
1 & 28 & 41 \\
2 & 29 & 24 \\
3 & 20 & 17 \\
4 & 1 & 1 \\
\hline
\end{tabular}

Table 2.1: The distribution of qualities assigned to Rotorua and Kawerau phase arrival time data. 


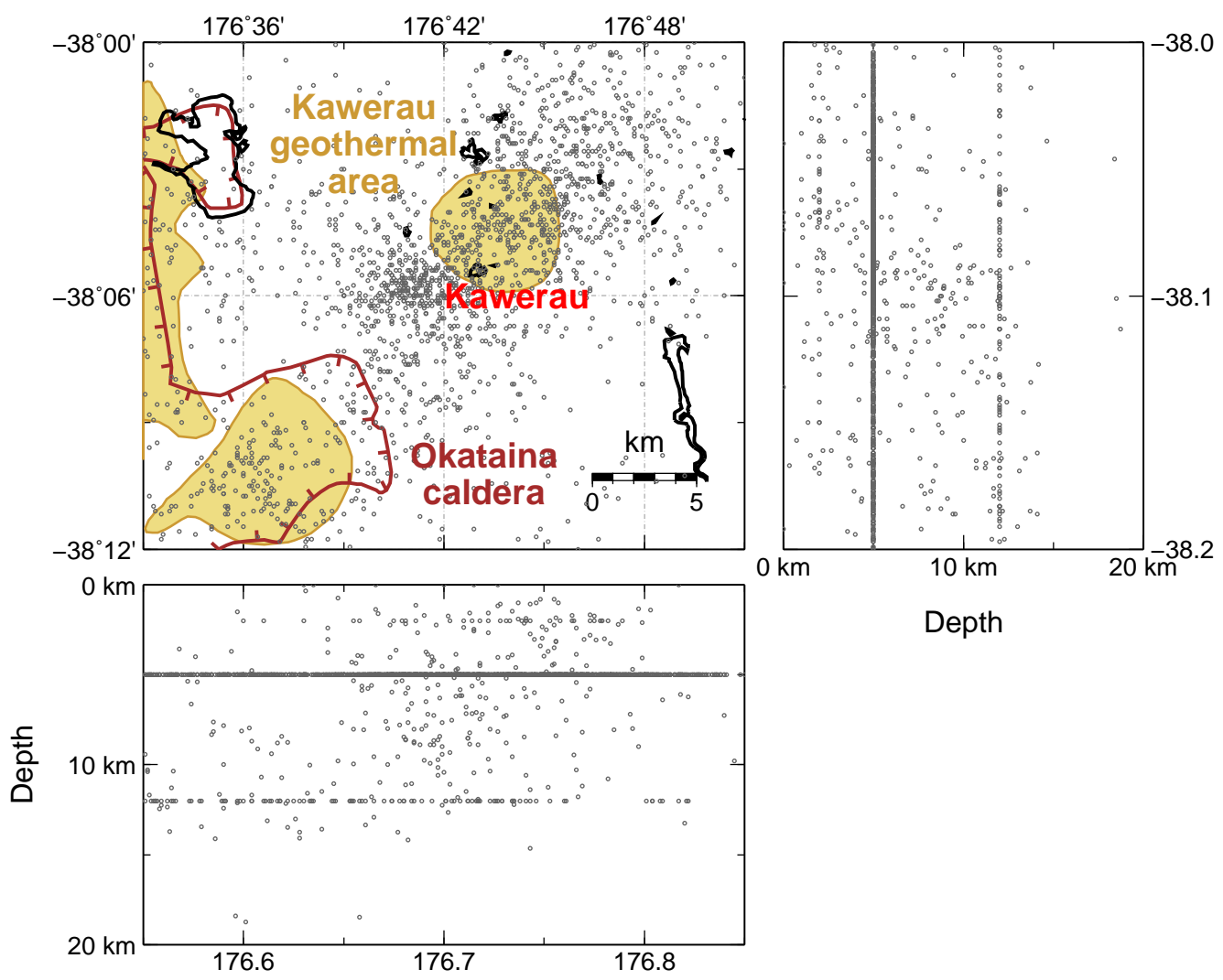

Figure 2.4: 1875 catalogue locations for Kawerau earthquakes. The two depth sections are E-W and $\mathrm{N}-\mathrm{S}$ profiles onto which all the seismicity has been projected. Yellow areas are geothermal systems. Brown hachured lines border calderas. Black lines mark lake boundaries. Note that the focal depths recorded in the catalogue are generally fixed during the hypocentre calculation at 2,5 or $12 \mathrm{~km}$. 


\subsection{Methods of analysis}

\subsubsection{1-D velocity model estimation}

We use Velest (Kissling et al., 1994) to obtain a reliable seismic velocity model with corresponding station corrections for both the Kawerau and the Rotorua geothermal systems. Velest is a "joint hypocentre-velocity model" inversion routine. This means that Velest attempts to find both the best hypocentres and the most appropriate velocity model (with associated station corrections) for a given set of earthquakes. This velocity model is termed the "minimum 1-D model" (Kissling, 1988), and represents the velocity structure that produces the minimum root mean squared (RMS) misfit between observed and predicted arrival times for the earthquakes in question. Station corrections are averaged arrival time residuals at each station and represent the 3-D velocity structure that the $1-\mathrm{D}$ model is unable to accommodate.

Given a set of estimated earthquake hypocentres and seismic velocities, Velest calculates a set of theoretical seismic arrival times $t_{\text {calc }}^{i}$ and compares them with the observed set of arrival time data $t_{o b s}^{i}$. Arrival time residuals are then calculated as follows:

$$
t_{\text {res }}^{i}=t_{\text {obs }}^{i}-t_{\text {calc }}^{i}
$$

Velest attempts to reduce the overall size of these residuals by adjusting the original set of locations and velocities to better match the observed arrival time data. To do this, the dependence of each arrival time residual on its earthquake's location and the velocity structure is approximated using a first 
order Taylor series expansion:

$$
t_{\text {res }}^{i}=\sum_{j=1}^{4} \frac{\delta t^{i}}{\delta h_{j}} \cdot \Delta h_{j}+\sum_{k=1}^{n} \frac{\delta t^{i}}{\delta m_{k}} \cdot \Delta m_{k}
$$

Here $h_{j}$ are the hypocentre of the earthquake and $m_{k}$ are the $n$ modelled velocity parameters. $\Delta h_{j}$ and $\Delta m_{k}$ are the adjustments to be made to these parameters. The calculation of $t_{\text {calc }}$ and the partial derivatives in Equation 2.2 constitute the forward part of the joint hypocentre-velocity model problem.

In matrix form, equation 2.2 can be written as:

$$
\mathbf{t}=\mathbf{A d}
$$

Here $\mathbf{t}$ is the vector of all $i$ arrival time residuals, $\mathbf{A}$ is the matrix of partial derivatives (the "design matrix") and $\mathbf{d}$ is the matrix of hypocentral and velocity model parameter adjustments. This set of linear equations is overdetermined and generally cannot be solved exactly for $\mathbf{d}$. Instead, equation 2.3 is solved in such a way that the sum of the squares of the residuals that are subsequently calculated using the new adjusted model parameters are minimised. This method of inversion is called "linearized least-squares" and is iterated several times until a stable minimum misfit model has been found.

The extent to which the model parameters are allowed to fit the data is controlled by a set of damping parameters which are added to the partial derivatives that constitute matrix A. A different damping parameter is applied to each type of model parameter (hypocentres, velocities and station corrections). A damping parameter of zero applies no restriction to the ad- 
justments that are made to the model parameters. There is no upper bound for damping parameters, but extremely high values ( 1000) effectively hold the model parameters constant throughout the inversion. In cases where the data are of poor quality, these damping parameters are required to avoid unstable inversions and erroneous final models that fit noise in the arrival time data.

The joint hypocentre--velocity model problem is highly non-linear (Kissling, 1988), and so the solution provided by Velest - which uses a linear approximation to fit arrival time data - must always be considered in its proper context. When solving non-linear problems, the possibility of multiple misfit minima must be anticipated. Several different velocity models may produce similarly small RMS misfits, making any absolute minimum difficult to identify if indeed one exists at all. The minimum 1-D model found after any one Velest inversion depends on the initial model from which the search begins. Therefore, one Velest run is generally not sufficient to determine the best minimum 1-D model. Instead, a series of runs using a variety of different initial models is called for. The resulting set of minimum 1-D models can then be interpreted, and a final solution chosen.

\subsubsection{Waveform cross-correlation}

Waveform cross-correlation is a procedure that is used to quantitatively describe the similarity between two functions, and to determine the time delay between them. In our case, these functions are velocity seismograms for pairs of earthquakes that have been recorded at common seismograph sta- 
tions. The cross-correlation function is defined as:

$$
c c(\tau)=n \int u_{1}(t) u_{2}(t+\tau) d t
$$

Here, $u_{1}$ and $u_{2}$ are the two seismograms, $n$ is a normalisation factor that ensures the function takes values between minus one and one

$$
n=\left(\int u_{1}^{2} d t \int u_{2}^{2} d t\right)^{-1 / 2}
$$

and $\tau$ is the delay time between the two seismograms (Kanasewich, 1981). The maximum value of $c c(\tau)$ represents the similarity between the two seismograms, while the delay time $\tau_{m}$ at which that maximum value is realised is the optimal time shift for aligning them.

Figure 2.5 shows two hypothetical examples of cross-correlation time delay estimation. In the first example (left), the seismograms are not similar and so the cross-correlation takes small values and has a relatively low maximum value. The second example (right) shows two similar seismograms that are poorly aligned. This time the cross-correlation function has a greater maximum value which is realised at a delay time that is equal to the misalignment of the two seismograms.

When a pair of seismograms are similar enough - that is, the maximum value for $c c(\tau)$ (from here on referred to as the cross-correlation coefficient) is above a given threshold - then $\tau_{m}$ can be used to improve their $\mathrm{P}$ - or S-wave travel time differences. For example, if a station has a picked P-wave arrival at time $t_{1}$ for an earthquake with origin time $t_{1}^{o}$, and another at time $t_{2}$ for 

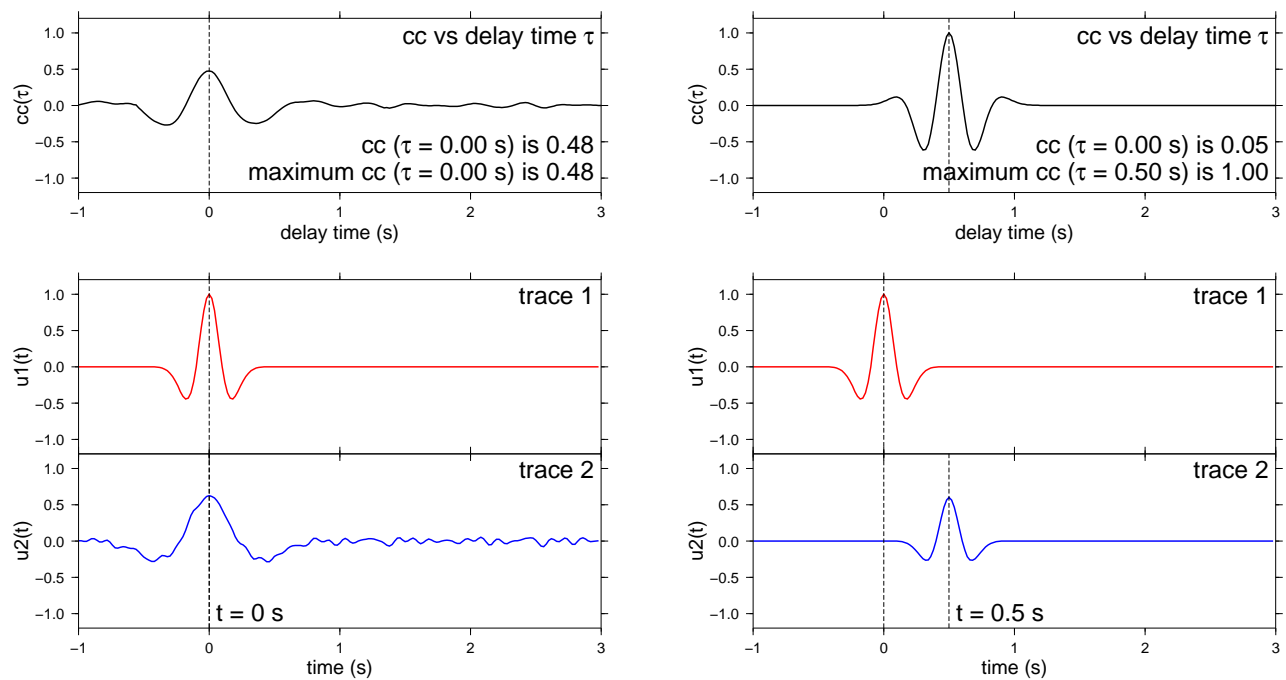

Figure 2.5: Two hypothetical examples of delay time estimation using crosscorrelation. left: Two well-aligned, but distinctly different traces are compared. The cross-correlation $(c c(\tau)$, top panel) is maximum when the delay time $\tau$ is zero, but has relatively small amplitude due to the dissimilarity between the functions. right: The two traces are similar, but poorly aligned. The maximum value for $c c(\tau)$ is higher in this case, and is realised when the delay time $\tau$ matches the offset between the two functions $(0.5 \mathrm{~s})$.

a second event with origin time $t_{2}^{o}$, then the travel time difference $\delta t$ is

$$
\delta t=\left(t_{2}-t_{2}^{o}\right)-\left(t_{1}-t_{1}^{o}\right)
$$

If an optimum delay time $\tau_{m}$ is then calculated for these two events at this station, then the adjusted travel time for the second seismogram becomes $\left(t_{2}+\tau_{m}-t_{2}^{o}\right)$ and the new cross-correlation-adjusted P-wave travel time difference $\delta t^{(c c)}$ is

$$
\delta t^{(c c)}=\left(t_{2}+\tau_{m}-t_{2}^{o}\right)-\left(t_{1}-t_{1}^{o}\right)=\delta t+\tau_{m}
$$

We use the procedure BCSEIS (Bispectrum Cross-Correlation package 
for SEISmic events) (Du and Thurber, 2004) to perform cross-correlation measurements for Rotorua and Kawerau. Here, cross-correlation is carried out within specified time windows containing P- and S-wave arrival picks on pairs of bandpass-filtered seismograms. Delay times are also estimated using the bispectrum method (Du et al., 2004, and refs therein) on windowed raw and filtered seismograms. The bispectrum method of delay time estimation works in the third-order spectral domain and is less sensitive to Gaussian noise than cross-correlation delay time estimation. Cross-correlation-derived time delay measurements are accepted or rejected depending on the similarity of the two waveforms in consideration, and also the consistency between the three time delay estimates.

\subsubsection{Double-difference earthquake relocation}

We perform our earthquake relocation using the double-difference procedure HypoDD of Waldhauser and Ellsworth (2000). This procedure uses travel time differences for pairs of earthquakes measured at common stations to constrain their locations. This takes advantage of the similar ray paths of seismic waves travelling from pairs of closely located earthquakes to relatively distant seismograph stations (Figure 2.6). Because these rays are similar, they are equally affected by the velocity heterogeneity they sample along their paths. If these heterogeneities are unmodelled, then the predicted travel times for the two rays will be in error, but they will be in error by an equal amount. Subtracting the observed travel times for these seismic waves removes this error, and the remaining travel time difference can be used to constrain the 
offset between the two earthquakes.

The double-difference method of earthquake relocation is one of several algorithms that attempt to account for unmodelled 3-D velocity heterogeneity through either the explicit calculation of station correction terms or the use of some variant thereof (e.g. Richards-Dinger and Shearer, 2000; Nicholson et al., 2004). One criticism of the double-difference technique is that it is unable to resolve the absolute locations of earthquakes and earthquake clusters as it uses only differential rather than absolute travel times. Menke and Schaff (2004), however, demonstrate that the double-difference algorithm not only resolves absolute earthquake locations, but is capable of improving the absolute locations obtained using traditional methods, especially when high precision cross-correlation-derived differential travel times are used. The double-difference method has successfully improved images of seismicity in a variety of environments around the globe (e.g. Prejean et al., 2002; Schaff et al., 2002; Lippitsch et al., 2005).

The term "double-difference" refers to the difference between observed and calculated travel time differences for a pair of earthquakes that are measured at a common station. The double-difference travel time residual $d r_{k}^{i j}$ is calculated as follows:

$$
d r_{k}^{i j}=\left(t_{k}^{i}-t_{k}^{j}\right)^{o b s}-\left(t_{k}^{i}-t_{k}^{j}\right)^{c a l c}
$$

Here, $t_{k}^{i}$ and $t_{k}^{j}$ are observed and calculated travel times at station $k$ for earthquakes $i$ and $j$, respectively. Theoretical travel times are calculated using estimated hypocentres for each earthquake. The double-difference travel 


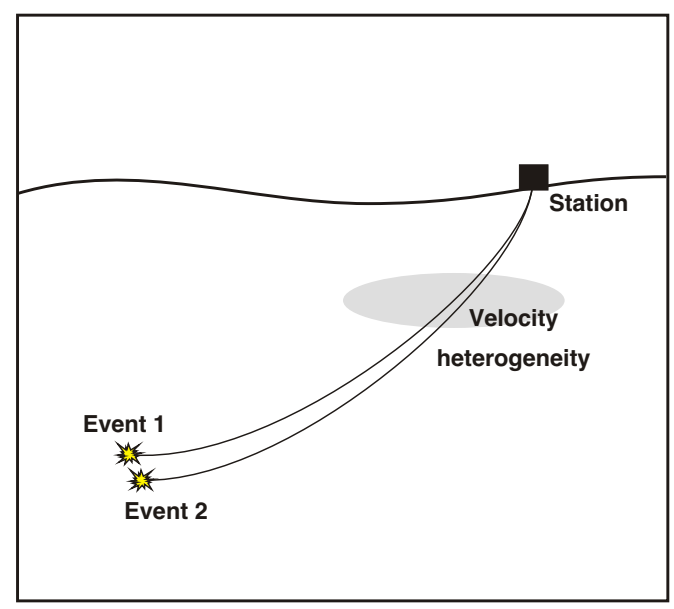

Figure 2.6: Schematic diagram illustrating the similarity of the seismic rays emanating from two nearby earthquakes. These rays equally sample unmodelled velocity structures as they travel to distant seismograph stations.

time residual can be related to perturbations in these hypocentres using a first order Taylor series expansion:

$$
d r_{k}^{i j}=\frac{\partial t_{k}^{i}}{\partial \mathbf{m}} \Delta \mathbf{m}^{i}-\frac{\partial t_{k}^{j}}{\partial \mathbf{m}} \Delta \mathbf{m}^{j}
$$

Here $\mathbf{m}^{i}$ and $\mathbf{m}^{j}$ are the estimated hypocentres for the two earthquakes. $\Delta \mathbf{m}^{i}$ and $\Delta \mathbf{m}^{j}$ are the adjustments to be made to the estimated hypocentres to make them better fit the data. Collation of the double-difference residuals in Equation 2.9 for all earthquake pairs and all stations leads to a system of linear equations that can be solved in an iterative least-squares sense as described in Section 2.3.1. An extra linear equation

$$
\sum_{i=1}^{n} \Delta \mathbf{m}_{i}=0
$$

is included to the system to limit the extent by which the centroid of the $n$ 
relocated earthquakes is allowed to move during the inversion.

Because the number of earthquake pairs grows as the square of the number of earthquakes being relocated, the system of linear equations (Equation 2.9) can become very large and their inversion can become very computerintensive and time consuming. For this reason the inversion can be performed using either singular value decomposition (SVD) (Waldhauser, 2001) or the conjugate gradient method LSQR of Paige and Saunders (1982). SVD is more robust, produces more reliable estimates of location uncertainty, but is far less efficient than LSQR (Waldhauser and Ellsworth, 2000). When more than around 100 earthquakes are being relocated, then the system of equations becomes too large and LSQR must be used (Waldhauser, 2001).

\subsubsection{Earthquake clustering and focal mechanism de- termination}

We use hierarchical clustering (see Everitt, 1974) to identify groups of similar earthquakes in the Rotorua and Kawerau data sets. Because cross-correlation provides a means of quantifying the similarity of earthquake seismograms, we define clusters of earthquakes based on their pairwise cross-correlation coefficients at a chosen "master" station. This clustering technique-which is described in Section 5.2.1 - works by linking together the most similar earthquakes (those with the highest correlation coefficients) in each earthquake set, then progressively linking events of decreasing similarity. The clustering stops when a specified similarity threshold has been reached.

If the similarity threshold is set high enough then only the most similar 
events are clustered together and the earthquakes within each cluster can be assumed to share common hypocentral and source parameters (Geller and Mueller, 1980). For example, Hansen et al. (2006) cluster events with correlation coefficients greater than 0.9 in the Nicoya Peninsula, Costa Rica, before calculating composite focal mechanisms for them.

We attempt to calculate composite focal mechanisms for each earthquake cluster by considering P-wave first motion polarity observations for all of their constituent events (Section 5.3.1). We apply the procedure Focmec (Snoke, 2003) to perform the focal mechanism calculation. This algorithm carries out a grid search of double-couple focal mechanism orientations and compares the $\mathrm{P}$-wave first motion polarities they predict with those that have been observed. If more than a specified number of theoretical and observed Pwave first motions match each other when a candidate mechanism is tested, then that mechanism is accepted as a possible solution for the clustered earthquakes. This method of focal mechanism inversion generally produces several solutions for a given set of $\mathrm{P}$-wave first motion polarity observations. If these solutions all share similar orientations, then the mechanism is well constrained and a preferred solution can be chosen. We take the best solution to be that with the median strike, dip and rake of the set of solutions found by Focmec. 


\section{Chapter 3}

\section{One-dimensional velocity model estimation for Rotorua and}

\section{Kawerau}

\subsection{Introduction}

This chapter provides a description of the steps we take to produce "minimum" 1-D seismic velocity models for Rotorua and Kawerau. The minimum 1-D velocity model is defined as the depth-varying seismic velocity profile that yields the minimum misfit between observed and calculated P- or Swave arrival times for a given set of earthquakes (Kissling, 1988). We use the inversion procedure Velest (Kissling et al., 1994) to carry out our inversions. A description of Velest is provided in Section 2.3.1. In Section 3.2 we describe the earthquake data selected for our inversions and how we choose them. Section 3.3 outlines the procedure we use to obtain our velocity mod- 
els, while Sections 3.4 and 3.5 describe the implementation of that procedure and the results we ultimately obtain.

\subsection{Earthquake selection}

As described in Section 2.2, our complete earthquake data sets consist of 504 and 1875 shallow (less than $20 \mathrm{~km}$ deep) events in Rotorua and Kawerau, respectively. These earthquakes were primarily recorded on Rotorua network and New Zealand national network seismometers (Figure 2.1). Of these events, only two have magnitudes of $M_{L} 5.0$ or more. We use the iterative least-squares inversion Velest (Kissling, 1995) to invert arrival time data from these earthquakes to produce our 1-D seismic velocity models.

In order to maximise the reliability of our Velest (Kissling, 1995) inversions, we include only the most locatable earthquakes from each of our two data sets. It is therefore necessary for us to determine parameters that allow us to identify the most locatable earthquakes. These parameters are chosen with the aim of selecting as many "good" earthquakes as possible without depleting our data set to the extent that any Velest inversion becomes unstable.

For an earthquake to be well locatable, it must be well observed. This means that the earthquake must have been recorded at numerous seismic stations. Therefore, earthquakes are rejected if they have less than a given number of observations. These seismic stations must also be spread over a wide azimuthal range about the earthquake. If this is not the case, that earthquake's epicentre will be biased along a direction determined by the 
geometry of the stations that recorded it. To avoid this, earthquakes with large azimuthal gaps are rejected. The locations of Rotorua and Kawerau within the Bay of Plenty and the absence of ocean bottom seismometers make this requirement a critical one, as many earthquakes are not observed over large $\left(180^{\circ}\right.$ or more) azimuthal ranges, (Figures A.1 and A.2 in the Appendix). An earthquake must also be observed sufficiently near to its epicentre that its depth can be confidently determined. For this reason, earthquakes are rejected if their nearest observation was recorded beyond a given minimum distance. We analyse the distributions of these parameters and choose a set of cut-off values that are appropriate for our data set.

Figures A.1 and A.2 in the appendix show the distribution of these parameters (and also magnitude) for all Rotorua (Figure A.1) and Kawerau (Figure A.2) earthquakes. Both earthquake sets have a median of seven observations. The Rotorua set has a wider median azimuthal gap of $183^{\circ}$ compared to that of $155^{\circ}$ for the Kawerau set. Most earthquakes were recorded within $10 \mathrm{~km}$ of their epicentres (as determined from their routine GeoNet locations), with more than $80 \%$ of the Rotorua earthquakes and $60 \%$ of the Kawerau earthquakes observed within this distance. These parameters are summarized in table 3.1. We do not use magnitude as an earthquake selection criterion as it is correlated with the number of observations an earthquake has and is therefore largely redundant.

For both Rotorua and Kawerau, we choose a minimum of eight phases with a maximum azimuthal gap of less than $180^{\circ}$ for an earthquake to be included in an inversion. The $180^{\circ}$ azimuthal requirement is at the looser end of cut-offs commonly used for local earthquake relocation and tomography 
studies (e.g. Sherburn et al., 2003; Kaypak and Eyidoğan, 2005; Rowlands, 2004) but is necessary due to the poor azimuthal coverage of earthquakes near the edge of the New Zealand and Rotorua seismograph networks (Figure 2.1). Also, a maximum distance of $10 \mathrm{~km}$ to the nearest station is set. This criterion is designed to exclude any remaining earthquakes with poorly determined depths. Over all, 143 (28\% of 504) earthquakes from Rotorua (Figure 3.1) and 420 (22\% of 1875) earthquakes from Kawerau (Figure 3.2) meet these criteria, which are summarised in Table 3.1. We refer to these events below as the Rotorua and Kawerau P-wave modelling earthquake sets.

\begin{tabular}{|c|c|c|c|}
\hline Criterion & median (Rotorua) & median (Kawerau) & cut-off value \\
\hline phases & 7 & 7 & 8 \\
azimuthal gap & $155^{\circ}$ & $183^{\circ}$ & $180^{\circ}$ \\
nearest station & $7.3 \mathrm{~km}$ & $7.0 \mathrm{~km}$ & $10 \mathrm{~km}$ \\
magnitude & 2.3 & 2.3 & not used \\
\hline
\end{tabular}

Table 3.1: Earthquake selection criteria for P-wave velocity inversions.

\subsection{Outline of procedure}

P- and S-wave minimum 1-D velocity models with corresponding station delays for Rotorua and Kawerau are determined using the following procedure.

First, using only $\mathrm{P}$-wave phase data, a minimum 1-D P-wave velocity model is found. Using this model as a starting point, S-wave data is included in a joint $\mathrm{P}$ - and $\mathrm{S}$-wave inversion to determine a $\mathrm{P}$ - and $\mathrm{S}$-wave velocity model. During this step, S-wave phases are up-weighted relative to similar quality $\mathrm{P}$-wave phases in order to ensure the resolved S-wave velocity model is influenced as much as possible by S-wave observations without losing the 


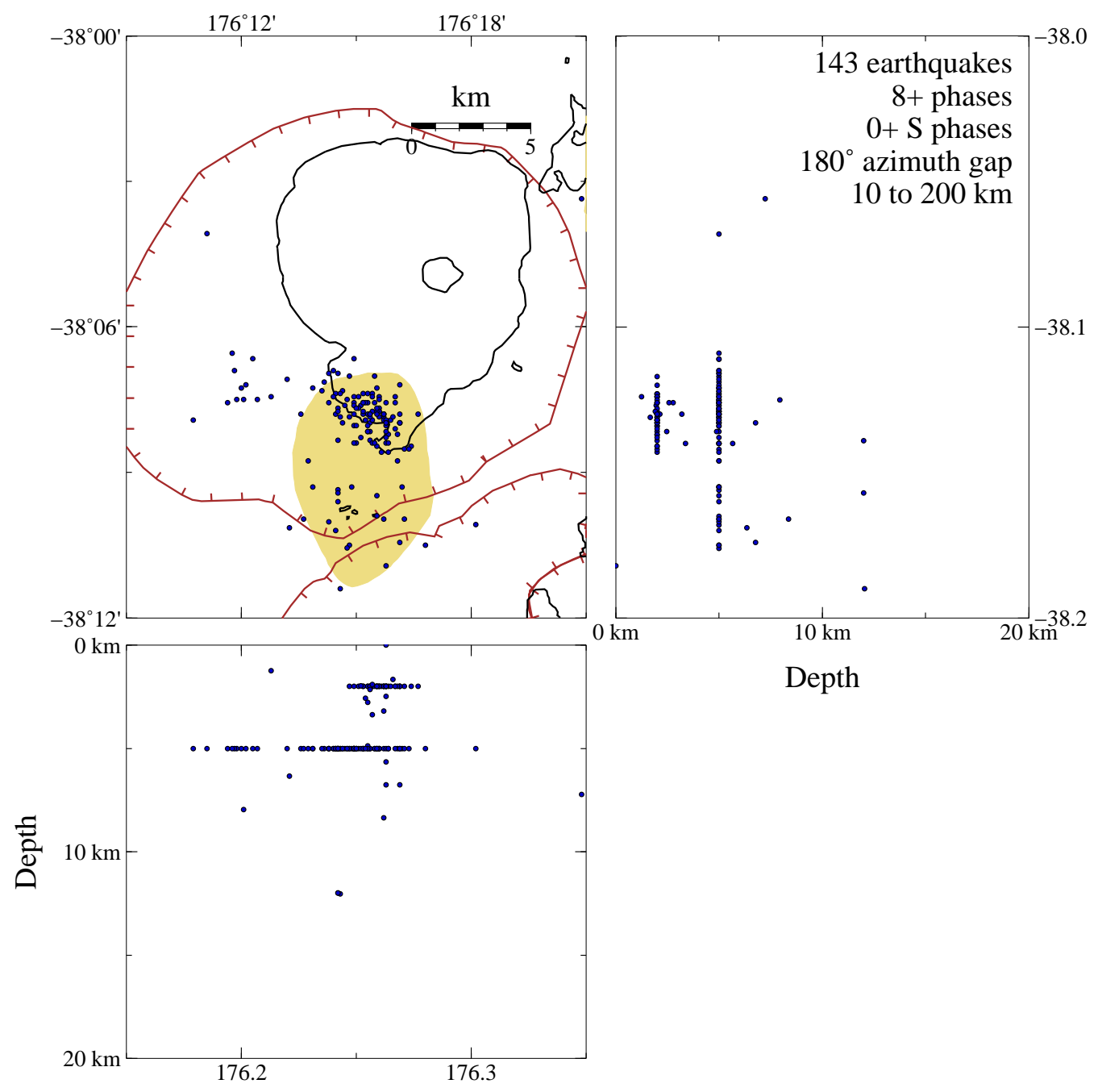

Figure 3.1: Initial GeoNet hypocentres for the 143 earthquakes in the Rotorua P-wave modelling set. Brown hachured lines mark calderas. Yellow areas are geothermal fields. Earthquake selection criteria are listed (see Table 3.1). 


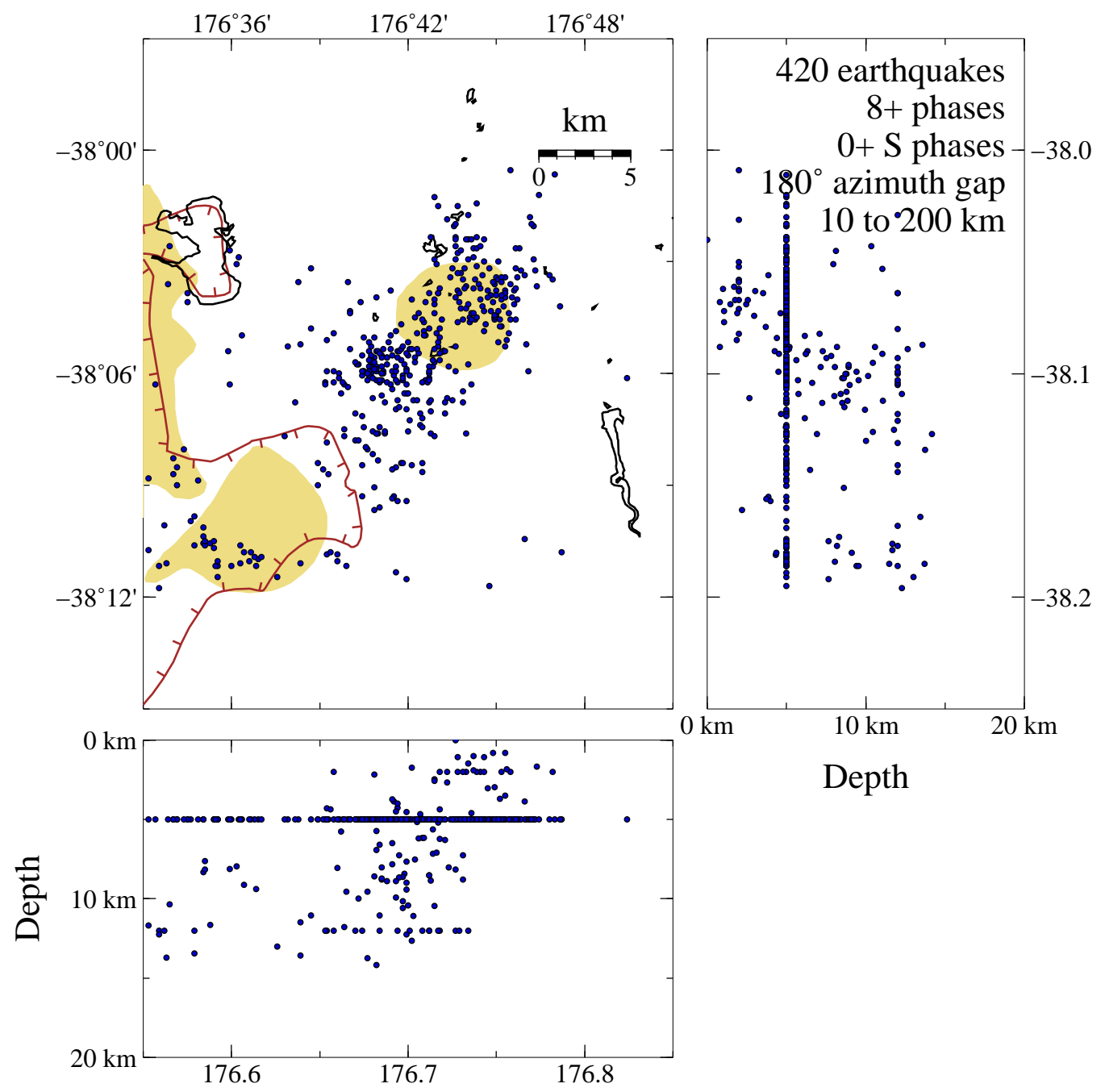

Figure 3.2: Initial GeoNet hypocentres for the 420 earthquakes in the Kawerau P-wave modelling set. Brown hachured lines mark calderas. Yellow areas are geothermal fields. Earthquake selection criteria are listed (see Table 3.1 ). 
stability the P-wave data provide.

\subsection{P-wave velocity model}

\subsubsection{Initial velocity models}

As mentioned in section 2.3.1, the minimum 1-D velocity model produced by Velest is influenced by the initial model it is given to start its search from. In order to to ameliorate any bias due to pre-conceived ideas as to what this final model should look like, we perform 1000 Velest inversions using randomly generated velocity models.

Velest does not solve for layer thickness within a velocity model, so we assign boundaries to each initial model at $-3,0,2,4,6,8,10,15,20,25$, 30 and $40 \mathrm{~km}$ depths. These depths are chosen to enhance resolution in the highly variable upper part of the model without introducing too many model parameters which would cause Velest to take longer to run and might lead to instability if a small number of earthquakes was used. The $-3 \mathrm{~km}$ depth boundary is required by Velest for station elevations to be accounted for.

A velocity is picked uniformly randomly between 1 and $6 \mathrm{~km} / \mathrm{s}$ for the -3 $\mathrm{km}$ layer, and between 6 and $10 \mathrm{~km} / \mathrm{s}$ for the $40 \mathrm{~km}$ layer. An intermediate velocity is then randomly picked for the $10 \mathrm{~km}$ layer. This splits the model into upper and lower parts. Within each part of the model, the remaining velocities are then picked from an ordered list of uniformly distributed random velocities bounded by the upper and lower velocities of that part. The only constraint we place on these velocity models is that the velocities must 
increase with depth. If this were not the case it would be possible to produce extremely unrealistic starting profiles which would in turn lead to unstable Velest inversions. Figure 3.3 shows 15 models generated in this way. Within each part of the model, velocities increase roughly linearly. Picking the 10 $\mathrm{km}$ layer velocity third ensures the model is likely to have different velocity gradients in its upper and lower parts. This enables us to test a wide variety of initial velocity profiles.

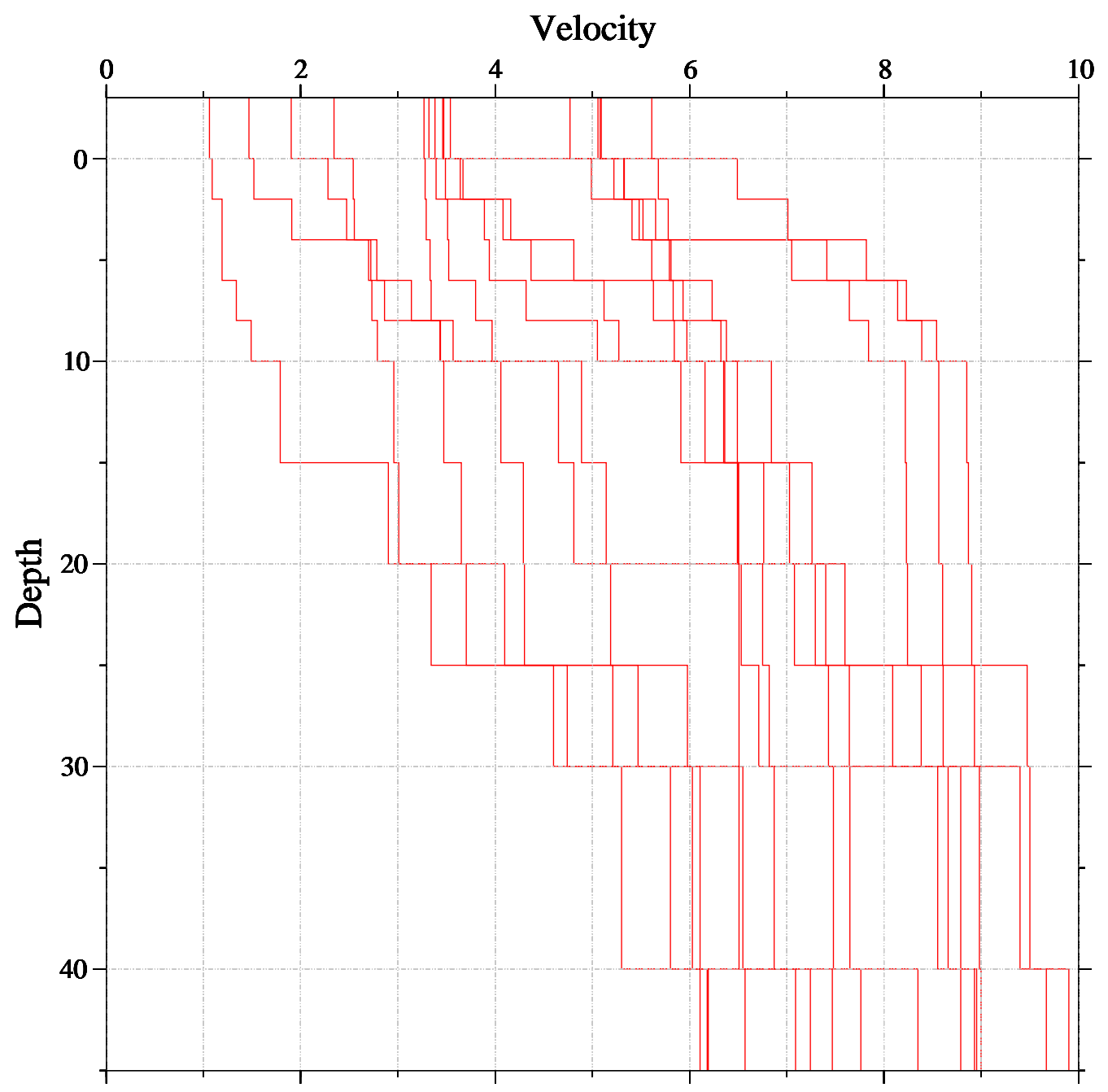

Figure 3.3: Fifteen randomly generated P-wave velocity models. 


\subsubsection{Control parameters}

The choices of a priori weights and damping parameters that influence the performance of least squares inversions should ideally be made with due deference to the uncertainties inherent in the data that are inverted. Moreover, the a posteriori appropriateness of these choices should be checked once the inversion has been carried out. In this and in following sections, several choices for inversion parameters are made without thorough analysis of data variance and without a posteriori verification. Instead, we choose parameters that are within reasonable bounds suggested by the designers of the inversions and used in similar earthquake location studies.

Velest allows damping to be applied to control the extent to which earthquake epicentres, earthquake depths, layer velocities and station corrections are allowed to vary (see Section 2.3.1). The higher the damping, the less these parameters are allowed to move during the inversion process. We set a damping value of 0.01 to earthquake epicentres and depths as suggested by Kissling (1995). Velocities and station corrections are damped with values of 0.5 and 1.0, respectively. These are heavily damped because, unlike for hypocentral parameters, the travel time derivatives for these accumulate over all events.

Observations recorded further than $200 \mathrm{~km}$ from an earthquake's epicentre are excluded from our inversions. This is because the velocity structure of New Zealand, particularly the TVZ, is highly laterally heterogeneous (e.g. Reyners et al., 2006; Nicholson et al., 2007) and observations recorded at distant stations would not reflect the local velocity structure of the regions 
in question and bias the resolved one-dimensional velocity models.

GeoNet uses qualities to describe the uncertainty of each arrival-time pick in routine processing. These range from 0 for clear, impulsive arrivals, to 4 for the noisiest, most uncertain picks. Velest automatically converts these qualities to weights via the following equation:

$$
W_{i}=\frac{1}{2^{2 q_{i}}}
$$

Here $q_{i}$ are GeoNet qualities (Table 3.2). Note that these weights decay more rapidly as quality worsens than those used in other studies using GeoNet data (e.g. Nicholson et al., 2007). This ensures highly uncertain poor quality picks have virtually no influence on the resolved seismicity and velocity model.

No low velocity layers are allowed in the resulting velocity models as they increase the non-linearity of the problem and can lead to instability in the inversions (Kissling, 1995).

\begin{tabular}{|c|c|}
\hline GeoNet quality & Velest weight \\
\hline 0 & 1 \\
1 & $1 / 4$ \\
2 & $1 / 16$ \\
3 & $1 / 64$ \\
4 & $1 / 256$ \\
\hline
\end{tabular}

Table 3.2: GeoNet qualities and Velest weights

\subsubsection{Results}

Figures 3.4 and 3.5 show the P-wave velocity models found by Velest for the 1000 inversions described above for Rotorua and Kawerau, respectively. Each histogram shows the distribution of velocities within each layer. Although the 
input models sample a vast range of velocities, the output models are more tightly constrained, particularly in the $4-10 \mathrm{~km}$ depth range. Deeper than this, any apparent convergence must be treated with caution, as relatively few rays pass through those layers and resolution is poor (see Figures A.3 and A.4 in the appendix). Shallower than around $4 \mathrm{~km}$, the velocities show a less constrained distribution, with two distinct peaks in both cases. This is likely due to the lateral heterogeneity of the region.

Figures 3.6 and 3.7 show the same models coloured according to the RMS earthquake misfit they produce. For Rotorua (Figure 3.6), there is a clear preference for the slower of the two shallow peaks shown in Figure 3.4.

Figures 3.8 and 3.9 show the earthquake hypocentres determined by Velest for each of the two data sets. These are mean locations with $95 \%$ error ellipses estimated from the scatter in their distribution after 1000 Velest inversions. The orientation of each ellipse is estimated using the principal components (eigenvectors) of the covariance matrix for the 1000 solutions. The sizes of the semi-major and semi-minor axes are calculated using a chi-squared distribution and the eigenvalues of the covariance matrix. This technique relies on the assumption that the solutions are normally distributed in the east, north and depth directions. Compared with their initial GeoNet locations (Figures 3.1 and 3.2), the epicentres appear more tightly clustered. Also, the effect of removing depth constraints at 2,5 and $12 \mathrm{~km}$ depths is evident.

Figures 3.10 and 3.11 show mean P-wave station corrections for Rotorua and Kawerau, respectively. The crosses in the middle of each symbol represent the standard deviation from the 1000 inversions. If the cross is larger than the circle, it is uncertain whether the correction is positive (blue, slow 

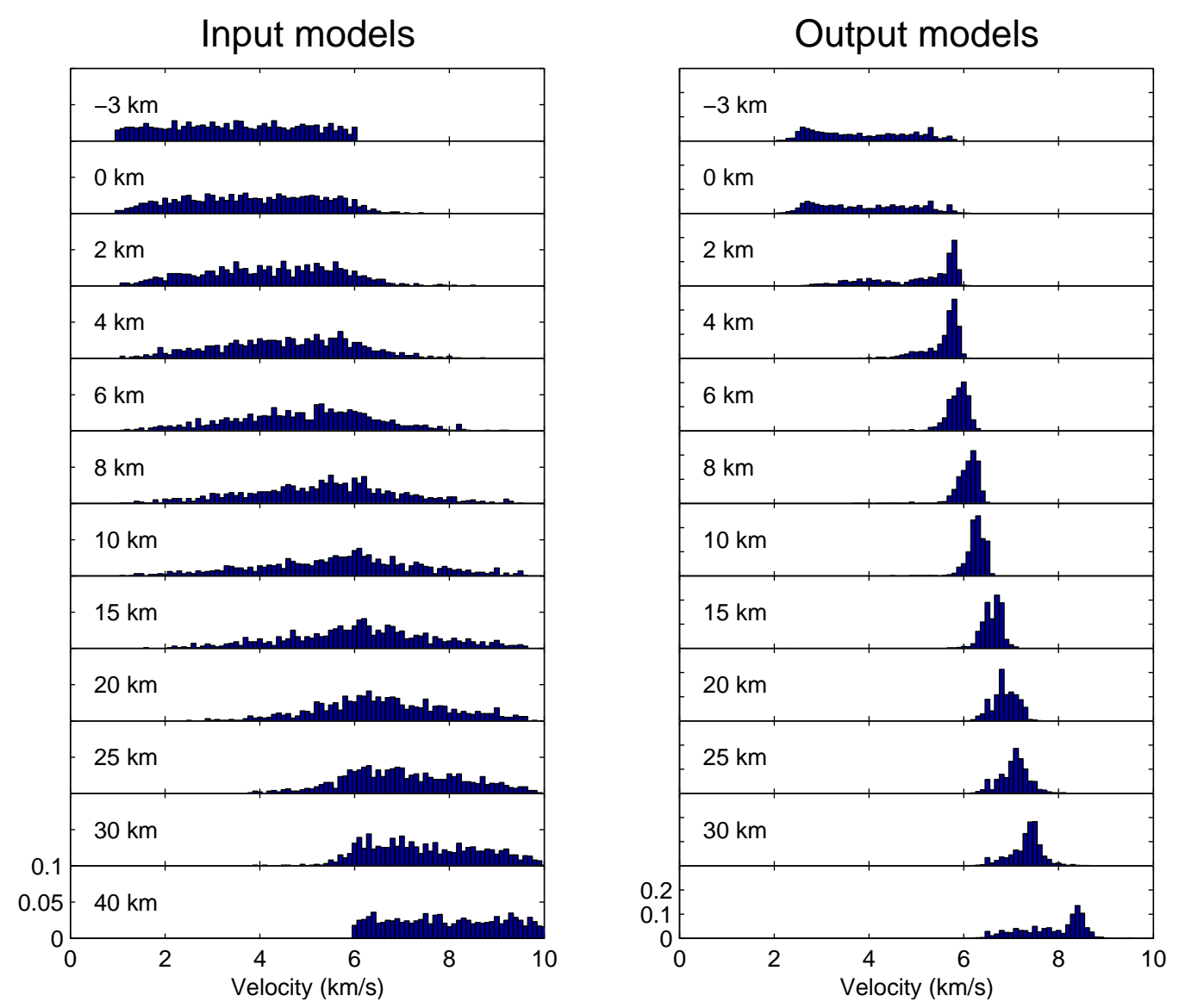

Figure 3.4: Histograms showing the distribution of velocities at each layer for 1000 initial (left) and final (right) P-wave velocity models for Rotorua. Earthquake selection criteria and Velest control parameters are listed. The number in each panel indicates the depth to the top of that layer. Vertical scales (bottom panel) are constant for each profile and are frequencies as proportions of the 1000 initial models. 

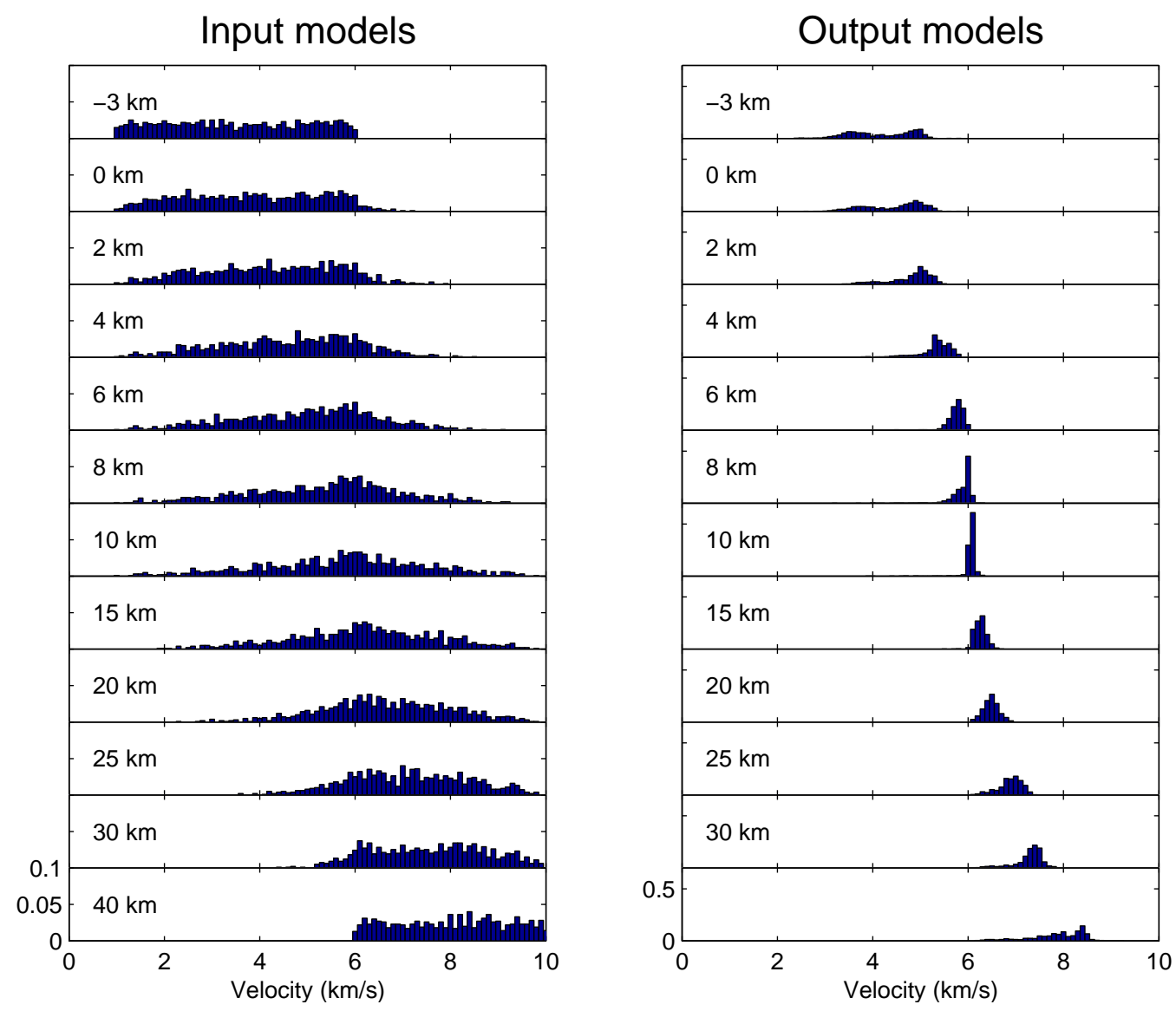

Figure 3.5: Histograms showing the distribution of velocities at each layer for 1000 initial (left) and final (right) P-wave velocity models for Kawerau. Earthquake selection criteria and Velest control parameters are listed. The number in each panel indicates the depth to the top of that layer. Vertical scales (bottom panel) are constant for each profile and are frequencies as proportions of the 1000 initial models. 


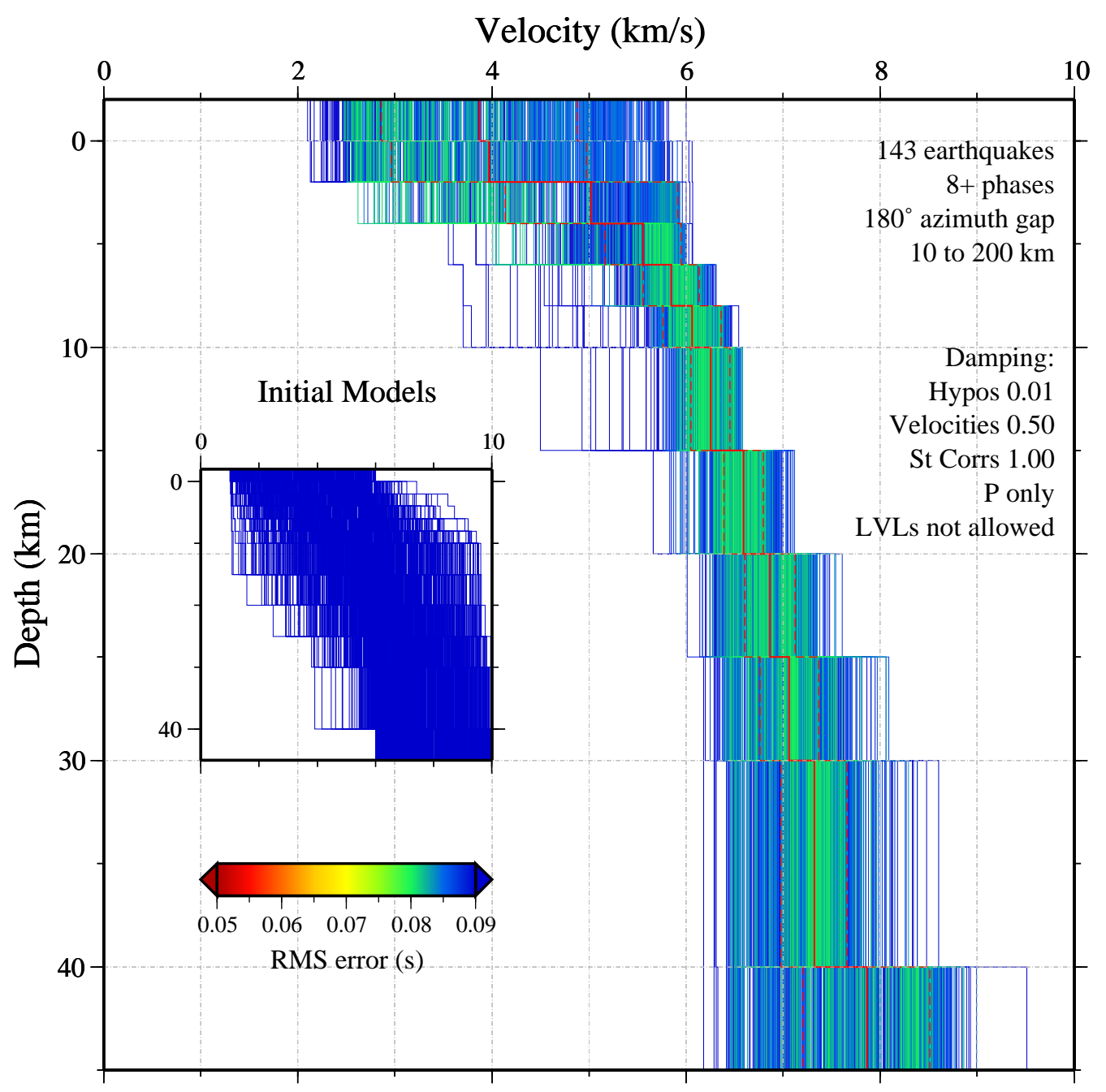

Figure 3.6: 1000 P-wave velocity models for Rotorua generated by Velest coloured according to the earthquake misfit they produce. Earthquake selection criteria and Velest control parameters are listed. "LVLs" are low velocity layers. The inset shows the distribution of input random models. The solid red line shows the mean velocity for each layer, bound by one standard deviation (dashed red lines). 


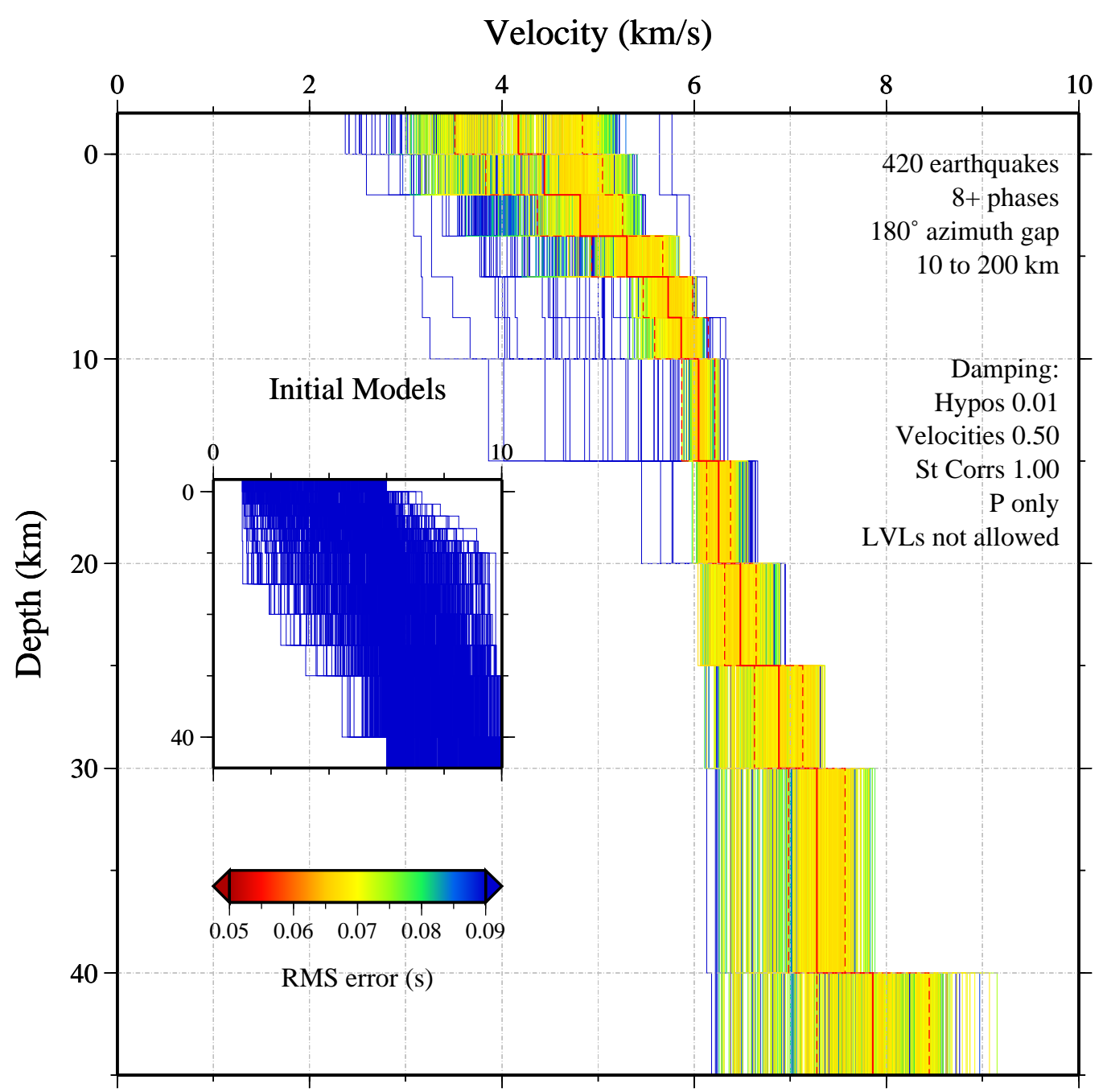

Figure 3.7: 1000 P-wave velocity models for Kawerau generated by Velest coloured according to the earthquake misfit they produce. Earthquake selection criteria and Velest control parameters are listed. "LVLs" are low velocity layers. The inset shows the distribution of input random models. The solid red line shows the mean velocity for each layer, bound by one standard deviation (dashed red lines). 


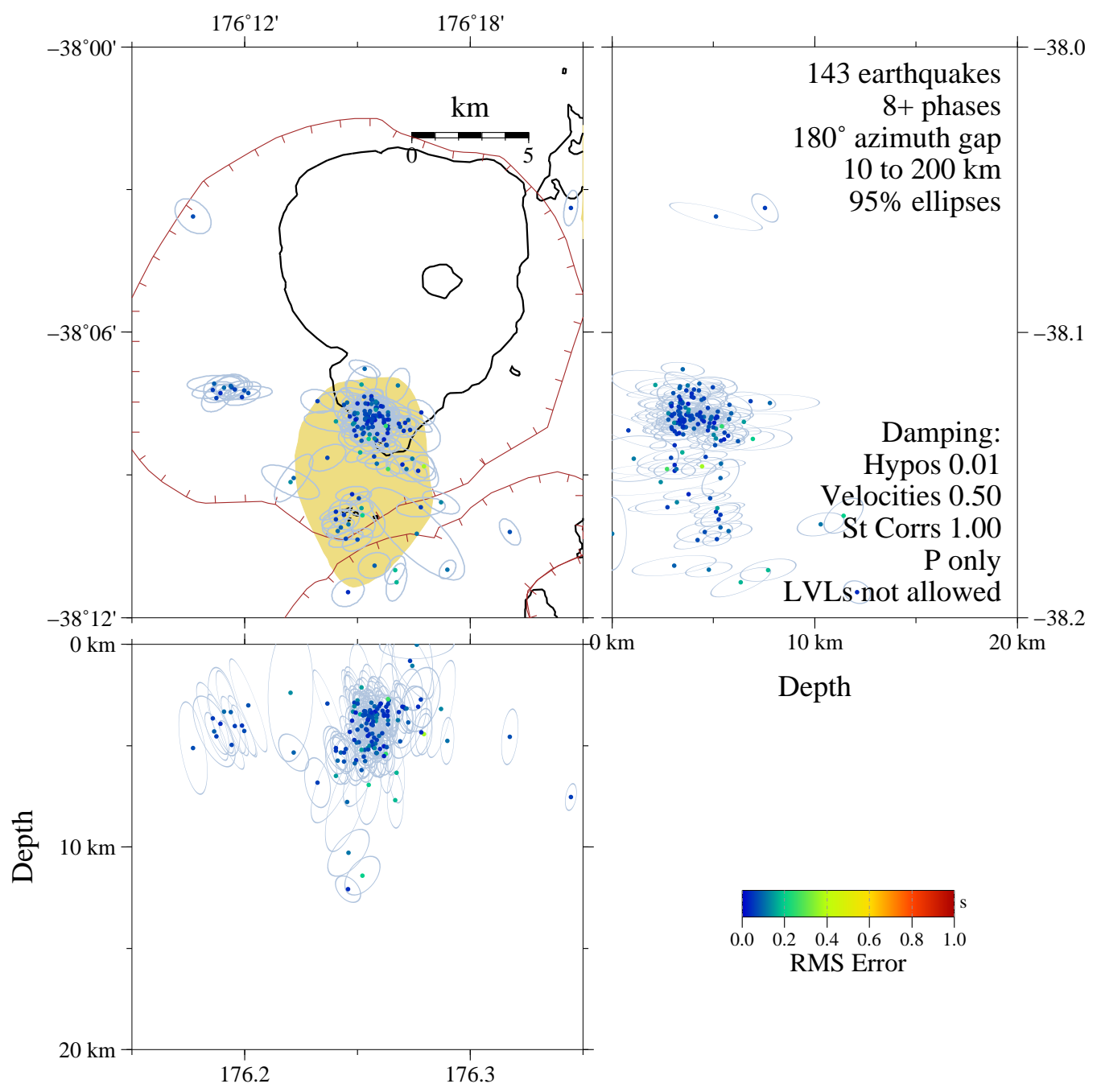

Figure 3.8: Final hypocentres for the Rotorua P-wave modelling earthquake set after 1000 Velest inversions. Selection criteria and Velest control parameters are listed. Dots are mean locations and are coloured by RMS misfit. Ellipses show 95\% confidence intervals, assuming normally distributed solutions in each dimension. Brown hachured lines mark calderas. Yellow areas are geothermal fields. 


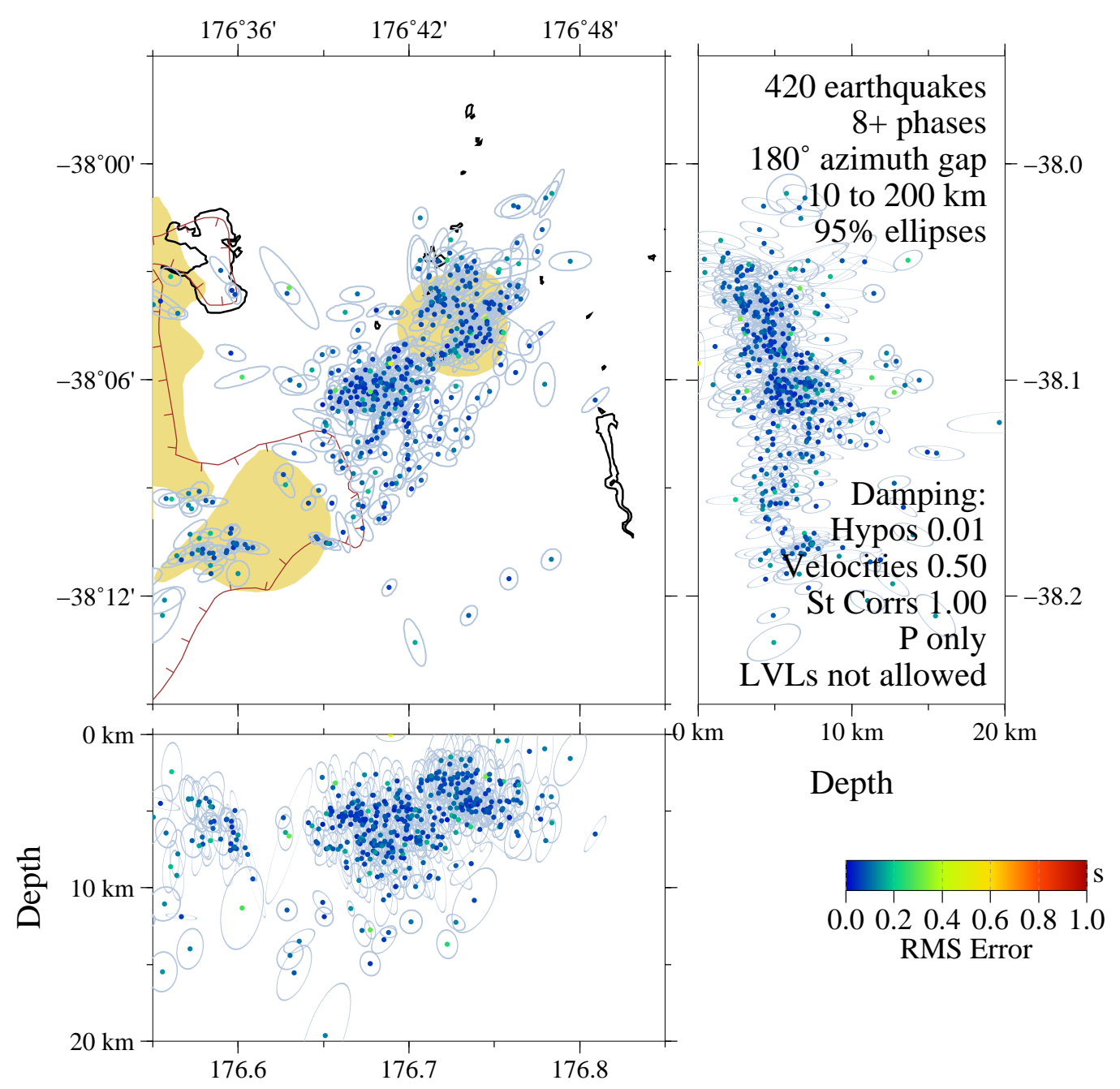

Figure 3.9: Final hypocentres for the Kawerau P-wave modelling earthquake set after 1000 Velest inversions. Selection criteria and Velest control parameters are listed. Dots are mean locations and are coloured by RMS misfit. Ellipses show 95\% confidence intervals, assuming normally distributed solutions in each dimension. Brown hachured lines mark calderas. Yellow areas are geothermal fields. 
P-wave paths) or negative (yellow, fast P-wave paths). Both plots show a roughly similar pattern of increasing station correction size with distance from the reference station (UTU for Rotorua, EDRZ for Kawerau, see Figure 2.1), mainly positive corrections (slow ray paths) within the central Taupo Volcanic Zone and along the east coast of the North Island, and negative corrections (fast ray paths) elsewhere. The station corrections for the Kawerau earthquakes are much larger than those for Rotorua. This could be due to the proximity of Kawerau and station EDRZ to the eastern boundary of the Taupo Volcanic Zone, making it more difficult for the 1-D model to accommodate the 3-D velocity structure of the region.

\subsubsection{Alternative models}

We carry out several sets of 1000 Velest inversions using earthquakes selected according to a variety of different criteria in both Rotorua and Kawerau. This enables us to test the influence that these criteria have over the resolved velocity models and station corrections. These criteria are listed in Table 3.3 .

Figures 3.12 and 3.13 show the mean P-wave velocity models obtained using Velest after applying these criteria to the Rotorua and Kawerau earthquake sets, respectively. In both cases, the models appear to be essentially the same, with particularly similar solutions for layers at or below $4 \mathrm{~km}$ depth. This should not be too surprising, as each trial uses subsets of the same set of earthquake data. What this does demonstrate is that a reliable P-wave velocity model solution can be obtained after applying earthquake 

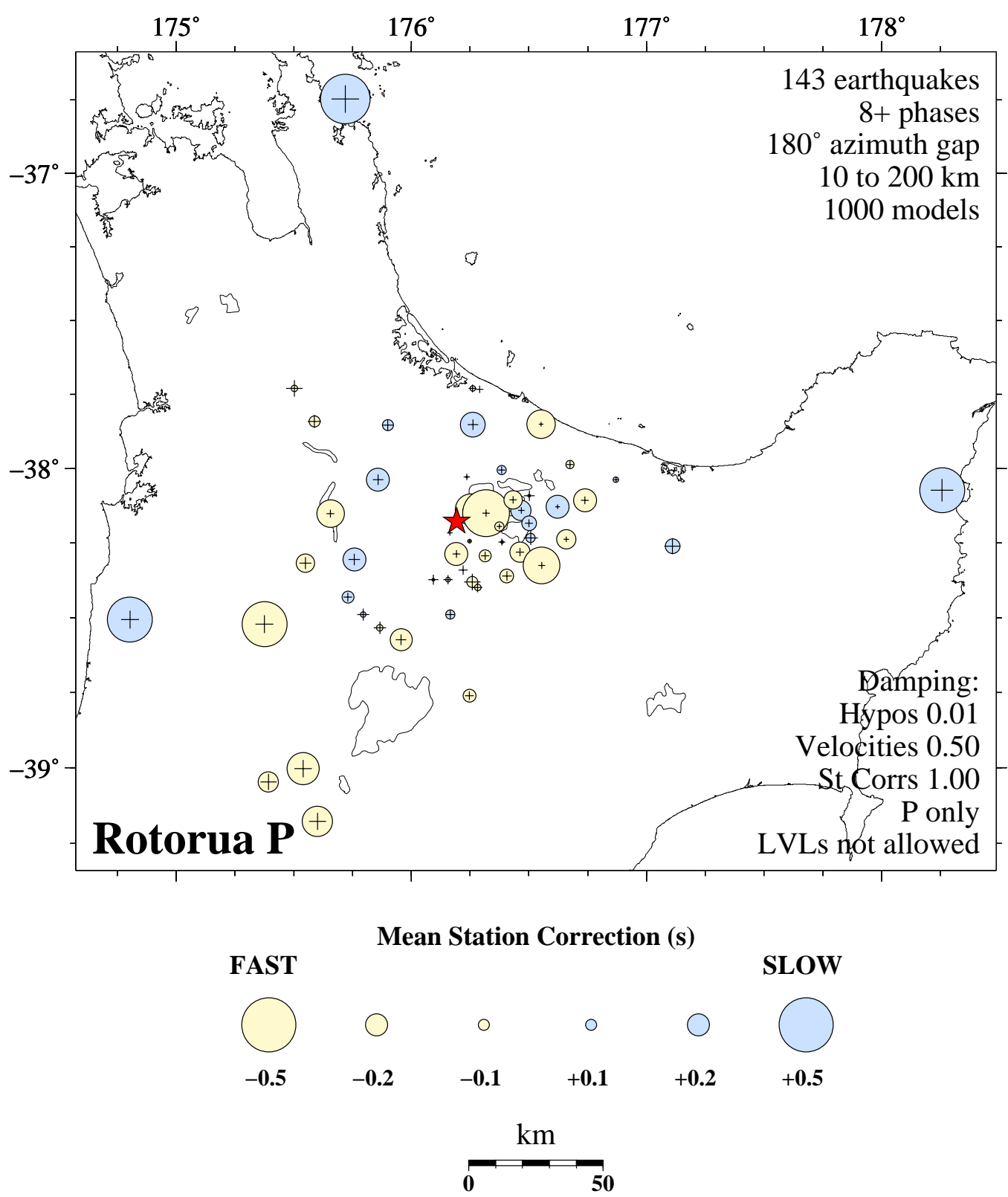

Figure 3.10: P-wave station corrections for Rotorua earthquakes. Circles are mean station corrections while crosses are standard deviations (same scale). Selection criteria and Velest control parameters are listed. Red star is UTU, the reference station, which by definition has no correction. 

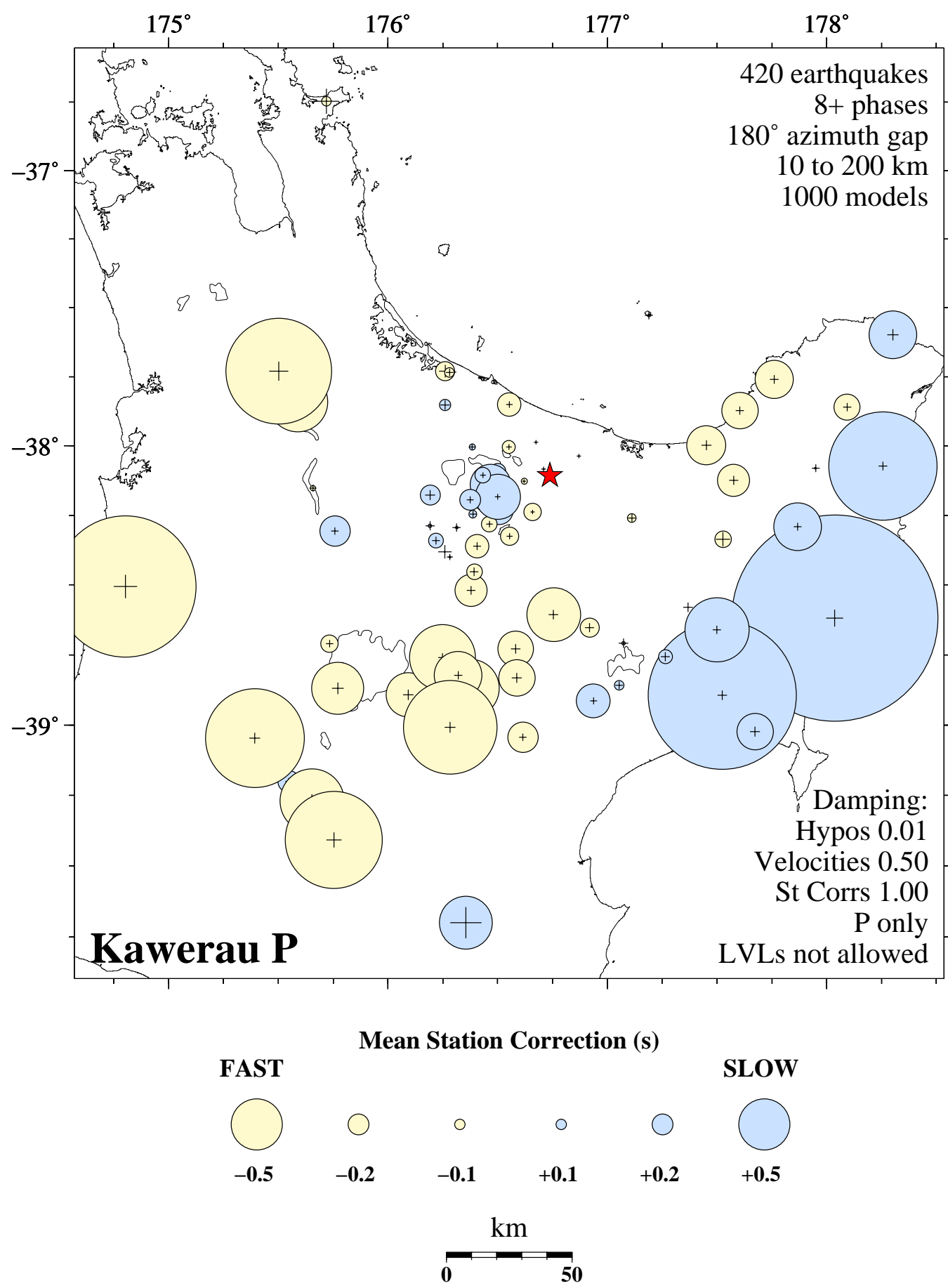

Figure 3.11: P-wave station corrections for Kawerau earthquakes. Circles are mean station corrections while crosses are standard deviations (same scale). Selection criteria and Velest control parameters are listed. Red star is EDRZ, the reference station, which by definition has no correction. 


\begin{tabular}{|l|l|l|l|l|l|l|}
\hline case & $\begin{array}{l}\text { Number } \\
\text { of } \\
\text { phases }\end{array}$ & $\begin{array}{l}\text { Azimuthal } \\
\text { gap }\left(^{\circ}\right)\end{array}$ & $\begin{array}{l}\text { Nearest } \\
\text { station } \\
(\mathrm{km})\end{array}$ & $\begin{array}{l}\text { Farthest } \\
\text { station } \\
(\mathrm{km})\end{array}$ & $\begin{array}{l}\text { Rotorua } \\
\text { events }\end{array}$ & $\begin{array}{l}\text { Kawerau } \\
\text { events }\end{array}$ \\
\hline $\mathbf{1}$ & $\mathbf{8}$ & $\mathbf{1 8 0}$ & $\mathbf{1 0}$ & $\mathbf{2 0 0}$ & $\mathbf{1 4 3}$ & $\mathbf{4 2 0}$ \\
2 & $6(7)$ & 180 & 10 & 200 & 191 & 585 \\
3 & 10 & 180 & 10 & 200 & 82 & 169 \\
4 & 8 & 120 & 10 & 200 & 83 & 135 \\
5 & 8 & 240 & 10 & 200 & 182 & 456 \\
6 & 8 & 180 & 5 & 200 & 78 & 184 \\
7 & 8 & 180 & 10 & 50 & 143 & 420 \\
\hline
\end{tabular}

Table 3.3: Different earthquake selection criteria tested for Rotorua and Kawerau. The bracketed number in the first column is for Kawerau only, where a minimum of 6 phases accepts too many earthquakes. The farthest station requirement is applied once earthquakes have been selected using the other three quality indicators. The bold row corresponds to the unaltered set of criteria.

quality identifiers chosen from a range of reasonable values, and that those given in Section 3.2 lie within that range.

We also test an alternative reference station for the Kawerau earthquake set. Station correction terms and layer velocities are calculated relative to a reference station, which itself is given a correction of zero seconds. In Section 3.4 the reference station for Kawerau is EDRZ (Edgecumbe), while in Figure 3.13 the reference station is TAZ (Tarawera, see Figure 2.1). For all but the two shallowest layers, the mean velocities shown in Figure 3.7 for reference station EDRZ are within $0.1 \mathrm{~km} / \mathrm{s}$ of those shown for TAZ in Figure 3.13 (black line). Such mismatches are small compared to the standard deviations in layer velocities we observe at those depths. This indicates that the well constrained parts of our velocity models are not significantly influenced by our choice of reference station.

The pink lines in Figures 3.12 and 3.13 show the mean velocity models 
obtained when phases recorded more than $50 \mathrm{~km}$ from their sources are excluded from the data set. These models appear to be poorly defined with relatively large standard deviations in velocities for layers more than $15 \mathrm{~km}$ deep. Encouragingly, these models also appear to be similar to the others shown in Figures 3.12 and 3.13 within the upper part of each model. This indicates that the velocities acquired for these shallow layers are not heavily influenced by distant stations and their varying surroundings, but are constrained by the local near-surface velocity structure.

We perform another set of 1000 inversions for Rotorua and Kawerau with the constraint on low velocity layers removed. Here, all the usual damping parameters, earthquake selection criteria and initial velocity models are applied. No velocity decreases are permitted in the initial models. Both mean models increase monotonically with depth with the exception of one layer in the Rotorua solution (Figure A.5 in the appendix). Here, there is a decrease in velocity between the surface layer and the $0 \mathrm{~km}$ layer. This decrease, however, is small compared to the standard deviations of these layer velocities, and so the assumption that there are no low velocity layers in the minimum 1-D model seems justified.

We also carry out a set of 100 Velest runs for both Kawerau and Rotorua using constant initial velocity models. These models range from 1 to $9 \mathrm{~km} / \mathrm{s}$ and are chosen randomly within this range. During these runs, the damping of velocities, station corrections and hypocentres are all loosened to 0.01 to allow the models to seek RMS minima before the inversions stop. In both cases, the models fail to achieve the same shape as those attained above, and appear straighter, with relatively high velocities shallower than $15-20 \mathrm{~km}$, 


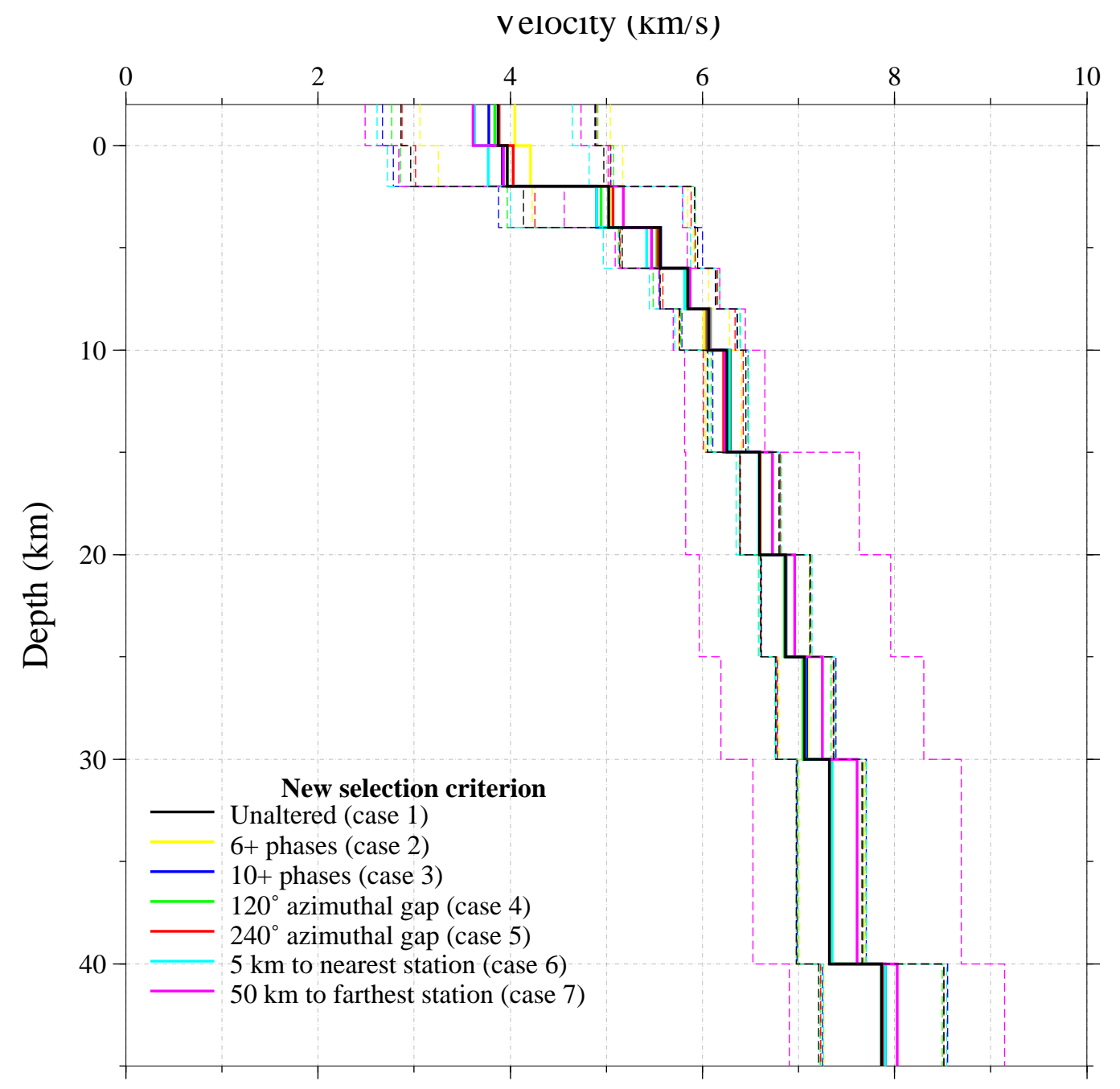

Figure 3.12: Mean P-wave velocity models (solid lines) for Rotorua from 1000 Velest inversions using a variety of earthquake selection criteria. In each case, one criterion differs from the value chosen for it in in section 3.2. Dashed lines enclose one standard deviation for each layer. 


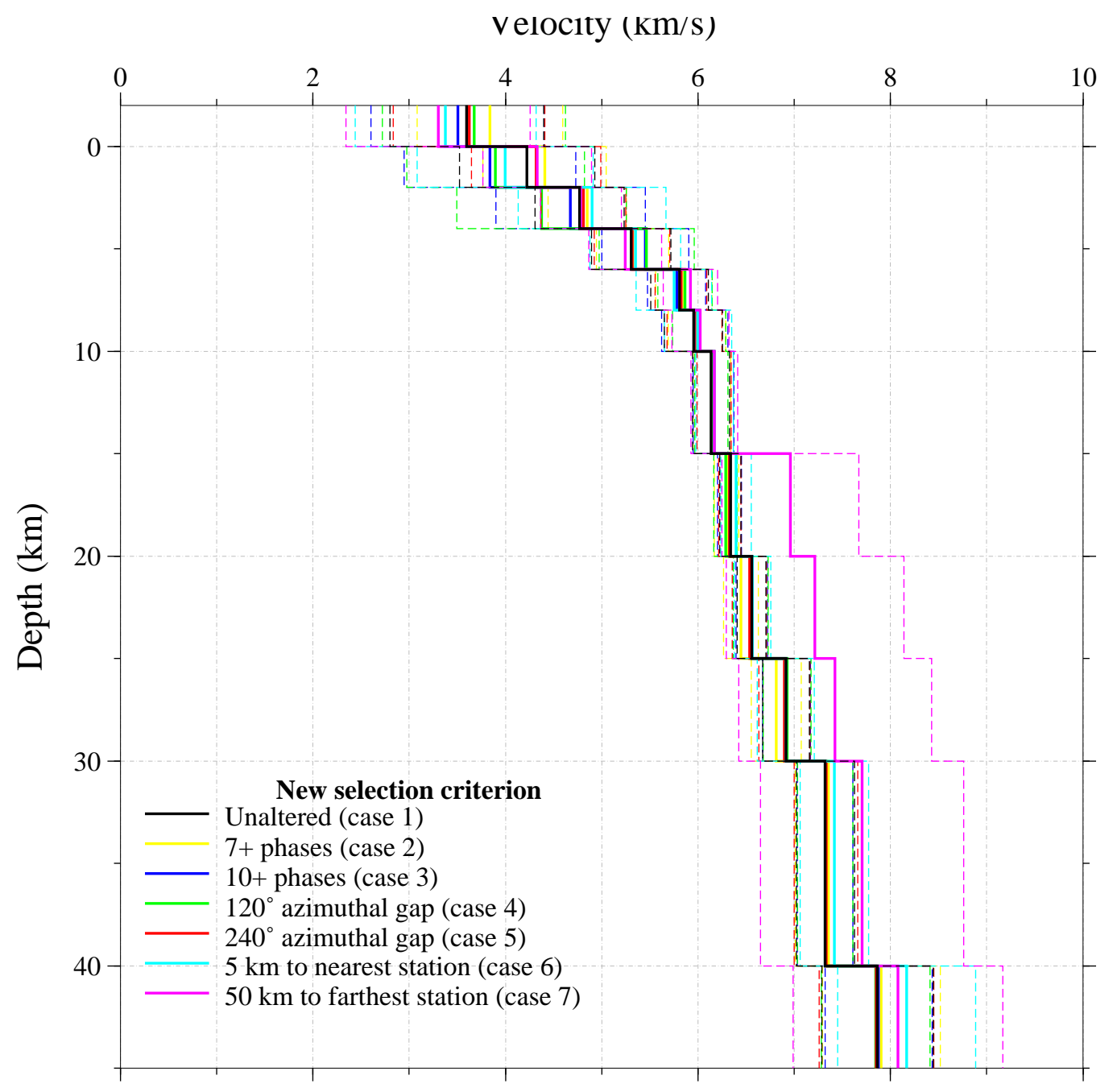

Figure 3.13: Mean P-wave velocity models (solid lines) for Kawerau from 1000 Velest inversions using a variety of earthquake selection criteria. In each case, one criterion differs from the value chosen for it in in section 3.2. Dashed lines enclose one standard deviation for each layer. 
and low velocities in deeper layers. These models are shown in Figures A.6 and A.7 in the appendix where they are coloured according to earthquake RMS misfit. Note that these models have relatively high (blue) misfits, particularly in the case of Rotorua, implying that the data are not well fit and the inversion is unable to overcome highly unrealistic initial velocity models.

\subsection{P- and S-wave velocity model}

\subsubsection{Earthquake selection}

We impose a fourth selection criterion to identify earthquakes for a joint $\mathrm{P}_{-}$ and S-wave velocity model inversion. Any earthquake with less than three S-wave observations is rejected. This leaves 112 earthquakes in the Rotorua set, and 376 in the Kawerau set. We include P-wave data in these inversions to better constrain earthquake hypocentres which in turn act to produce more reliable P- and S-wave velocity models. These earthquakes' catalogue locations are shown in Figures 3.14 and 3.15.

\subsubsection{Initial velocity models}

We randomly produce combined P- and S-wave velocity models for 1000 Velest runs as follows: P-wave velocities are randomly picked within one standard deviation of the means found for each layer in Section 3.4. Again, velocities are not permitted to decrease with depth. A random S-wave velocity model is then produced in the same way as described for the P-wave models in Section 3.4, with the exception that S-wave velocities are not al- 


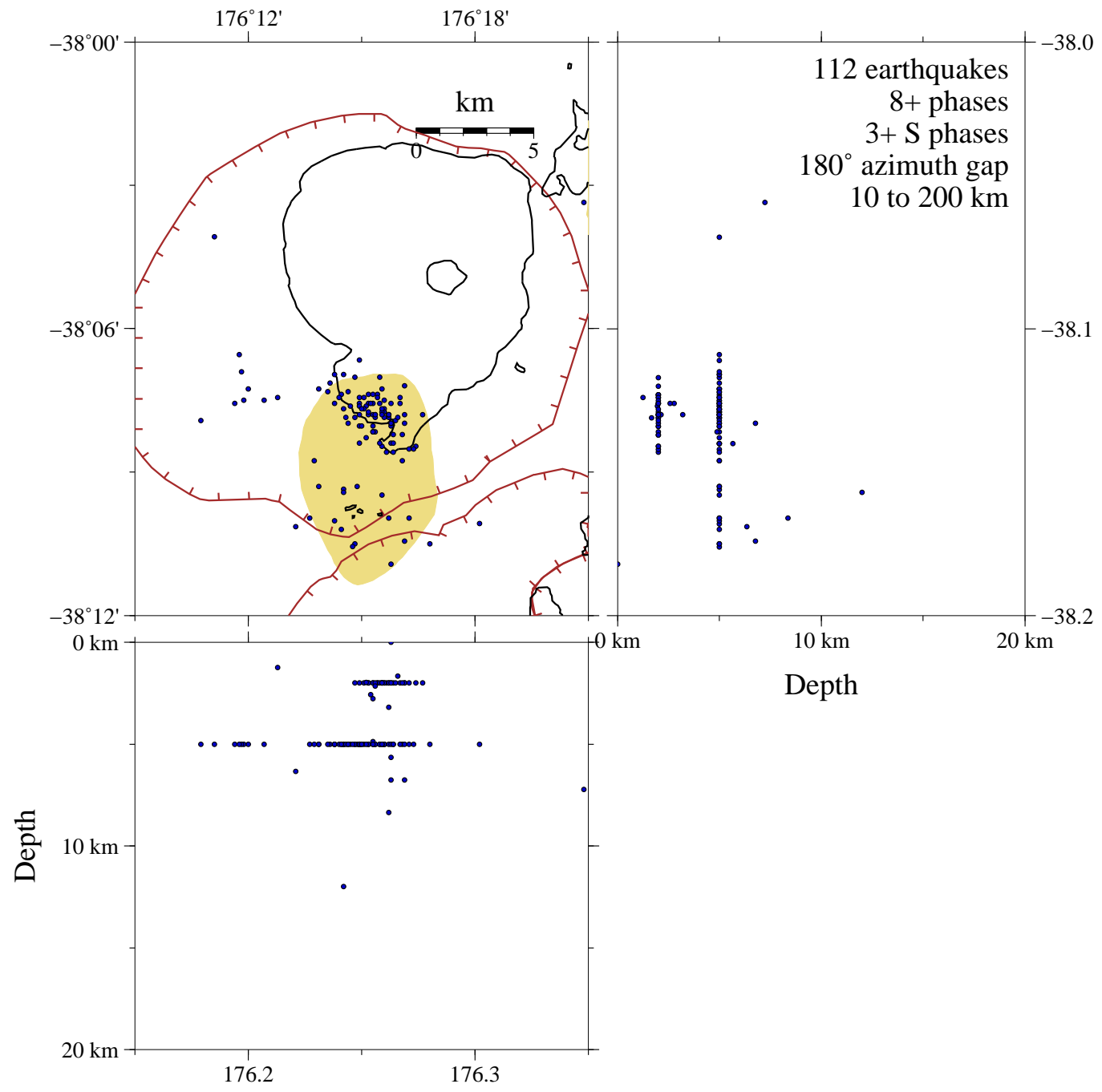

Figure 3.14: Initial GeoNet hypocentres for the 112 earthquakes in the Rotorua $\mathrm{P}$ - and S-wave velocity modelling set. Brown hachured lines mark calderas. Yellow areas are geothermal fields. 


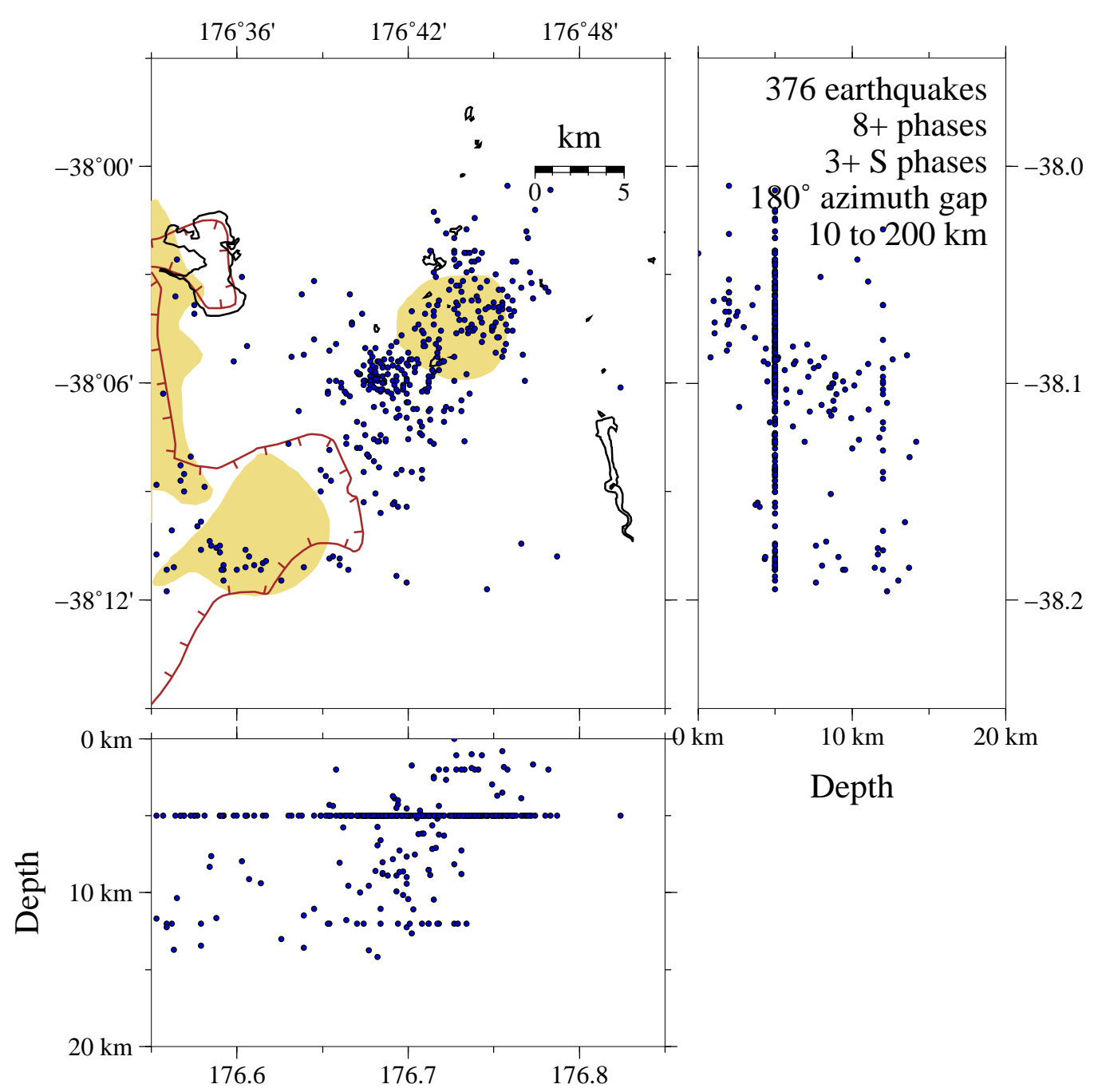

Figure 3.15: Initial GeoNet hypocentres for the 376 earthquakes in the Kawerau P- and S-wave velocity modelling set. Brown hachured lines mark calderas. Yellow areas are geothermal fields. 
lowed to exceed P-wave velocities for any given layer within any model, and the $-3 \mathrm{~km}$ velocities are between 0 and $3 \mathrm{~km} / \mathrm{s}$ and those for the $40 \mathrm{~km}$ layer are between 3 and $9 \mathrm{~km} / \mathrm{s}$.

Figure 3.16 shows 15 such random models. The blue lines are P-wave velocity models constrained by the P-wave inversion solution for Kawerau (see Figure 3.7). The red lines are random S-wave velocity models.

\subsubsection{Control parameters}

For each joint $\mathrm{P}$ - and S-wave inversion, we use the same control parameters as for the P-only runs, with one exception. As the aim of this task is to produce S-wave velocity models that are relevant to our two sets of earthquakes, we want the outcome to be influenced as much as possible by S-wave arrival time data rather than the $\mathrm{P}$-wave data which were used to resolve the $\mathrm{P}$ wave velocity models in Section 3.4. To do this, we up-weight each S phase by a factor of two relative to P phases of equal GeoNet quality. This weighting is artificial and does not fairly represent the quality of the $\mathrm{P}$ phase arrival times compared to those of the S phases. Consequently, the P-wave velocity model and station corrections cannot be expected to be as realistic as those found in the $\mathrm{P}$-wave inversions.

\subsubsection{Results}

Figures 3.17 and 3.18 show the minimum 1-D velocity models after 1000 Velest joint P- and S-wave inversions for Rotorua and Kawerau, respectively. In both cases, the output $\mathrm{P}$-wave velocity models seem to remain within the 


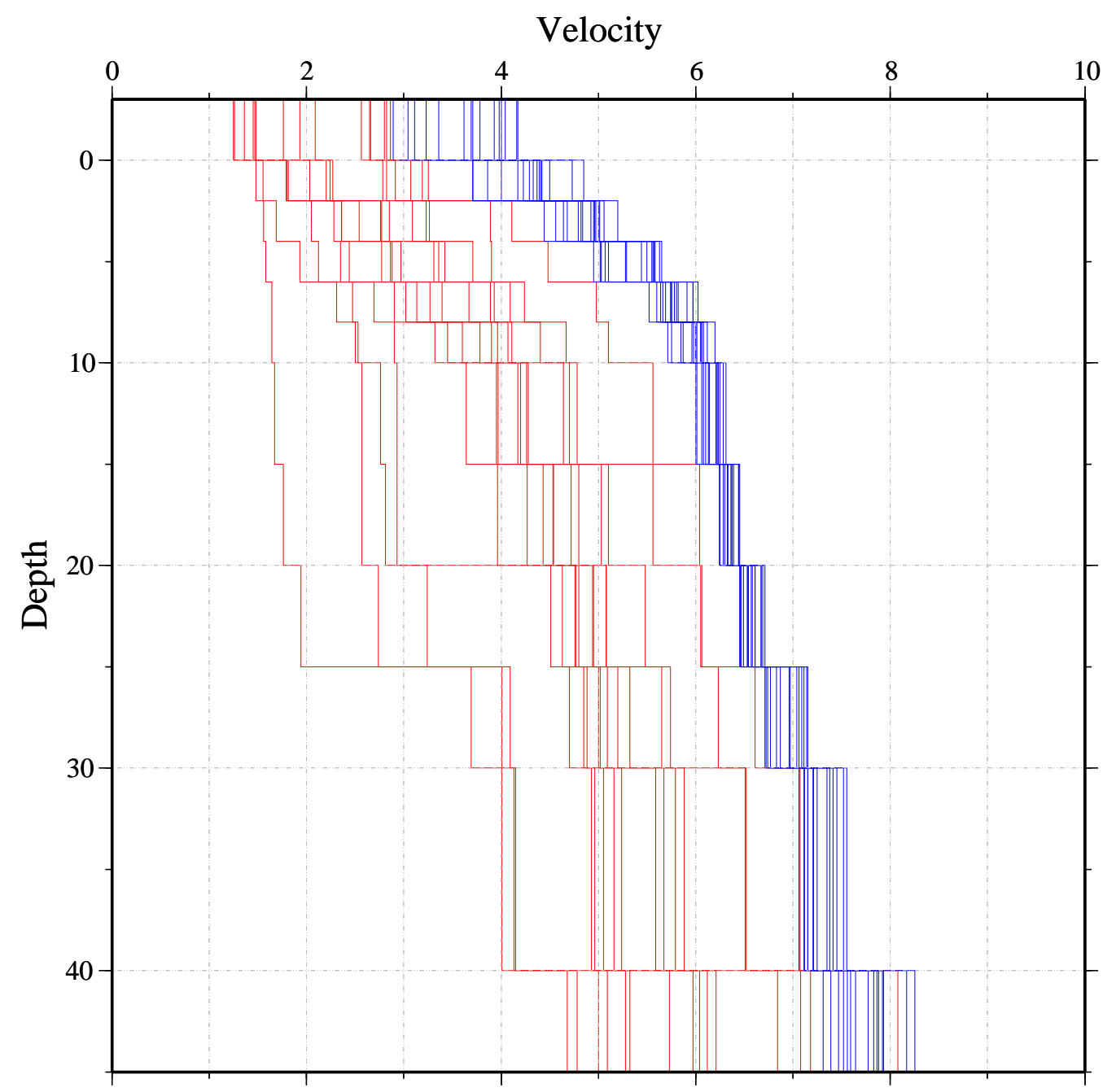

Figure 3.16: Fifteen randomly generated $\mathrm{P}$ - and S-wave velocity models. Blue lines are P-wave models (see text for explanation). Red lines are Swave models. 
bounds set by the P-wave inversions, particularly for layers deeper than 2 $\mathrm{km}$. In the upper two layers, the final $\mathrm{P}$-wave velocities tend to be slower than their initial values. The S-wave models also appear tightly constrained at most depths. The initial S-wave velocity models sample a wide range of velocities within each layer, so this stability is encouraging. It must be noted, however, that the presence of $\mathrm{P}$-wave data, and the narrow range of sampled P-wave velocity models may influence these S-wave velocity models, making them seem better resolved than they truly are by the S-wave data alone. These models are also shown in Figures 3.19 and 3.20 where they are coloured according to their associated earthquake arrival time misfit. These figures also show the ratio of mean P- and S-wave velocities within each layer.

The mean velocities we obtain for each layer from our joint P-and Swave inversions are listed in Tables 3.4 and 3.5 for Rotorua and Kawerau, respectively. Standard deviations from the 1000 inversions are also listed. As mentioned in section 3.4.3, the small standard deviations listed for the deepest layers are not indicative of the extent to which our data constrain the velocities at these depths.

Figures 3.21 and 3.22 show the mean hypocentres for the Rotorua and Kawerau P- and S-wave velocity modelling earthquake sets, respectively, after 1000 P- and S-wave inversions. Again, these solutions appear more tightly clustered than their GeoNet counterparts (Figures 3.14 and 3.15). Within the Kawerau geothermal field, the cloud of earthquakes shown in Figure 3.15 has shifted to the south and condensed into two northeast-southwest trending streaks (Figure 3.22). It is possible, however, that these streaks are artefacts, as the $95 \%$ confidence ellipses for these events' epicentres also predominantly 

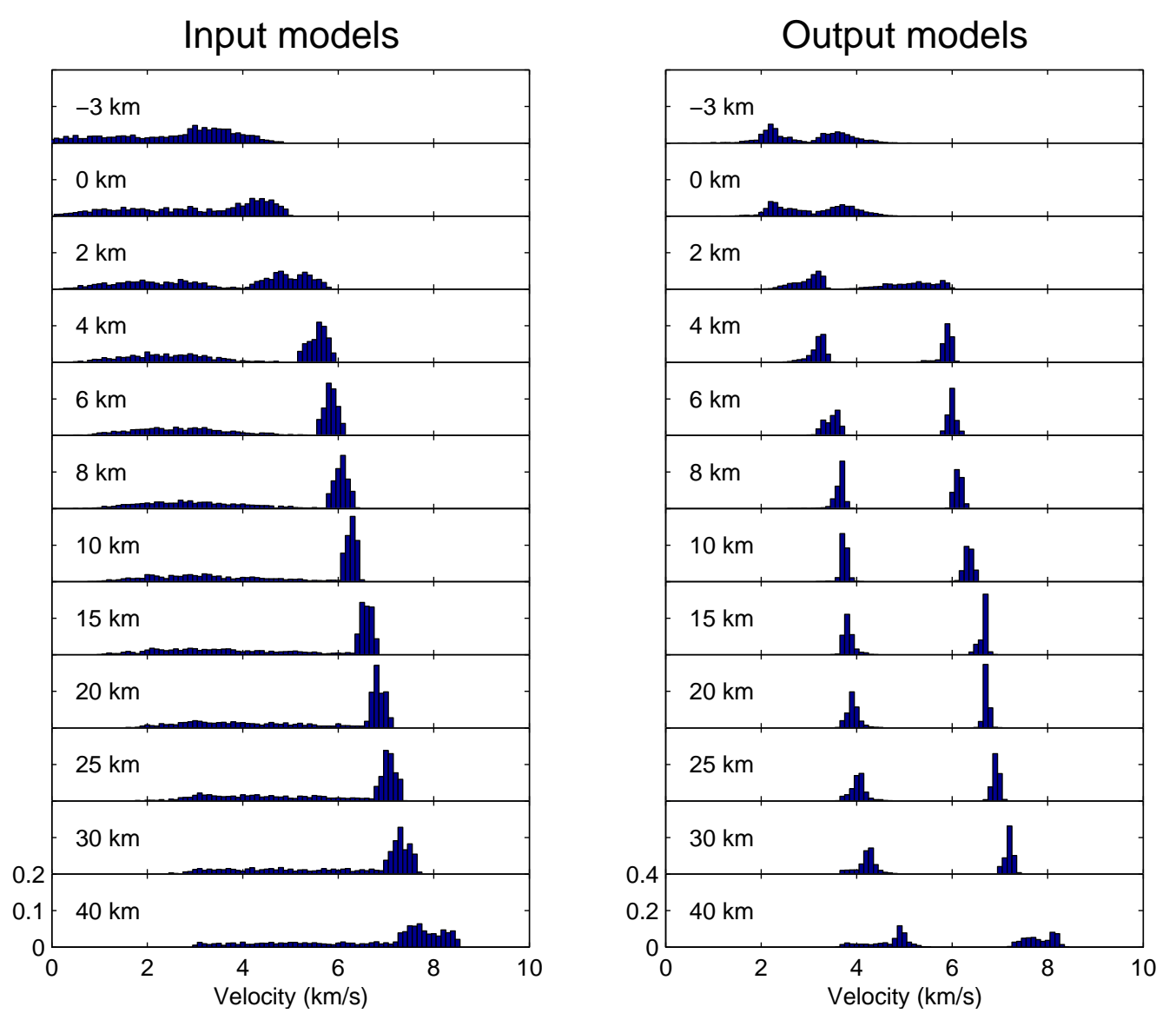

Figure 3.17: Histograms showing the distribution of velocities at each layer for 1000 initial (left) and final (right) P- and S-wave velocity models for Rotorua. Earthquake selection criteria and Velest control parameters are listed. The number in each panel indicates the depth to the top of that layer. Vertical scales (bottom panel) are constant for each profile and are frequencies as proportions of the 1000 initial models. 

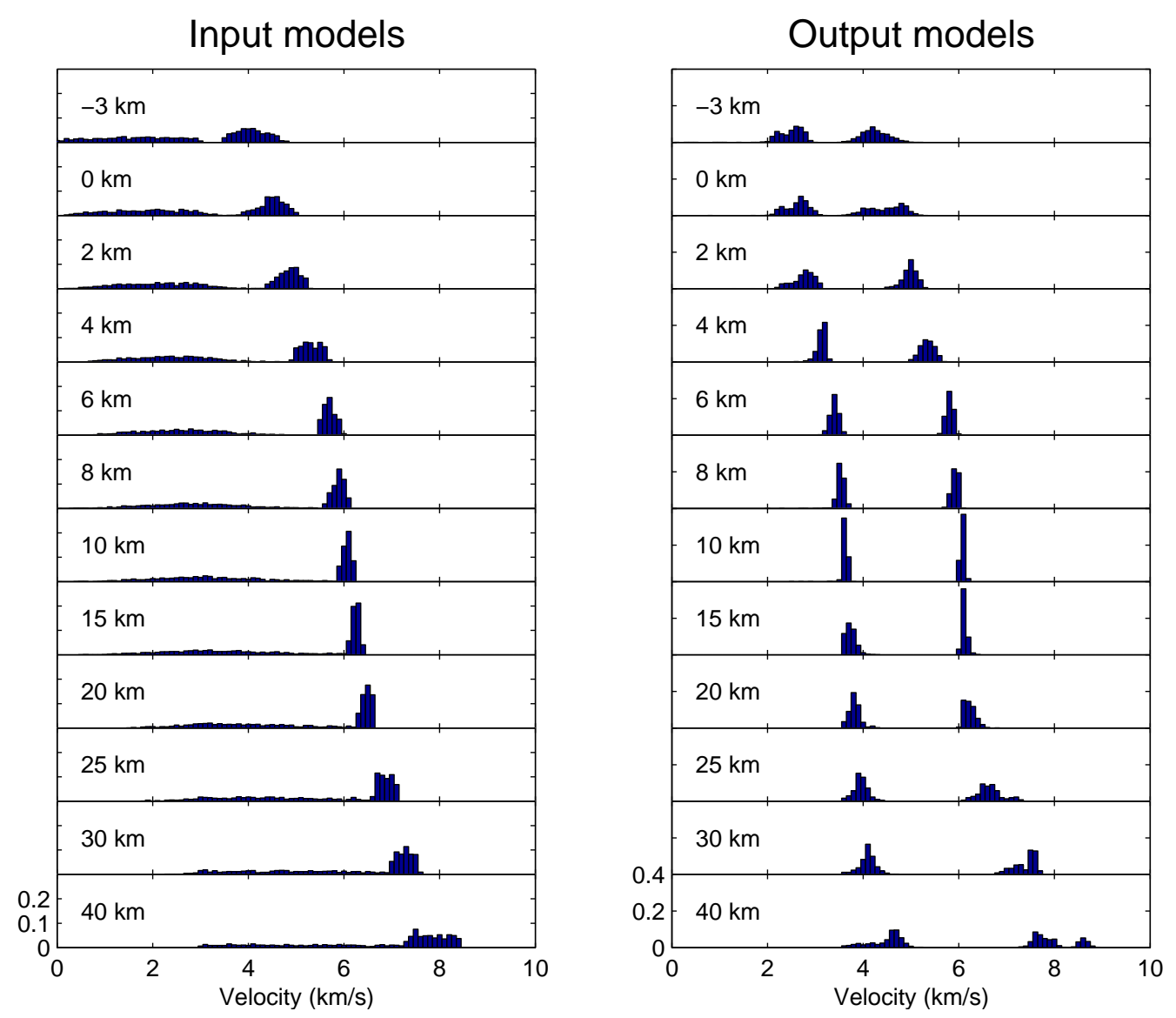

Figure 3.18: Histograms showing the distribution of velocities at each layer for 1000 initial (left) and final (right) P- and S-wave velocity models for Kawerau. Earthquake selection criteria and Velest control parameters are listed. The number in each panel indicates the depth to the top of that layer. Vertical scales (bottom panel) are constant for each profile and are frequencies as proportions of the 1000 initial models. 


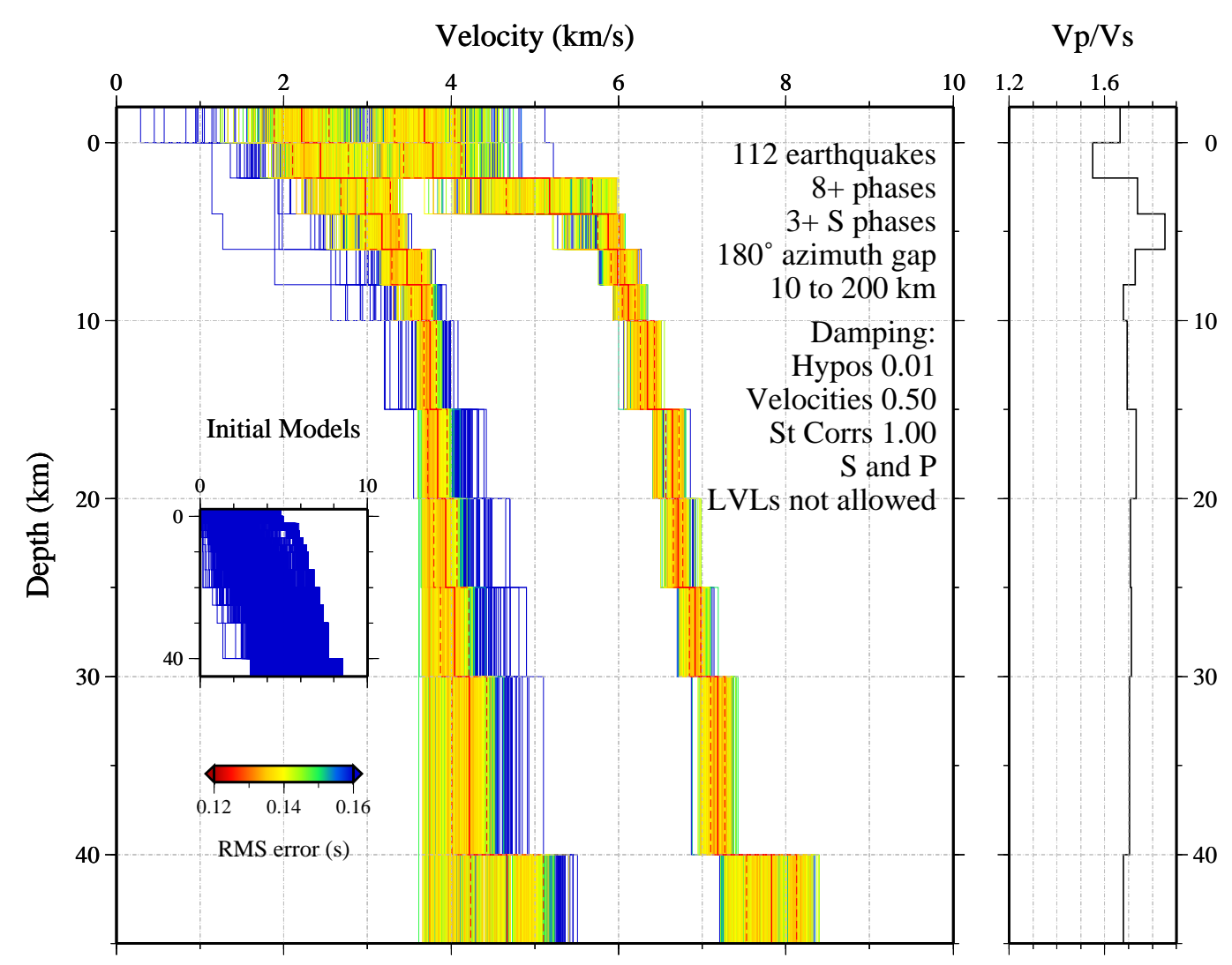

Figure 3.19: (left) $1000 \mathrm{P}$ - and S-wave velocity models for Rotorua generated by Velest coloured according to the earthquake misfit they produce. Earthquake selection criteria and Velest control parameters are listed. "LVLs" are low velocity layers. The inset shows the distribution of input random models. The solid red line shows the mean velocity for each layer, bound by one standard deviation (dashed red lines). (right) $V_{P} / V_{S}$ calculated from mean layer P- and S-wave velocities. 


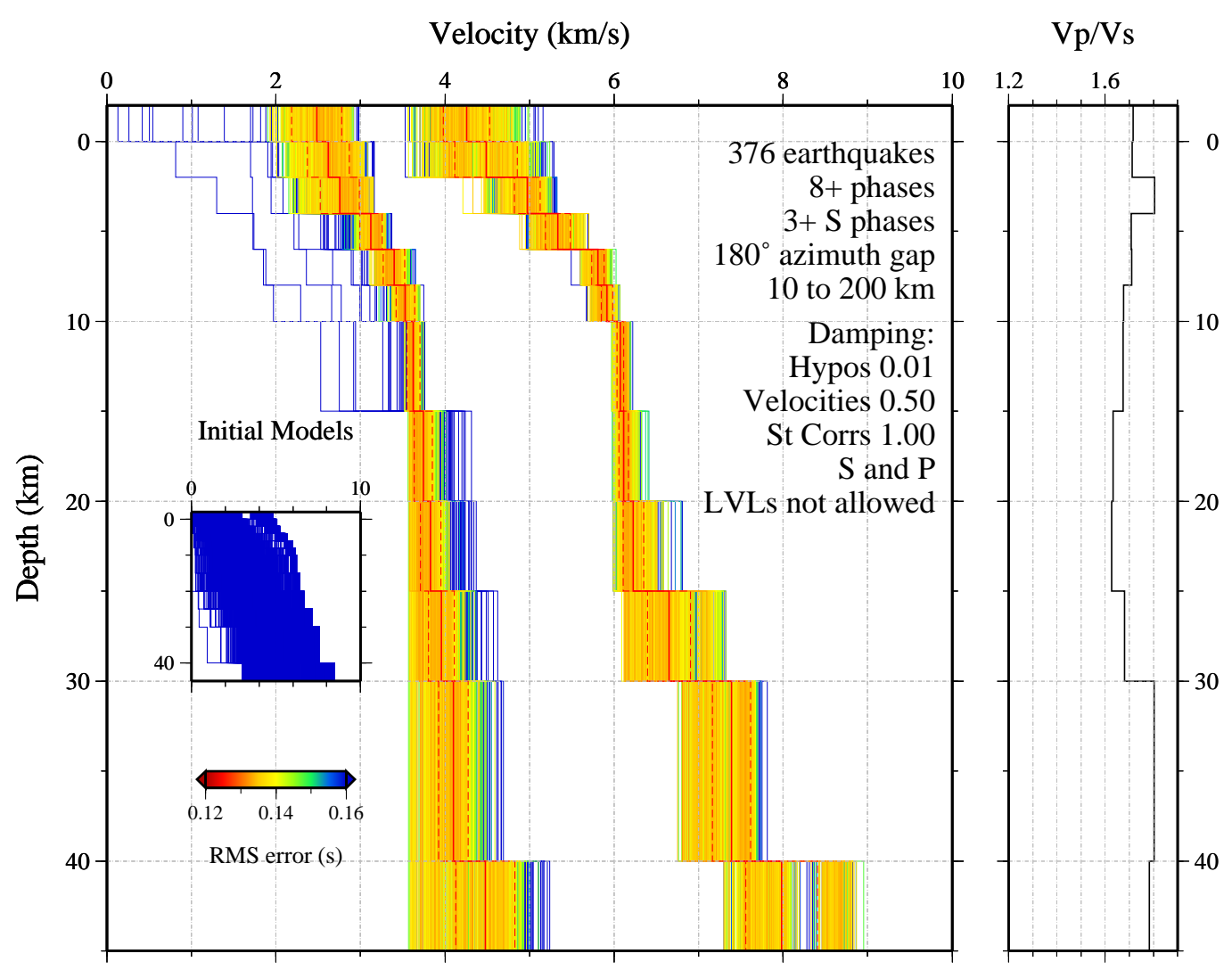

Figure 3.20: (left) $1000 \mathrm{P}$ - and S-wave velocity models for Kawerau generated by Velest coloured according to the earthquake misfit they produce. Earthquake selection criteria and Velest control parameters are listed. "LVLs" are low velocity layers. The inset shows the distribution of input random models. The solid red line shows the mean velocity for each layer, bound by one standard deviation (dashed red lines). (right) $V_{P} / V_{S}$ calculated from mean layer P- and S-wave velocities. 


\begin{tabular}{|l|l|l|l|l|}
\hline $\begin{array}{l}\text { Depth } \\
(\mathrm{km})\end{array}$ & $\begin{array}{l}\text { P velocity } \\
(\mathrm{km} / \mathrm{s})\end{array}$ & $\begin{array}{l}\text { P deviation } \\
(\mathrm{km} / \mathrm{s})\end{array}$ & $\begin{array}{l}\text { S velocity } \\
(\mathrm{km} / \mathrm{s})\end{array}$ & $\begin{array}{l}\text { S deviation } \\
(\mathrm{km} / \mathrm{s})\end{array}$ \\
\hline-3 & 3.68 & 0.36 & 2.21 & 0.33 \\
0 & 3.78 & 0.35 & 2.44 & 0.33 \\
2 & 5.17 & 0.52 & 2.98 & 0.30 \\
4 & 5.88 & 0.13 & 3.17 & 0.20 \\
6 & 5.99 & 0.08 & 3.47 & 0.18 \\
8 & 6.12 & 0.08 & 3.65 & 0.13 \\
10 & 6.34 & 0.08 & 3.75 & 0.07 \\
15 & 6.64 & 0.08 & 3.84 & 0.11 \\
20 & 6.71 & 0.06 & 3.93 & 0.14 \\
25 & 6.91 & 0.07 & 4.04 & 0.17 \\
30 & 7.19 & 0.08 & 4.22 & 0.21 \\
40 & 7.83 & 0.30 & 4.67 & 0.43 \\
\hline
\end{tabular}

Table 3.4: Final P- and S-wave velocity models with corresponding standard deviations for Rotorua.

\begin{tabular}{|l|l|l|l|l|}
\hline $\begin{array}{l}\text { Depth } \\
(\mathrm{km})\end{array}$ & $\begin{array}{l}\text { P velocity } \\
(\mathrm{km} / \mathrm{s})\end{array}$ & $\begin{array}{l}\text { P deviation } \\
(\mathrm{km} / \mathrm{s})\end{array}$ & $\begin{array}{l}\text { S velocity } \\
(\mathrm{km} / \mathrm{s})\end{array}$ & $\begin{array}{l}\text { S deviation } \\
(\mathrm{km} / \mathrm{s})\end{array}$ \\
\hline-3 & 4.25 & 0.28 & 2.48 & 0.30 \\
0 & 4.48 & 0.37 & 2.62 & 0.25 \\
2 & 4.97 & 0.15 & 2.76 & 0.23 \\
4 & 5.34 & 0.15 & 3.12 & 0.13 \\
6 & 5.81 & 0.07 & 3.40 & 0.13 \\
8 & 5.92 & 0.07 & 3.53 & 0.11 \\
10 & 6.07 & 0.04 & 3.63 & 0.07 \\
15 & 6.11 & 0.05 & 3.74 & 0.11 \\
20 & 6.23 & 0.12 & 3.83 & 0.12 \\
25 & 6.65 & 0.25 & 3.96 & 0.15 \\
30 & 7.39 & 0.23 & 4.10 & 0.18 \\
40 & 7.98 & 0.42 & 4.48 & 0.35 \\
\hline
\end{tabular}

Table 3.5: Final P- and S-wave velocity models with corresponding standard deviations for Kawerau. 
align in that direction.

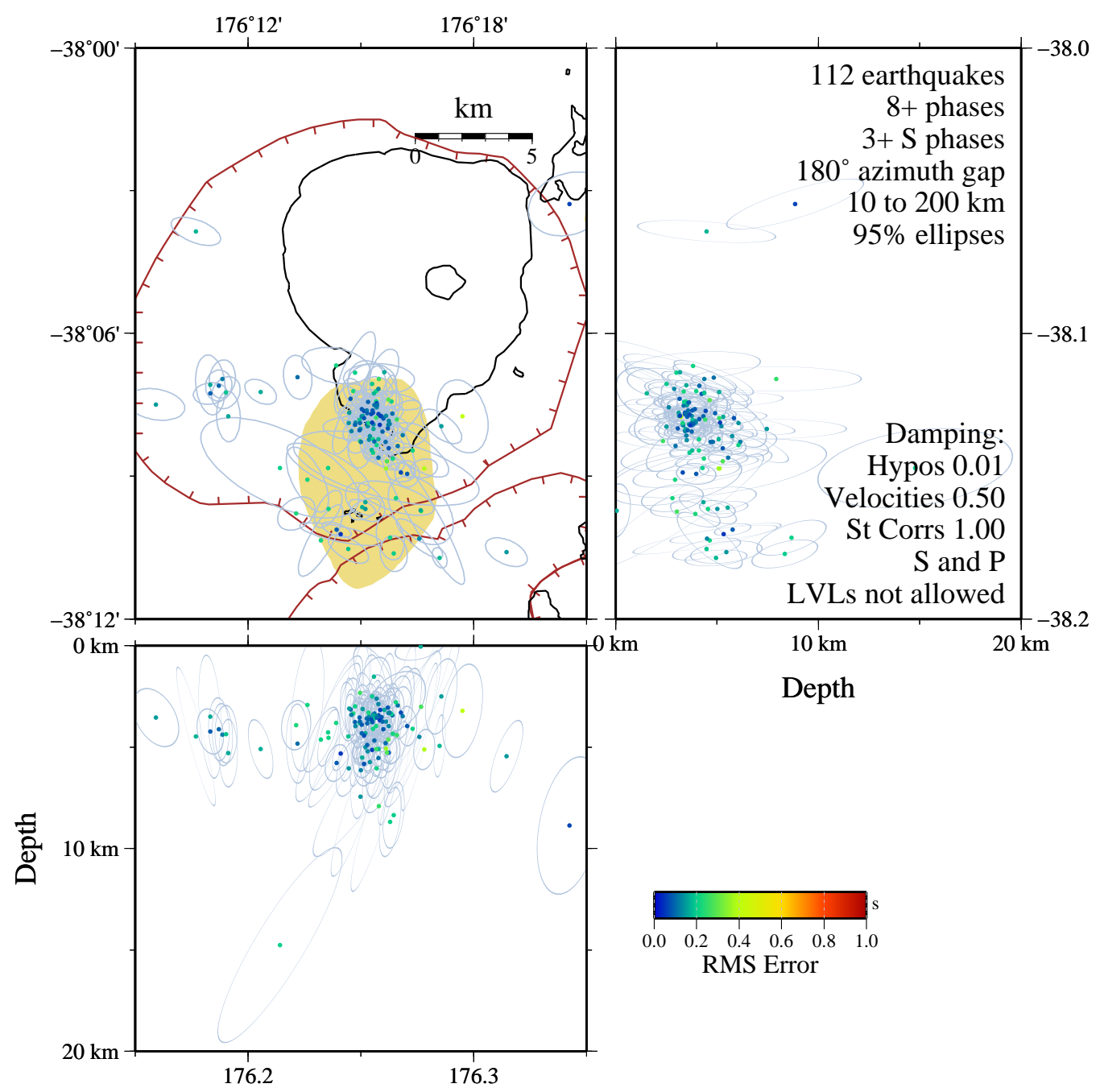

Figure 3.21: Final hypocentres for the Rotorua P- and S-wave velocity modelling earthquake set after 1000 Velest inversions. Selection criteria and Velest control parameters are listed. Dots are mean locations and are coloured by RMS misfit. Ellipses show 95\% confidence intervals, assuming normally distributed solutions in each dimension. Brown hachured lines mark calderas. Yellow areas are geothermal fields.

S-wave station corrections are shown in Figures 3.23 and 3.24. These show a similar pattern to the P-wave corrections far from the Rotorua and Kawerau geothermal fields (Figures 3.10 and 3.11, respectively), but at shorter 


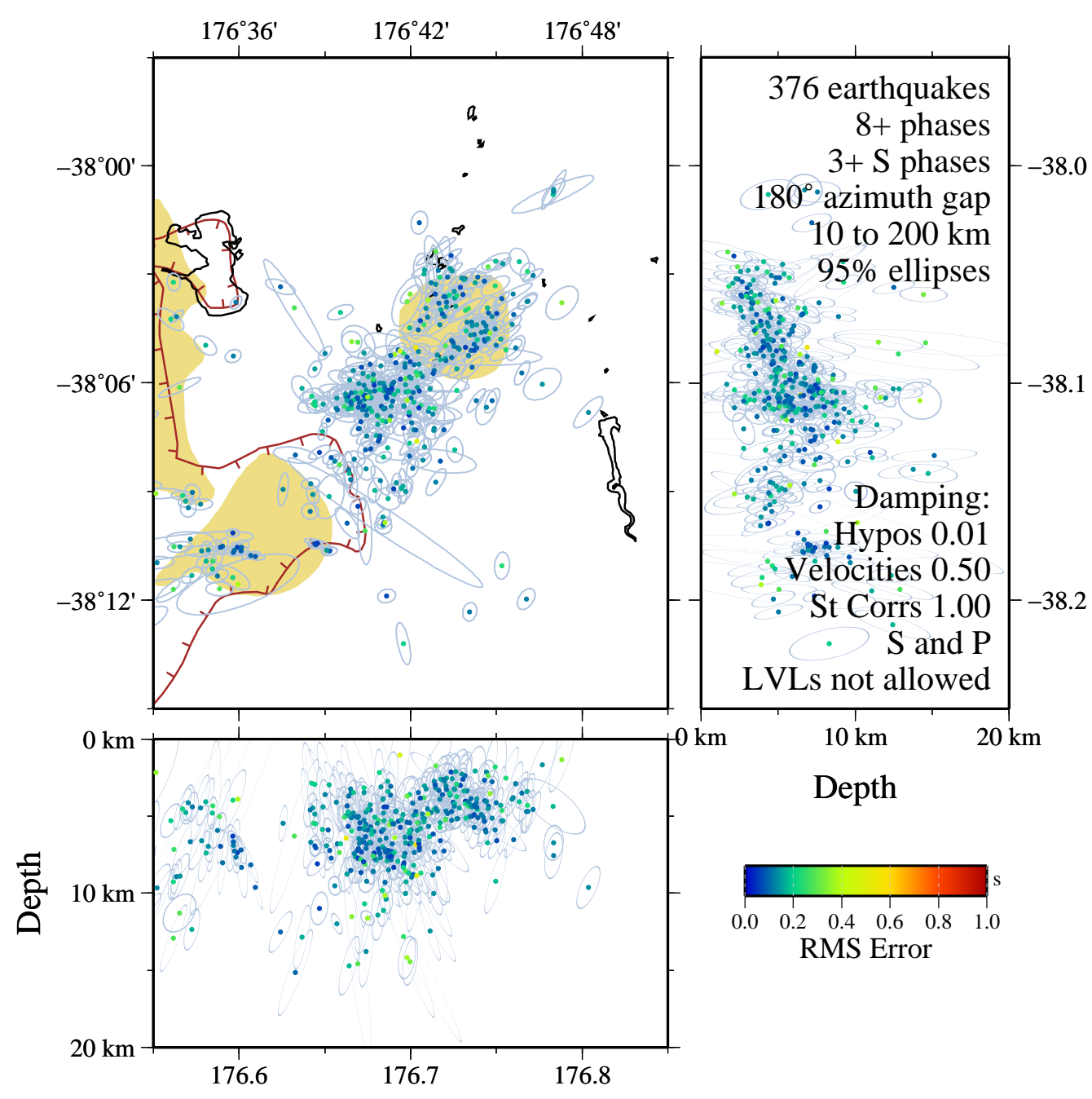

Figure 3.22: Final hypocentres for the Kawerau P- and S-wave velocity modelling earthquake set after 1000 Velest inversions. Selection criteria and Velest control parameters are listed. Dots are mean locations and are coloured by RMS misfit. Ellipses show 95\% confidence intervals, assuming normally distributed solutions in each dimension. Brown hachured lines mark calderas. Yellow areas are geothermal fields. 
distances the distribution is more variable.

\subsubsection{Discussion}

The earthquake locations obtained when we invert P- and S-wave arrival times don't appear as well constrained as the locations obtained when using P-wave data alone. For example, the ellipses around the hypocentres in Figure 3.8 appear smaller than those in 3.21, indicating the scatter in our locations increases when S-wave data are included. This seemingly counterintuitive result could be due the use of high weights for S-wave data relative to $\mathrm{P}$-wave data during the $\mathrm{P}$ - and $\mathrm{S}$-wave inversions. This weighting may lead to earthquake locations being primarily constrained by S-wave data, which are generally less accurate than P-wave arrival times. Another reason for the increased location scatter could be the increased range of possible Pand S-wave velocity models compared to P-wave models alone. Because the ellipses in Figures 3.21 and 3.22 represent the extent to which differing velocity models influence earthquake locations, the increased model variability may be manifest as increased scatter in the final set of earthquake locations.

The $V_{P} / V_{S}$ ratios in the well constrained part of our velocity models (4 to $15 \mathrm{~km}$ depth) range between 1.68 and 1.73 in Rotorua, and 1.63 and 1.71 in Kawerau, consistent with the Wadati diagrams shown in Figures B.1 and B.2 in the appendix. These low values are similar that of 1.71 obtained by Chatterjee et al. (1985) using Wadati diagrams for the geothermally active Yellowstone National Park region. Chatterjee et al. (1985) attribute this low $V_{P} / V_{S}$ ratio to the presence of hot water at pressures and temperatures 

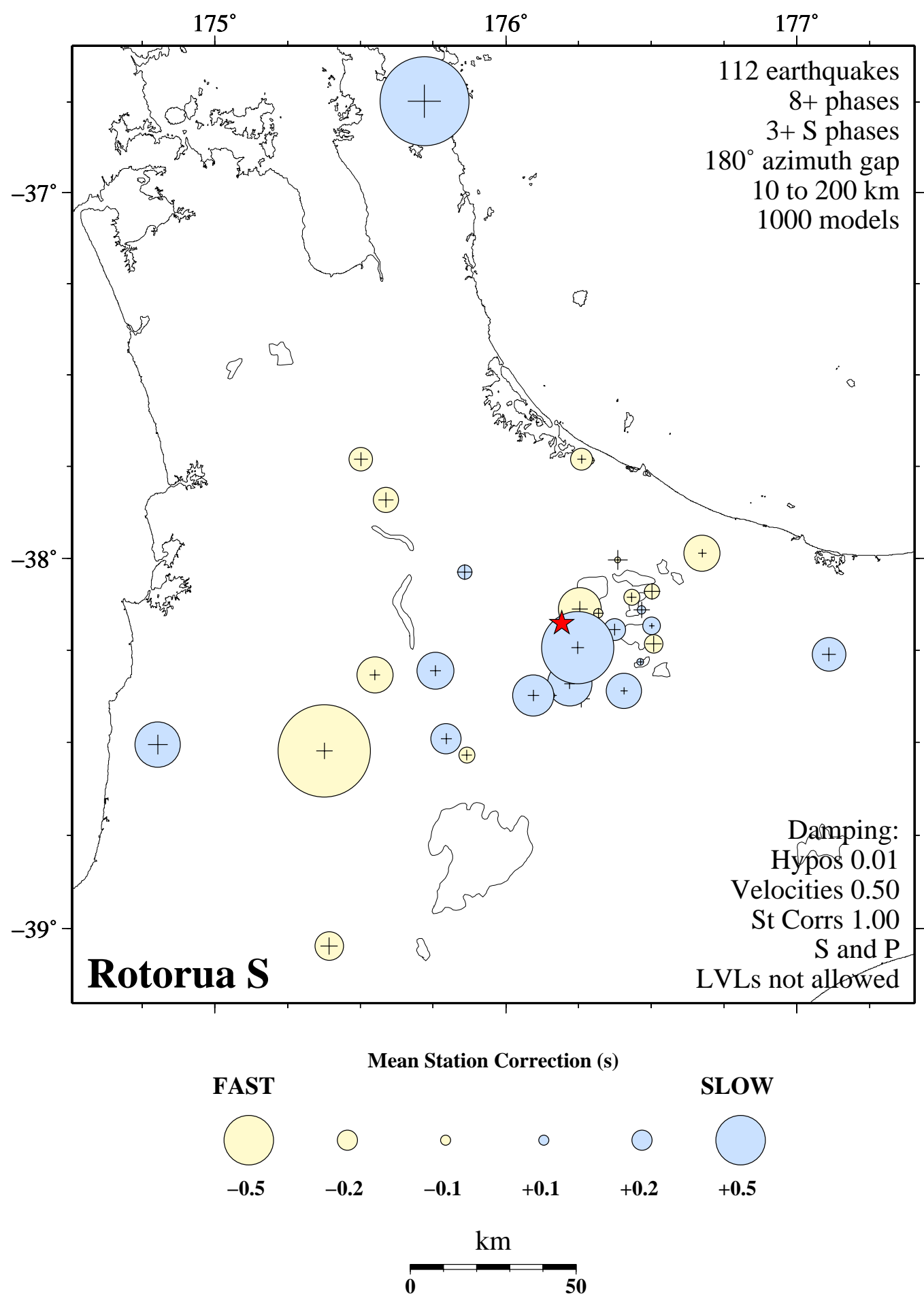

Figure 3.23: S-wave station corrections for Rotorua earthquakes after joint $\mathrm{P}$ - and S-wave Velest inversions. Circles are mean station corrections while crosses are standard deviations (same scale). Selection criteria and Velest control parameters are listed. Red star is UTU, the reference station, which by definition has no correction. 

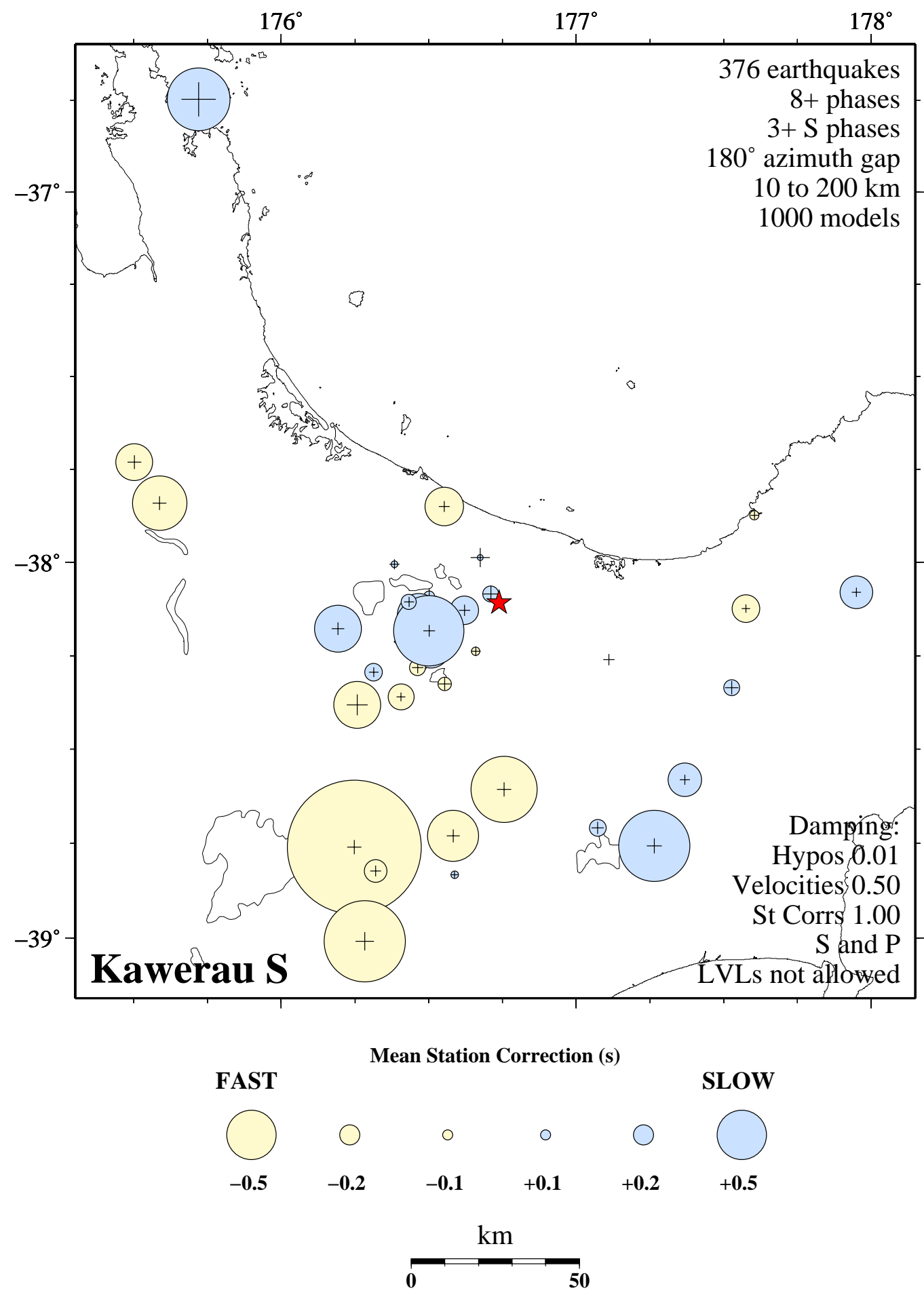

Figure 3.24: S-wave station corrections for Kawerau earthquakes after joint $\mathrm{P}$ - and S-wave Velest inversions. Circles are mean station corrections while crosses are standard deviations (same scale). Selection criteria and Velest control parameters are listed. Red star is EDRZ, the reference station, which by definition has no correction. 
near the water-steam transition in the Yellowstone area. These ratios are also consistent with those of Reyners et al. (2006), who use 3-D seismic tomography in the central North Island and obtain ratios of around 1.65 to 1.70 at similar depths in the central TVZ.

The P-wave station corrections for the Kawerau earthquake set exhibit a striking pattern of large positive values on the east coast of the North Island (Figure 3.11). This indicates the rays from Kawerau to the east coast sample slow seismic velocities relative to our minimum 1-D models. At first this result seems surprising as the westward-subducting Pacific plate exists at increasingly shallow depths to the east of the TVZ. However, Reyners et al. (2006) find that for depths shallower than around $25 \mathrm{~km}$, P-wave velocities tend to decrease between the TVZ and the eastern North Island above the subducting plate. This indicates our P-wave station corrections are representative of shallow $3-\mathrm{D}$ velocity heterogeneity.

We compare the final P-wave velocity models with that obtained for the central North Island by Stratford and Stern (2006) using active-source seismic imaging techniques. For the TVZ, the modelled P-wave velocities of Stratford and Stern (2006) increase smoothly between 5.5 and $5.9 \mathrm{~km} / \mathrm{s}$ as depth increases from 2 to $15 \mathrm{~km}$ (Figure 3.25). This is consistent with the well-resolved part (4 to $15 \mathrm{~km}$ depth) of our P-wave velocity models. Our models, however, lack the sharp velocity increase found by Stratford and Stern (2006) near $15 \mathrm{~km}$ depth in the TVZ. This suggests these models represent an average velocity structure for all ray paths to stations both within and outside the TVZ at these depths. 


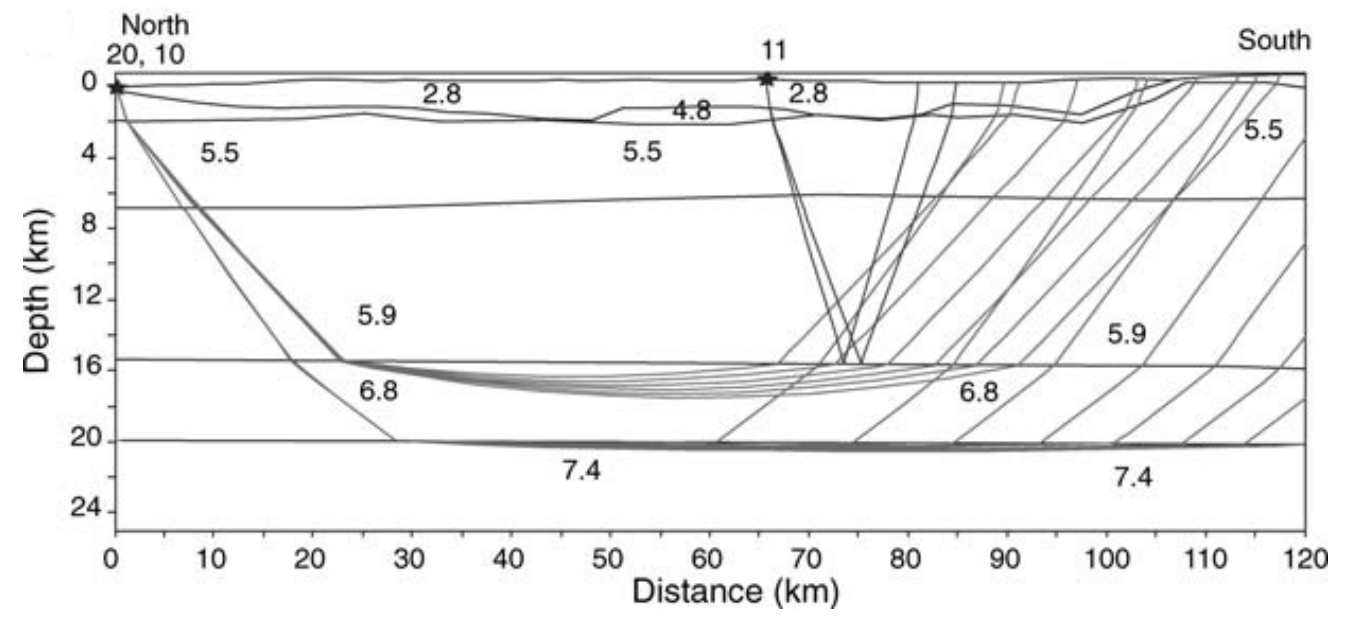

Figure 3.25: P-wave velocity model for a line running north to south along the Taupo Volcanic Zone. P-wave velocities are labelled and seismic ray paths are overlain. From Stratford and Stern (2006).

\subsection{Summary}

Using a joint hypocentre-velocity model inversion, we develop P- and S-wave velocity models for Rotorua and Kawerau. We test the influence that several earthquake selection criteria and inversion control parameters have on the resulting models and find the solutions are consistent in most cases. We also show that these models are well constrained by earthquake data at seismogenic depths (around 4 to $15 \mathrm{~km}$ ), making them well suited for their subsequent application in the calculation of double-difference earthquake locations.

This method of velocity model determination requires relatively few assumptions on the structure of the minimum 1-D model that is produced. However, layer boundaries are held fixed and velocity decreases with increasing depth are not allowed. Despite this, the best constrained parts of our 
models are in reasonable accord with those found using other techniques and the station corrections match the geological structure of the region. These make this technique well suited to earthquake location studies in regions where shallow earthquakes occur but the velocity structure near seismogenic depths is not well known. 


\section{Chapter 4}

\section{Double-difference relocation}

\section{using phase measurements and cross-correlation data}

\subsection{Introduction}

In this chapter we obtain accurate double-difference locations for well-recorded events in the Rotorua and Kawerau earthquake sets. In Section 4.2 we describe the steps we undertake to measure precise differential travel times for pairs of earthquakes measured at common stations using the cross-correlation method described in Section 2.3.2. Section 4.3 describes the implementation of the double-difference location technique (Section 2.3.3) using a combination of catalogue-based travel times and the cross-correlation-derived data. 


\subsection{Waveform cross-correlation}

\subsubsection{Cross-correlation method}

We follow the method of Du et al. (2004) to measure precise cross-correlation derived travel time differences. For each pair of earthquakes measured at a common station, the following procedure is carried out. First, we match Pand S-wave arrival time picks in the phase catalogue with their corresponding vertical-component seismograms. We then band-pass filter these seismograms to eliminate both the long period noise and high frequency scattering that would otherwise degrade any resulting correlation measurement.

We define time windows around each $\mathrm{P}$ - and S-wave arrival time pick. Cross-correlation is carried out within these windows and the optimum delay times are determined (Figure 4.1). In cases where a P- but no S-wave arrival time pick is found in the archive or vice versa, we use an arrival time estimate in the place of the missing datum. These are calculated using the following approximate relationship (Schaff and Waldhauser, 2005):

$$
t_{S}-t_{o} \approx \frac{V_{P}}{V_{S}}\left(t_{P}-t_{o}\right)
$$

Here $V_{P} / V_{S}$ is an estimate for the ratio of $\mathrm{P}$ - to $\mathrm{S}$-wave speeds between the event and the station, $t_{P}$ and $t_{S}$ are $\mathrm{P}$ - and $\mathrm{S}$-wave arrival times, respectively, and $t_{o}$ is the event's catalogued origin time. We set $V_{P} / V_{S}$ to 1.7 , an intermediate value for Rotorua and Kawerau which we estimate using the velocity models obtained in Chapter 3 and Wadati diagrams, with the assumption that the ratio is constant at all depths (Kisslinger and Engdahl, 


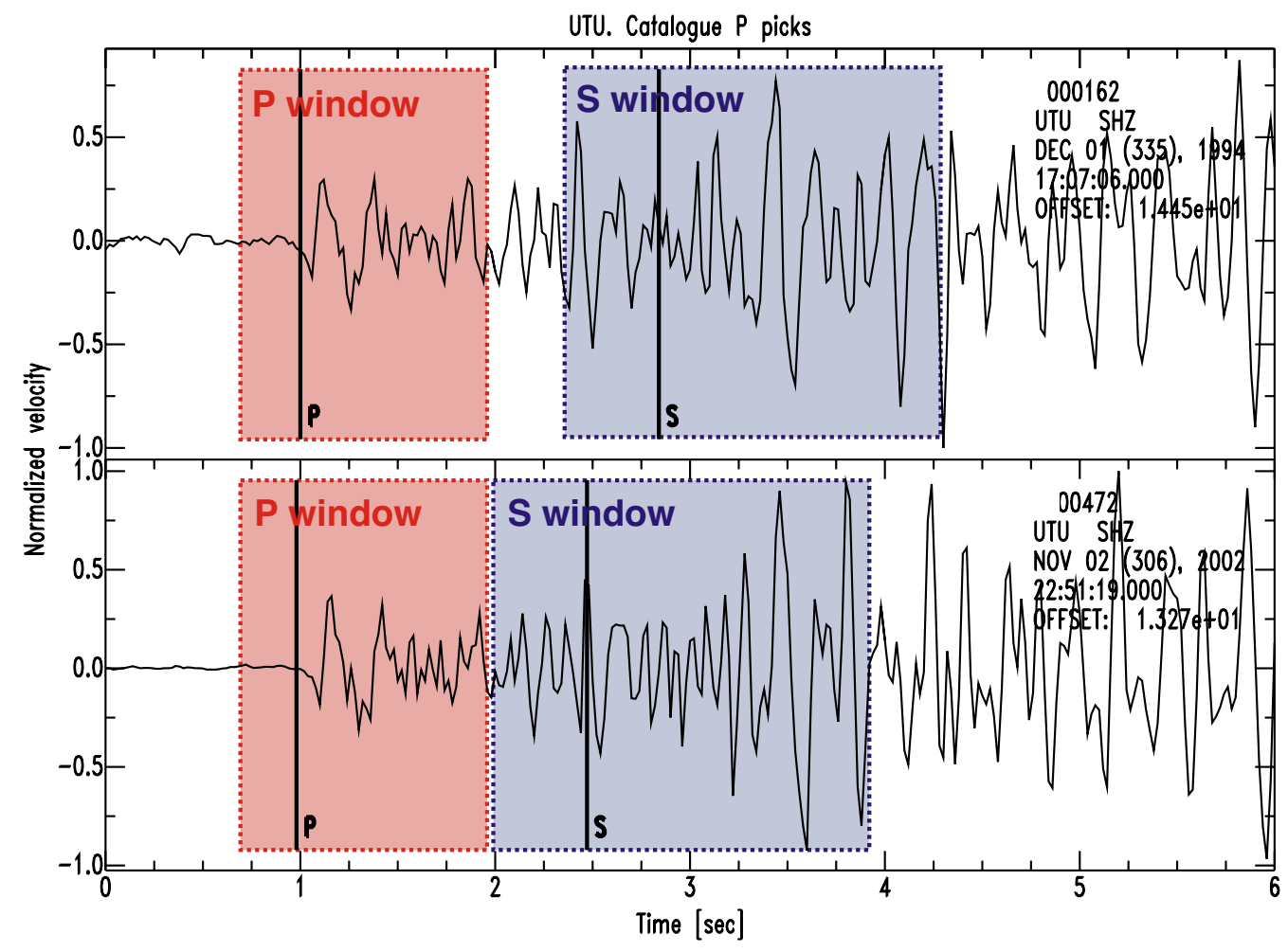

Figure 4.1: Raw seismograms from two Rotorua earthquakes measured at station UTU (Utuhina, see Figure 2.1). Cross-correlation time windows are shown around each phase arrival time pick. The S-wave arrival time on the lower seismogram is an estimate made in the absence of a catalogued pick.

1973). These Wadati diagrams (Figures B.1 and B.2 in the appendix) are constructed from all $\mathrm{P}$ - and S- wave arrival time pairs in the arrival time data.

Delay time estimates are then found for each phase. The first is measured using time-domain cross-correlation on band-pass filtered waveforms (Section 2.3.2). The second is measured using the bispectrum method ( $\mathrm{Du}$ et al., 2004) on the same band-pass filtered seismograms. The bispectrum method works similarly to cross-correlation but, because it operates in the third order 
spectral domain, it is less sensitive to Gaussian noise than cross-correlation. The third measurement is also made using the bispectrum method, but on unfiltered seismograms.

We choose a cross-correlation coefficient $(c c)$ threshold $c c^{\text {lim }}$ along with an upper limit $c c^{\lim (u)}$ and a lower limit $c c^{\lim (l)}$ (see Section 4.2.4). All correlation-derived measurements with coefficients above the threshold $c c^{\text {lim }}$ are accepted provided they and their bispectrum method-drived counterparts are close to each other. The estimates are deemed to be "close" when they are within a specified number $(\Delta)$ of samples of each other. In addition, if an event pair has a correlation coefficient that is greater than the upper limit $c c^{\lim (u)}$ at any station, then all correlation-derived measurements with coefficients above the lower limit $c c^{\lim (l)}$ are accepted. Again, these measurements are only chosen when the three delay time estimates are consistent.

While these criteria provide a stringent screen against inconsistent data, they also offer correlation measurements with relatively low coefficients (between $c c^{\lim (l)}$ and $\left.c c^{l i m}\right)$ a second chance at selection. Provided the two events in question are similar enough, and the bispectrum- and correlation-derived delays are consistent, then data that would otherwise be abandoned are used to bolster the resulting set of delay times and improve the quality of the relative earthquake locations we subsequently obtain.

\subsubsection{Data}

Our waveform database consists of 25055 seismograms measured at 196 and 119 stations for Kawerau and Rotorua, respectively. Of these seismograms, 
$79 \%$ were recorded on vertical components, primarily on short period instruments at sampling rates of 50 samples per second. In cases where the sampling rate is higher than this, we down-sample the seismograms to 50 samples per second to avoid ambiguously defined time windows.

We find 14463 and $4167 \mathrm{P}$ and S phase picks in the Kawerau and Rotorua phase data catalogues, respectively. $66 \%$ of these are P-wave arrival times. In addition, we generate $482 \mathrm{P}$ - and $3625 \mathrm{~S}$-wave arrival time estimates for Kawerau, and $141 \mathrm{P}$ - and 1781 S-wave arrival time estimates for Rotorua.

\subsubsection{Tests of control parameters}

We select two small sets of earthquakes from the Rotorua and Kawerau catalogues in order to test the cross-correlation technique we are using. The Rotorua test set is a group of twenty events that occurred during a one hour period on the night of the 19th of January, 2001 (Figure 4.2, left). The Kawerau test set is made up of sixteen events that occurred in the Kawerau geothermal field over five hours on the morning of December the 25th, 1996 (Figure 4.2, right). We use these sets of earthquakes to identify appropriate filtering and time window parameters before cross-correlating the data sets in their entirety. We choose these earthquakes for our tests because they occur over short periods of time and have reasonably clustered epicentres. The seismograms recorded from these earthquakes are likely to be similar and so should produce reliable cross-correlation measurements. 

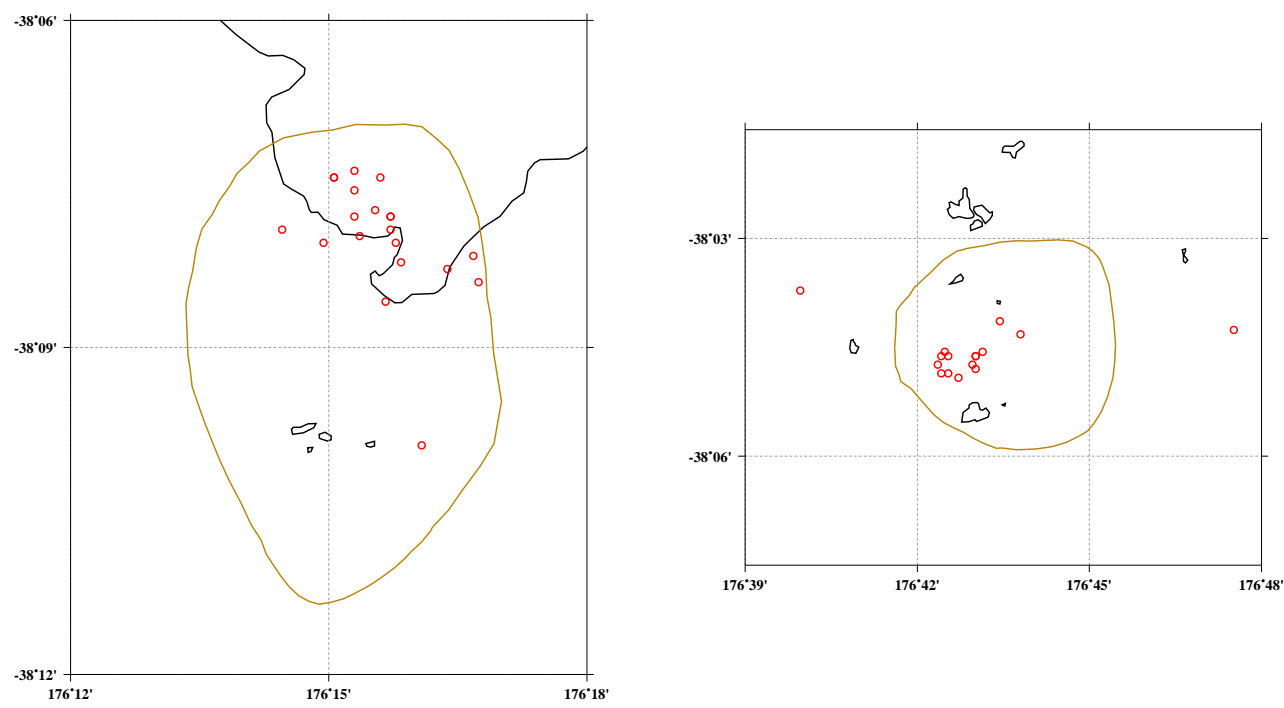

Figure 4.2: Archived epicentres for earthquakes used to test the crosscorrelation technique. (left) The Rotorua test set. (right) The Kawerau test set. Brown lines border geothermal areas. Black lines mark lake boundaries.

\section{Filtering}

To examine the influence that different filtering frequencies have on our resulting cross-correlation coefficients, we apply the cross-correlation procedure described in Section 4.2.1 to our Kawerau test earthquakes using band-pass filters with various lower- and upper frequency limits. For each trial, we observe how the cross-correlation coefficients behave before choosing our preferred frequency limits.

Figures 4.3 and 4.4 show the results that are obtained when our Kawerau test earthquake set are cross-correlated after band-pass filtering using various lower frequency limits. Here, seismograms are cross-correlated in $2.56 \mathrm{~s}$ (128 sample) windows around their $\mathrm{P}$ picks. In each case, the upper frequency limit is fixed at $10 \mathrm{~Hz}$, while the lower frequency limit is allowed to vary between 1 and $5 \mathrm{~Hz}$. Within this range, the median correlation coefficients 


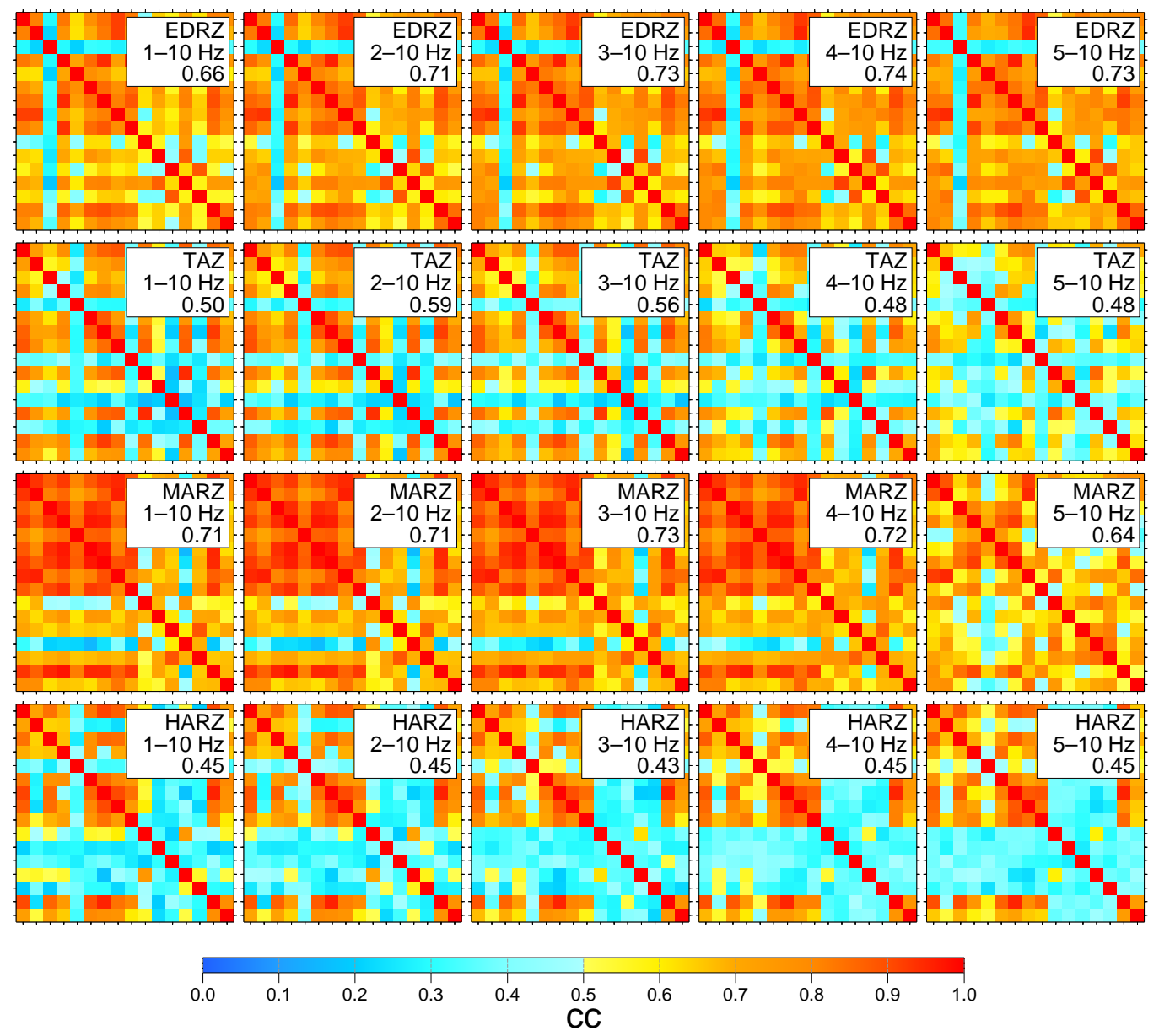

Figure 4.3: Correlation coefficient matrices found after applying band-pass filters with various lower frequency limits to windowed $\mathrm{P}$-wave arrivals from the Kawerau test set. Upper frequency limits are held at $10 \mathrm{~Hz}$ while lower frequency limits are varied. Within each matrix, the $i j^{\text {th }}$ entry represents the correlation coefficient between the $i^{\text {th }}$ and $j^{\text {th }}$ earthquakes at that station. Correlation coefficients range in size from zero to one. Stations, frequency limits and median coefficients are labelled. Earthquakes are ordered chronologically from the upper-left corner of each matrix. 


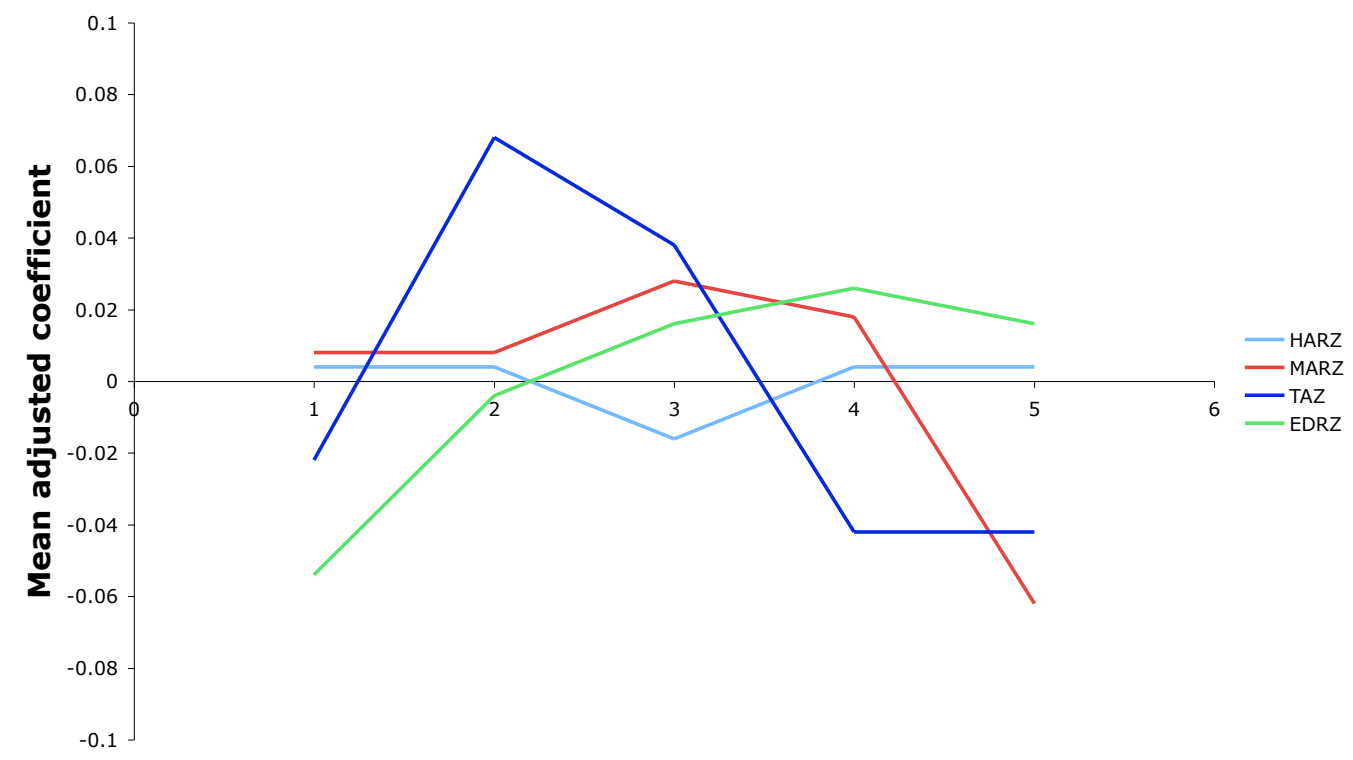

Lower frequency limit $(\mathrm{Hz})$

Figure 4.4: Median correlation coefficients found after applying band-pass filters with various lower frequency limits to windowed $\mathrm{P}$-wave arrivals from the Kawerau test set. Stations are (pale blue) HARZ, (red) MARZ, (dark blue) TAZ and (green) EDRZ. Median coefficients are adjusted to vary about zero for comparison between stations.

at each station vary by up to around 0.1 .

These graphs show that waveform similarity tends to improve to a point, then decrease as low frequency signals are progressively eliminated. At stations TAZ (Tarawera) and MARZ (Manawahe, Figure 2.1) this decrease is evident as a visible loss of structure in the resulting coefficient matrices at 4 or $5 \mathrm{~Hz}$. We take an intermediate frequency of $2 \mathrm{~Hz}$ as appropriate for our data sets.

Figures 4.5 and 4.6 show the results of a second set of trials in which bandpass filters with upper frequency limits between 5 and $10 \mathrm{~Hz}$ are tested. This time the lower frequency limit is held constant at $1 \mathrm{~Hz}$. For all but one 


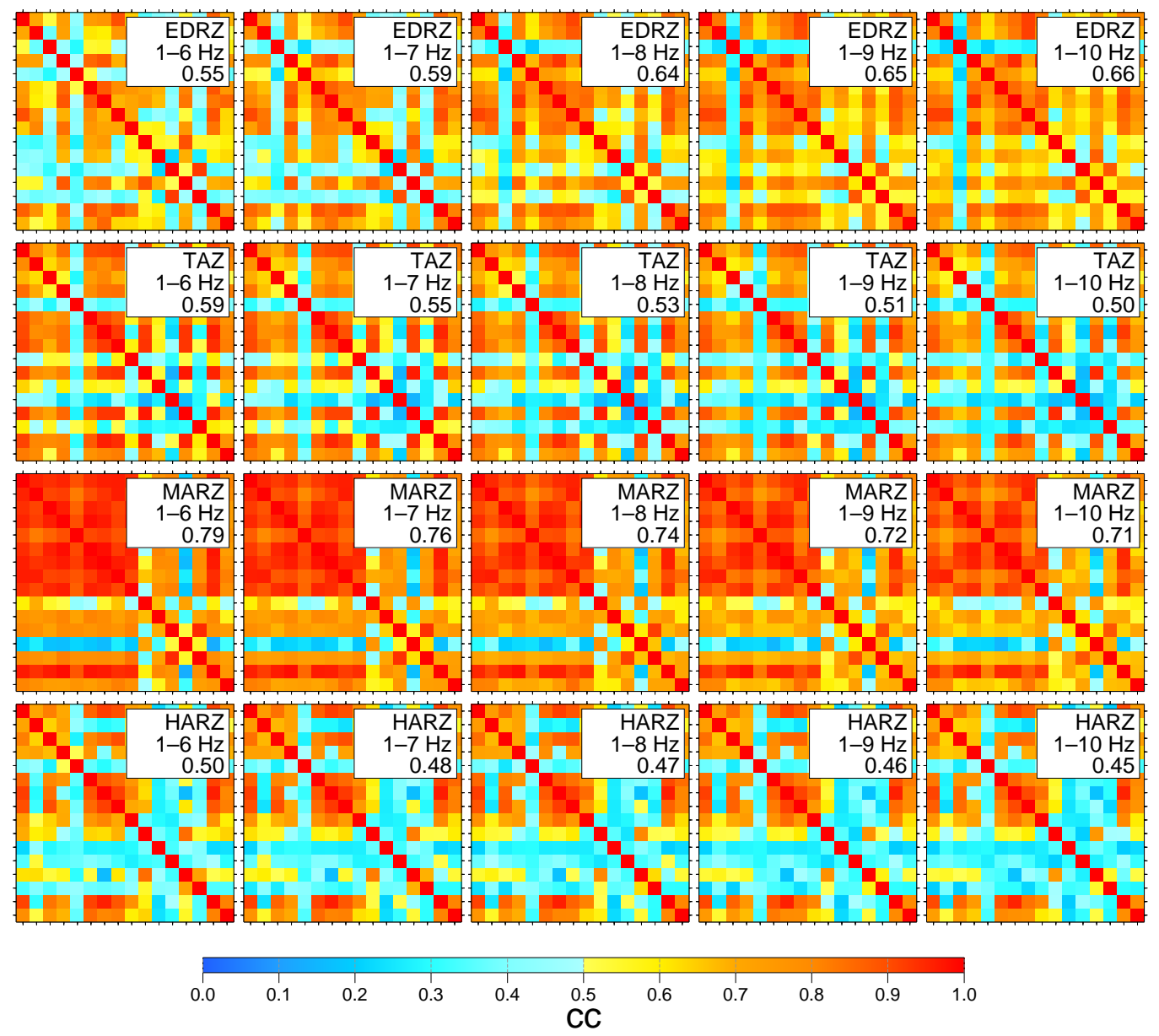

Figure 4.5: Correlation coefficient matrices found after applying band-pass filters with various upper frequency limits to windowed P-wave arrivals from the Kawerau test set. Lower frequency limits are held at $1 \mathrm{~Hz}$ while upper frequency limits are varied. Within each matrix, the $i j^{\text {th }}$ entry represents the correlation coefficient between the $i^{\text {th }}$ and $j^{\text {th }}$ earthquakes at that station. Correlation coefficients range in size from zero to one. Stations, frequency limits and median coefficients are labelled. Earthquakes are ordered chronologically from the upper-left corner of each matrix. 


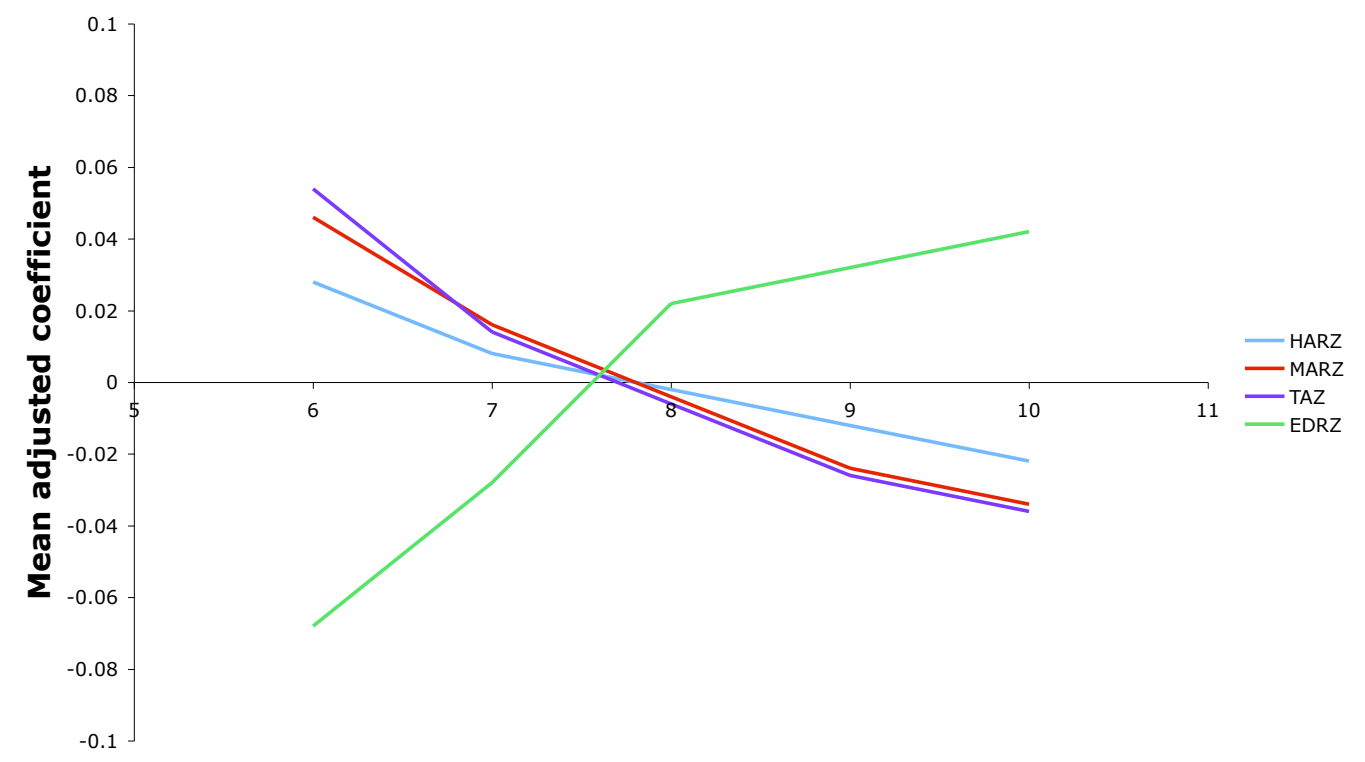

Upper frequency limit ( $\mathrm{Hz})$

Figure 4.6: Median correlation coefficients found after applying band-pass filters with various upper frequency limits to windowed $\mathrm{P}$-wave arrivals from the Kawerau test set. Stations are (pale blue) HARZ, (red) MARZ, (dark blue) TAZ and (green) EDRZ. Median coefficients are adjusted to vary about zero for comparison between stations.

station (EDRZ), the similarity between waveforms degrades as increasingly high-frequency signals are included. This is not surprising in a highly heterogeneous region such as the TVZ where high-frequency scattering is expected to be recorded in seismograms. However, because many of the earthquakes in our data sets are small, we expect their seismograms to predominantly consist of relatively high frequency waves. Accordingly, we resist using too low an upper frequency cut-off so as not to eliminate too much genuine earthquake signal. We take an upper frequency limit of $8 \mathrm{~Hz}$ as appropriate for our data.

These frequency limits are similar to those used in other earthquake stud- 
ies in which cross-correlation is employed. For example Nakahara (2004) find that cross-correlation coefficients break down at $8 \mathrm{~Hz}$ based on the correlation of aftershocks of the 1995 Hyogo-Ken Nanbu earthquake in Japan. Hayes et al. (2004) filter their seismograms from Waoiuru, New Zealand between 2 and $10 \mathrm{~Hz}$, as do Waldhauser and Ellsworth (2000) in applying crosscorrelation and double-difference relocation methods to earthquakes on the Hayward fault in Northern California.

Note that the frequency response at each station is influenced by local site conditions, which in volcanic regions may be highly variable. As a result, the use of a single filtering regime for all stations may not be optimal. This is suggested by the variable performance between the stations plotted in Figures 4.4 and 4.6. While we haven't explored this possibility, it may be an interesting avenue for investigation in future cross-correlation studies.

\section{Correlation time windows}

\begin{tabular}{|c|c|c|}
\hline \multirow{2}{*}{ percentile } & \multicolumn{2}{|c|}{ S minus P time (seconds) } \\
\cline { 2 - 3 } & Rotorua & Kawerau \\
\hline minimum & 0.2 & 0.4 \\
10 & 1.1 & 1.2 \\
20 & 1.8 & 1.7 \\
median & 2.9 & 2.6 \\
80 & 4.7 & 4.7 \\
90 & 7.3 & 5.7 \\
maximum & 21.1 & 21.8 \\
\hline
\end{tabular}

Table 4.1: Distribution of archived S- minus P-wave arrival times for Rotorua and Kawerau. Arrival times are from all stations and events in our earthquake data sets.

We must choose time windows in which to cross-correlate our seismo- 
grams. While these windows must be wide enough for a thorough search of delay times to be made, especially when highly uncertain theoretical arrival times are used, they must also be small enough to exclude any unwanted signal that may contaminate the resulting delay time measurements. Such contaminants include noise before the $\mathrm{P}$ arrival, scattered phases after the $\mathrm{P}$ and $\mathrm{S}$ arrivals, and the existence of $\mathrm{S}$-waves in the $\mathrm{P}$ window or vice versa.

Table 4.1 summarizes the distribution of all S- minus P-wave arrival times in our catalogued data set. We set our $\mathrm{P}$ windows to start 0.3 seconds (15 samples) before the P pick and end 0.96 seconds (48 samples) after it. As the tenth percentile S- minus P-wave arrival time for both Rotorua and Kawerau is greater than 0.96 seconds, these $\mathrm{P}$ windows should exclude any $\mathrm{S}$-wave arrivals on around $90 \%$ of our seismograms. A larger $\mathrm{S}$ window is used, beginning 0.5 seconds before the S-wave pick and ending 1.4 seconds after it (Figure 4.1).

In other studies, $\mathrm{P}$ windows that extend up to around two seconds beyond the picked P-wave arrival are typically used (e.g. Waldhauser and Ellsworth, 2000). Schaff et al. (2004) test a variety of window lengths and find that although smaller windows generally produce higher similarity measurements than longer windows, they also produce larger residuals after doubledifference relocation. While our 1.28 second $\mathrm{P}$ window is not as wide as the largest windows that are commonly used, it is still large enough to contain several cycles of seismic signal (at around 5 to $10 \mathrm{~Hz}$, Figure 4.1) and produce precise delay time measurements, as demonstrated in Figures 4.7 and 4.8 . 


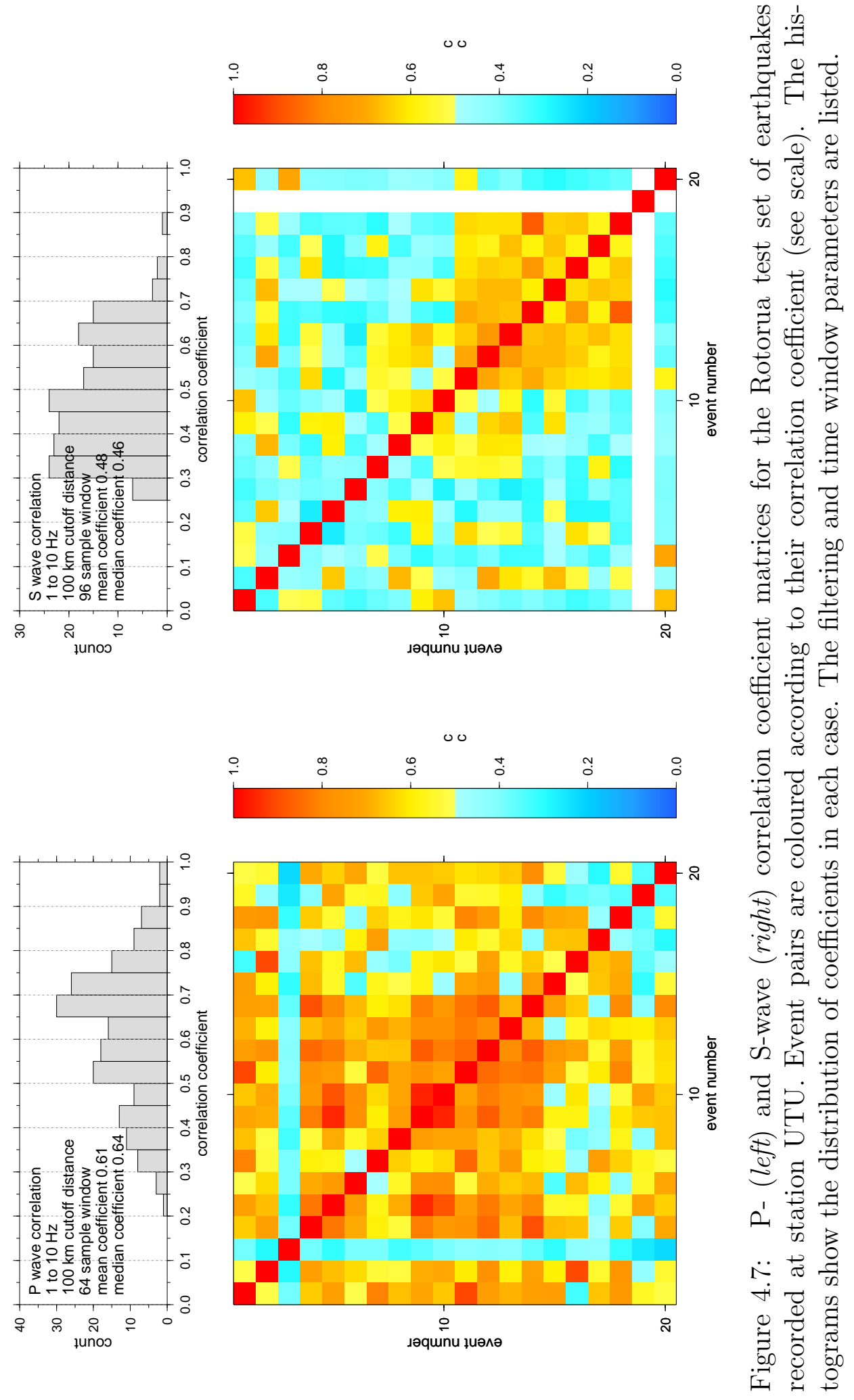



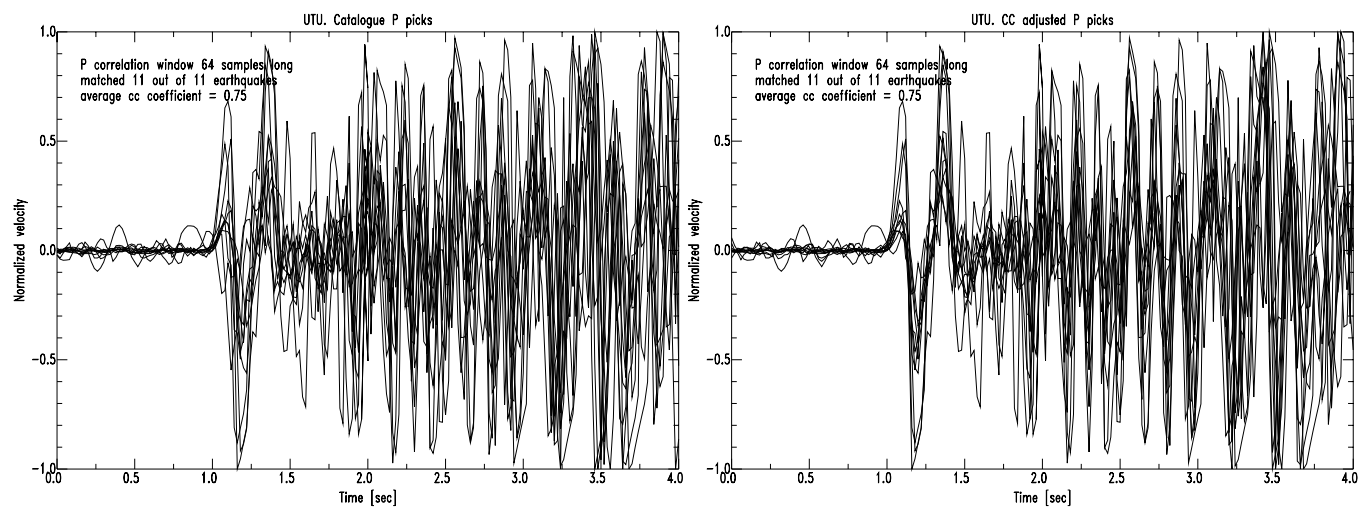

Figure 4.8: Unfiltered seismograms from eleven earthquakes in our Rotorua test set (events 1,4,5,7,9,10,11,12,13,14 and 18 in Figure 4.7). The overlaid traces are aligned using (left) catalogued $\mathrm{P}$-wave arrival time picks, and (right) arrival times that have been adjusted using cross-correlation. Each seismogram shares a P-wave correlation coefficient of 0.8 or more with at least one of the other seismograms shown.

\subsubsection{Cross-correlation results}

We cross-correlate our full Rotorua and Kawerau earthquake sets at all stations using the filtering and time window parameters described in Section 4.2.3. We then select or reject these data according the criteria described in Section 4.2.1 and the following limits: $c c^{\lim (l)}=0.5, c c^{\lim }=0.7, c c^{\lim (u)}=$ 0.8 , and $\Delta=2$ samples. These limits are similar to those used by Du et al. (2004) apart from $c c^{\lim (l)}$ and $\Delta$, where a more lenient cut-off of 0.3 and a more stringent allowance of one sample are used. We impose a higher $c c^{\lim (l)}$ to ensure poor measurements with very low correlation coefficients are never included in our data set.

Figure 4.9 shows the distribution of cross-correlation coefficients for the data that pass these selection criteria. A total of 85206 and 902487 P- and S-wave measurements from Rotorua and Kawerau, respectively, are accepted. Although this constitutes a large amount of data, it is only a small fraction of 
the total amount that could be obtained when all earthquake pairs and all stations are considered. For example, if one station measures all 504 earthquakes in the Rotorua set, that station would generate 126756 cross-correlation measurements, many more than the number that pass our selection criteria for all stations combined.

Although we begin with an equal number of $\mathrm{P}$ - and S-wave arrival time picks and estimates, only $21 \%$ of our correlation measurements are S-wave delay times. This is because $\mathrm{S}$-wave seismograms generally cross-correlate less well than P-wave seismograms do (Du et al., 2004) (Figure 4.7) due to P-coda waves impinging on the windowed S-wave train.

In all, $24 \%$ of the final set of correlation measurements have $c c$ values between $c c^{l i m(u)}$ and $c c^{\text {lim }}$. Of these, $46 \%$ are S-wave measurements. Within this range, relatively few correlation data are deemed acceptable, and the number of accepted data increases markedly at the middle $c c$ limit $c c^{\text {lim }}$ of 0.7 (Figure 4.9).

Figure 4.9 also shows how many correlation-derived delay times each earthquake pair produces (top panels). While most event pairs have only a small number of cross-correlation based time delays, a significant portion have acceptable cross-correlation measurements at several stations and so should have well constrained hypocentres when double-difference locations are found. 


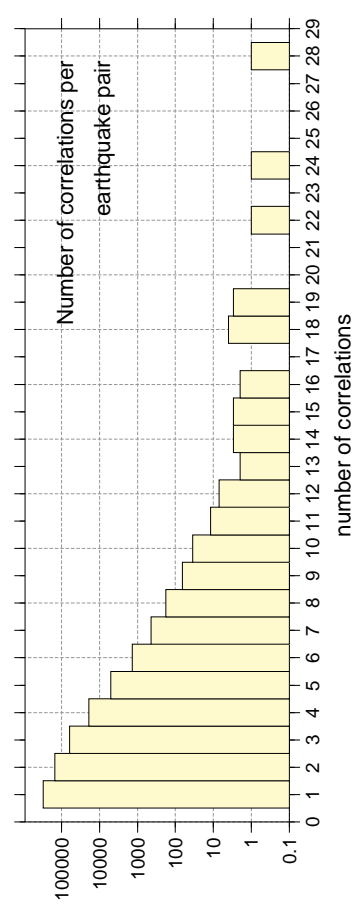

suled әуеnbuцеә

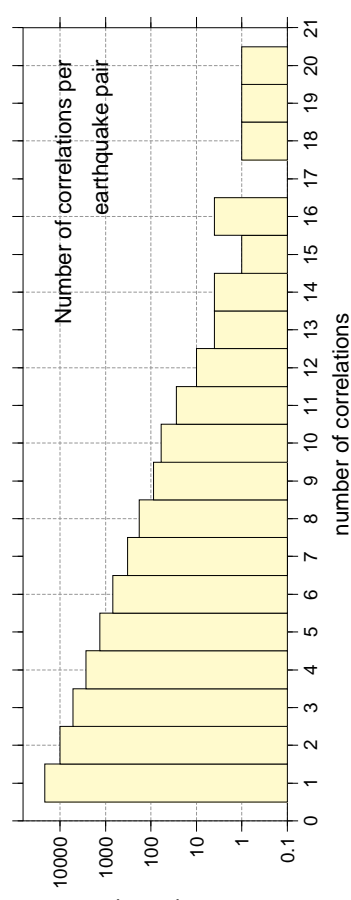

sıled әуепьцциеә
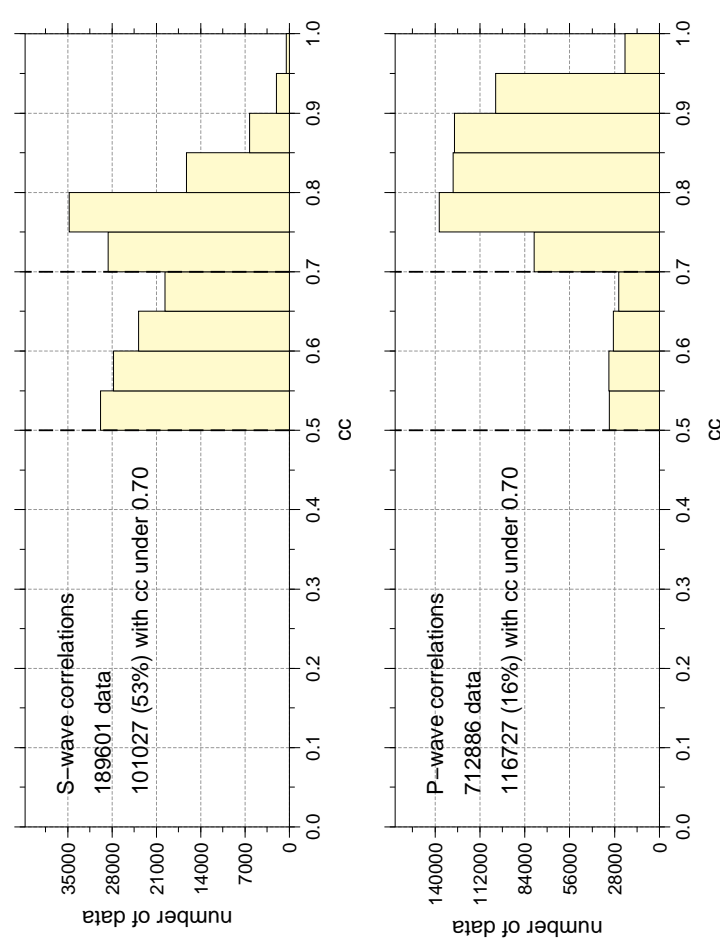

它

눙

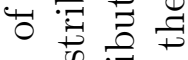

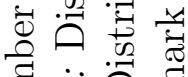

छ $\ddot{\Xi}$

乙.

范 है

- 霅

政

远苞.

元

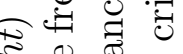

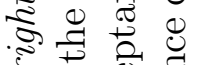

'承范

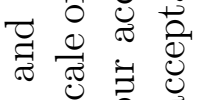

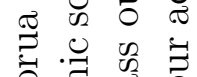

잉

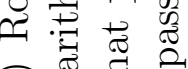

๙

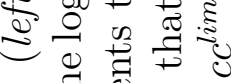
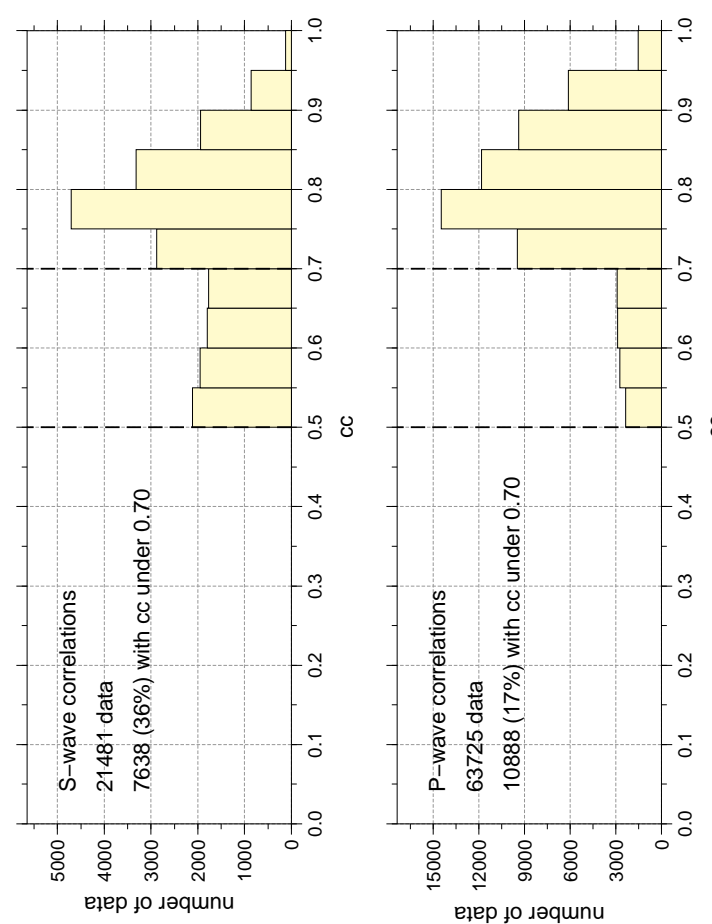

苛 吾

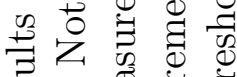

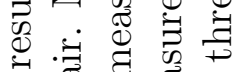

藏

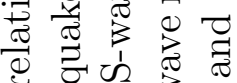

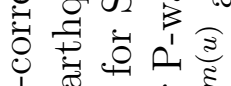

1 010 告

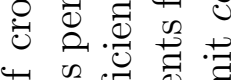

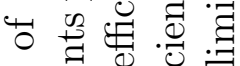

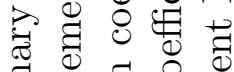

范泀.

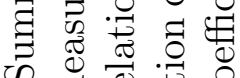

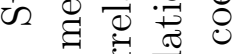

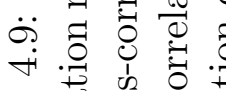

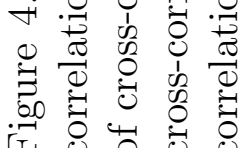




\subsection{Double-difference earthquake relocation}

\subsubsection{Double-difference location method}

We use the procedure hypoDD (Waldhauser and Ellsworth, 2000) to determine locations for earthquakes in our Rotorua and Kawerau data sets. A description of how hypoDD uses travel time differences to find earthquake locations is given in Section 2.3.3.

\subsubsection{Data selection}

We aim to produce accurate locations for as many of the earthquakes in our Rotorua and Kawerau data sets as we can. To begin, we select all earthquakes which have at least one picked S-wave arrival time in the phase pick catalogues. This removes six of the 504 events in Rotorua and 101 of the 1875 earthquakes in Kawerau.

Where possible, we replace the catalogued hypocentres of our earthquakes with the mean locations determined using Velest in Chapter 3 (Figures 3.21 and 3.22). We update 112 and 376 hypocentres in the Rotorua and Kawerau earthquake sets, respectively.

We then calculate catalogue P- and S-wave arrival time differences for pairs of earthquakes within each data set. Here, we only retain data for earthquake pairs that are located within $10 \mathrm{~km}$ of each other and have at least eight common observations. This threshold is equal to the number of degrees of freedom (two hypocentres, each with four coordinates) in the location of an event pair (Waldhauser, 2001). This further reduces the number of 
earthquakes in our Rotorua set to 227 while 756 events from Kawerau are retained.

We match our catalogue based differential times with the cross-correlationderived data described in Section 4.2.4. These two data sets contain 201 and 724 matching events in Rotorua and Kawerau, respectively. The remaining 58 events in our catalogue differential time database have no matching cross-correlation-based measurements. Table 4.2 summarizes the number of cross-correlation- and catalogue-based data we use to relocate our selected earthquake sets. There are many more cross-correlation-derived measurements than catalogue-based data for these earthquakes because our catalogue set contains only pairs of earthquakes with eight or more observations while our cross-correlation set contains all earthquake pairs regardless of how many observations they have.

\begin{tabular}{|c|c|c|}
\hline \multirow{2}{*}{ data type } & \multicolumn{2}{|c|}{ number of data } \\
\cline { 2 - 3 } & Rotorua & Kawerau \\
\hline catalogue P & 18447 & 95355 \\
catalogue S & 5582 & 54693 \\
correlation P & 22278 & 165961 \\
correlation S & 9217 & 48191 \\
\hline
\end{tabular}

Table 4.2: The number of catalogue and cross-correlation based P- and Swave differential travel times we use to relocate our Rotorua and Kawerau earthquake sets

\subsubsection{Velocity models}

We utilise the velocity models described in Chapter 3 while relocating earthquakes from Rotorua and Kawerau. For all except the uppermost layer, we take the mean $\mathrm{P}$-wave velocity, S-wave velocity and $\mathrm{P}$-wave standard devia- 
tion from the $1000 \mathrm{P}$ - and S-wave solutions in each area (Tables 3.4 and 3.5). HypoDD uses a $\mathrm{P}$-wave velocity and a $\mathrm{P}$ - to $\mathrm{S}$-wave speed ratio to calculate travel times when relocating earthquakes. A P- to S-wave velocity ratio is calculated using equation 4.2

$$
\frac{V_{P}}{V_{S}}=\frac{\sum_{i=2}^{n} \omega^{i} \frac{V_{P}^{i}}{V_{S}^{i}}}{\sum_{i=2}^{n} \omega^{i}}
$$

Here $n$ is the number of modelled layers, while $V_{P}^{i}$ and $V_{S}^{i}$ are P- and Swave speeds, respectively, for the $i^{\text {th }}$ layer. $\omega^{i}$ is the reciprocal of the $i^{\text {th }} \mathrm{P}$ wave standard deviation and is used to up-weight well-constrained velocities relative to velocities that are poorly constrained. We obtain ratios of 1.71 and 1.69 for Rotorua and Kawerau, respectively.

Table 4.3 shows the P-wave velocity models we use for Rotorua and Kawerau. Note that we do not use station corrections as these are made redundant by the double-difference technique.

\subsubsection{Data weighting and reweighting}

We use both catalogue- and cross-correlation-derived travel time differences to relocate our two earthquake sets. As described above, these two types of data are measured using distinctly different techniques (phase picking and waveform cross-correlation) and are of varying degrees of quality. We take care to ensure our final set of earthquake locations are primarily constrained by the most reliable measurements in each data set. This is achieved via the application of weights to our data both before the earthquake relocation 


\begin{tabular}{|c|c|c|}
\hline \multirow{2}{*}{ Depth $(\mathrm{km})$} & \multicolumn{2}{|c|}{ Velocity $(\mathrm{km} / \mathrm{s})$} \\
\cline { 2 - 3 } & Rotorua & Kawerau \\
\hline 0 & 3.8 & 4.5 \\
2 & 5.2 & 5.0 \\
4 & 5.9 & 5.3 \\
6 & 6.0 & 5.8 \\
8 & 6.1 & 5.9 \\
10 & 6.3 & 6.1 \\
15 & 6.6 & 6.1 \\
20 & 6.7 & 6.2 \\
25 & 6.9 & 6.6 \\
30 & 7.2 & 7.4 \\
40 & 7.8 & 8.0 \\
\hline
\end{tabular}

Table 4.3: P-wave velocity models used for double-difference earthquake relocation in Rotorua and Kawerau.

procedure is carried out and also during the inversion process. These weights dictate the extent to which each travel time difference is allowed to influence the final locations obtained from hypoDD. A measurement with a high weight has more influence than one with a comparatively low weight. The weighting scheme used by hypoDD is summarized as:

$$
w_{i}=w_{i}^{a p} w_{i}^{r e s} w_{i}^{\text {dist }}
$$

Here, $w_{i}$ is the weight applied to the $i^{\text {th }}$ datum and $w_{i}^{a p}$ is the a priori weight for that measurement. $w_{i}^{\text {res }}$ and $w_{i}^{\text {dist }}$ are dynamic weights that are applied during the inversion to remove suspect data with high residuals and large interevent distances. These are described later in this section.

Table 4.4 shows how GeoNet phase pick qualities are converted to a priori weights for hypoDD. This table mimics the weights that hypoDD uses for Northern California Seismic Network (NCSN) phase picks. The weight we 
apply to each catalogue differential travel time is the average of those for the two picks in consideration. Note that although phase picks with assigned qualities of four are given zero weight, they are not necessarily discarded as the resulting travel time differences can still have non-zero weight due to this averaging. Catalogued P-wave travel time differences are up-weighted by a factor of two relative to S-wave measurements of equal quality.

\begin{tabular}{|c|c|}
\hline GeoNet quality & hypoDD weight \\
\hline 0 & 1 \\
1 & 0.5 \\
2 & 0.2 \\
3 & 0.1 \\
4 & 0 \\
\hline
\end{tabular}

Table 4.4: Conversion of GeoNet phase pick qualities to weights for hypoDD. Pick weights are averaged to produce weights for each travel time difference.

Cross-correlation-derived travel time differences are weighted by their correlation coefficients. This enables delay times from well correlated seismograms to take precedence over the more uncertain delay times from seismograms that do not correlate as strongly. The choice of correlation coefficient limits ensures these weights are all positive. Because we cross-correlate around many more theoretical S-wave arrival time estimates than we do for P-waves (Section 4.2.2), the set of S-wave correlation data is likely to contain more erroneous measurements than the P-wave data. To account for this, we down-weight our S-wave cross-correlation-derived delay times by a factor of five relative to otherwise similar P-wave measurements.

We up-weight our correlation-derived travel times by a factor of ten relative to catalogue-derived measurements. This factor is an order of magnitude less than that used by Waldhauser and Ellsworth (2000) for earthquakes in 
Northern California where the seismograph network is denser than in the TVZ and many more correlation measurements can be made per earthquake pair. This means that while correlation-derived travel time differences are given priority over catalogue-based data, they are not so heavily weighted as to make the catalogue data redundant, especially in cases where only a few correlation-derived measurements are available to constrain our earthquake locations. Our a priori weighting scheme is summarized in Table 4.5.

\begin{tabular}{|c|c|}
\hline Data type & hypoDD weight \\
\hline correlation P & 1 \\
correlation S & 0.2 \\
catalogue P & 0.1 \\
catalogue S & 0.05 \\
\hline
\end{tabular}

Table 4.5: a priori weights used in hypoDD for $\mathrm{P}$ - and S-wave travel time differences measured using catalogue phase picks and waveform crosscorrelation.

Dynamic weights are used to remove residual outliers and data from earthquake pairs with distant locations during the inversion process. We apply these after four iterations using only a priori weights to obtain locations and residual distributions for our data sets.

\section{Residual weighting}

$w_{i}^{\text {res }}$ is a weight that depends on the $i^{\text {th }}$ double-difference residual from the preceding iteration and is defined by the relationship (Waldhauser and Ellsworth, 2000):

$$
w_{i}^{r e s}=\max ^{3}\left(0,1-\left(\frac{\left|d r_{i}\right|}{\alpha \cdot d r_{s p}}\right)^{3}\right)
$$


Here, $d r_{i}$ is the $i^{t h}$ residual and $d r_{s p}$ is the residual spread, which is defined as follows:

$$
\operatorname{spread}=\text { median }(\mid x-\text { median }(x) \mid) / 0.67449
$$

This is a robust analogue to standard deviation and is roughly equal to the standard deviation for data drawn from a Gaussian distribution (Hampel et al., 1986; Nicholson et al., 2004). The residual weight is designed to be close to unity for data with small residuals, and to drop rapidly to zero as the residuals approach a given cut-off value of $\alpha$ residual spreads. $\alpha$ is typically set between 3 and 6 (Waldhauser and Ellsworth, 2000) to remove non-Gaussian outliers.

In order to determine appropriate cut-offs, we separately trial each type of data (correlation-derived and catalogued) using hypoDD. In each case the inversion is performed using singular value decomposition (SVD, Section 2.3.3) over four iterations. For the cross-correlation test we only relocate pairs of earthquakes with eight or more correlation-derived travel time differences. For the catalogue test we only relocate earthquake pairs with eleven (Rotorua) or twelve (Kawerau) catalogue-based travel time differences. For these trials $\mathrm{P}$-wave data are up-weighted by a factor of two relative to $\mathrm{S}$-wave data of equal quality. No dynamic reweighting is applied.

Figure 4.10 shows the distribution of double-difference residuals we obtain after the fourth iteration in the above test for cross-correlation-derived data. Each plot is overlain by the normal probability density function (red line) with a standard deviation and mean equal to the spread and median, 
respectively, of the residuals in question. The cross-correlation residuals have spreads of around $60 \mathrm{~ms}$ for both Rotorua and Kawerau. It is evident from these plots that the residuals are non-Gaussian, with longer tails and a more pronounced central peak than the overlain normal distributions.

A weakness of cross-correlation delay time estimation is that it can produce high correlation coefficients for seismograms that are a full cycle out of alignment (cycle skipping). This means that our data set may contain delay time measurements that are one period of seismic signal in error. If the predominant frequency in our seismograms is near $5 \mathrm{~Hz}$, then this error can be as large as 0.2 seconds. We account for this by setting our residual cut-off for cross-correlation derived data to four standard deviations (around $240 \mathrm{~ms})$.

Figure 4.11 shows the distribution of double-difference residuals we obtain for our catalogue data. Here, the distributions have spreads of around $140 \mathrm{~ms}$ and also appear non-Gaussian. We set our cut-off to four standard deviations for these data. This removes travel time differences that are in error by around $560 \mathrm{~ms}$ or more.

\section{Distance weighting}

$w_{i}^{\text {dist }}$ is a weight that depends on the distance between the two earthquakes for which the $i^{\text {th }}$ travel time difference is calculated. It is calculated using the relationship (Waldhauser and Ellsworth, 2000):

$$
w_{i}^{d i s t}=\max ^{a}\left(0,1-\left(\frac{s_{i}}{c}\right)^{a}\right)
$$



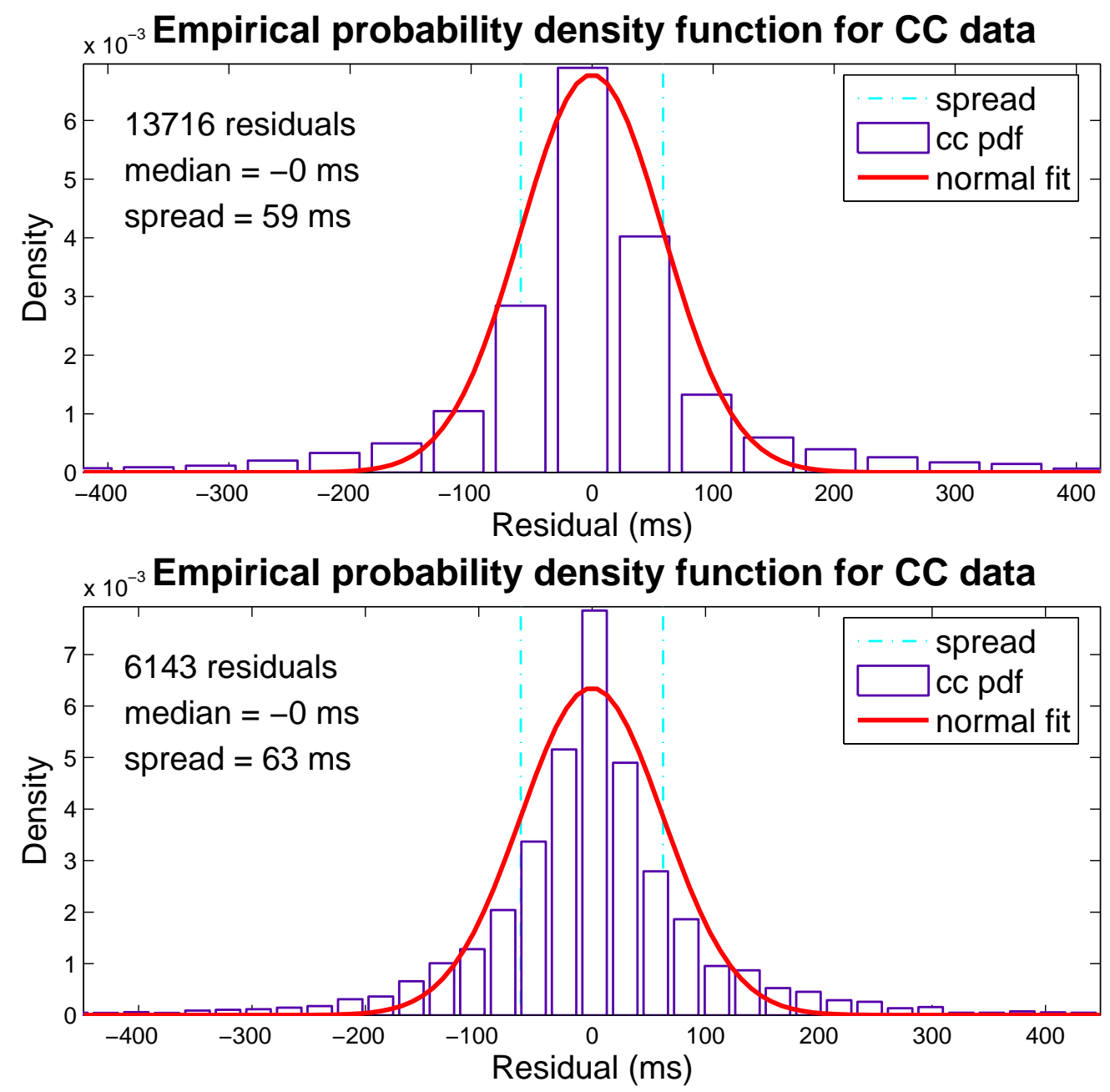

Figure 4.10: Double-difference residuals for (top) Rotorua and (bottom) Kawerau after relocating earthquake pairs with 8 or more cross-correlation derived travel time differences. The histogram is an empirical probability density function (pdf) for all cross-correlation data residuals. Overlain is the normal distribution (red line) with the same median and standard deviation (spread, see text). Dashed blue lines are spread increments. The median and spread are listed. 

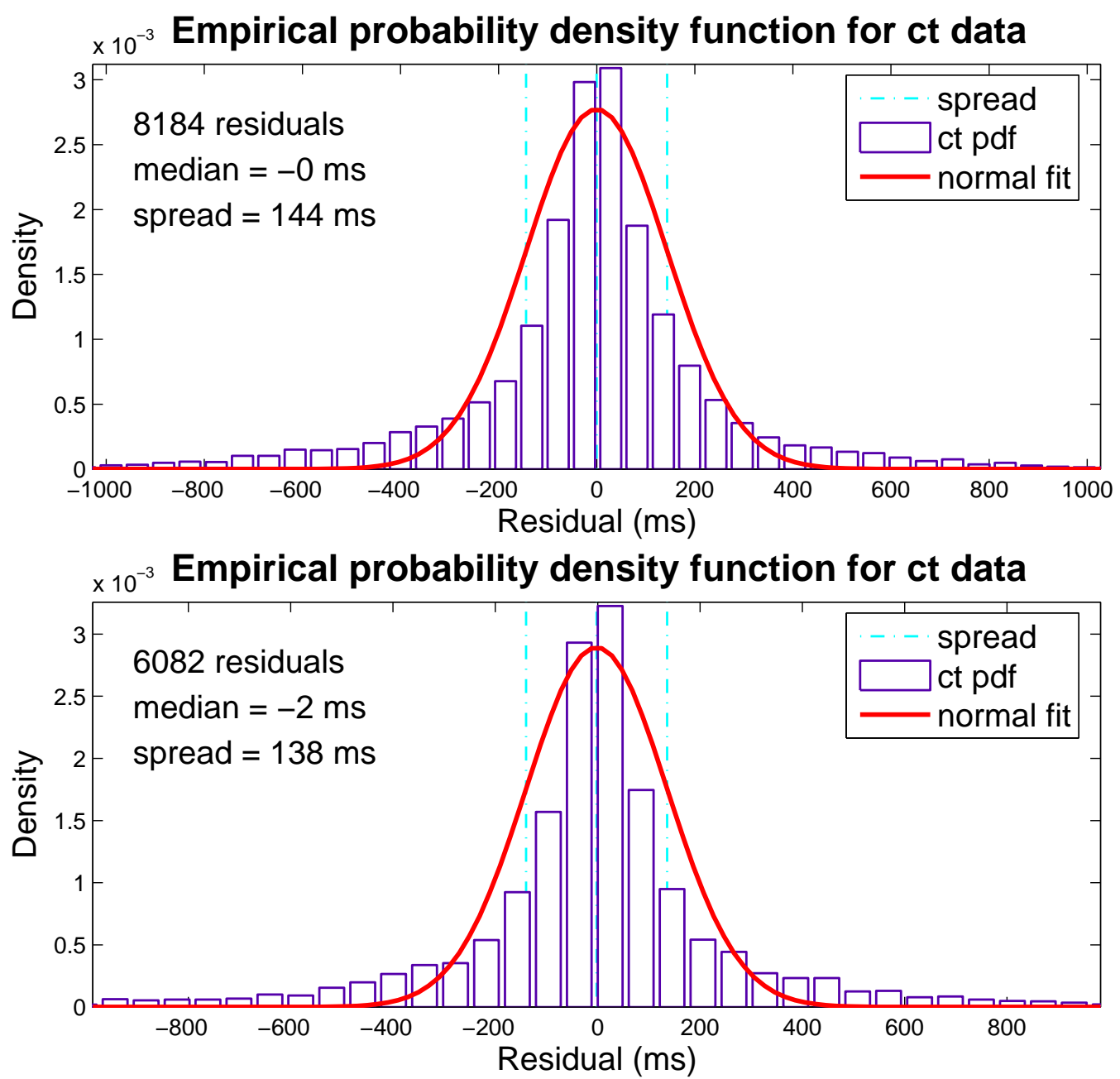

Figure 4.11: Double-difference residuals for (top) Rotorua and (bottom) Kawerau after relocating earthquake pairs with at least 11 and 12 catalogued travel time differences, respectively. The histogram is an empirical probability density function (pdf) for all catalogue data residuals. Overlain is the normal pdf (red line) with the same median and standard deviation (spread, see text). Dashed blue lines are spread increments. The median and spread are listed. 
Here $s_{i}$ is the distance between the two earthquakes, while $c$ is a distance cut-off we choose. The index $a$, which controls the shape of the function, is five for cross-correlation data and three for catalogue data (Waldhauser and Ellsworth, 2000). This makes the drop in weights to zero near the cutoff distance more abrupt for correlation-derived measurements than for their catalogue-based counterparts.

Cross-correlation derived data are based on the similarity of waveforms for closely spaced events, so the distance at which this similarity breaks down must be considered. Beyond this distance, any time delay measurement should be treated with suspicion as $3-\mathrm{D}$ (and potentially $4-\mathrm{D}$ ) velocity heterogeneity and differences in earthquake source mechanisms degrade the similarity between observed waveforms. Geller and Mueller (1980) infer from the similarity of small M 2.7 earthquakes in California that they must be within one quarter of the predominant seismic wavelength of each other. For a shear wave speed of $3.5 \mathrm{~km} / \mathrm{s}$ and frequency of $5 \mathrm{~Hz}$, this amounts to a maximum separation of approximately $200 \mathrm{~m}$. Schaff et al. (2004) test the performance of correlation measurements for interevent separations of up to $2 \mathrm{~km}$ and find that they are a significant improvement on phase pick data even at these distances. Nakahara (2004) also test how waveform similarity behaves with interevent distance and find that their correlation coefficients break down at around 4 to $5 \mathrm{~km}$ interevent separation.

Figure 4.12 shows how our cross-correlation double-difference residuals change with interevent distance. These are grouped into $100 \mathrm{~m}$ bins and their medians (top) and spreads (middle) are plotted. In Rotorua (left) the spreads increase for separations up to around $2.5 \mathrm{~km}$, where they are almost three 
times as large as the spread of the unbinned data set. At greater distances they appear to break down and the medians also appear to become biased. In Kawerau the spreads also increase monotonically to a separation of around $3 \mathrm{~km}$, beyond which they also break down. Based on these observations we choose a distance cut-off of $2.5 \mathrm{~km}$ for our dynamic cross-correlation weights.

Catalogue-based travel time differences do not depend on waveform similarity and so are reliable to greater interevent separations. However, as double-difference earthquake relocation relies on the assumption that eventstation distances are much greater than interevent distances, a cut-off is still required. Figure 4.13 shows how our catalogue based double-difference residuals change with interevent distance. This time the dependence of binned residual spreads on interevent separation is not as clear as in Figure 4.12 and we choose a distance cut-off of $10 \mathrm{~km}$ for our dynamic catalogue weights.

The variation of $w_{i}^{\text {dist }}$ (Equation 4.6) with interevent distance is plotted in Figure 4.14. The functions for cross-correlation derived and cataloguebased P- and S-wave data are are scaled by their a priori weights. These functions give precedence to cross-correlation-derived measurements for small interevent distances. As the interevent distance increases to $2.5 \mathrm{~km}$, the cross correlation weights drop abruptly to zero. Beyond this distance, only catalogue based travel time differences are allowed into the inversion.

\subsubsection{Inversion method and earthquake linkage}

The size of our earthquake sets require the double-difference inversion to be carried out using LSQR (Paige and Saunders, 1982), a method that exploits 


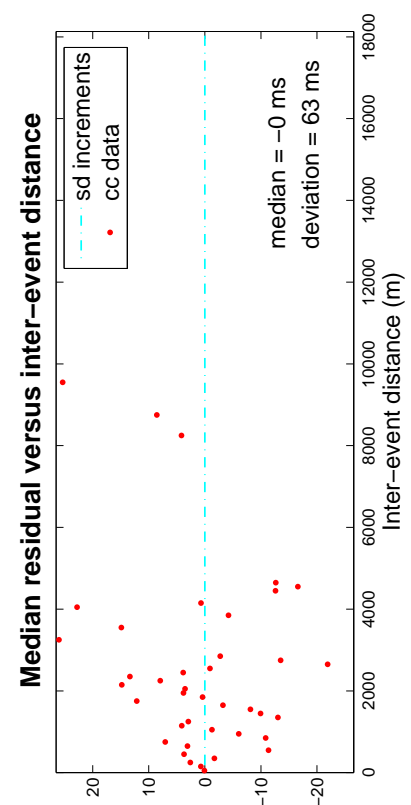

(sw) ןenp!səג ue!pəW

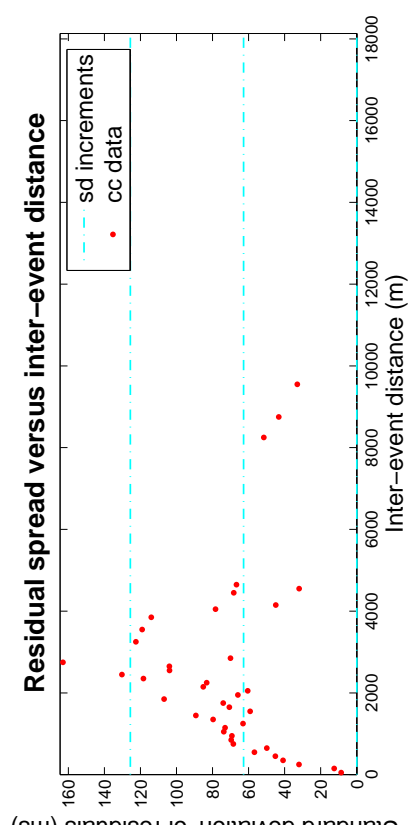

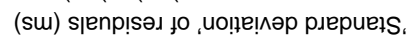

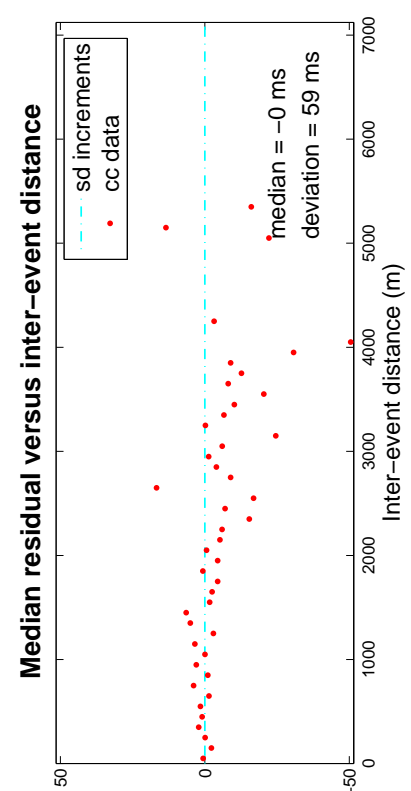

(sw) ןenp!səı ue!pəW

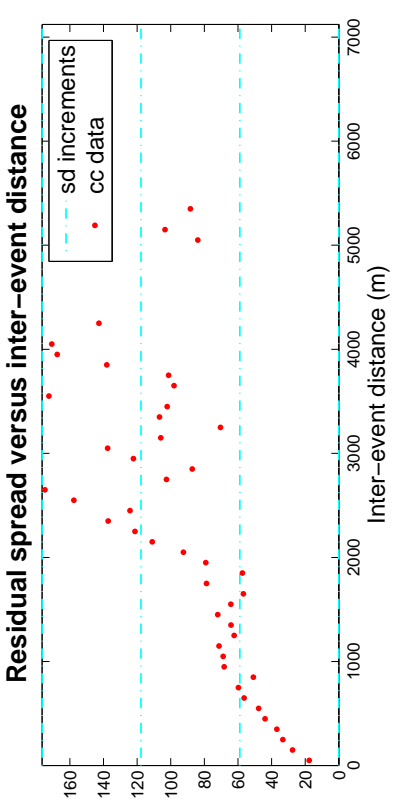

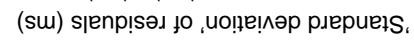

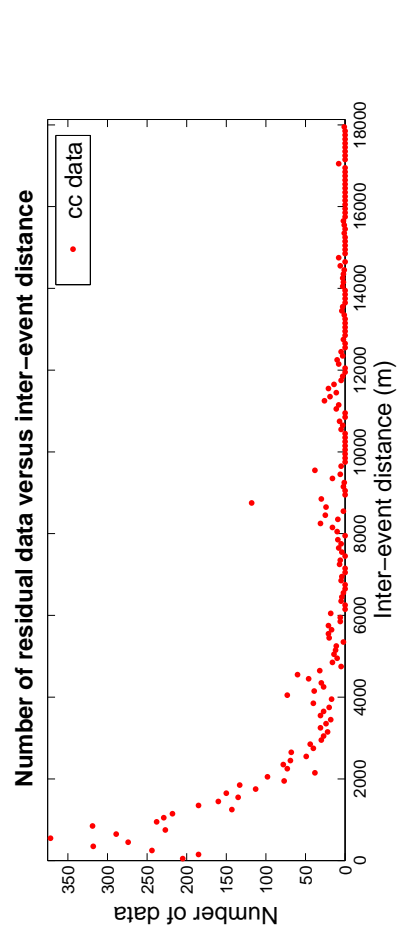

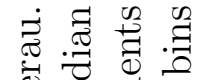
远

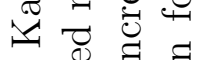

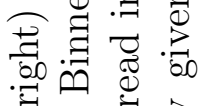

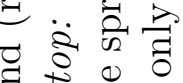

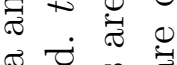

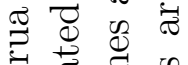
需 요 焉芫范 क्ष 8 范 is

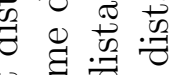

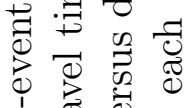

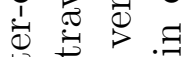

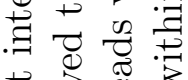
$\vec{b} \cdot \vec{c}$

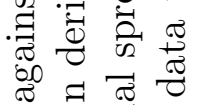
के 焉营莺 음 a శึ 耐它 के

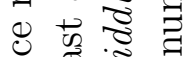

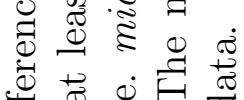
里

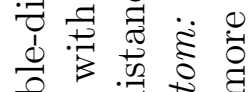
青: :

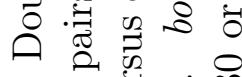
宇 국

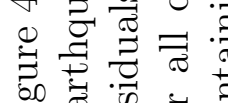

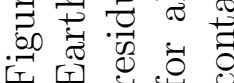




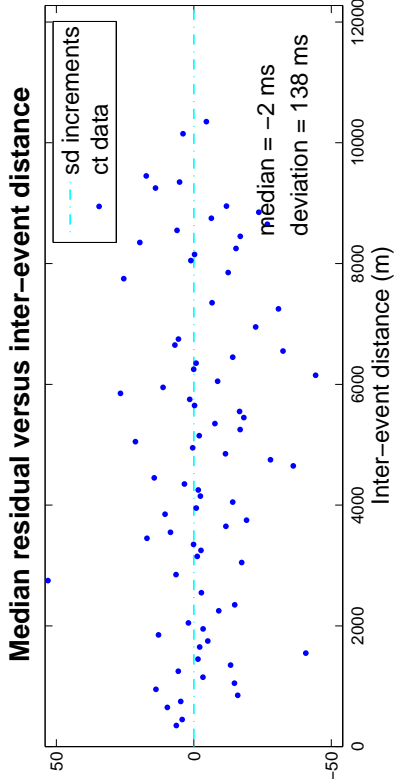

(su) ןenp!̣səd ue!pəW
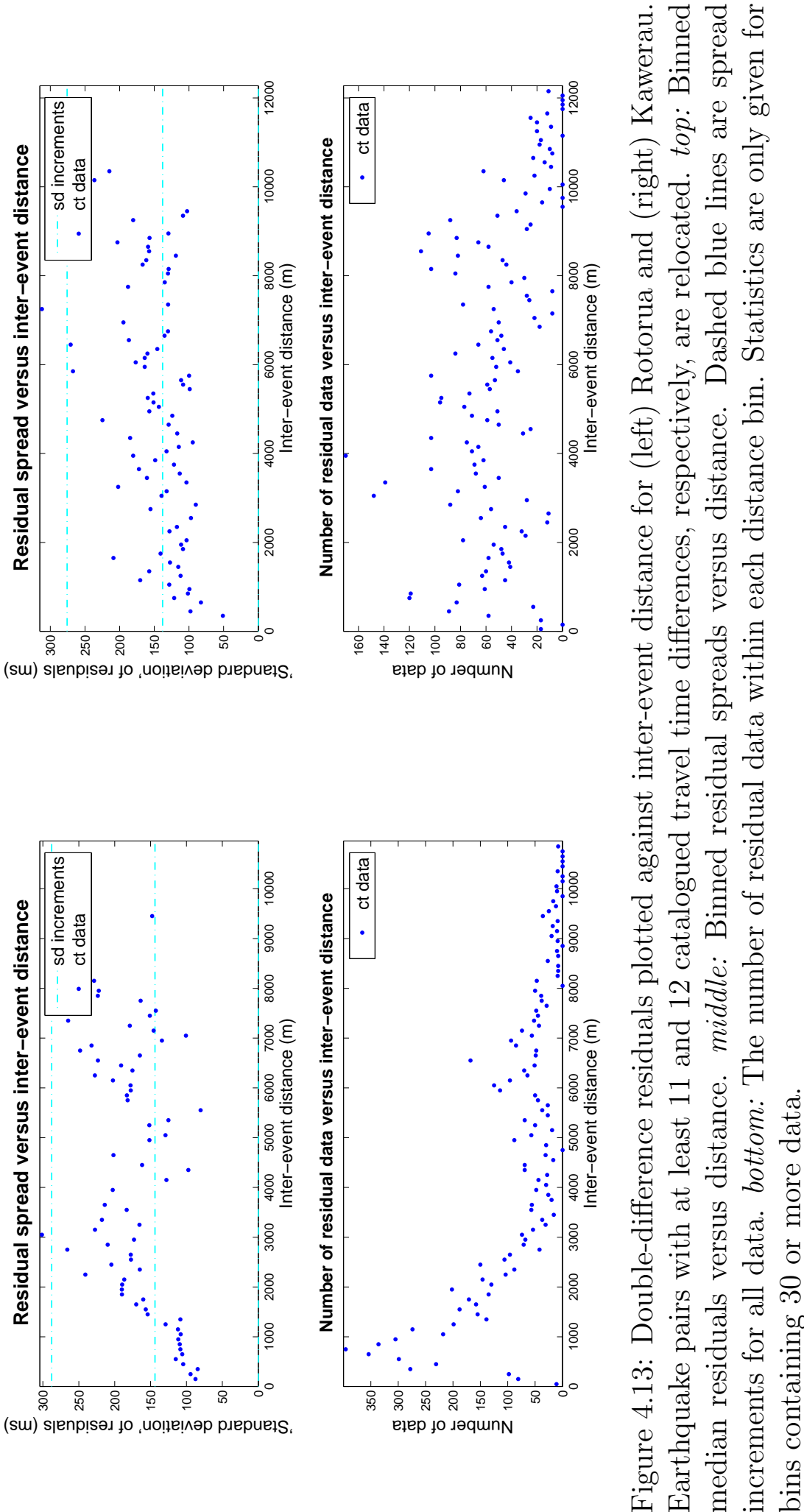

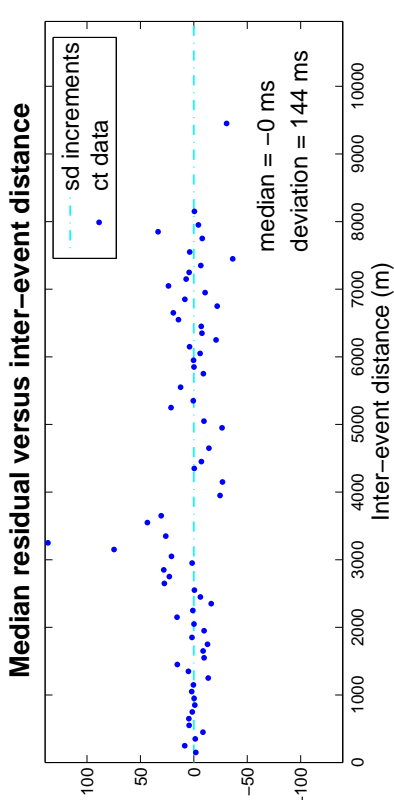

(su) ןenpı̣səג ue!̣pəW
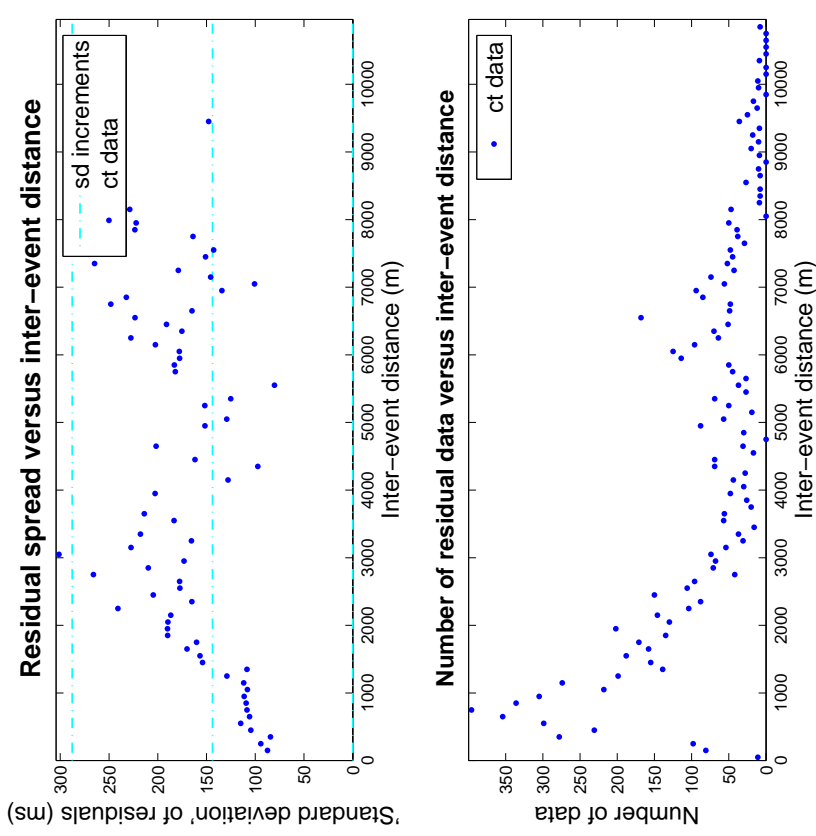

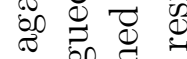

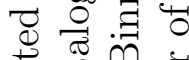

递通

닉

है है है

$\exists \ddot{\mathscr{\varepsilon}}$

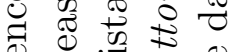

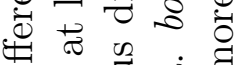

d.

药

จ 药

ејер to ıәqunN 


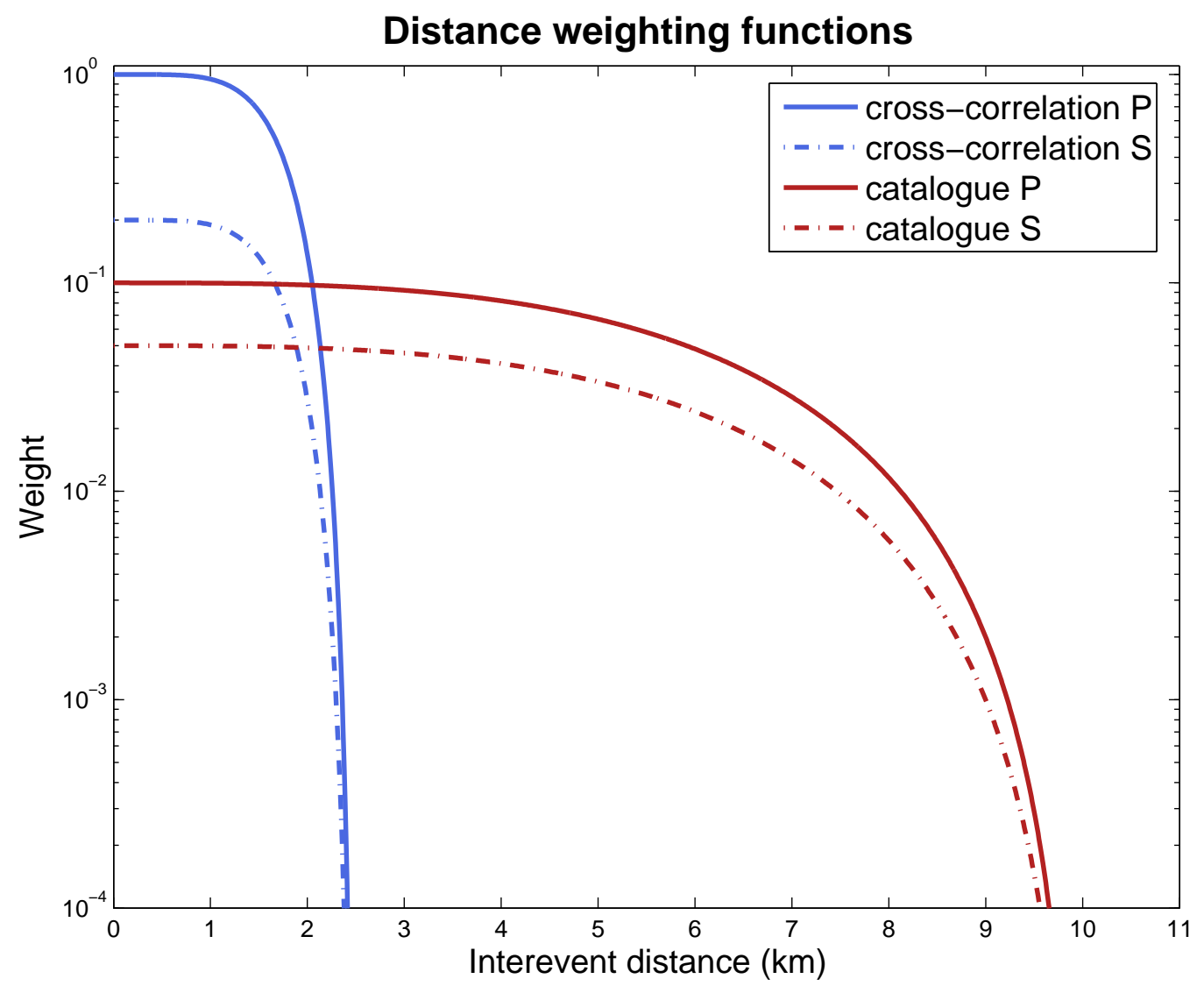

Figure 4.14: Interevent distance reweighting functions for hypoDD. Each function is scaled by the a priori weight for that data type (see text). Further weighting is applied to account for data quality and residual size.

the sparseness of the design matrix to efficiently invert large data sets. This method, however, is not as robust as singular value decomposition (SVD), so care must be exercised in its application (Waldhauser and Ellsworth, 2000). This involves the use of a damping parameter to limit the extent to which earthquake locations are allowed to move during the inversion process. If there are too few data or the data are of poor quality, then the inversion can become "unstable" (Waldhauser, 2001) and either more high quality data or a larger damping parameter need to be used. 
We assess the performance of the inversion using the condition number of the design matrix (see Sections 2.3.1 and 2.3.3 for a description of the design matrix). This is defined as the ratio of the largest to smallest eigenvalues for that matrix and for "well conditioned" problems should assume a value between about 40 and 80 (Waldhauser, 2001). If the condition number is too high then the damping parameter needs to be increased. However, the damping parameter should be no higher than around 100 otherwise the inversion becomes overdamped and the earthquake locations are barely allowed to move at all.

HypoDD constructs subgroups of linked events before applying double difference relocation to them. A pair of events are linked when the number of differential travel time observations they share is above a specified minimum value. In Section 4.3.2 we selected earthquake pairs with eight or more catalogue-based differential travel time observations for relocation using hypoDD. Figures 4.15 and 4.16 show how well these earthquakes are linked by our cross-correlation data. For Rotorua, 8957 earthquake pairs are linked by our cross-correlation data, $31 \%$ of which share at least four crosscorrelation measurements (solid grey lines). In Kawerau, only 14\% of 59603 cross-correlation linked event pairs share four or more cross-correlation measurements. To avoid situations where an event pair's location is dominated by one or two heavily-weighted cross-correlation-derived data (Section 4.3.4) we require an event pair to share four (Rotorua) or six (Kawerau) additional travel time differences for them to be grouped and subsequently relocated. These additional observations can be either cross-correlation- or cataloguebased. Using these criteria, we construct one group of 162 earthquakes for 


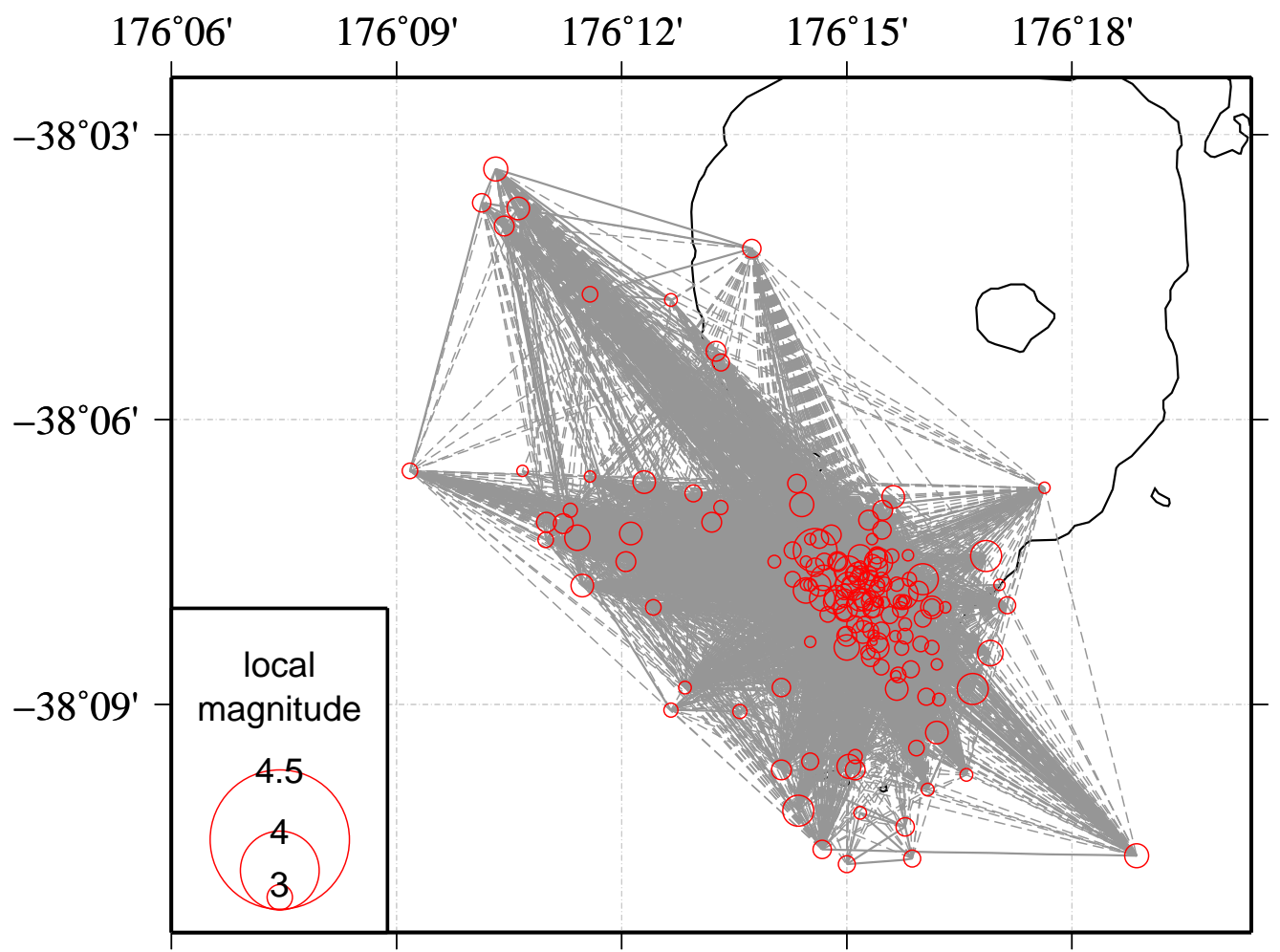

Figure 4.15: Initial (Catalogue and Velest) locations for 162 relocatable earthquakes in Rotorua. Earthquake symbol sizes indicate rupture dimensions calculated from local magnitudes, assuming a stress drop of $1 \mathrm{MPa}$. Solid grey lines link event pairs with four or more cross-correlation-derived travel times. Dashed grey lines link event pairs which share fewer than four crosscorrelation data. Lake boundaries (black lines) are shown for reference.

Rotorua. For Kawerau, three groups consisting of 330, 45 and 8 events, respectively, are selected along with a further ten groups of two events each.

Figure 4.17 shows how the condition number varies when different damping parameters are used while relocating these earthquakes. For Rotorua (blue lines) the condition number is within acceptable limits (dotted lines) when the damping parameter is between 50 and 85. We choose a damping value of 60 for our Rotorua earthquakes as this produces a condition number 


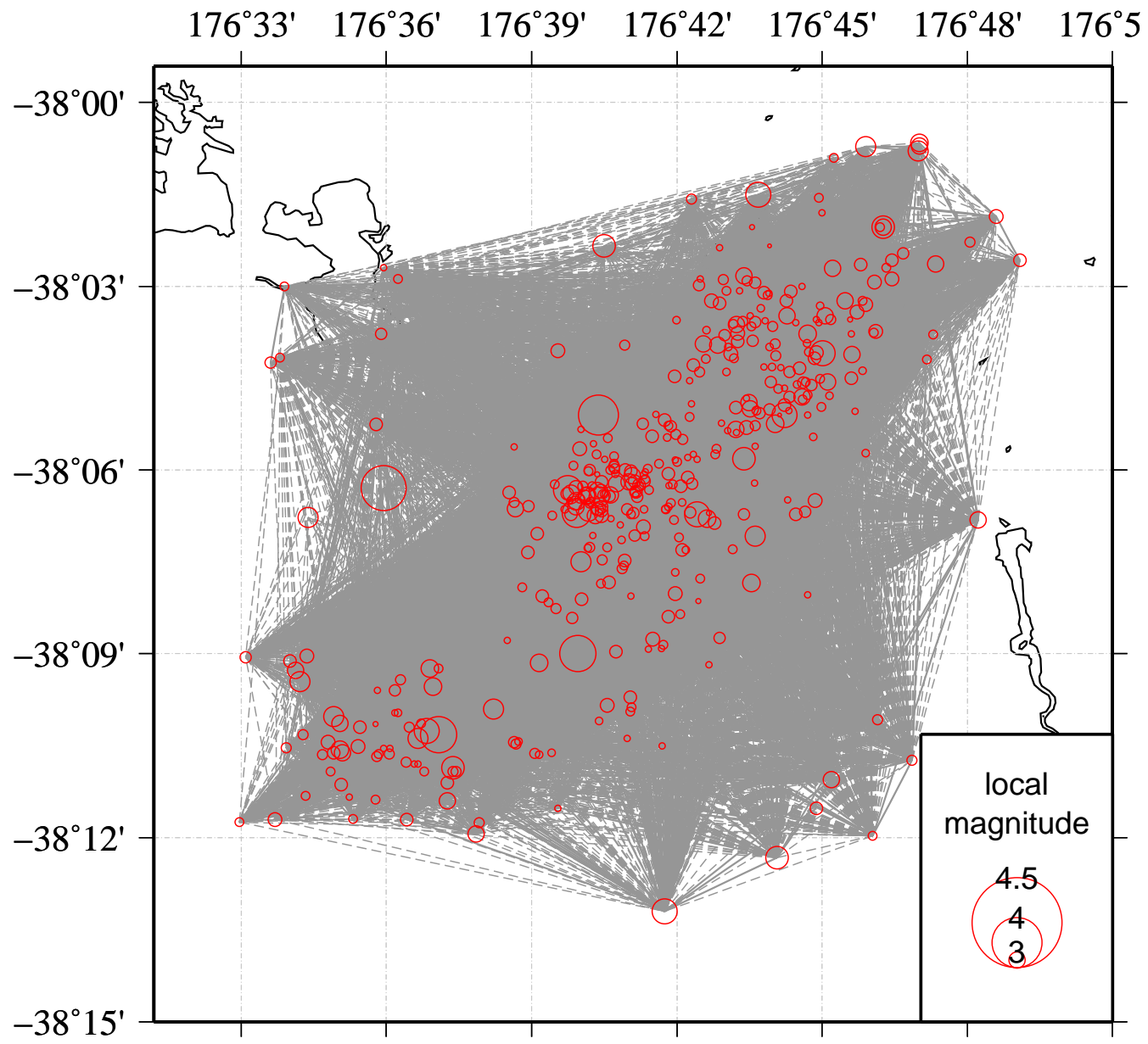

Figure 4.16: Initial (Catalogue and Velest) locations for 403 relocatable earthquakes in Kawerau. Earthquake symbol sizes indicate rupture dimensions calculated from local magnitudes, assuming a stress drop of $1 \mathrm{MPa}$. Solid grey lines link event pairs with four or more cross-correlation-derived travel times. Dashed grey lines link event pairs which share fewer than four crosscorrelation data. Lake boundaries (black lines) are shown for reference. 


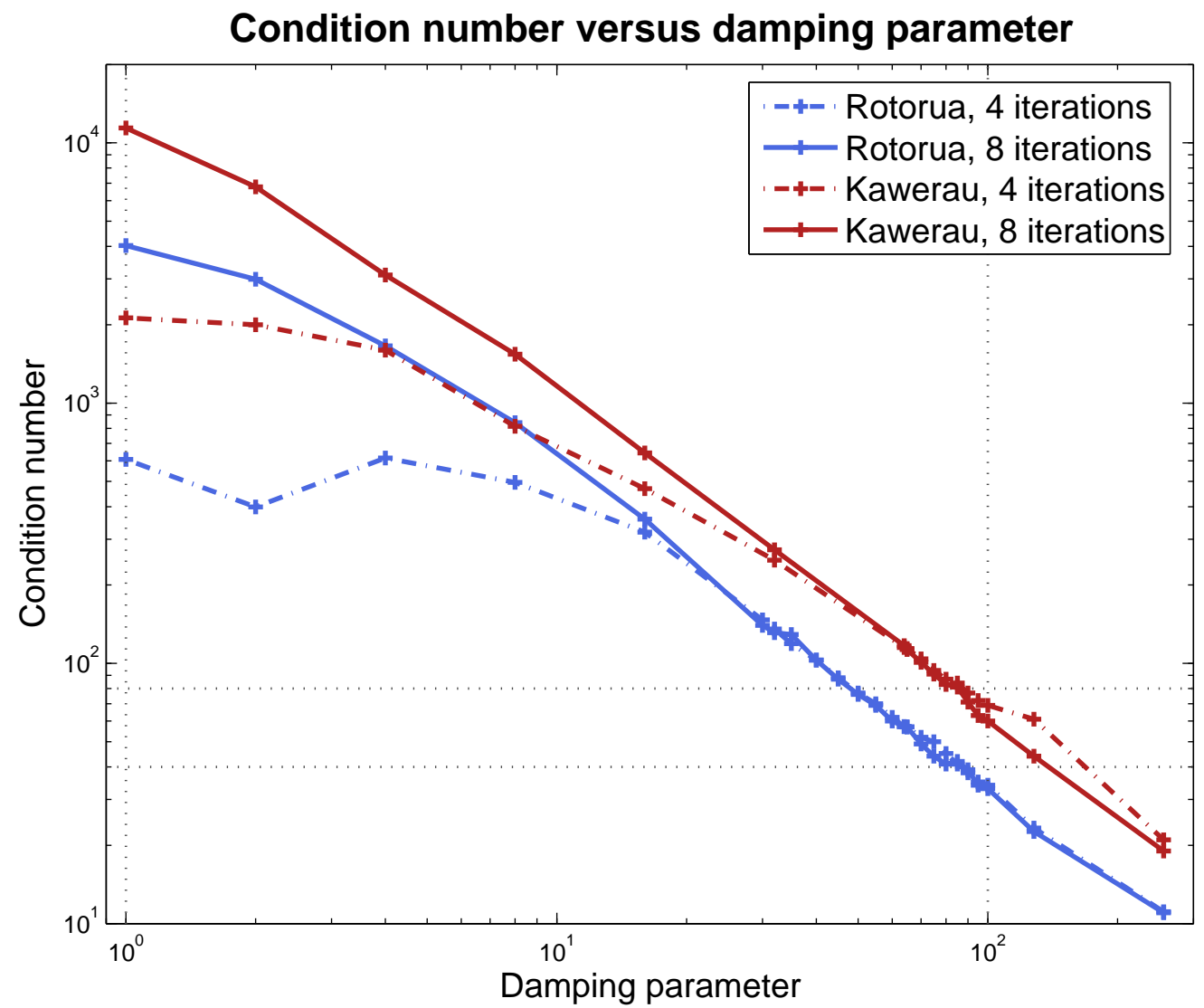

Figure 4.17: Condition number versus damping parameter for hypoDD after four and eight iterations as described in section 4.3.4 for Rotorua and Kawerau. Dotted lines mark the limits of acceptable values for these parameters.

of 60 , which lies in the middle of the range of acceptable values it can take. For Kawerau, the condition number for the largest subgroup is displayed (red lines). This is generally higher than for Rotorua and only reaches acceptable values when the damping parameter is greater than 80 . Consequently, we choose a damping value of 90 for the Kawerau earthquake set. This greater damping value means the hypocentres in Kawerau will not be allowed to move as freely during the relocation process as those in Rotorua. 


\subsubsection{Final locations}

Figures 4.18 and 4.19 show the locations we obtain for the Rotorua and Kawerau earthquake sets, respectively, after relocating using HypoDD. Earthquake rupture sizes are calculated using the moment-magnitude scaling relationships of Hanks and Boore (1984) and a constant stress drop of $1 \mathrm{MPa}$. These earthquakes (red circles) are scaled to match their rupture areas.

In Rotorua these earthquakes cluster more tightly after relocation, particularly at the southern shore of Lake Rotorua, at Whakarewarewa to the south of Rotorua City, and also at Mount Ngongotaha to the west of Rotorua (Figure 1.2). None of these earthquakes have focal depths greater than 10 $\mathrm{km}$.

In Kawerau the relocated earthquake hypocentres are also more tightly clustered than before relocation. This is especially true for earthquakes within Okataina Caldera to the southwest of Kawerau, where earthquake hypocentres tend to cluster around Puhipuhi Hill, and also in the northwestern part of the Kawerau geothermal field (Figure 1.3). These earthquakes are also clustered in depth and reach maximum focal depths of around 12 $\mathrm{km}$.

These maps do not display estimates of location error because Paige and Saunders (1982) and Waldhauser (2001) warn that the uncertainties reported by the inversion method LSQR are unreliable. To obtain some characterisation of the uncertainty in our final set of locations, we re-invert the second largest group of events (45 earthquakes) in the Kawerau earthquake set using singular value decomposition (SVD) and compare the outcome to the 

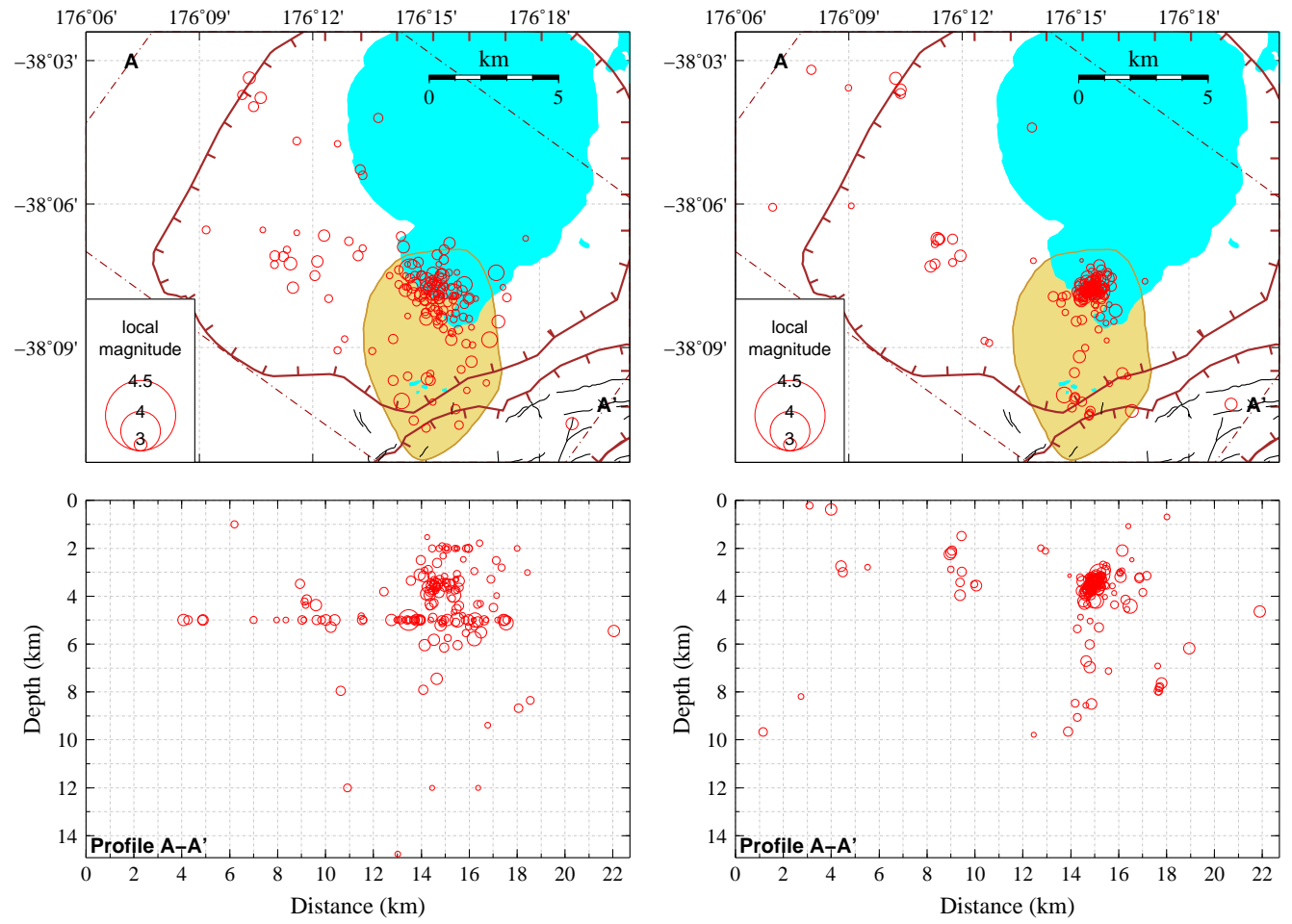

Figure 4.18: Initial (left) and final (right) hypocentres for the Rotorua set of relocatable earthquakes. 155 of 162 earthquakes are relocated. Red circles are earthquakes with sizes indicating rupture dimensions calculated from local magnitudes, assuming circular ruptures and a stress drop of $1 \mathrm{MPa}$. Black lines are faults. Brown hachured lines mark calderas. Yellow areas are geothermal fields. The bottom panel shows earthquake focal depths along profile A-A' (red box in top panel).

results we obtain with LSQR. The mean uncertainties in the east, north and depth directions reported for the LSQR inversion are 44.5, 39.5 and $53.2 \mathrm{~m}$, respectively, while those reported by SVD are 21.7, 13.3 and $36.5 \mathrm{~m}$. This suggests the uncertainties reported by LSQR are overestimated. However, we also compare the locations we obtain using these two methods. Figure 4.20 shows (left) the locations obtained using LSQR and (right) those found with SVD for this subgroup of earthquakes. Encouragingly, the epicentres 

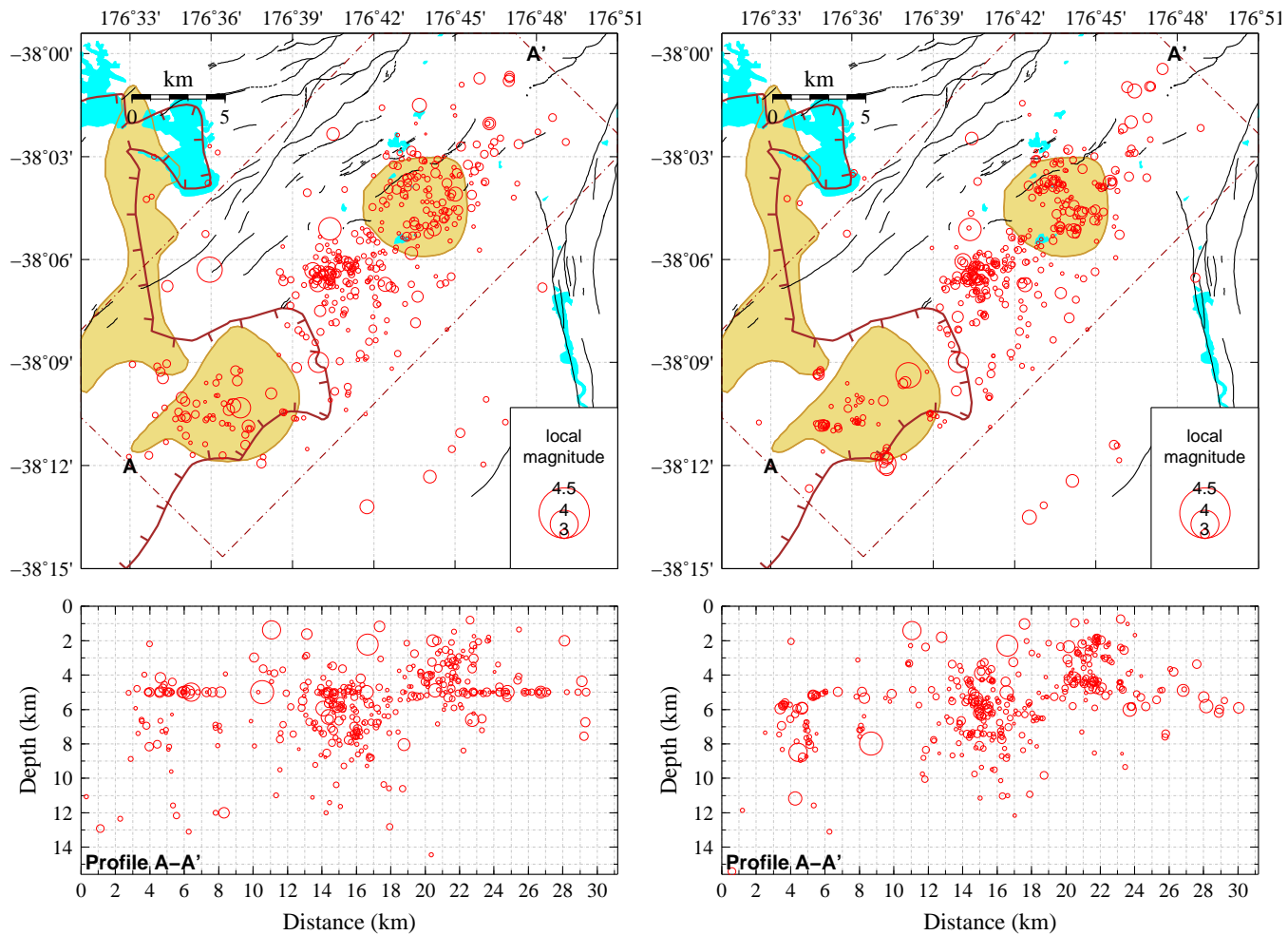

Figure 4.19: Initial (left) and final (right) hypocentres for the Kawerau set of relocatable earthquakes. 400 of 403 earthquakes are relocated. Earthquake symbol sizes indicate rupture dimensions calculated from local magnitudes, assuming circular ruptures and a stress drop of $1 \mathrm{MPa}$. Black lines are faults. Brown hachured lines mark calderas. Yellow areas are geothermal fields. The bottom panel shows earthquake focal depths along profile A-A' (red box in top panel).

obtained using the two methods are quite similar, but the depths obtained using LSQR are more dispersed than those found using SVD. The locations found using these two inversion techniques differ on average by 286, 613 and $824 \mathrm{~m}$ in the east, north and depth directions, respectively. This suggests the uncertainties in our locations are likely to be of the order of a few hundred rather than tens of metres in each coordinate direction as reported by HypoDD. 
As mentioned in Section 2.3.3, the double-difference method of earthquake relocation is capable of resolving the absolute positions of earthquake clusters as well as the relative offsets between the earthquakes within them (Menke and Schaff, 2004). The formal uncertainties reported by HypoDD, however, are of positions relative to the centroids of these clusters, which have their own uncertainty. This may be a reason why the errors reported by hypoDD are apparently underestimated.
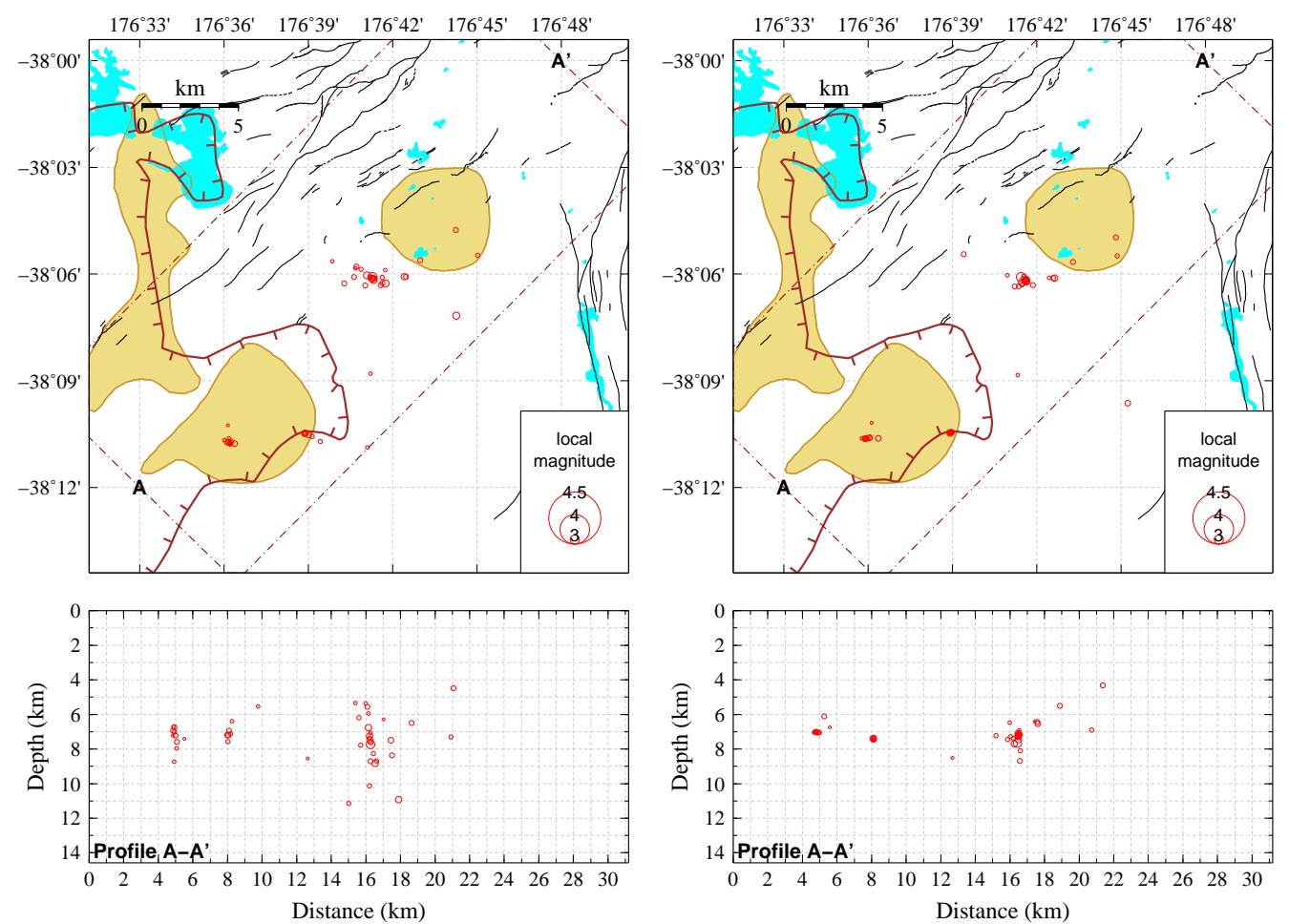

Figure 4.20: LSQR (left) and SVD (right) hypocentres for 45 of the Kawerau set of relocatable earthquakes (see text for details). Earthquake symbol sizes indicate rupture dimensions calculated from local magnitudes, assuming circular ruptures and a stress drop of $1 \mathrm{MPa}$. Black lines are faults. Brown hachured lines mark calderas. Yellow areas are geothermal fields. The bottom panel shows earthquake focal depths along profile A-A' (red box in top panel). 
Figure 4.21 shows relocated earthquake latitudes, longitudes and depths plotted against time for Rotorua (left) and Kawerau (right). These diagrams show that the earthquakes are not only tightly clustered in space, but also in time. Localised bursts of earthquake activity appear as short vertical streaks in these graphs, with shorter streaks indicating more tightly confined locations than longer streaks. Note that no earthquakes that occurred in Rotorua and very few that occurred in Kawerau prior to 1992 have been relocated. This is primarily due to the lack of seismograph stations in the region before that time (Figure 2.2). We analyse the nature of these clustered earthquakes more thoroughly in Chapter 5.

\subsection{Summary}

In this chapter we have used double-difference earthquake relocation with a mixture of catalogue- and correlation-based travel time differences for pairs of earthquakes observed at common stations to produce a set of reliable earthquake hypocentres for both Rotorua and Kawerau. We have carefully selected only the most "locatable" earthquakes from each region and chosen a set of inversion control parameters to suit our data set. During the inversion process, we have made use of the 1-D seismic velocity models we produced for these regions in Chapter 3.

Although these earthquakes are recorded primarily at permanent vertical component seismograph stations, we have been able to determine precise hypocentres for a significant number of them. We observe that the doubledifference locations are more tightly clustered than those in the earthquake 

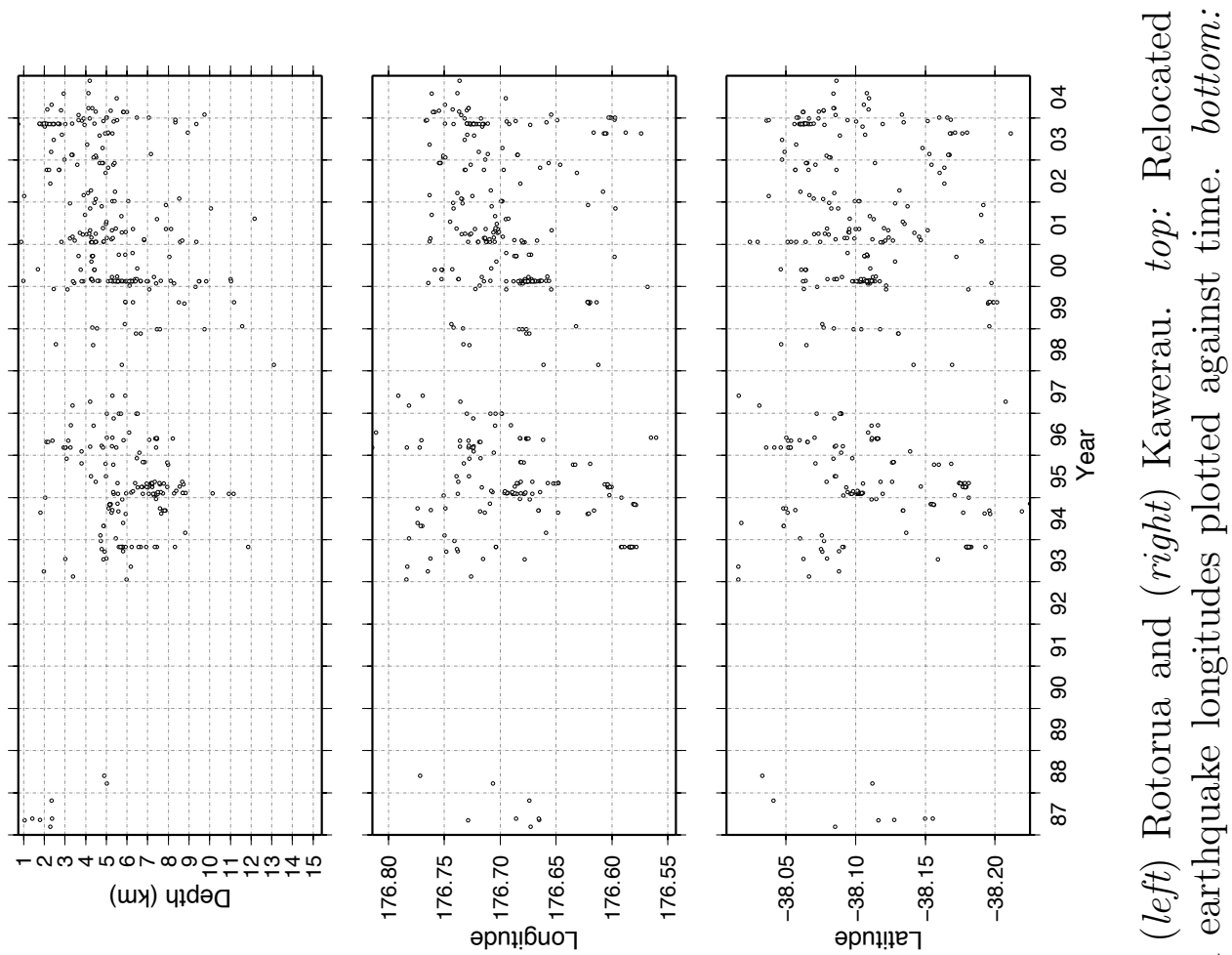

$$
\text { (ux) पІdә઼ }
$$
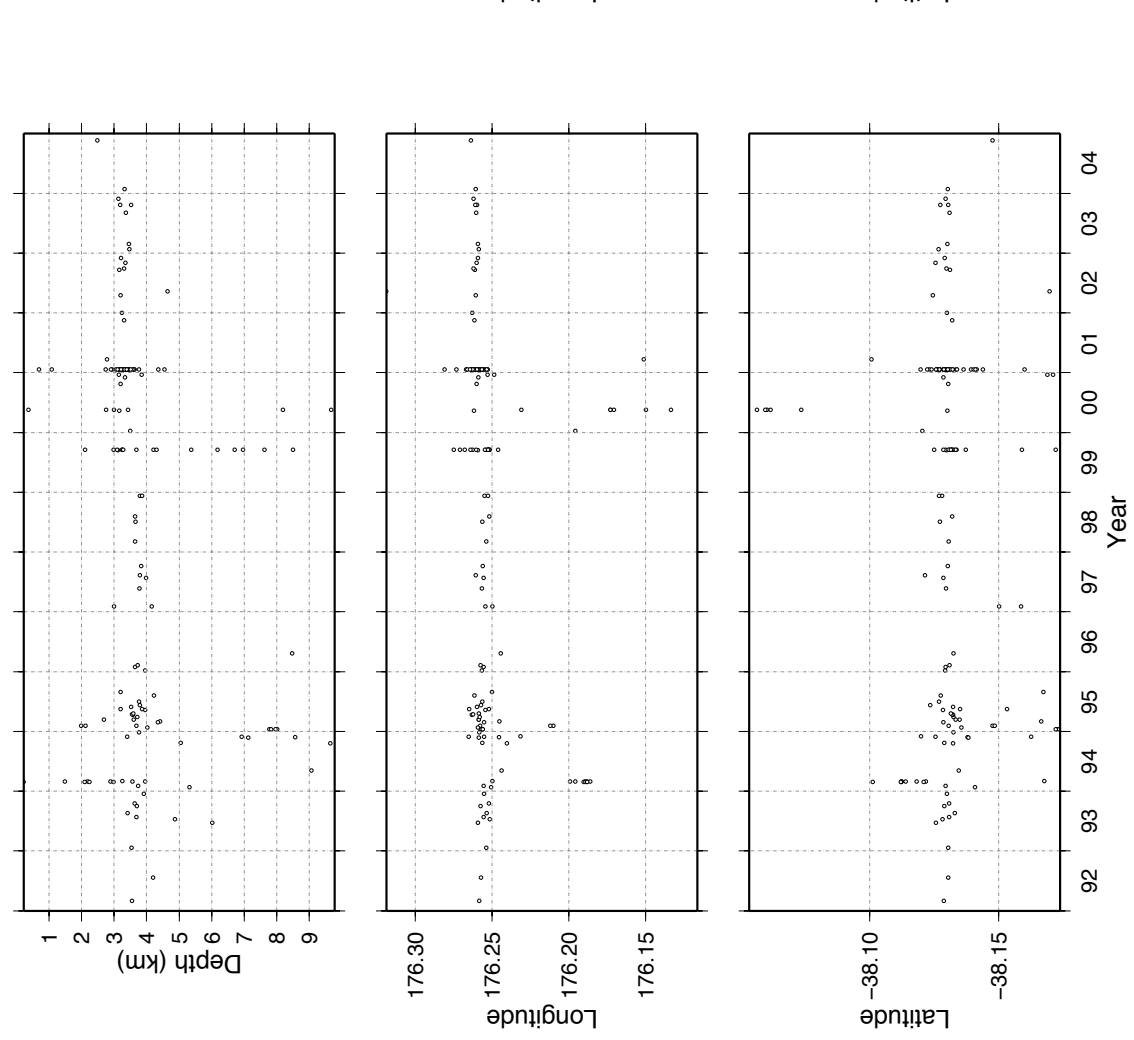

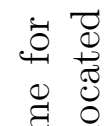

品

员

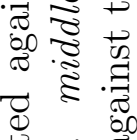

志 营

प

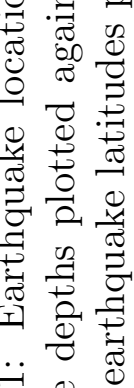
국

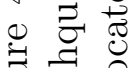
㡙 
catalogue. In Rotorua, the earthquakes collapse into distinct clusters near Rotorua City and also Mount Ngongotaha. In Kawerau, the earthquakes align into a northeast trending band of seismicity. Almost all of the relocated earthquakes have focal depths shallower than $12 \mathrm{~km}$. We estimate the uncertainties in these earthquake locations are likely to be of the order of hundreds of metres in each coordinate direction. Using techniques similar to those outlined in this chapter, precise hypocentres will be increasingly obtainable for catalogued earthquake sets in the TVZ and New Zealand as the national seismograph network and other local networks improve and expand. 


\section{Chapter 5}

\section{Spatiotemporal patterns and focal mechanism determination}

\subsection{Introduction}

In this chapter we analyse the spatial and temporal characteristics of the relocated earthquake sets from Rotorua and Kawerau. Section 5.2 describes the steps we take to identify clusters of similar earthquakes using the crosscorrelation results described in Chapter 4, while Section 5.3 describes our attempt to find composite focal mechanisms for these clusters.

\section{$5.2 \quad$ Earthquake clustering}

Earthquakes with similar locations and source mechanisms should produce similar seismograms at the same seismograph station (Poupinet et al., 1984; Geller and Mueller, 1980). In Chapter 4 we described how we used cross- 
correlation to measure waveform similarity and time delays between seismograms from pairs of earthquakes measured at common stations. In this section we apply hierarchical clustering to these cross-correlation data and identify clusters of repeating similar events within these two areas. This method of clustering is commonly applied for the analysis of seismicity patterns (Cattaneo et al., 1999; Barani et al., 2007) and the identification of similar earthquakes for the computation of composite focal mechanisms (e.g. Hansen et al., 2006).

\subsubsection{Earthquake clustering method}

Hierarchical clustering is a technique applied to data to identify groups of events that are close together according to a given definition of distance and a specified distance threshold. In this case those data are seismograms, and the distances between them are the complements of (i.e. one minus) their P-wave cross-correlation coefficients. The clustering procedure works as follows: First, the two closest observations within the data set are linked. These two observations are then treated as a single group and a new set of distances is calculated. Here, the distance between any two groups can be taken as one of the shortest distance (nearest neighbour linkage), the longest distance (farthest neighbour linkage) or the average distance (average linkage) between their constituent events. The process is then repeated until all observations are connected. A final set of clusters are chosen by grouping events and groups of events that are linked with distances less than a specified threshold. 
We cluster our earthquakes using P-wave cross-correlation data from station UTU (Utuhina) for Rotorua and EDRZ (Edgecumbe, see Figure 2.1) for Kawerau. These stations are are both relatively close to their respective study areas and have recorded the majority of earthquakes in each of our two data sets. For Rotorua, 413 of the 504 catalogued earthquakes can be satisfactorily cross-correlated with each other at station UTU. In Kawerau, 1220 of 1875 earthquakes share cross-correlation data at station EDRZ. Because EDRZ opened in March, 1993, any earthquakes that occurred before that time are not considered in this clustering.

Average linkage is used to cluster the earthquakes from Rotorua and Kawerau. This is not as stringent as farthest neighbour linkage but ensures that all of the earthquakes clustered together correlate well with each other on average. The distance between two clusters $r$ and $s$ is calculated using the following relationship:

$$
d(r, s)=\frac{1}{n_{r} n_{s}} \sum_{i=1}^{n_{r}} \sum_{j=1}^{n_{s}}\left(1-c c_{r i, s j}\right)
$$

Here, $n_{r}$ and $n_{s}$ are the number of earthquakes within each cluster, and $c c_{r i, s j}$ are their correlation coefficients. We also test nearest neighbour linkage on these earthquakes but find that this method groups them into a small number of large clusters that clearly do not represent the natural grouping of seismicity in Rotorua and Kawerau.

Figure 5.1 summarizes the results we obtain when the Rotorua (left) and Kawerau (right) earthquake sets are clustered using various distance thresholds. Our correlation coefficient threshold must be high enough to ensure 
the earthquakes that are clustered are truly similar, but low enough to allow as many similar events as possible to be clustered together. The top panel in Figure 5.1 shows the number of relocated earthquake clusters that are obtained, while the middle panel shows the number of the full set (blue line) and relocated set (purple line) of earthquakes clustered for each distance threshold. Not surprisingly, these numbers tend to increase as more lenient thresholds are applied. In Rotorua, however, the number of clusters drops when the threshold exceeds 0.1. This is accompanied by a decrease in the rate at which the number of clustered earthquakes grows. This suggests that rather than new clusters of similar earthquakes being formed at higher distance thresholds, clusters of potentially dissimilar earthquakes are amalgamating into relatively few clusters of increasing size. The Kawerau earthquakes do not exhibit the same behaviour, indicating that increasing numbers of small clusters are formed at higher distance thresholds.

Visual inspection of relocated hypocentres indicates that for distance thresholds above 0.1 , earthquakes with distinctly different hypocentres begin to cluster together. As the threshold increases, the clusters become larger and less numerous. We use the criterion of Caliński and Harabasz (1974) $(\mathrm{CH})$, to evaluate the distribution of the relocated and clustered earthquake hypocentres. This number is the ratio of a measure of between-cluster variance to within-cluster variance in earthquake locations (see Equations 5-9 in Teanby et al., 2004). A high value for $C H$ indicates the clusters are distinct and contain tightly constrained earthquake hypocentres. The $C H$ criterion is applied in many diverse problems that make use of cluster analysis, including the identification of shear-wave splitting measurements in seismic anisotropy 

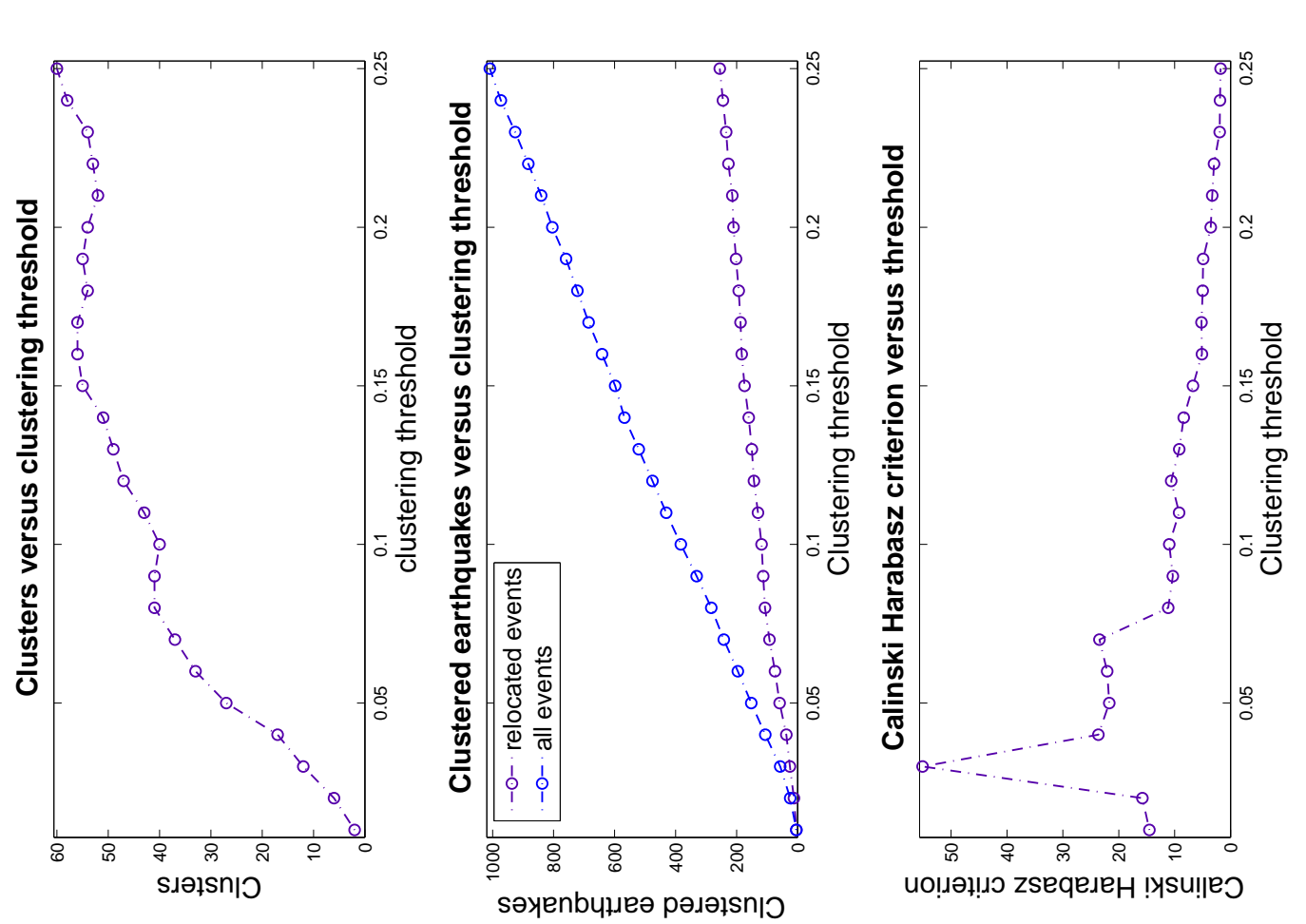

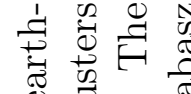
○ 娄

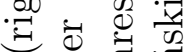
₹ द्वे $\overrightarrow{0} \Xi . \Xi \circlearrowright$ 空过泀 च्च ङF跑

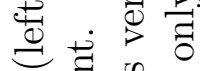
ब. क्ष 苟 正 ग 品 은 $\begin{array}{llll}4 & & 0 & 0 \\ 0 & 0 & 0 & 0\end{array}$
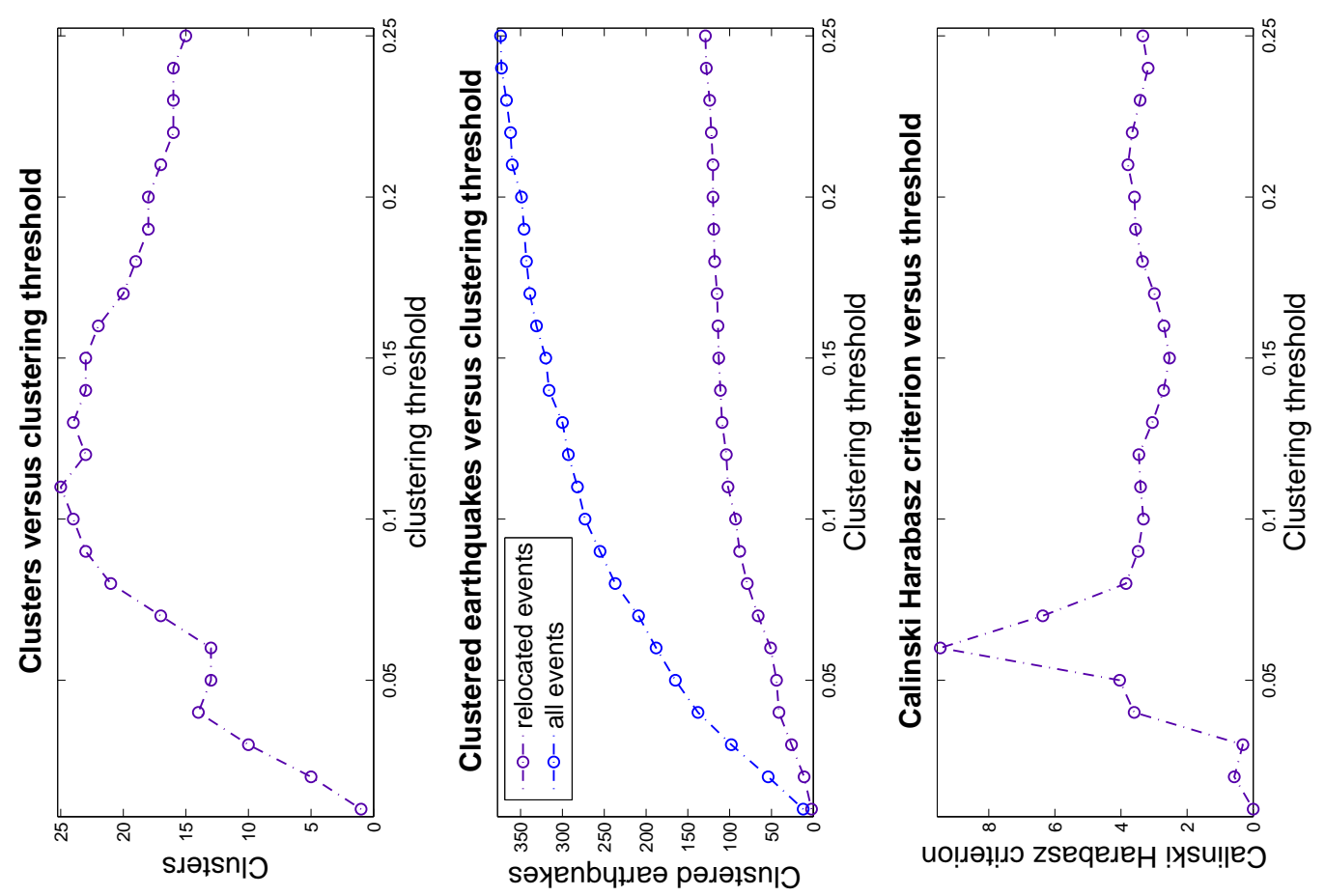

记

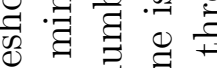
$\exists \exists . \exists$. ه 类

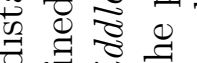
㐘运自

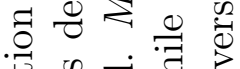

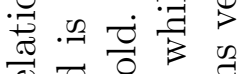

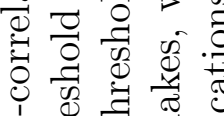

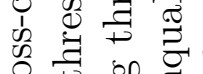
o

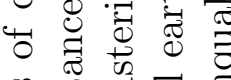

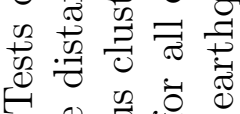

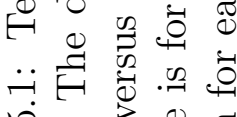

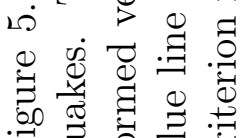

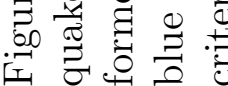


studies (Teanby et al., 2004).

The bottom panel in Figure 5.1 shows how $C H$ varies when different distance thresholds are used. $C H$ is maximum when stringent distance thresholds of 0.06 and 0.03 are applied for Rotorua and Kawerau, respectively. This is not surprising as the number of clusters is small and the earthquakes they contain are very similar and so should have similar locations. A distance threshold of 0.1 produces moderate values for $\mathrm{CH}$. Beyond this, $\mathrm{CH}$ decreases for the Kawerau earthquake set as more loosely linked events are clustered together.

On the basis of the measurements summarized in Figure 5.1, we choose a distance threshold of 0.1 to cluster these earthquake sets. This is the same as that used by Hansen et al. (2006) when clustering earthquakes in Costa Rica prior to determining focal mechanisms for them.

\subsubsection{Rotorua earthquake clusters}

Figure 5.2 shows the epicentres of the relocated and clustered Rotorua earthquakes. Here, 24 clusters of two or more relocated events are found. Recall that some earthquakes could not be relocated using the double-difference method because they were recorded at too few stations (see Chapter 4). Together, these clusters contain 93 relocated earthquakes. The largest of these clusters contains 26 relocated events (brown stars) and a further 25 that are not relocated. These occur just north of Rotorua City in the southern part of Lake Rotorua (Figure 1.2). The second and third largest clusters in Rotorua consist of eight (purple circles) and five (blue triangles) relocated events, 
respectively and also occur just north of Rotorua City. Note that the earthquakes near Mount Ngongotaha, which have tightly clustered epicentres, are also clustered by waveform similarity (yellow stars). These earthquakes' epicentres are not close to Henderson's quarry which sits at the northeastern foot of Mount Ngongotaha (Figure 1.2). Another cluster (brown circles) on the northwestern boundary of Rotorua caldera is also evident. The epicentres of these events appear to have a more dispersed distribution than those in other clusters. These events are on the edge of the network of doubledifference relocated earthquakes (Figure 4.15). Based on the similarity of these earthquakes' seismograms, their locations are probably more tightly constrained than Figure 5.2 suggests.

Seismograms that were recorded at station UTU for these earthquakes are shown in Figure 5.3. These are band-pass filtered between 2 and $8 \mathrm{~Hz}$ (Section 4.2.3). The seismograms on the left are aligned using their catalogue P-wave arrival time picks (plotted at $1 \mathrm{~s}$ ), while those shown on the right are aligned using $\mathrm{P}$-wave arrival times that are adjusted using crosscorrelation-derived delay times. The seismograms within these clusters are clearly similar, and this similarity persists right through the P-wave coda and to a lesser extent into the S-wave arrival. Note that the seismograms also appear quite similar between these clusters, but also show distinct differences (for example between 1.5 and $2 \mathrm{~s}$ for the first and second clusters). This is likely due to the similar locations of these clusters. The ray paths from these earthquakes to station UTU are similar and sample the same velocity structure as each other, giving rise to similar seismograms. Our high cross-correlation clustering threshold of 0.9 reduces the likelihood of small 


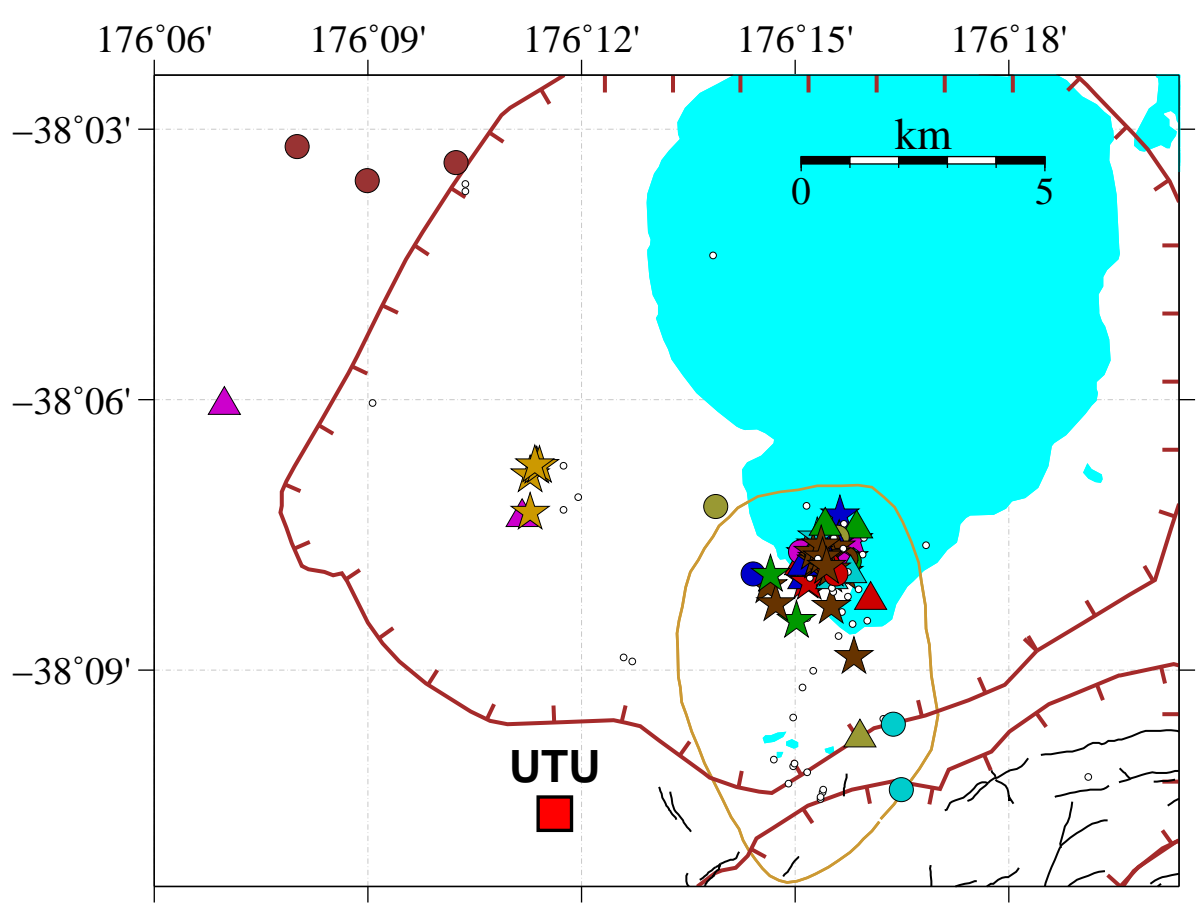

Figure 5.2: Clustered epicentres for the relocated Rotorua earthquake set. Each cluster has its own coloured symbol. Small black circles are earthquakes that are not clustered. Station UTU (large red square) is plotted. Brown hachured lines mark calderas. The yellow line borders the Rotorua geothermal area. The three largest clusters are illustrated with brown stars, purple circles and blue triangles, respectively.

earthquakes with similar locations but distinct rupture characteristics being clustered together.

Figures 5.4, 5.5 and 5.6 show the epicentres and magnitudes of the earthquakes in the largest, second largest and Mount Ngongotaha cluster, respectively. The top panel is a plot of magnitude versus time for the clustered events. The two largest clusters span the entire period between 1992 and 2005 and have local magnitudes of between 1.8 and 3.1. By contrast, all events in the Mount Ngongotaha cluster occurred on a single day in February, 1994. 

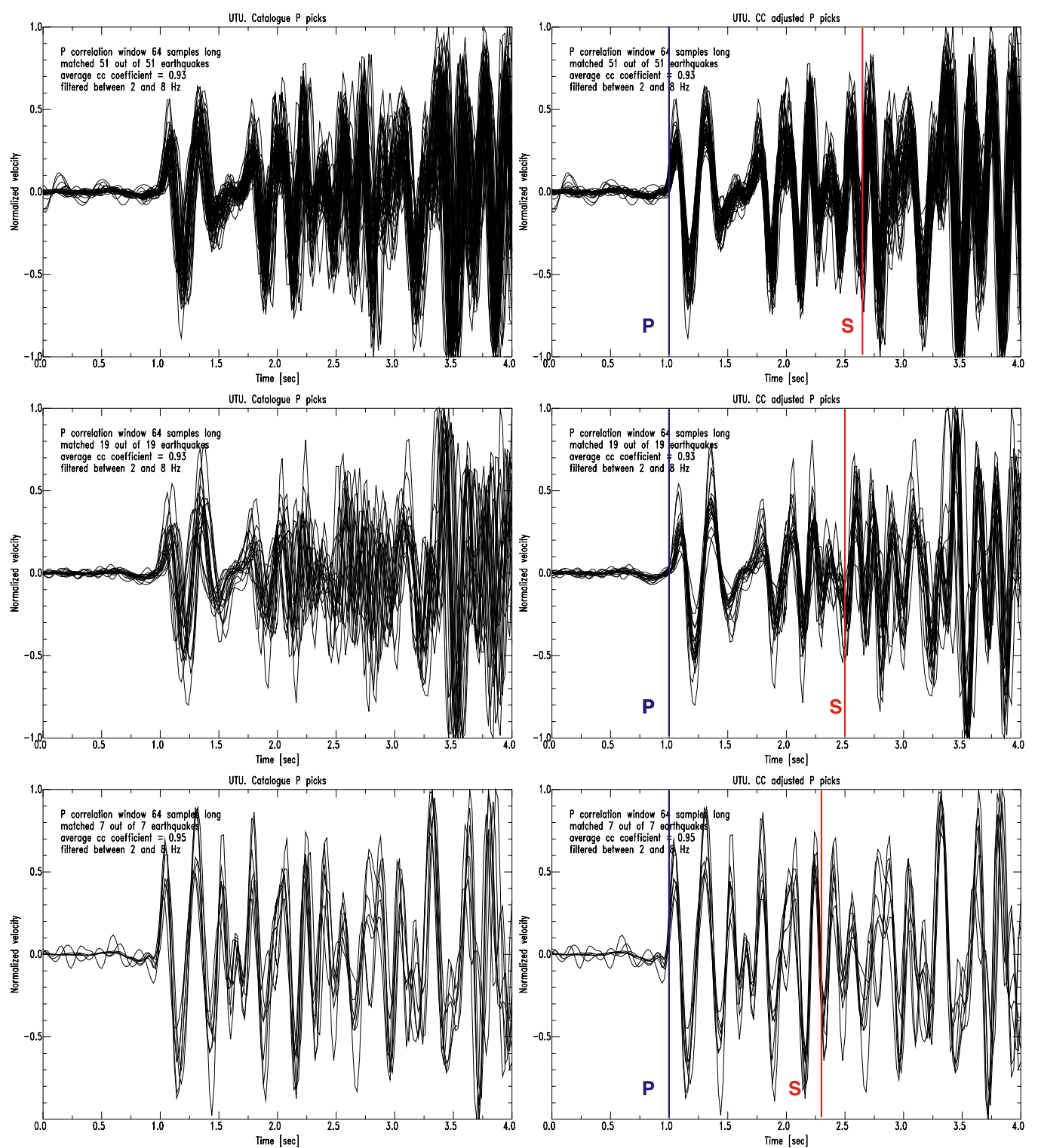

Figure 5.3: Filtered seismograms from the largest Rotorua cluster (top, brown stars in Figure 5.2), the second largest Rotorua cluster (middle, purple circles in Figure 5.2) and the Mount Ngongotaha cluster (bottom, yellow stars in Figure 5.2). The seismograms were recorded at station UTU (Utuhina, see Figure 2.1). The overlain traces are aligned using (left) catalogued Pwave arrival time picks, and (right) arrival times that have been adjusted using cross-correlation. The plotted S-wave arrival time is estimated using the median picked S-P time for these seismograms. The clusters consist of (top) 51, (middle) 19 and (bottom) 7 events. Of these, 26, 8 and 5 events, respectively, have been relocated. 
The right hand panels in Figures 5.4, 5.5 and 5.6 show the epicentres of these clustered earthquakes. These include events that are relocated using hypoDD (circles) and those that are not (catalogue locations, squares). Clearly the relocated epicentres are more tightly constrained than the remaining catalogue locations. These earthquakes share an average correlation coefficient of at least 0.9 with each other at station UTU and so should have very similar epicentres. Only those earthquakes that are rejected for relocation are shown. Therefore, the dispersed catalogue locations do not indicate that all catalogued epicentres are poorly resolved in the Rotorua area. However, the relocated earthquake set includes only 155 out of 504 earthquakes (31\%) in the complete Rotorua set. The earthquakes that are not relocatable represent a large proportion of the earthquake catalogue. If we assume that the clustered earthquakes all have roughly the same location, then the scatter in the catalogue locations provides an an indication of the level of uncertainty in the catalogued hypocentres. i.e. we can use the difference in hypocentres within a single cluster to judge the uncertainty in catalogue hypocentres as a whole. The standard deviation in the north, east and depth directions of the double-difference and catalogue locations for the largest cluster are listed in Table 5.1.

Here, the uncertainty in the catalogue locations are of the order of 2 to 3 $\mathrm{km}$ in each coordinate direction. For well observed earthquakes - earthquakes that we have been able to relocate using hypoDD - the uncertainty in the north and east direction is reduced to around $1 \mathrm{~km}$. 


\begin{tabular}{|c|c|c|c|c|}
\hline \multirow{2}{*}{ Earthquakes } & \multirow{2}{*}{ Events } & \multicolumn{3}{|c|}{ Standard deviations $(\mathrm{km})$} \\
\cline { 3 - 5 } & & North & East & Depth \\
\hline $\begin{array}{c}\text { relocated } \\
(\text { hypoDD) }\end{array}$ & 26 & 0.49 & 0.37 & 1.58 \\
\hline $\begin{array}{c}\text { relocated } \\
\text { (catalogue) }\end{array}$ & 26 & 0.99 & 0.92 & 2.42 \\
\hline $\begin{array}{c}\text { not relocated } \\
\text { (catalogue) }\end{array}$ & 25 & 3.80 & 2.74 & 2.61 \\
\hline $\begin{array}{c}\text { entire cluster } \\
\text { (catalogue) }\end{array}$ & 51 & 2.78 & 2.09 & 2.60 \\
\hline
\end{tabular}

Table 5.1: Earthquake location scatter for the largest cluster in the Rotorua earthquake set. The cluster consists of 51 earthquakes, 26 of which were relocated using the double-difference method hypoDD.

\subsubsection{Kawerau earthquake clusters}

Figure 5.7 shows the epicentres of the clustered and relocated Kawerau earthquakes. A total of 118 relocated earthquakes are grouped into 40 clusters of two or more relocated events. While more relocated earthquakes are clustered in Kawerau than in Rotorua, the clusters in Kawerau are smaller, with the largest consisting of only six relocated earthquakes and a further 13 that are not relocated.

As mentioned above, earthquakes that occurred before March, 1993 are not clustered as station EDRZ was not open before this time. In an attempt to identify more families of similar events, we cluster the Kawerau earthquakes using cross-correlation data from station TAZ (Tarawera). This station has been operating since 1984 and has measured more of these earthquakes than EDRZ. We find that only 107 relocated earthquakes are clustered when correlation data from TAZ is used. This is likely due to lower correlation coefficients caused by the greater distance between the earthquakes 


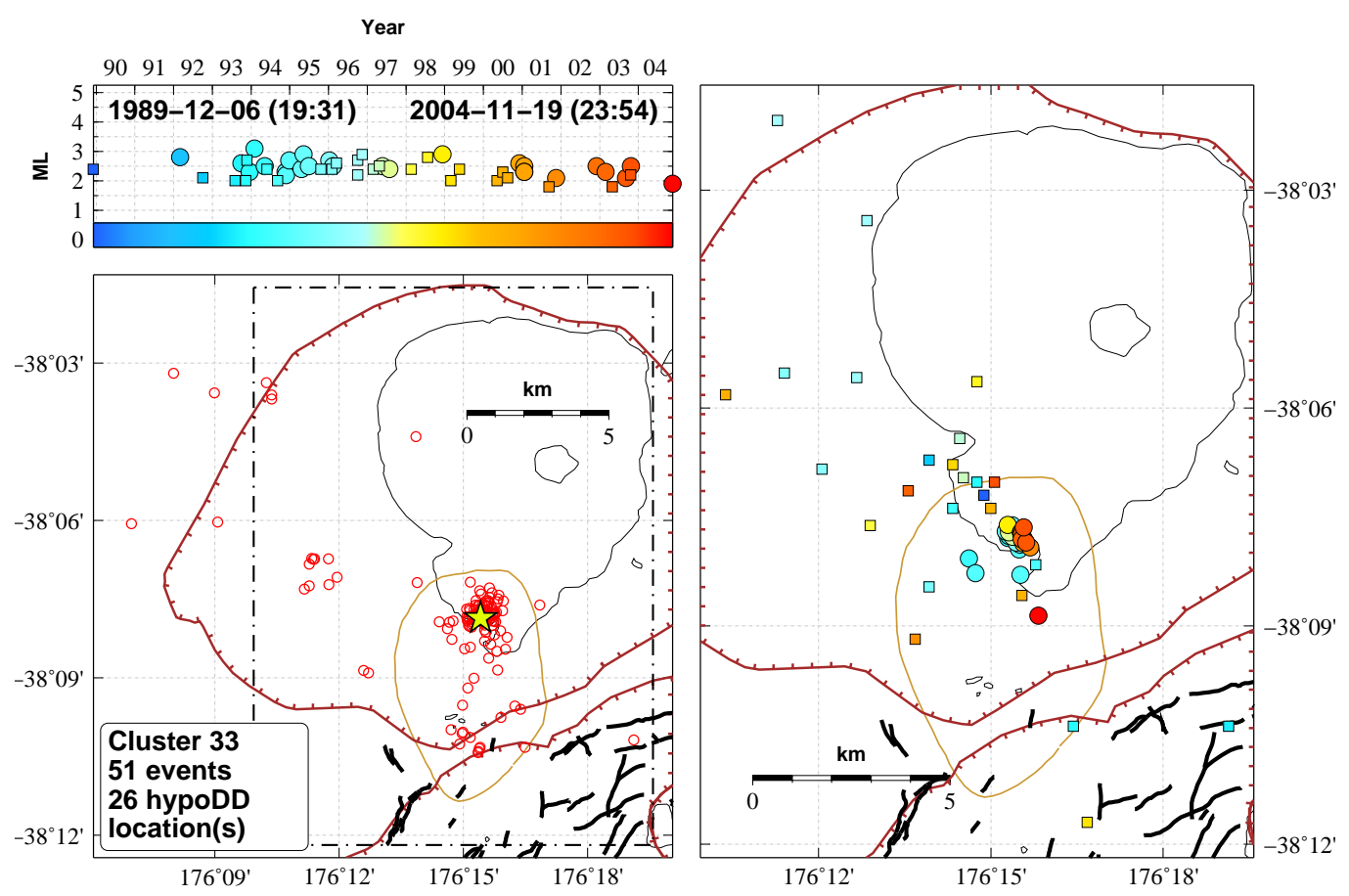

Figure 5.4: The largest Rotorua cluster. top: Magnitude versus time. left: Epicentres for all relocated events. The dashed black box surrounds the cluster. The yellow star is the cluster centroid. right: Clustered epicentres. Circles mark relocated epicentres while squares mark catalogue locations for earthquakes that are not relocated. Symbol colours show earthquake timing (see colour scale). Calderas (brown hachured lines), lakes (thin black lines), faults (thick black lines) and geothermal areas (yellow lines) are shown.

and station TAZ compared to that for EDRZ. Again, 24 out of 41 clusters contain only two relocated events. The clusters described in the remainder of this chapter are defined using data from station EDRZ (Figure 2.1).

Figure 5.8 shows vertical seismograms recorded at station EDRZ for three of the Kawerau clusters. The seismograms are band-pass filtered between 2 and $8 \mathrm{~Hz}$ (Section 4.2.3). As for the Rotorua clusters shown in Figure 5.3 , the alignment of these seismograms improves when their P-wave arrival time picks are adjusted using cross-correlation-derived time delays (right). 


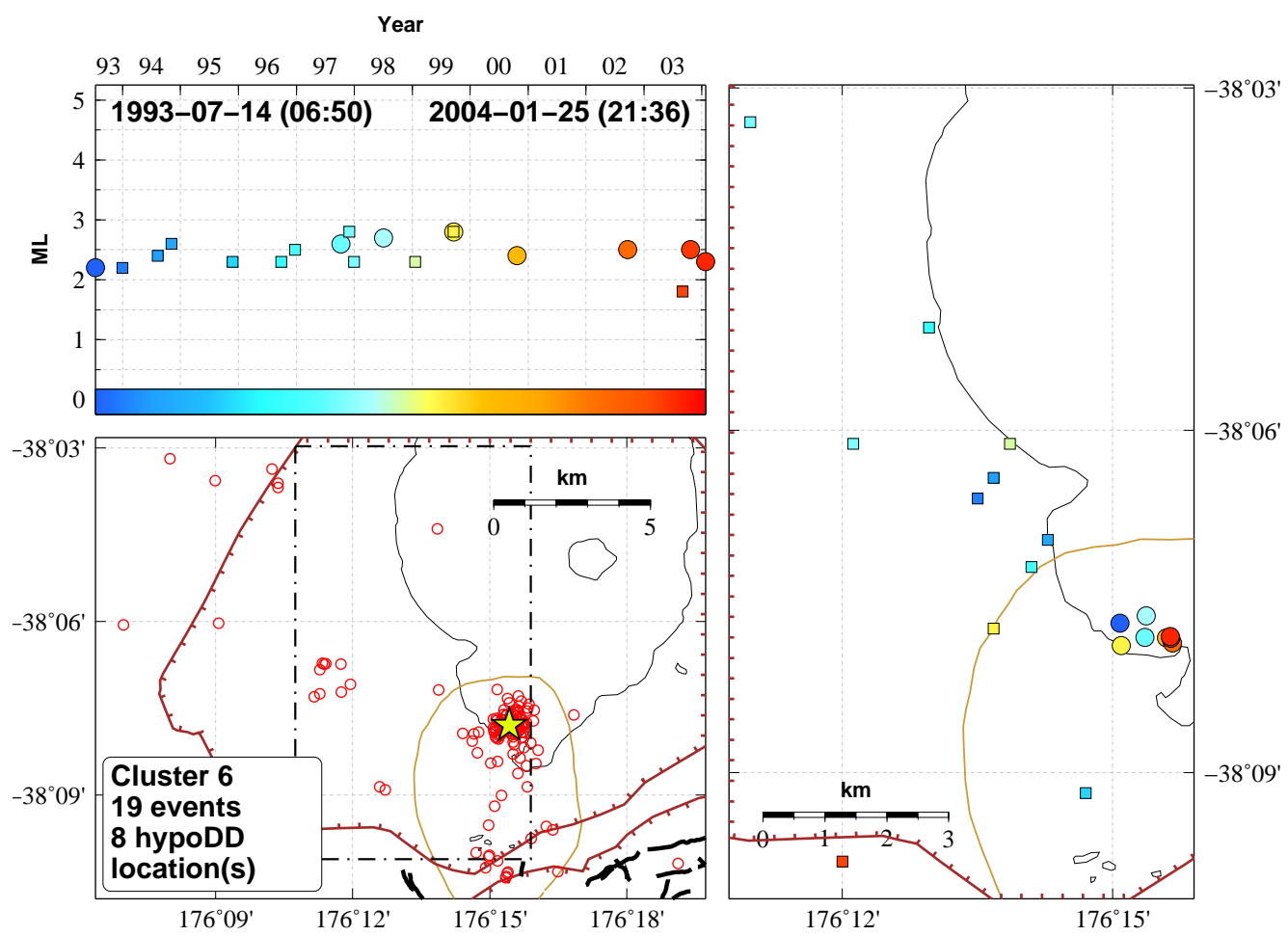

Figure 5.5: The second largest Rotorua cluster. top: Magnitude versus time. left: Epicentres for all relocated events. The dashed black box surrounds the cluster. The yellow star is the cluster centroid. right: Clustered epicentres. Circles mark relocated epicentres while squares mark catalogue locations for earthquakes that are not relocated. Symbol colours show earthquake timing (see colour scale). Calderas (brown hachured lines), lakes (thin black lines), faults (thick black lines) and geothermal areas (yellow lines) are shown.

Again, the clustered seismograms are similar, but their similarity appears to break down near the S-wave arrival. This behaviour, which is not evident in the Rotorua clusters, could be due to slightly different source mechanisms between these events or temporal changes in the seismic velocity structure between them and station EDRZ (Schaff et al., 2004).

Figures 5.9, 5.10 and 5.11 show epicentres for the three clusters whose seismograms are shown in Figure 5.8. For the remainder of this discussion, 


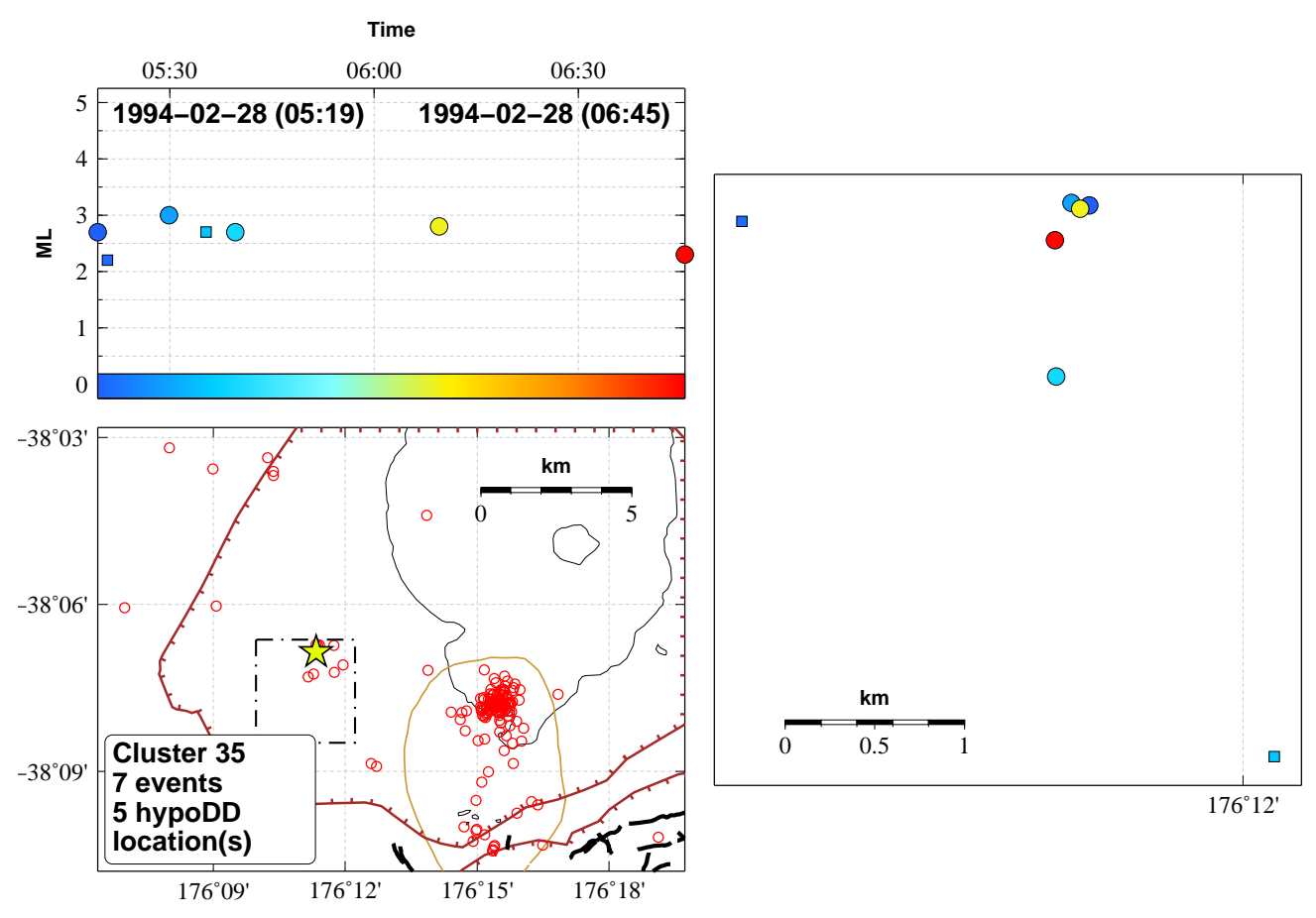

Figure 5.6: The Mount Ngongotaha cluster. top: Magnitude versus time. left: Epicentres for all relocated events. The dashed black box surrounds the cluster. The yellow star is the cluster centroid. right: Clustered epicentres. Circles mark relocated epicentres while squares mark catalogue locations for earthquakes that are not relocated. Symbol colours show earthquake timing (see colour scale). Calderas (brown hachured lines), lakes (thin black lines), faults (thick black lines) and geothermal areas (yellow lines) are shown.

I will refer to these clusters as the southern Okataina, the Kawerau and the northern Okataina clusters, respectively, as two of the clusters are located in the eastern part of Okataina caldera, while the third is located just south of the Kawerau geothermal field (Figure 1.3). These clusters occur over relatively short periods of time compared with the large clusters in the Rotorua earthquake set (Figures 5.4 and 5.5).

While most of the relocated epicentres in these clusters are confined to distinct source areas, a few "rogue" events are not and appear to be erro- 


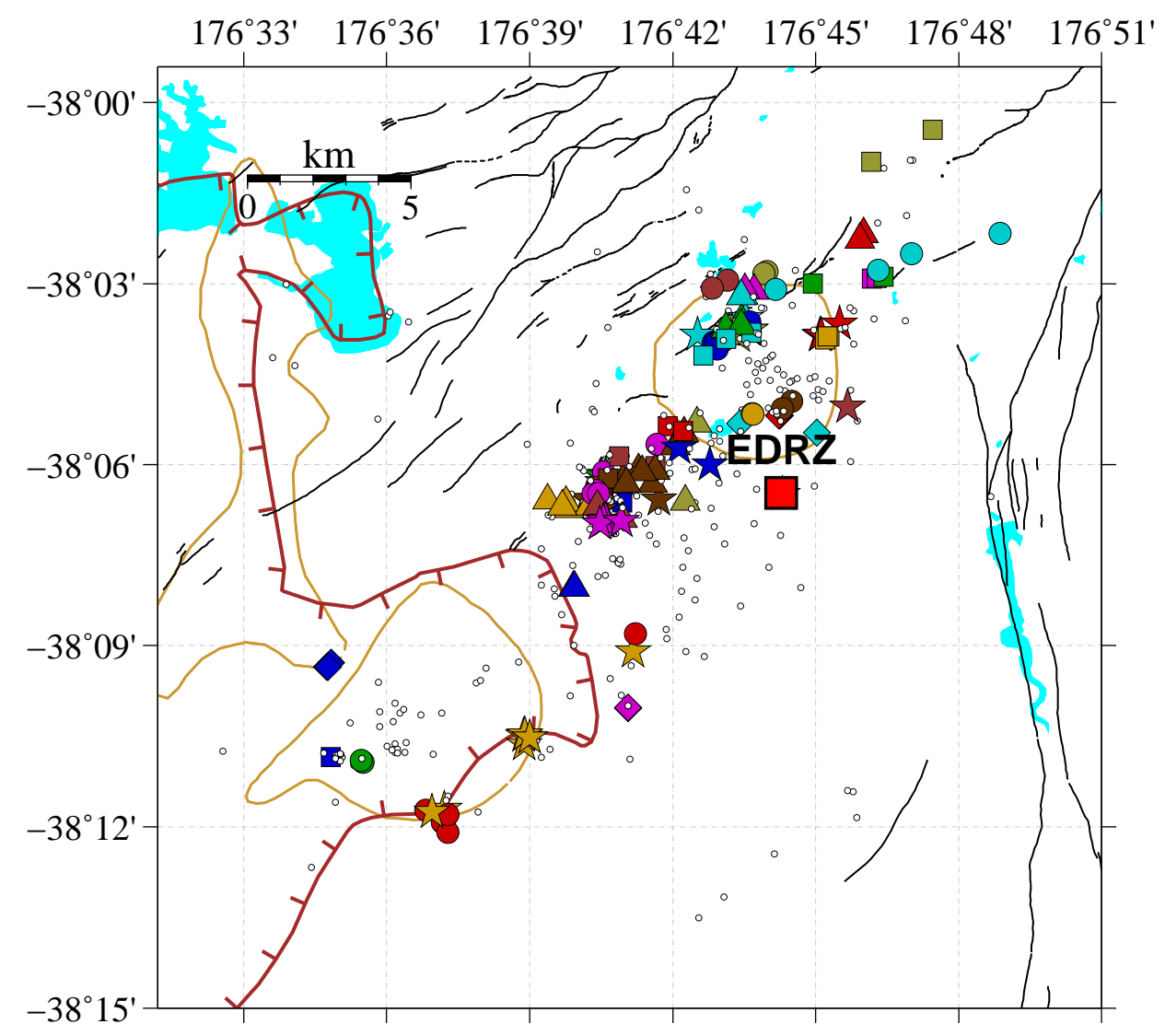

Figure 5.7: Clustered epicentres for the relocated Kawerau earthquake set. Each cluster has its own coloured symbol. Small black circles are earthquakes that are not clustered. Station EDRZ (large red square) is plotted. Brown hachured lines mark calderas. The yellow lines border geothermal areas.

neously linked to the rest of the events in their respective clusters. One explanation for this could be that these earthquakes have been mislocated and are likely to have ruptured nearer to the rest of the cluster than they have been placed by the double-difference method. Figures 5.9, 5.10 and 5.11 (top panels), however, show that these clusters generally occur as short bursts of activity, and that the apparent rogue events occur some time earlier or later. This suggests that these events are not closely related to the 

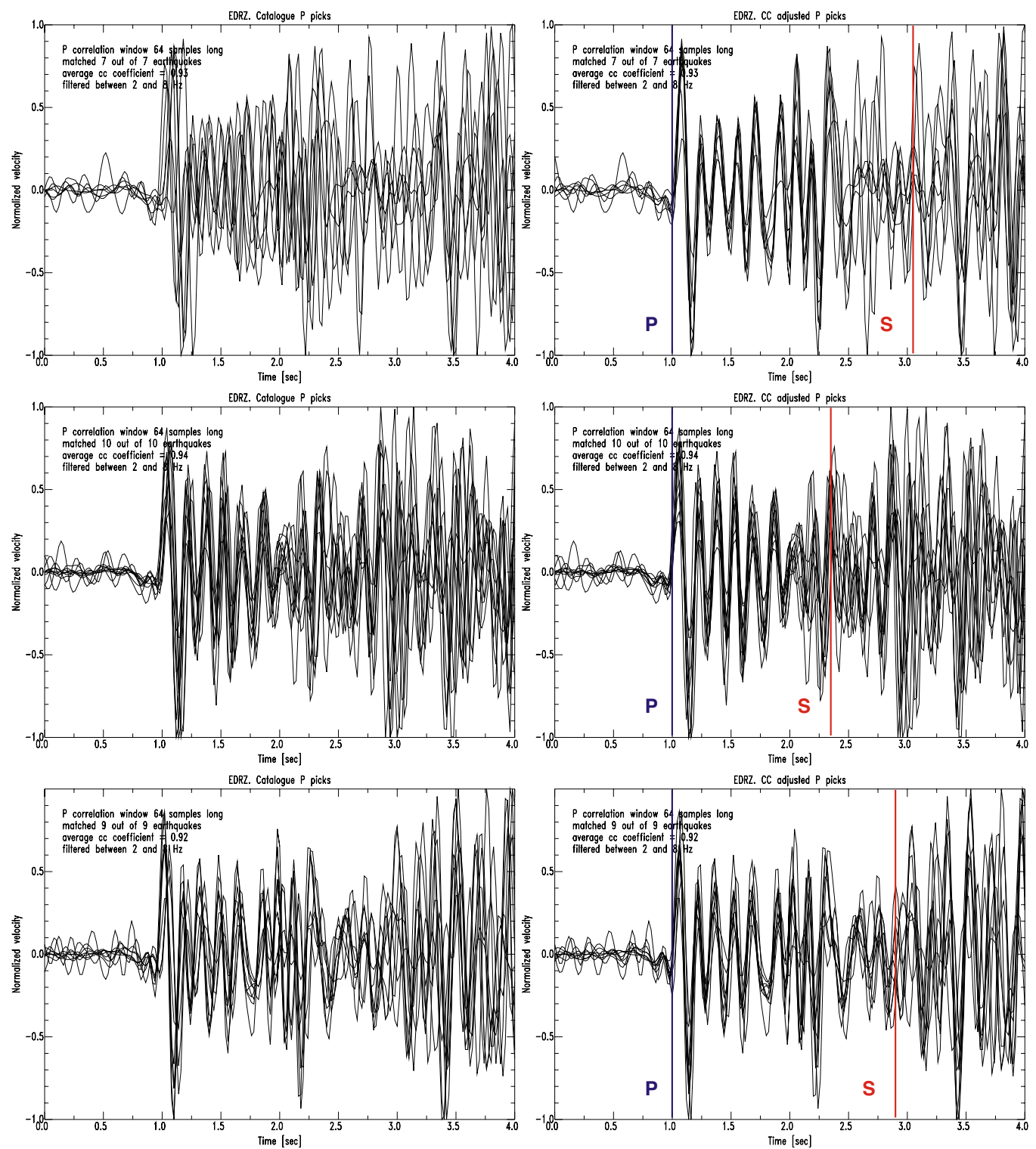

Figure 5.8: Filtered seismograms from the southern Okataina cluster (top, red circles in Figure 5.7), the Kawerau cluster (middle, brown triangles in Figure 5.7) and the northern Okataina cluster (bottom, yellow stars in Figure 5.7). The seismograms were recorded at station EDRZ (Edgecumbe, see Figure 2.1). The overlain traces are aligned using (left) catalogued $\mathrm{P}$-wave arrival time picks, and (right) arrival times that have been adjusted using cross-correlation. The plotted S-wave arrival time is estimated using the median picked S-P time for these seismograms. The clusters consist of (top) 7, (middle) 10 and (bottom) 9 events. Of these, 5, 7 and 7 events, respectively, have been relocated. 


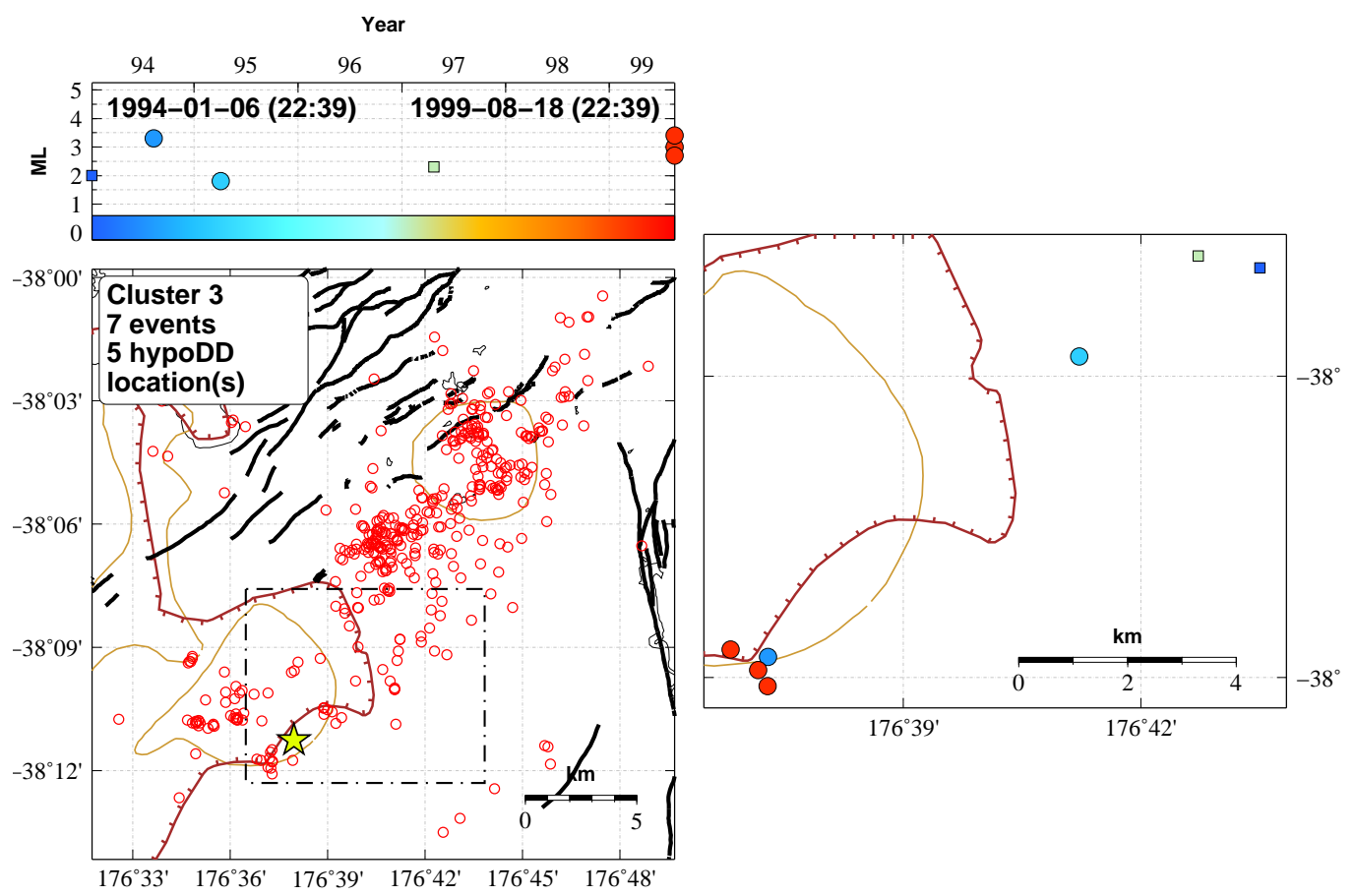

Figure 5.9: The southern Okataina cluster. top: Magnitude versus time. left: Epicentres for all relocated events. The dashed black box surrounds the cluster. The yellow star is the cluster centroid. right: Clustered epicentres. Circles mark relocated epicentres while squares mark catalogue locations for earthquakes that are not relocated. Symbol colours show earthquake timing (see colour scale). Calderas (brown hachured lines), lakes (thin black lines), faults (thick black lines) and geothermal areas (yellow lines) are shown.

rest of their clusters and there is no reason to believe their double-difference locations are in error to the extent suggested above. The similarity of the seismograms recorded by station EDRZ is likely due to these events sharing similar source mechanisms and their seismic waves sampling similar seismic velocities as they travel to station EDRZ. 


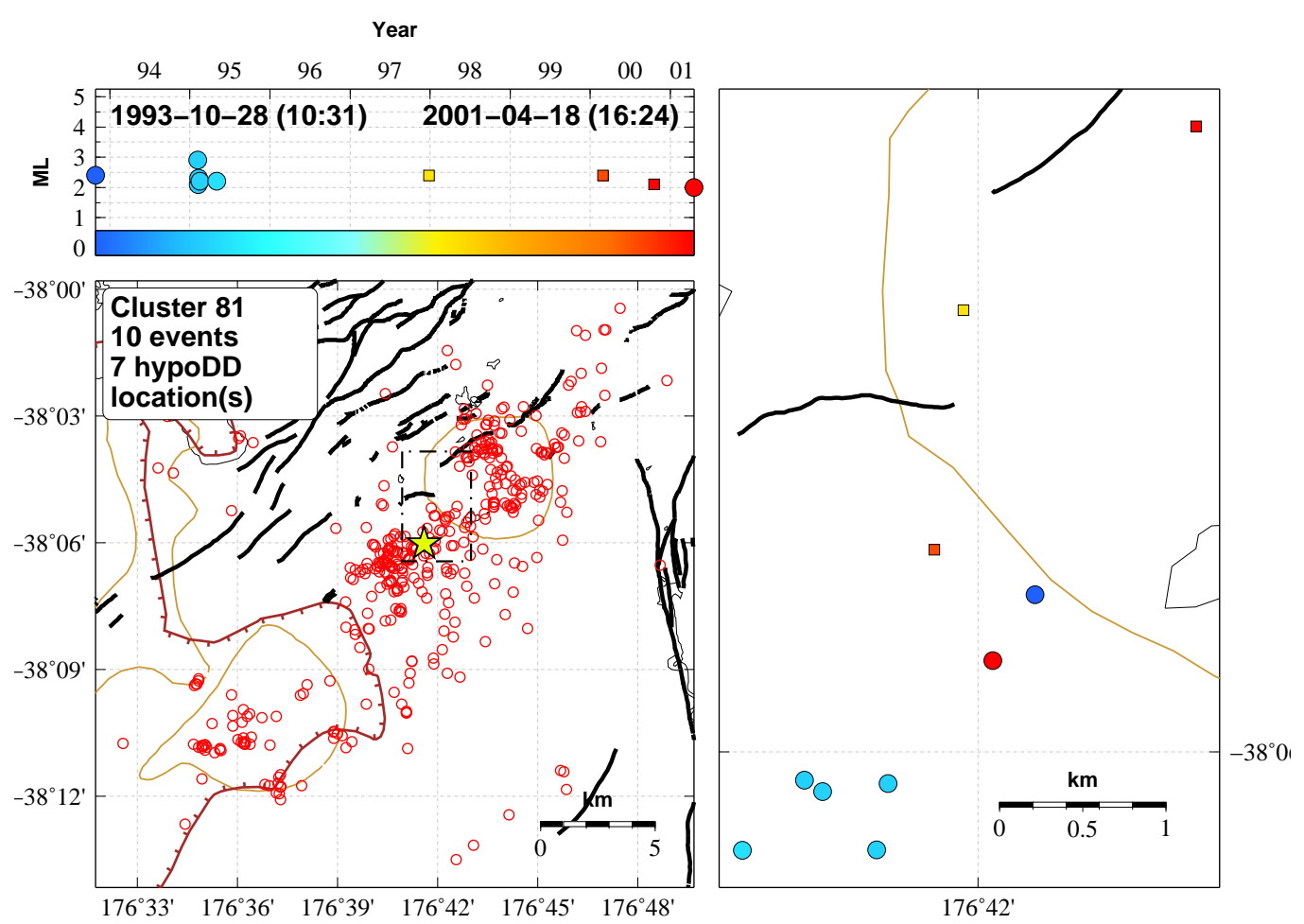

Figure 5.10: The Kawerau cluster. top: Magnitude versus time. left: Epicentres for all relocated events. The dashed black box surrounds the cluster. The yellow star is the cluster centroid. right: Clustered epicentres. Circles mark relocated epicentres while squares mark catalogue locations for earthquakes that are not relocated. Symbol colours show earthquake timing (see colour scale). Calderas (brown hachured lines), lakes (thin black lines), faults (thick black lines) and geothermal areas (yellow lines) are shown.

\subsubsection{Summary}

By applying hierarchical clustering to cross-correlation coefficient data for Rotorua and Kawerau, we have been able to identify clusters of similar events in each of our two earthquake sets. In Rotorua, the earthquakes appear to cluster primarily into large families of small events located just north of Rotorua City. These clusters are long-lived sequences of repeating similar earthquakes spread throughout the duration of this study. The Rotorua 


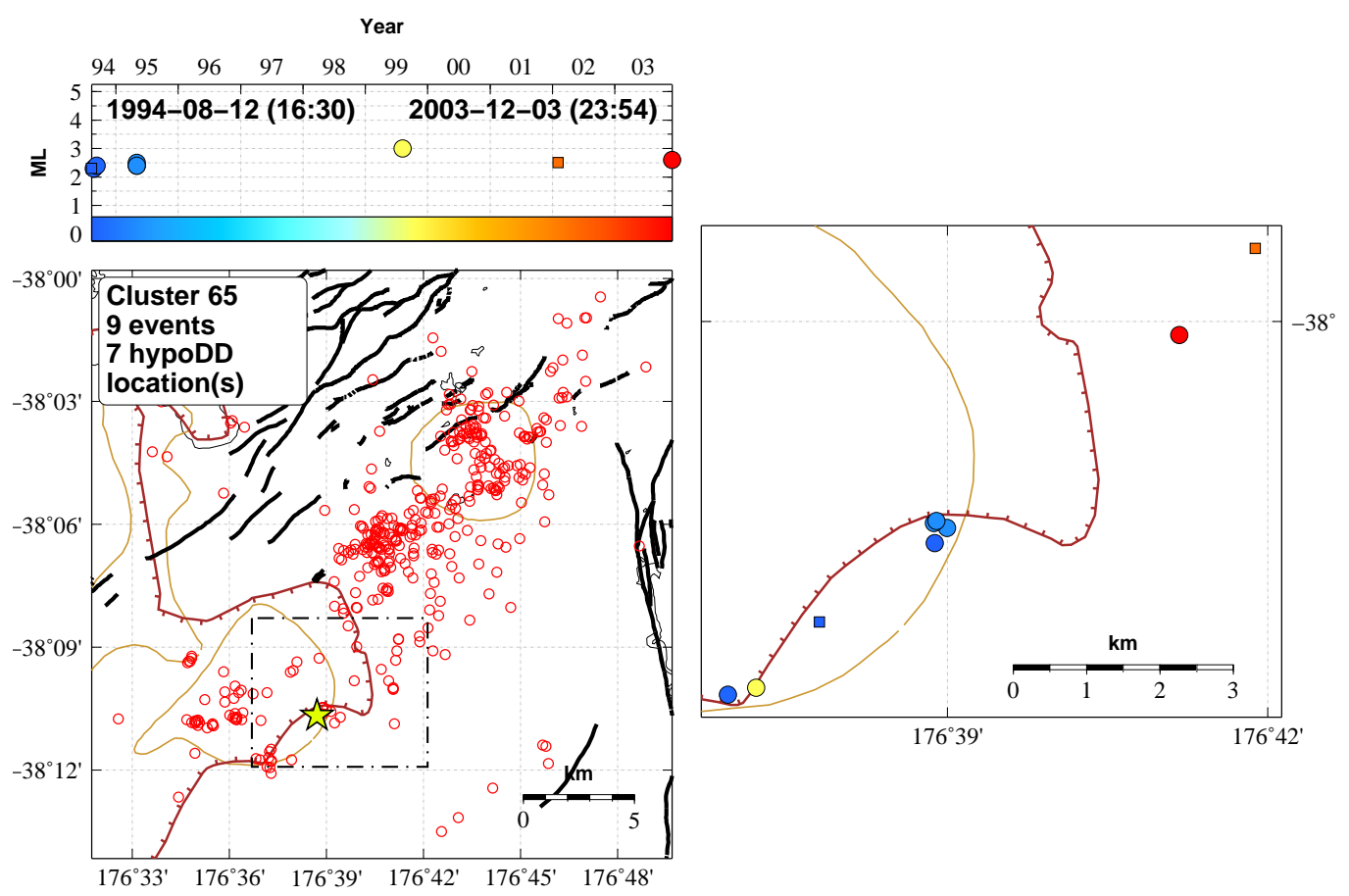

Figure 5.11: The northern Okataina cluster. top: Magnitude versus time. left: Epicentres for all relocated events. The dashed black box surrounds the cluster. The yellow star is the cluster centroid. right: Clustered epicentres. Circles mark relocated epicentres while squares mark catalogue locations for earthquakes that are not relocated. Symbol colours show earthquake timing (see colour scale). Calderas (brown hachured lines), lakes (thin black lines), faults (thick black lines) and geothermal areas (yellow lines) are shown.

earthquake set also contains short-lived bursts of seismicity, particularly beneath Mount Ngongotaha and at the northwestern edge of Rotorua caldera.

In Kawerau, the performance of the clustering is not as reliable; loosely related earthquakes appear to produce similar seismograms at station EDRZ. Many clusters, however, consist of almost identical events with very similar double-difference locations. We do not identify any long-lived clusters in Kawerau. Instead, the relocated Kawerau earthquake set mainly consists of shorts bursts of seismicity and earthquake doublets located throughout the 
region.

Prejean (2002) clearly observe diffusion-like seismicity patterns in the Long Valley caldera in California, where the propagation of magmaticallyderived fluids are traced by the locations of the earthquakes that are triggered. While fewer earthquakes are recorded in Kawerau and Rotorua, and even fewer are able to be located with great accuracy, the pattern of spasmodic and tightly clustered earthquakes are suggestive of similar processes operating within these geothermal areas.

\subsection{Focal mechanism determination}

We have attempted to calculate focal mechanisms for the earthquake clusters described in section 5.2. These clusters consist of earthquakes with highly similar seismograms as recorded at stations UTU and EDRZ for Rotorua and Kawerau, respectively. Based on this similarity, we deem these earthquakes to have similar source mechanisms. This means that $\mathrm{P}$-wave first motion polarity observations for earthquakes within each cluster can be collectively used to determine focal mechanisms on a cluster by cluster basis. While these earthquakes may have only a few polarity observations each, the combined set of polarities for an entire cluster may be enough for a focal mechanism to be determined. Further, because we simultaneously inspect all seismograms for a cluster at each station, first motion polarities that were hitherto ambiguous can become more obvious and subsequently be used to better constrain the focal mechanisms. 


\subsubsection{Focal mechanism method}

The use of numerous small earthquakes to constrain a single "composite" focal mechanism is a practice that has been applied with various degrees of success in the past, including studies of earthquake swarms in the Taupo Volcanic Zone (e.g. Hunt and Latter, 1982; Webb et al., 1986). The underlying assumption is that the events share a common focal mechanism. This assumption is usually based on the similarity of earthquake locations and the timing of the swarm in question. We assume that the focal mechanisms for earthquakes within the clusters we identify are the same, but our assumption is based on the the similarity of waveforms recorded at stations UTU and EDRZ as described in Section 5.2. We compute focal mechanisms for four of these clusters using the following procedure:

First, we simultaneously inspect raw vertical component seismograms on a station by station basis and pick P-wave first motion polarities. If the earthquakes within a cluster all have the same location and focal mechanism, then the P-wave polarities at each station should be consistent. We only pick first motion polarities when the majority of earthquakes recorded at each station have the same apparent polarity. Some stations, however, may have reversed vertical components, and an upward first motion may appear to be downward or vice versa. We use the list of station polarity reversals compiled for New Zealand seismograph stations (Hurst, 2007, pers. comm.) to identify reversed polarities and adjust the first motion picks accordingly. We assume that stations that do not have listed polarities are not reversed at any time. 
A location is then calculated for each cluster from which to calculate azimuths and takeoff angles for P-waves to each station. This is taken as the centroid of the double-difference-relocated earthquakes within each cluster. These locations are shown as yellow stars in Figures 5.4, 5.9, 5.10 and 5.11 for the four clusters for which we ultimately obtain focal mechanisms.

We obtain P-wave azimuths and takeoff angles using the procedure Hash (Hardebeck and Shearer, 2005) and the seismic velocity models we obtain in Chapter 3 (Tables 3.4 and 3.5). Because these earthquakes are shallow, and there are few stations close to Rotorua and Kawerau, most of these takeoff angles sample the outer part of the focal sphere (takeoff angles near $90^{\circ}$ ), leaving the centre of the sphere (takeoff angles near $0^{\circ}$ or $180^{\circ}$ ) relatively sparsely populated.

If a cluster has 14 or more P-wave polarity observations, we compute a focal mechanism for it using the procedure Focmec (Snoke, 2003). This procedure performs a systematic grid search of all possible focal mechanism solutions. For each candidate focal mechanism, a theoretical P-wave first motion polarity is produced for each azimuth-takeoff angle pair in the first motion data set. If less than a specified number of theoretical polarities match those that have been observed, then the candidate mechanism is rejected as a solution. Using this technique, a set of solutions is obtained and a final mechanism is chosen if those solutions are consistent. The variability in the set of focal mechanism solutions provides an indication of how well the focal mechanism is constrained by the data, with highly variable solution sets indicating poorly constrained focal mechanisms. 


\subsubsection{Focal mechanism results}

Figure 5.12 shows focal mechanism solutions for the largest Rotorua earthquake cluster (top left), the southern Okataina cluster (top right), the Kawerau cluster (bottom left) and the northern Okataina cluster (bottom right) described in Section 5.2.3. The solutions (grey lines) are those that predict polarity errors in less than $10 \%$ of the $\mathrm{P}$-wave first motion data set. The final solution is chosen to have the median strike, dip and rake of the full set of solutions shown. These focal mechanism solutions are summarised in Table 5.2 .

\begin{tabular}{|c|l|c|c|c|c|}
\hline name & location & events & strike & dip & rake \\
\hline cluster 33 & Rotorua & 51 & 305 & 35 & -76 \\
cluster 3 & Okataina & 7 & 90 & 48 & -59 \\
cluster 81 & Kawerau & 10 & 88 & 41 & -73 \\
cluster 65 & Okataina & 9 & 288 & 50 & -30 \\
\hline
\end{tabular}

Table 5.2: Focal mechanism solutions for Rotorua and Kawerau. Strikes, dips and rakes are in degrees.

Figure 5.13 shows these focal mechanisms plotted alongside the relocated seismicity and known faults in the central Taupo Volcanic Zone. All three focal mechanisms in the Kawerau area are indicative of normal earthquake ruptures on east-northeast to northeast striking fault planes. These mechanisms are similar to the majority of those described by Hurst et al. (2002) for the Taupo Volcanic Zone, and also those of the 1987 Edgecumbe earthquake and its aftershocks (Anderson et al., 1990). The northeastern orientation and normal sense of these mechanisms are consistent with the observed northwest to southeast extension of the region (Darby and Meertens, 1995). The mechanism for the Kawerau cluster, however, is indicative of earthquakes rupturing 

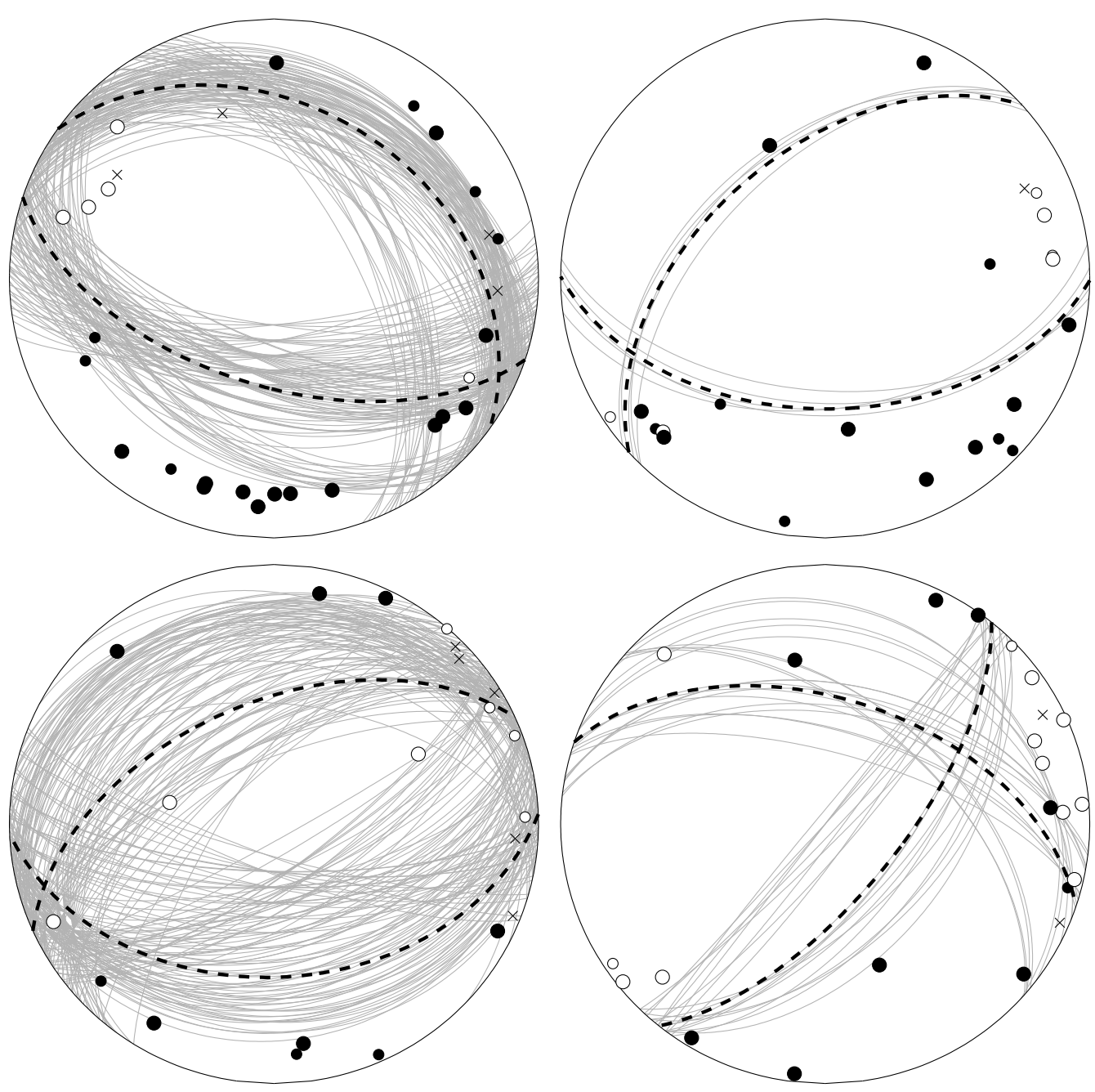

Figure 5.12: Focal mechanism solutions for the largest Rotorua cluster and three Kawerau clusters. The plots are lower-hemisphere zenithal equal area projections. Filled black circles are compressions, white circles are dilatations. Crosses are emergent $\mathrm{P}$-wave arrivals. Large symbols are impulsive P-wave onsets. Grey lines are acceptable solutions. Dashed lines show the median solution. The clusters are: (top left) the largest Rotorua cluster (Figure 5.4), (top right) the southern Okataina cluster (Figure 5.9), (bottom left) the Kawerau cluster (Figure 5.10) and (bottom right) the northern Okataina cluster (Figure 5.11). 
on faults oriented in a more easterly direction than the strike of the faults in the nearby Taupo fault belt and the extension of the region would suggest. Hurst et al. (2002) observe that the normal mechanisms of the Taupo Volcanic Zone exhibit considerable variability in strike. This suggests that although the regional tectonics of the Taupo Volcanic Zone govern the nature in which earthquakes slip to first order, the orientations of the faults on which they slip are governed by local variations in rock strength and structure.

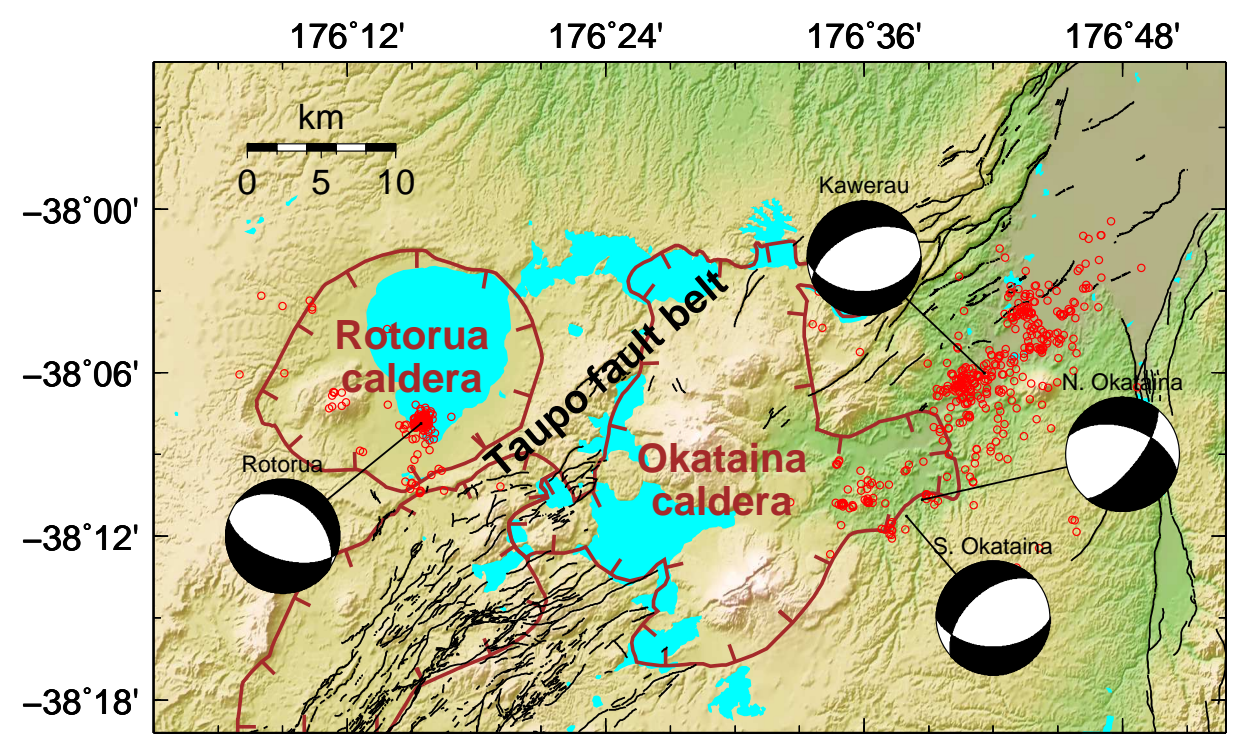

Figure 5.13: Focal mechanisms for Rotorua and Kawerau. Each mechanism is connected to the centroid of the cluster it pertains to. Also plotted are double-difference earthquake locations (red circles), calderas (brown hachured lines) and faults (black lines).

The focal mechanism for the largest Rotorua cluster is also normal, consistent with an extensional tectonic regime. This mechanism is similar to those obtained by (Darby and Meertens, 1995) for the same location. Unlike the Kawerau solutions, however, this mechanism is indicative of earthquake ruptures on southeast trending fault planes. Because Rotorua is located away 
from the Taupo fault belt, in the relatively quiet western part of the Taupo Volcanic Zone, it is likely that the orientations of fault ruptures are governed by local processes such as magmatism and caldera deformation.

\subsection{Summary}

We have analysed the spatial and temporal occurrence of earthquakes in Rotorua and Kawerau by applying a dendritic clustering technique to the cross-correlation coefficients obtained in Section 4.2. These clusters exhibit high waveform similarity and, in most cases, tightly constrained earthquake hypocentres. The clusters in Rotorua are dominated by long-lived sequences of similar earthquakes in the southern part of Lake Rotorua, although sporadic seismicity does occur in other parts of the region, such as beneath Mount Ngongotaha. The earthquake clusters we determine for Kawerau do not consist of as many earthquakes as those in Rotorua, and generally represent short-lived bursts of seismic activity.

We have managed to determine composite focal mechanisms for relatively few of these earthquake clusters using P-wave first motion polarities. Those that we do obtain, however, are consistent with those that have been observed in the central Taupo Volcanic Zone, and the extensional tectonics of the region. In these two cases, augmenting catalogued P-wave first motions on the basis of cross-correlation results has not enabled many more focal mechanisms to be calculated because the new polarities are tightly clustered in the focal sphere. 


\section{Chapter 6}

\section{Discussion and conclusions}

\section{1 $1-\mathrm{D}$ velocity models}

The earthquakes that rupture in and around Rotorua and Kawerau are small and have been recorded on a sparse network of primarily vertical-component seismometers. As a result, the set of catalogued earthquake locations for Rotorua and Kawerau exhibit significant scatter, limiting their usefulness for the interpretation of seismogenic structures and processes in these two geothermal areas. Although the Rotorua seismograph network is growing, and numerous temporary networks have been deployed in the Taupo Volcanic Zone over the past two decades, little work has been done to accurately relocate these archived sets of shallow earthquakes.

We have estimated seismic velocities beneath Rotorua and Kawerau using large sets of linearized hypocentre-velocity model inversions. The "minimum" 1-D P- and S-wave velocity models (Kissling, 1988) we obtain are well resolved at seismogenic depths in these two regions. To explore the full 
range of velocity models constrained by earthquake data in these areas, we applied the inversion 1000 times to the two data sets, each time using a different randomly generated starting model. The variation in $\mathrm{P}$ - and S-wave velocities for each layer have enabled us to quantify the effect that different starting models have on the solutions we obtain and to identify where the models are well constrained.

These models are not well constrained at depths shallower than around $4 \mathrm{~km}$ : at these depths, the calculated velocities assume a bimodal distribution (Figures 3.4 and 3.5), suggesting the seismic rays are affected by two distinct shallow geological environments. Within the Taupo Volcanic Zone the shallow velocities should be relatively low (Stratford and Stern, 2006) as basement rocks are buried beneath around $2 \mathrm{~km}$ of seismically slow volcanic material (Wilson et al., 1995). To the east and west of the Taupo Volcanic Zone, however, the basement outcrops, producing faster shallow Pand S-wave velocities. This distribution is evident in the accompanying set of P- and S-wave station correction terms (Figures 3.10, 3.11, 3.23 and 3.24), where relatively fast velocities (yellow symbols) are sampled to the east and west of the Taupo Volcanic Zone.

Between 4 and $15 \mathrm{~km}$ depths, the velocities are better constrained (Figures 3.4 and 3.5 ), with small (less than $0.1 \mathrm{~km} / \mathrm{s}$ ) standard deviations in each set of 1000 solutions. This consistency is due to good ray coverage at these depths beneath Rotorua and Kawerau. We compare the P-wave velocity models we calculate with those obtained by Stratford and Stern (2006) who use active-source travel time data to model seismic velocities in the central North Island (Figure 3.25). Stratford and Stern (2006) observe that seismic 
velocities throughout the central North Island are significantly laterally heterogeneous. The best resolved (4 to $15 \mathrm{~km}$ depth) velocities in the $\mathrm{P}$-wave models we calculate are in accord with those that Stratford and Stern (2006) obtain for the Taupo Volcanic Zone. Deeper than $15 \mathrm{~km}$, however, the velocities we calculate increase with depth more slowly than those of Stratford and Stern (2006). Because only rays that travel to the most distant stations sample the deepest seismic velocities, this mismatch is likely due to the increased influence that geological structures outside the TVZ have on the velocities we calculate at these depths.

Deeper than $15 \mathrm{~km}$, the seismic velocities we calculate appear to be well defined, but are questionable as they are constrained by relatively few data. This is not a problem in studies such as this in which the final P- and Swave velocity models are used to calculate hypocentres for locally-observed earthquakes. While it is tempting to simply include more data from distant seismograph stations to improve resolution at depth, in a setting such as the central North Island, the velocities encountered by seismic waves as they travel to these stations may not be representative of those beneath the area being studied. The models we calculate are best constrained near seismogenic depths, suggesting a better way to improve the resolution of deep velocities in future studies would be to use earthquakes covering a wider range of focal depths (e.g., Reyners et al., 2006). In the Taupo Volcanic Zone, earthquakes tend only to occur at depths less than around $10 \mathrm{~km}$ (Bryan et al., 1999) and on the deep subducting Pacific plate. Reflected phases and converted deep phases may be used to improve the resolvability of deep velocities in future investigations. 


\subsection{Double-difference relocation}

\subsubsection{Waveform cross-correlation}

Archived phase travel time differences for pairs of earthquakes in Rotorua and Kawerau can be markedly improved through the careful application of waveform cross-correlation delay time estimation. Figures 4.8, 5.3 and 5.8 demonstrate how the alignment of vertical seismograms for sets of similar earthquakes is improved when $\mathrm{P}$-wave arrival time picks are adjusted using cross-correlation-derived delay times.

One advantage of the cross-correlation method of delay time estimation is that phase arrival times do not have to be known with great accuracy before the calculation is made. In many cases, an S-wave arrival time estimate based on a P-wave arrival time pick or vice versa is sufficient. However, these estimates can be in error by a significant amount if the $V_{P} / V_{S}$ ratio is not precisely known. For example, if $V_{P} / V_{S}$ is estimated with $5 \%$ uncertainty, then the S-wave travel time estimated by Equation 4.1 will have an uncertainty of at least $5 \%$. For a P-wave travel time of the order of $4 \mathrm{~s}$ and a $V_{P} / V_{S}$ ratio of 1.7, this amounts to an uncertainty of around $0.3 \mathrm{~s}$ in the S-wave estimate. This uncertainty increases when error in the $\mathrm{P}$-wave arrival time pick is considered. Moreover, Equation 4.1 is an approximate relationship which relies on the assumption that $V_{P} / V_{S}$ is constant with depth. Consequently, the possibility of cycle-skipped delay time measurements being made cannot be ruled out. However, because the P- and S- wave correlation time windows we use are wide compared to these errors, accurate delay time measurements should still be found even when highly uncertain arrival time estimates are 
used.

Not surprisingly, vertical-component S-wave seismograms do not lend themselves to cross-correlation delay time estimation as well as P-wave seismograms do, with only around one quarter of the resulting data set being made up of S-wave delay times (Figure 4.9). This is likely to be due to the degrading effect that uncertain arrival time picks and interfering P-coda waves have on S-wave cross-correlation measurements, especially on verticalcomponent seismograms.

A relatively high percentage $(53 \%$, see Figure 4.9$)$ of the Kawerau set of S-wave delay times are accompanied by low cross-correlation coefficients (between $c c^{l i m(l)}$ and $c c^{\text {lim }}$, see Section 4.2.1). This might suggest that the Kawerau earthquakes are not as similar as those in the Rotorua set. However, the two sets of P-wave correlation coefficients appear similar and make no such suggestion. Another explanation is that the S-wave arrivals in Kawerau are more contaminated by scattered P-coda waves than those in Rotorua. This scattering, however, should be the same so long as the earthquakes rupture in the same place and the along-path seismic velocity structure does not change. Because the Kawerau clusters occur over relatively short periods of time, it is likely that the hypocentres within them move as these clusters take place.

\subsubsection{Double-difference earthquake relocation}

By applying the double-difference method of earthquake relocation to cataloguebased and cross-correlation-derived travel time data, we have produced accu- 
rate images of the seismicity both in and around the Rotorua and Kawerau geothermal areas. The relocated earthquake hypocentres are more tightly clustered than their archived counterparts, and appear to coincide with known geological structures within each area.

In Rotorua, the earthquakes collapse into three distinct areas of seismicity (Figure 4.18). The most active of these is located in the southern part of Lake Rotorua just north of Rotorua City, while a second group of earthquakes are located south of Rotorua City near Whakarewarewa and a third is located to the west of Rotorua beneath Mount Ngongotaha (Figure 1.2). These areas coincide with the two Rotorua City rhyolite domes and the Mount Ngongotaha rhyolite dome, respectively (Wood, 1992; Hunt, 1992). In Kawerau the relocated earthquakes appear to align in a broad northeastward trending zone of seismicity (Figure 4.19). Within the Kawerau geothermal field, these earthquakes align in two parallel northeast-striking features, the northernmost of which appears to match mapped faults within the area (Figure 1.3). In Okataina caldera, the relocated hypocentres are deeper and collapse into several discrete source areas.

Based on the mismatch between the hypocentres we obtain for Kawerau using two inversion techniques (LSQR and SVD, Section 2.3.3) we estimate that the uncertainties in the earthquake locations are of the order of hundreds of metres in each coordinate direction. This is an indication of the level of uncertainty in the resolved hypocentres. A better way to assess the true uncertainty would be to use Monte Carlo-style tests to gauge the effects that different velocity models, data types, inversion control parameters and station distributions have on the final set of locations that are obtained. We 
suggest this as a future avenue of research.

\subsection{Spatiotemporal patterns and focal mech- anism determination}

\subsubsection{Earthquake clustering}

We have applied hierarchical clustering to the cross-correlation data we obtained in Section 4.2 to identify clusters of similar earthquakes in Rotorua and Kawerau. Based on the similarity of their seismograms at stations UTU and EDRZ, we infer that the earthquakes within these clusters have similar locations and similar source mechanisms.

The clusters we identify for Rotorua are dominated by two large clusters in the southern part of Lake Rotorua (Figures 5.4 and 5.5), which persist over the entire period of time spanned by the earthquake data. These clusters are made up of sequences of similar earthquakes which rupture in the same source area. Further analysis of the seismograms from such clusters may reveal temporal changes in the processes that cause these earthquakes and the local velocity structure near Rotorua. Another cluster in the Rotorua earthquake set occurs beneath Mount Ngongotaha. Here, the clustered earthquakes take place over a relatively short period of time, indicating that the seismicity there is more sporadic than in Rotorua City.

The relocated earthquake hypocentres for the largest Rotorua cluster are far less scattered than those for the same earthquakes in the earthquake catalogue (Figure 5.4). Because this cluster consists of earthquakes which 
are likely to have occurred in roughly the same location, this implies the hypocentres we have calculated are a significant improvement to those contained in the catalogue, which may be in error by 2 to $3 \mathrm{~km}$ in each coordinate direction (Table 5.1).

The clustering results for Kawerau reveal no long-lived sequences of similar events, with smaller clusters dominating the data set. Again, these clusters are more sporadic than those in Rotorua City.

Some of the clusters in Kawerau contain events which appear to have been erroneously linked to groups of other genuinely similar earthquakes (Figures 5.9 and 5.11). This is likely due to the apparent similarity of small earthquakes with simple and short-lived source functions. Although these earthquakes might be quite different in nature or rupture on different asperities on different faults, they may generate highly similar seismograms at a common station provided they are reasonably close together.

For future investigations, a more robust way to cluster earthquakes might be to consider their cross-correlation coefficients at more than one seismograph station. If an earthquake is linked to another by data from one station but not the others, then it is probable that that link is erroneous and the earthquakes are not as similar as suggested by that station's seismograms. On the other hand, if an earthquake is not linked to another at one station, but is at several others, then there may have been a change in the velocity structure along the path between those earthquakes and that station. 


\subsubsection{Focal mechanism determination}

The determination of focal mechanisms for shallow earthquakes using archived data in Rotorua and Kawerau has proved a difficult task, limited primarily by the number of stations in the TVZ at any time. By amalgamating P-wave first motion observations within clusters of earthquakes, we have been able to determine a total of four composite focal mechanisms for Rotorua and Kawerau.

We compute three focal mechanisms in the Kawerau area and one in Rotorua (Figure 5.12). Two of the Kawerau focal mechanisms are for clusters that occurred on the eastern boundary of Okataina caldera (Figures 5.9 and 5.11). These focal mechanisms are both dip-slip in nature and indicate these earthquakes ruptured on east-northeast striking normal faults. Such faults are consistent with an extensional tectonic regime, but their strikes are more easterly than those of mapped faults in the area and the orientation one would expect in a region of south-eastward extension (Darby and Meertens, 1995). This suggests the orientation of these faults is controlled by local geological features such as the boundary of the Okataina caldera. The third focal mechanism is for a cluster of earthquakes just south of Kawerau (Figure 5.10) and exhibits a similar orientation to the Okataina solutions.

The Rotorua focal mechanism is for the largest of the Rotorua earthquake clusters, which has relocated hypocentres in the southern part of Lake Rotorua (Figure 5.4). Like the Kawerau solutions, this dip-slip mechanism indicates that these earthquakes are extensional in nature. Unlike the Kawerau solutions, however, this mechanism suggests these earthquake ruptured 
on an east-southeast striking normal fault. This is similar to the results of Hurst et al. (2002), who use data from a dense seismometer array deployment in 1995 to determine focal mechanisms throughout the TVZ.

As mentioned above, the major limiting factor on our ability to constrain focal mechanisms in Rotorua and Kawerau is the availability of P-wave first motion data. Of course, the best way to overcome this problem is to deploy a dense array of seismograph stations throughout the region. This, however, is not always feasible, so other ways around the problem need to be found. The method we use to determine focal mechanisms on a cluster by cluster basis increases the number of observations available to constrain a solution if different earthquakes within each cluster are observed by different stations. The first motion data, however, are usually restricted to observations made at stations in the Rotorua and New Zealand seismograph networks (Figure 2.1). We are able to find focal mechanisms for clusters which contain earthquakes that occur during the temporary deployment of dense seismograph arrays in the region. This means the focal mechanisms we obtain may be dominated by data from relatively few of the clustered earthquakes.

Another way to constrain focal mechanisms is to use S- to P-wave amplitude ratio measurements as well as $\mathrm{P}$-wave first motion polarities. These data, however, require careful treatment as the emergence angles of their respective seismic waves must be well known in order that the effects that the free surface of Earth have on amplitudes can be corrected for (Snoke, 2003). Moreover, Hardebeck and Shearer (2003) find that the level of noise inherent in S- to P-wave amplitude ratio data limit their usefulness when constraining focal mechanisms for small earthquakes. S- to P-wave ratios have helped to 
constrain focal mechanisms in the TVZ in the past using data from dense temporary seismograph deployments (e.g. Hurst et al., 2002). With careful application, S- to $\mathrm{P}$-wave amplitude ratios measured on routinely archived seismograms may also be used to calculate or at least verify focal mechanisms in Rotorua and Kawerau.

\subsection{Conclusions and suggestions for future work}

The following conclusions can be drawn based on the work we have undertaken to relocate and cluster earthquakes in Rotorua and Kawerau, and the observations and issues discussed in this chapter.

- Reliable 1-D seismic velocity models can be determined using archived arrival time data in Rotorua and Kawerau. Between around 4 and $15 \mathrm{~km}$ depths, the velocity models are well constrained and are consistent with those determined for the same region using active-source seismology and passive-source 3-D tomography.

- Precise delay times can be found for Rotorua and Kawerau earthquake pairs measured at common stations using waveform cross-correlation of archived seismograms. These delay times are clearly more accurate than those that are calculated using catalogue data alone.

- We have determined accurate hypocentres for archived earthquakes in Rotorua and Kawerau using the double-difference method of relocation. In Rotorua, these locations coincide with known geological structures, 
while in Kawerau they delineate a northeast trending zone of seismic activity.

- Many of the relocated earthquakes in Rotorua occur in a small area in the southern part of Lake Rotorua. These earthquakes have very similar sources and are extensional in nature. These earthquakes define a continuing sequence of seismicity that has been occurring for at least 15 years and may be useful as a repeating source of nearly identical seismic waves in future seismological studies of the area. Note, however, that the small number of relocated events and limited time spanned by the catalogue has not enabled us to detect any large scale changes within the geothermal system in response to borehole closures.

- The catalogued locations for earthquakes in Rotorua have typical uncertainties of 2 to $3 \mathrm{~km}$ in the east, north and depth directions. We base this estimation on the scatter in catalogue locations for a cluster of similar events in this area.

Waveform cross-correlation provides a means of measuring precise delay times and identifying clusters of similar events within earthquake catalogues. Cross-correlation measurements also provide insight into the evolution of earthquake clusters and the seismic velocity structure in which they occur. In future investigations, it may be interesting to explore how the similarity of earthquake seismograms changes within clusters of similar events (e.g., Schaff and Beroza, 2004). Such changes may indicate that the nature of along-path scattering between earthquakes and the stations that record them has changed. This may be due to changes in the local velocity structure or 
slight differences in these earthquakes' locations. If seismograms for these events are aligned on their cross-correlation-adjusted P-wave arrivals, it may be possible to detect systematic changes in S-wave arrival times. If the clustered earthquakes rupture in a similar way, such behaviour would indicate that their hypocentres are migrating or path effects are changing. If so, the locations of these earthquakes can be used to trace transient fluctuations in stress due to the movement of fluids or the effects of previous earthquakes along faults. 


\section{Bibliography}

Allis, R. G. (1997). Natural state and response to development of Kawerau geothermal field, New Zealand. In GRC Transactions, volume 21, pages $3-10$.

Allis, R. G., Currie, S. A., Leaver, J. D., and Sherburn, S. (1985). Results of injection testing at Wairakei geotherml field, New Zealand. In GRC Transactions, pages 289-294.

Allis, R. G. and Lumb, J. T. (1992). The Rotorua geothermal field, New Zealand: its physical setting, hydrology and response to exploitation. Geothermics, 21:7-24.

Anderson, H., Smith, E., and Robinson, R. (1990). Normal faulting in a back arc basin: Seismological characteristics of the March 2, 1987, Edgecumbe, New Zealand, earthquake. Journal of Geophysical Research, 95(B4):47094723.

Barani, S., Ferretti, G., Massa, M., and Spallarossa, D. (2007). The waveform similarity approach to identify dependent events in instrumental seismic catalogues. Geophysical Journal International, 168(1):100-108. 
Beavan, J., Tregoning, P., Bevis, M., Kato, T., and Meertens, C. (2002). Motion and rigidity of the Pacific plate and implications for plate boundary deformation. Journal of Geophysical Research B: Solid Earth, 107(B10):2261.

Bibby, H. M., Caldwell, T. G., Davey, F. J., and Webb, T. H. (1995). Geophysical evidence on the structure of the Taupo Volcanic Zone and its hydrothermal circulation. Journal of Volcanology and Geothermal Research, $68: 29-58$.

Bibby, H. M., Dawson, G. B., Rayner, H. H., Bennie, S. L., and Bromley, C. J. (1992). Electrical resistivity and magnetic investigations of the geothermal systems in the Rotorua area, New Zealand. Geothermics, 21(1-2):43-64.

Bignall, G. and Harvey, C. C. (2005). Geoscientific review of the Kawerau geothermal field. Technical report, Institute of Geological and Nuclear Sciences.

Bryan, C. J., Sherburn, S., Bibby, H. M., Bannister, S. C., and Hurst, A. W. (1999). Shallow seismicity of the Central Volcanic Zone, New Zealand: its distribution and nature. New Zealand Journal of Geology and Geophysics, $42: 533-542$

Caliński, T. and Harabasz, J. (1974). A dendrite method for cluster analysis. Communications in statistics, 3:1-27.

Cattaneo, M., Augliera, P., Spallarossa, D., and Lanza, V. (1999). A waveform similarity approach to investigate seismicity patterns. Natural hazards, 19:123-138. 
Chatterjee, S. N., Pitt, A. M., and Iyer, H. M. (1985). $V_{p} / V_{s}$ ratios in the Yellowstone National Park region, Wyoming. Journal of Volcanology and Geothermal Research, 26(3-4):213-230.

Darby, D. J. and Meertens, C. M. (1995). Terrestrial and GPS measurements of deformation across the Taupo back arc and Hikurangi forearc regions in New Zealand. Journal of Geophysical Research, 100(B5):8221-8232.

Du, W. and Thurber, C. H. (2004). BCSEIS (Bispectrum Cross-Correlation package for SEISmic events). Department of Geology \& Geophysics, University of Wisconsin-Madison.

Du, W., Thurber, C. H., and Eberhart-Phillips, D. (2004). Earthquake relocation using cross-correlation time delay estimates verified with the bispectrum method. Bulletin of the Seismological Society of America, 94(3):856866.

Evans, K. F., Moriya, H., Niitsuma, H., Jones, R. H., Phillips, W. S., Genter, A., Sausse, J., Jung, R., and Baria, R. (2005). Microseismicity and permeability enhancement of hydrogeologic structures during massive fluid injections into granite at $3 \mathrm{~km}$ depth at the Soultz HDR site. Geophysical Journal International, 160(1):388-412.

Everitt, B. (1974). Cluster analysis. Heinemann Educational, London.

Geller, R. J. and Mueller, C. S. (1980). Four similar earthquakes in Central California. Geophysical Research Letters, 7(10):821-824.

Hampel, F. R., Ronchetti, E. M., Rousseeuw, P. J., and Stahel, W. A. (1986). 
Robust statistics : the approach based on influence functions. John Wiley, New York.

Hanks, T. C. and Boore, D. M. (1984). Moment-magnitude relations in theory and practice. Journal of Geophysical Research, 89(B7):6229-6235.

Hansen, S. E., Schwartz, S. Y., DeShon, H. R., and González, V. (2006). Earthquake relocation and focal mechanism determination using waveform cross correlation, Nicoya Peninsula, Costa Rica. Bulletin of the Seismological Society of America, 96(3):1003-1011.

Hardebeck, J. L. and Shearer, P. M. (2003). Using S/P amplitude ratios to constrain the focal mechanisms of small earthquakes. Bulletin of the Seismological Society of America, 93(6):2434-2444.

Hardebeck, J. L. and Shearer, P. M. (2005). HASH: a FORTRAN program for computing earthquake first motion focal mechanisms. United States Geological Survey.

Harris, R. A. (1998). Introduction to special section: Stress triggers, stress shadows, and implications for seismic hazard. Journal of Geophysical Research, 103(B10):24347-24358.

Hayes, G., Reyners, M., and Stuart, G. (2004). The Waiouru, New Zealand, earthquake swarm: Persistent mid crustal activity near an active volcano. Geophysical Research Letters, 31.

Hole, J. K., Stevens, N. F., and Wadge, G. (2005). Surface deformation at 
rotorua, new zealand measured by ers insar, 1996-2003. In ESA Special Publication, pages 941-946.

Hubbert, M. and Rubey, W. (1959). Role of fluid pressure in mechanics of overthrust faulting. Geological Society of America Bulletin, 70:115-166.

Hunt, T. M. (1992). Gravity anomalies, caldera structure, and subsurface geology in the Rotorua area, New Zealand. Geothermics, 21(1/2):65-74.

Hunt, T. M. and Latter, J. H. (1982). A survey of seismic activity near Wairakei Geothermal Field New Zealand. Journal of Volcanology and Geothermal Research, 14:319-334.

Hurst, A. W., Bibby, H. M., and Robinson, R. R. (2002). Earthquake focal mechanisms in the central Taupo Volcanic Zone and their relation to faulting and deformation. New Zealand Journal of Geology and Geophysics, 45(4):527-536.

Kanasewich, E. R. (1981). Time sequence analysis in geeophysics. The University off Alberta press, Edmonton, Alberta, Canada.

Kaypak, B. and Eyidoğan, H. (2005). One-Dimensional crustal structure of the Erzincan basin, Eastern Turkey and relocations of the 1992 Erzincan earthquake $(M s=6.8)$ aftershock sequence. Physics of the Earth and Planetary Interiors, 151:1-20.

Kissling, E. (1988). Geotomography with local earthquake data. Reviews of geophysics, 26(4):659-698. 
Kissling, E. (1995). Velest user's guide. Institute of Geophysics, ETH Zuerich.

Kissling, E., Ellsworth, W., Eberhart-Phillips, D., and Kradolfer, U. (1994). Initial reference models in seismic tomography. Journal of Geophysical Research, 99:19635-19646.

Kisslinger, C. and Engdahl, E. R. (1973). The interpretation of the Wadati diagram with relaxed assumptions. Bulletin of the Seismological Society of America, 63(5):1723-1736.

Lamarche, G. (1992). Seismic reflection survey in the geothermal field of the Rototrua caldera, New Zealand. Geothermics, 21(1/2):109-119.

Lamarche, G. and Lebrun, J. F. (2000). Transition from strike-slip faulting to oblique subduction: Active tectonics at the Puysegur margin, South New Zealand. Tectonophysics, 316(1-2):67-89.

Lippitsch, R., White, R. S., and Soosalu, H. (2005). Precise hypocentre relocation of microearthquakes in a high-temperature geothermal field: the Torfajökull central volcano, Iceland. Geophysical Journal International, 160:370-387.

Lomax, A., J., V., Volant, P., and Berge, C. (2000). Probabilistic earthquake location in 3D and layered models: Introduction of a Metropolis-Gibbs method and comparison with linear locations. In Thurber, C. and Rabinowitz, N., editors, Advances in Seismic Event Location, pages 101-134. Kluwer, Amsterdam. 
Menke, W. and Schaff, D. (2004). Absolute earthquake locations with differential data. Bulletin of the Seismological Society of America, 94:2254-2264.

Nakahara, H. (2004). Correlation distance of waveforms for closely located events-I. Implication of heterogeneous structure around the source region of the 1995 Hyogo-Ken Nanbu, Japan, earthquake $\left(M_{W}=6.9\right)$. Geophysical Journal International, 157:1255-1268.

Nicholson, T., Clarke, D., and Townend, J. (2007). Regional earthquake location using empirical travel times in a region of strong lateral velocity heterogeneity. Geophysical Journal International. submitted.

Nicholson, T., Sambridge, M., and Gudmundsson, Ó. (2004). Threedimensional empirical traveltimes: construstion and applications. Geophysical Journal International, 156:307-328.

Paige, C. C. and Saunders, M. A. (1982). LSQR: An algorithm for sparse linear equations and sparse least squares. ACM Transactions on Mathematical Software, 8(1):43-71.

Poupinet, G., Ellsworth, W. L., and Frecchet, J. (1984). Monitoring veloccity variations in the crust using earthquake doublets: an application to the Calaveras Fault, California. Journal of Geophysical Research, 89(B7):5719-5731.

Prejean, S., Ellsworth, W., Zoback, M., and Waldhauser, F. (2002). Fault structure and kinematics of the Long Valley Caldera region, California, revealed by high-accuracy earthquake hypocenters and focal mechanism stress inversions. Journal of Geophysical Research, 107(B12):2355. 
Prejean, S. G. (2002). The interaction of tectonic and magmatic processes in the Long Valley caldera, California. PhD thesis, Stanford University.

Reyners, M. (1998). Plate coupling and the hazard of large subduction thrust earthquakes at the Hikurangi subduction zone, New Zealand. New Zealand Journal of Geology and Geophysics, 41(4):343-354.

Reyners, M., Eberhart-Phillips, D., Stuart, G., and Nishimura, Y. (2006). Imaging subduction from the trench to $300 \mathrm{~km}$ depth beneath the central North Island, New Zealand, with $V_{P}$ and $V_{P} / V_{S}$. Geophysical Journal International, 165(2):565-583.

Richards-Dinger, K. B. and Shearer, P. M. (2000). Earthquake locations in southern California obtained using source-specific station terms. Journal of Geophysical Research, 105(B5):10939-10960.

Richardson, W. P. (1989). The Matata earthquake of 1977 May 31: a recent event near Edgecumbe, Bay of Plenty, New Zealand. New Zealand Journal of Geology and Geophysics, 32(1):17-30.

Robinson, R. (1989). Aftershocks of the 1987 Edgecumbe earthquake, New Zealand: seismological and structural studies using portable seismographs in the epicentral region. New Zealand Journal of Geology and Geophysics, $32: 61-72$.

Rowe, C. A., Thurber, C. H., and White, R. A. (2004). Dome growth behavior at Soufriere Hills Volcano, Montserrat, revealed by relocation of volcanic event swarms, 1995-1996. Journal of Volcanology and Geothermal Research, 134:199-221. 
Rowlands, D. (2004). Seismic investigations of active volcanoes in extensional tectonic settings. $\mathrm{PhD}$ thesis, University of Cambridge.

Schaff, D. P. and Beroza, G. C. (2004). Coseismic and postseismic velocity changes measured by repeating earthquakes. Journal of Geophysical Research B: Solid Earth, 109(10):B10302 1-14.

Schaff, D. P., Bokelmann, G. H., Ellsworth, W. L., Zanzerkia, E., Waldhauser, F., and Beroza, G. C. (2004). Optimizing correlation techniques for improved earthquake location. Bulletin of the Seismological Society of America, 94(2):705-721.

Schaff, D. P., Bokelmann, G. H. R., Beroza, G. C., Waldhauser, F., and Ellsworth, W. L. (2002). High-resolution image of Calaveras Fault seismicity. Journal of Geophysical Research, 107(B9):2186.

Schaff, D. P. and Waldhauser, F. (2005). Waveform cross-correlation-based differential travel-time measurements at the Northern California seismic network. Bulletin of the Seismological Society of America, 95(6):24462461.

Scott, B. J., Gordon, A. G., and Cody, A. D. (2005). Recovery of the Rotorua geothermal field, New Zealand: Progress, issues and consequences. Geothermics, 34:161-185.

Sherburn, S. (1992). Characteristics of earthquake sequences in the Central Volcanic Region, New Zealand. New Zealand Journal of Geology and Geophysics, 35(1):57-68. 
Sherburn, S., Bannister, S., and Bibby, H. (2003). Seismic velocity structure of the Central Volcanic Zone, New Zealand, from local earthquake tomography. Journal of Volcanology and Geothermal Research, 122:69-88.

Sibson, R. H. and Rowland, J. V. (2003). Stress, fluid pressure and structural permeability in seismogenic crust, North Island, New Zealand. Geophysical Journal International, 154(2):584-594.

Snoke, L. A. (2003). FOCMEC: FOCal MEChanism determinations. Virginia Tech.

Stark, M. (1990). Imaging injected water in the Geysers reservoir using microearthquake data. In GRC Transactions, volume 14, pages 1697-1704.

Stratford, W. R. and Stern, T. A. (2006). Crust and upper mantle structure of a continental backarc: central North Island, New Zealand. Geophysical Journal International, 166(1):469-484.

Sutherland, R., Berryman, K., and Norris, R. (2006). Quaternary slip rate and geomorphology of the Alpine fault: Implications for kinematics and seismic hazard in southwest New Zealand. Bulletin of the Geological Society of America, 118(3-4):464-474.

Teanby, N. A., Kendall, J. M., and van der Baan, M. (2004). Automation of shear-wave splitting measurements using cluster analysis. Bulletin of the Seismological Society of America, 94(2):453-463.

Townend, J. and Zoback, M. D. (2000). How faulting keeps the crust strong. Geology, 28(5):399-402. 
Villamor, P. and Berryman, K. (2001). A late quaternary extension rate in the Taupo Volcanic Zone, New Zealand, derived from fault slip data. New Zealand Journal of Geology and Geophysics, 44(2):243-269.

Waldhauser, F. (2001). hypoDD - A Program to compute double-difference hypocenter locations. U.S Geological Survey.

Waldhauser, F. and Ellsworth, W. (2000). A double-difference earthquake location algorithm: method and application to the Northern Hayward fault, California. Bulletin of the Seismological Society of America, 90:1353-1368.

Wallace, L. M., Beavan, J., McCaffrey, R., and Darby, D. (2004). Subduction zone coupling and tectonic block rotations in the North Island, New Zealand. Journal of Geophysical Research, 109(B12):1-21.

Webb, T. H., Ferris, B. G., and Harris, J. S. (1986). The Lake Taupo, New Zealand, earthquake swarms of 1983. New Zealand Journal of Geology and Geophysics, 29(4):377-389.

Wilson, C. J. N., Houghton, B. F., McWilliams, M. O., Lanphere, M. A., Weaver, S. D., and Briggs, R. M. (1995). Volcanic and structural evolution of Taupo Volcanic Zone, New Zealand: a review. Journal of Volcanology and Geothermal Research, 68:1-28.

Wood, C. P. (1992). Geology of the Rotorua geothermal system. Geothermics, $21(1 / 2): 25-41$.

Wood, C. P., Brathwaite, R. L., and Rosenberg, M. D. (2001). Basement 
structure, lithology and permeability at Kawerau and Ohaaki geothermal fields, New Zealand. Geothermics, 30:461-481. 
Appendix A

One-dimensional velocity model estimation 

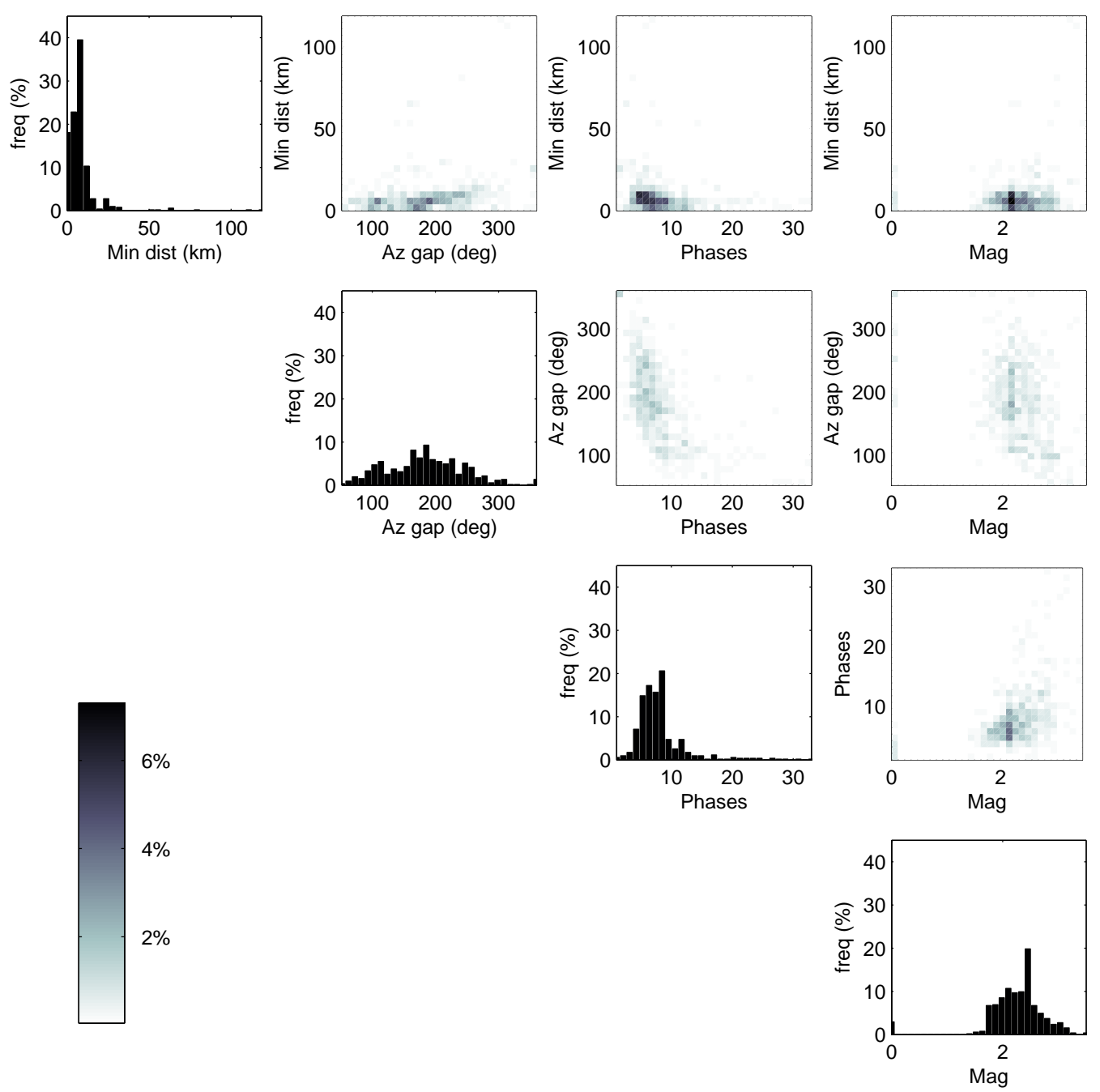

Figure A.1: Earthquake quality indicators for all 504 Rotorua earthquakes. Histograms (on diagonal) show (left to right) distance to the nearest station, maximum azimuthal gap, number of observations and magnitude. Off diagonal panels compare distributions of these paremeters. 

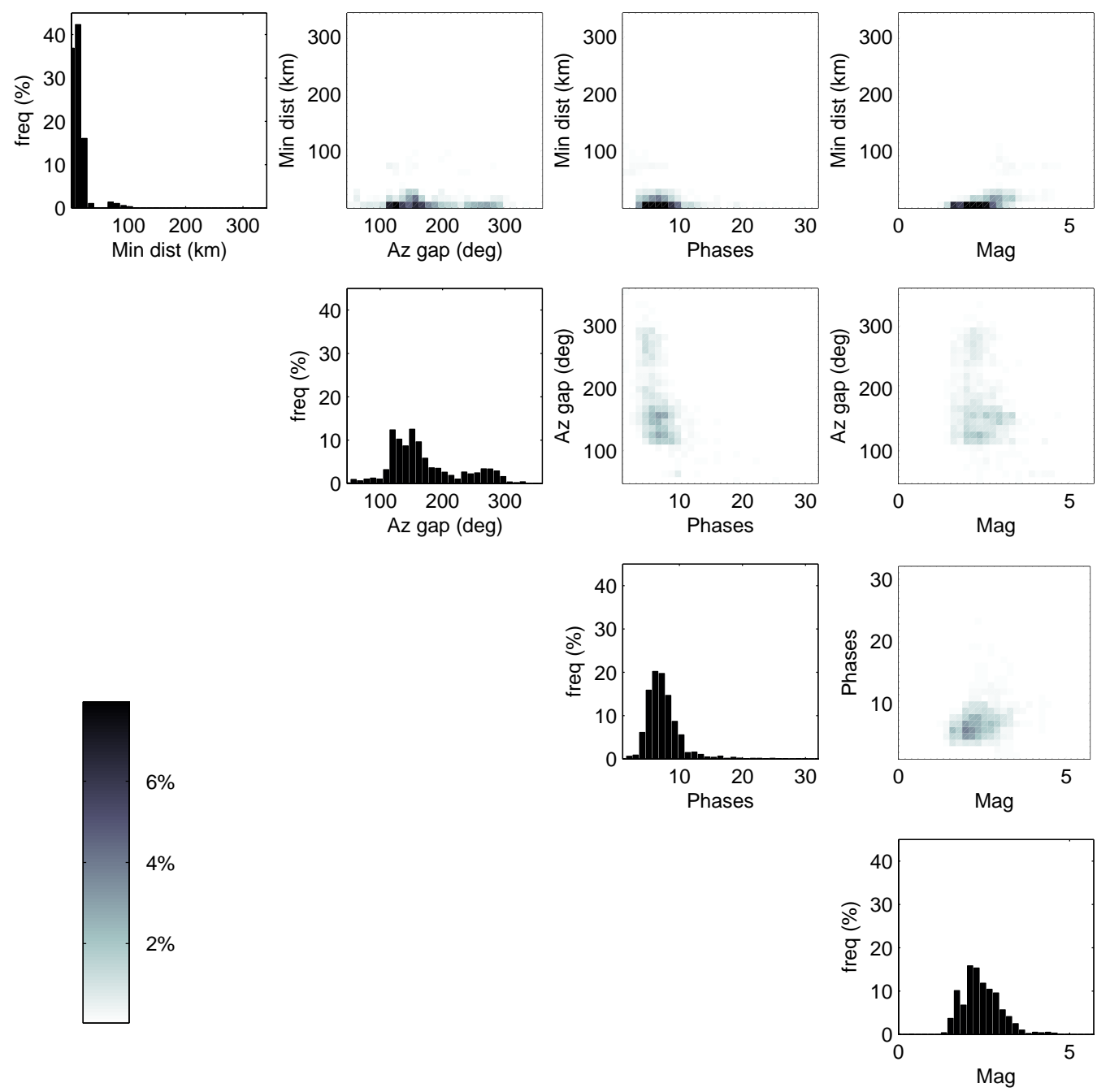

Figure A.2: Earthquake quality indicators for all 1875 Kawerau earthquakes. Histograms (on diagonal) show (left to right) distance to the nearest station, maximum azimuthal gap, number of observations and magnitude. Off diagonal panels compare distributions of these parameters. 

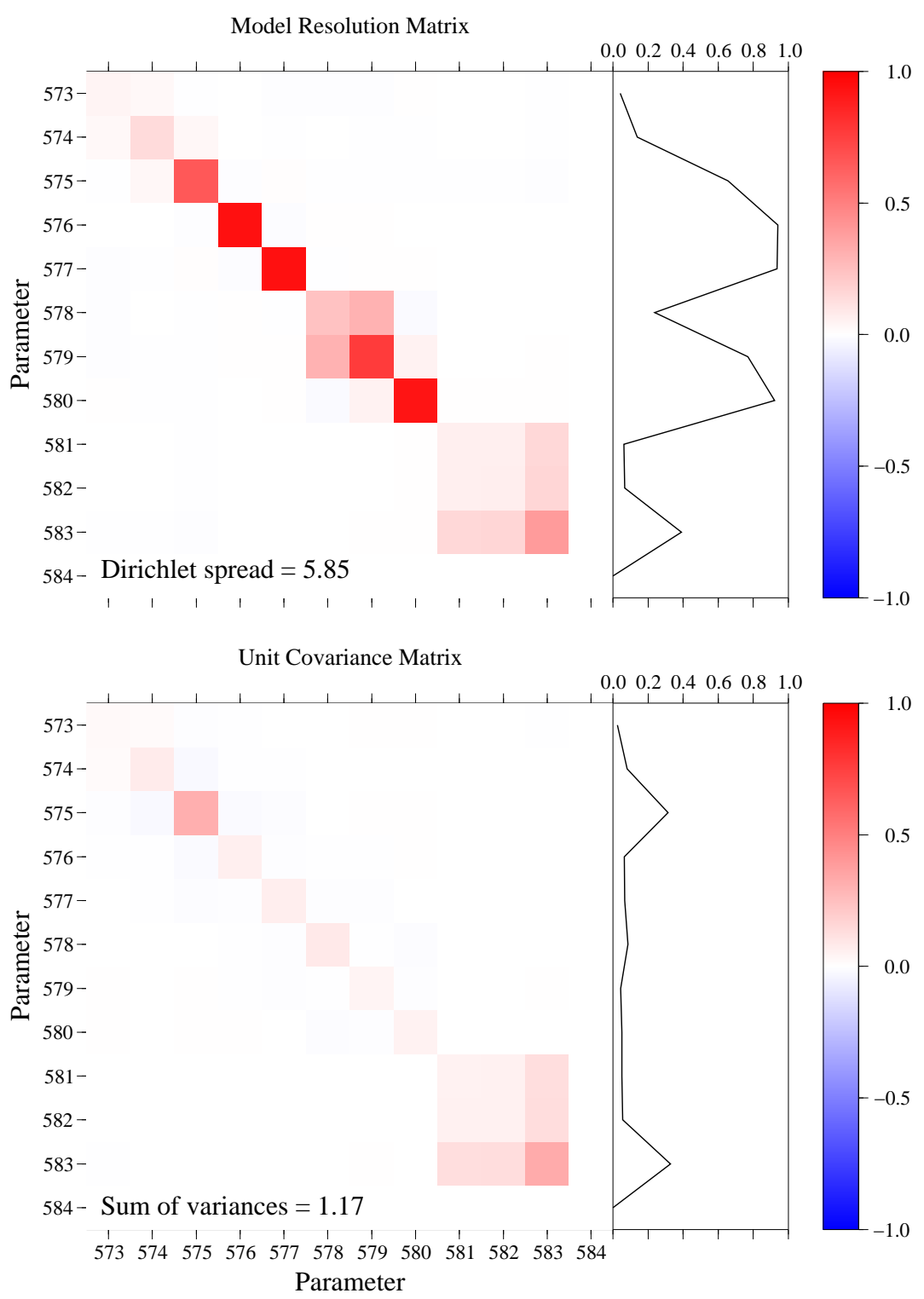

Figure A.3: Model resolution (top) and covariance (bottom) matrices for the Rotorua P-wave modelling earthquake set. The twelve parameters are layer velocities with the shallowest layer at the top left hand corner of each matrix. The right hand panels graph the diagonal terms of each matrix. Velocities are well constrained for layers with both high resolution and low variance. 

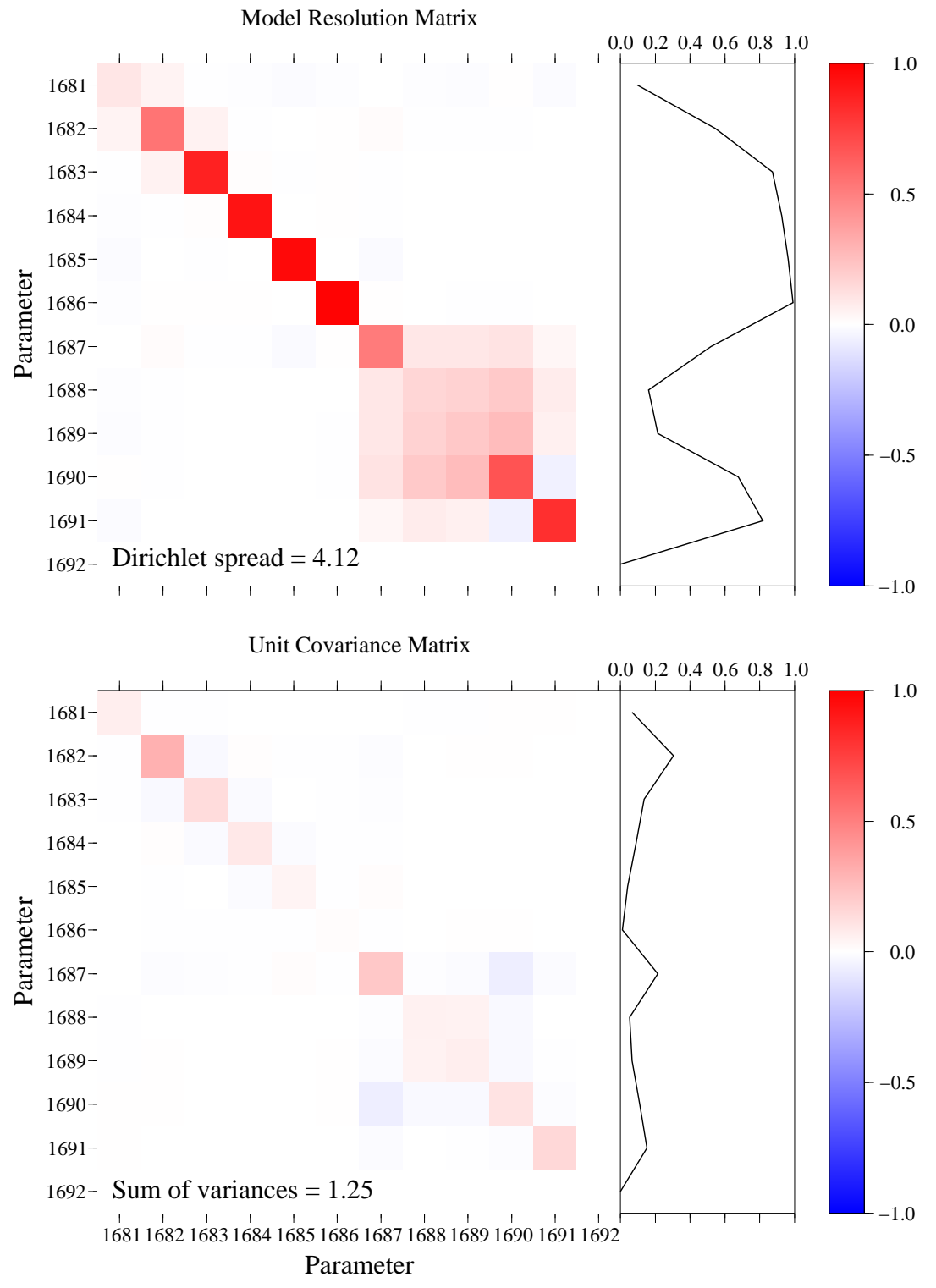

Figure A.4: Model resolution (top) and covariance (bottom) matrices for the Kawerau P-wave modelling earthquake set. The twelve parameters are layer velocities with the shallowest layer at the top left hand corner of each matrix. The right hand panels graph the diagonal terms of each matrix. Velocities are well constrained for layers with both high resolution and low variance. 


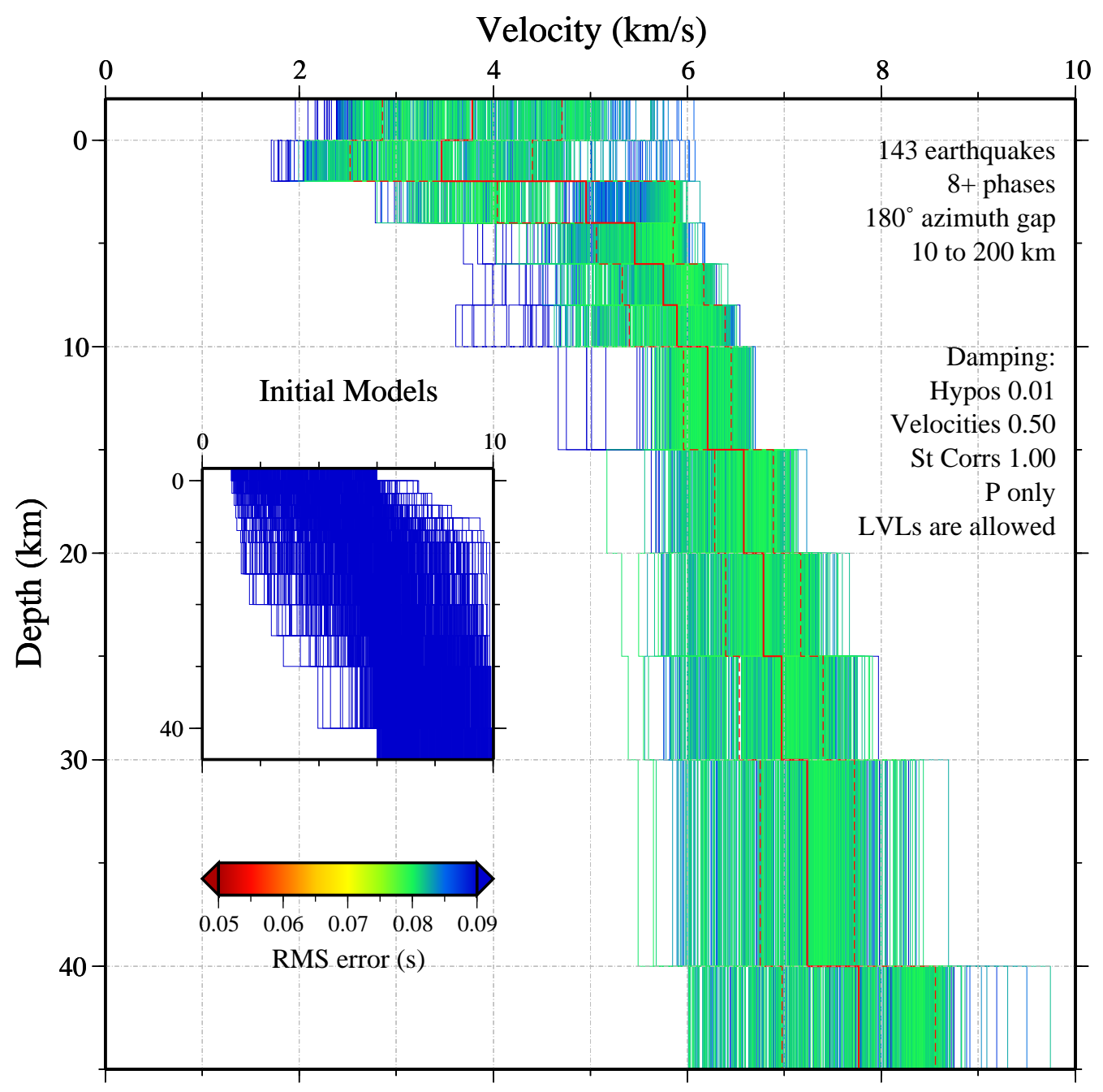

Figure A.5: 1000 P-wave velocity models for Rotorua generated by Velest with the restriction on low velocity layers (LVLs) removed. Earthquake selection criteria and Velest control parameters are listed. The inset shows the distribution of input random models. The solid red line shows the mean velocity for each layer, bound by one standard deviation (dashed red lines). 


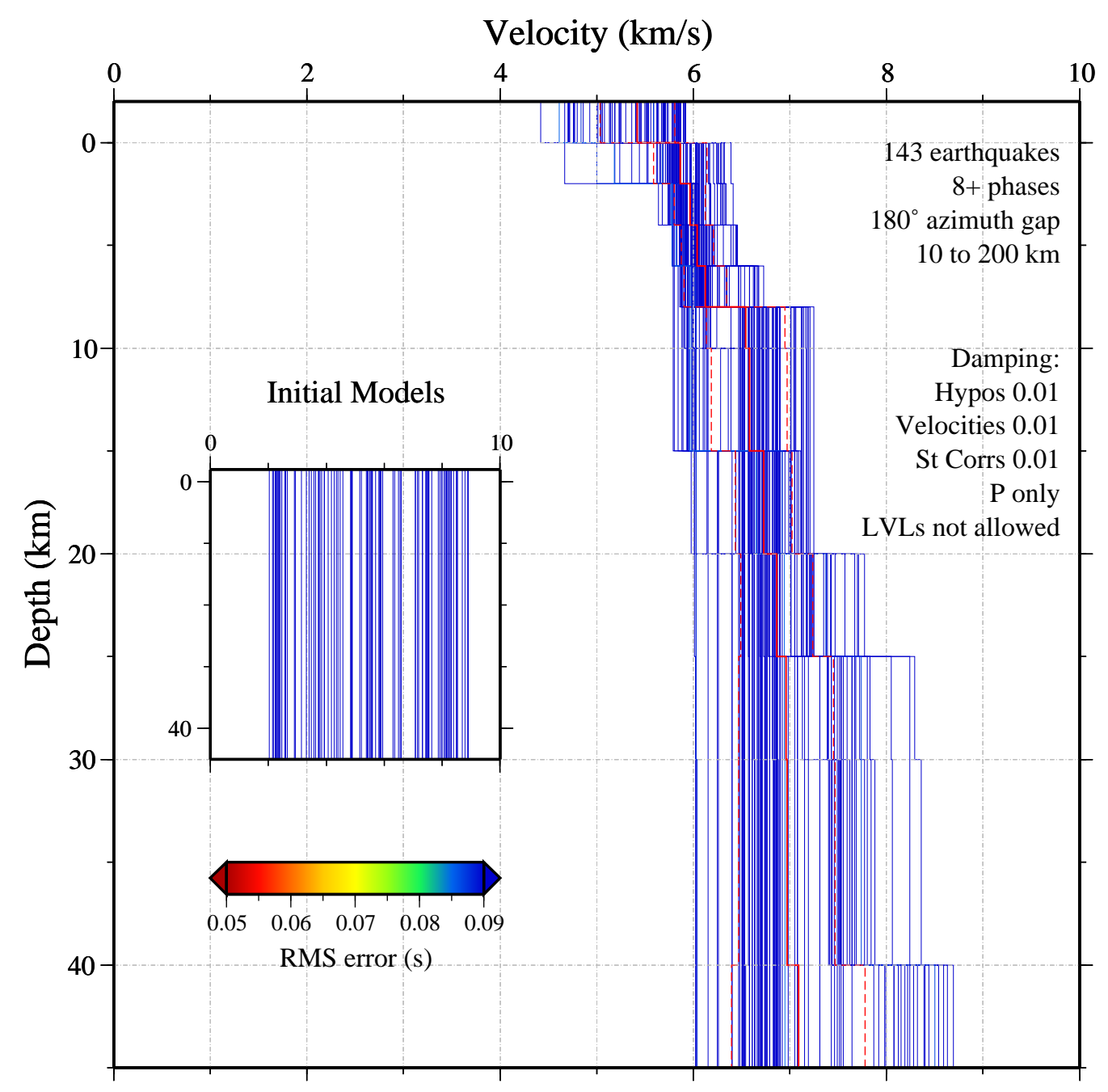

Figure A.6: 100 P-wave velocity models for Rotorua generated by Velest coloured according to the earthquake misfit they produce. Earthquake selection criteria and Velest control parameters are listed. The inset shows the distribution of constant input models. The solid red line shows the mean velocity for each layer, bound by one standard deviation (dashed red lines). 


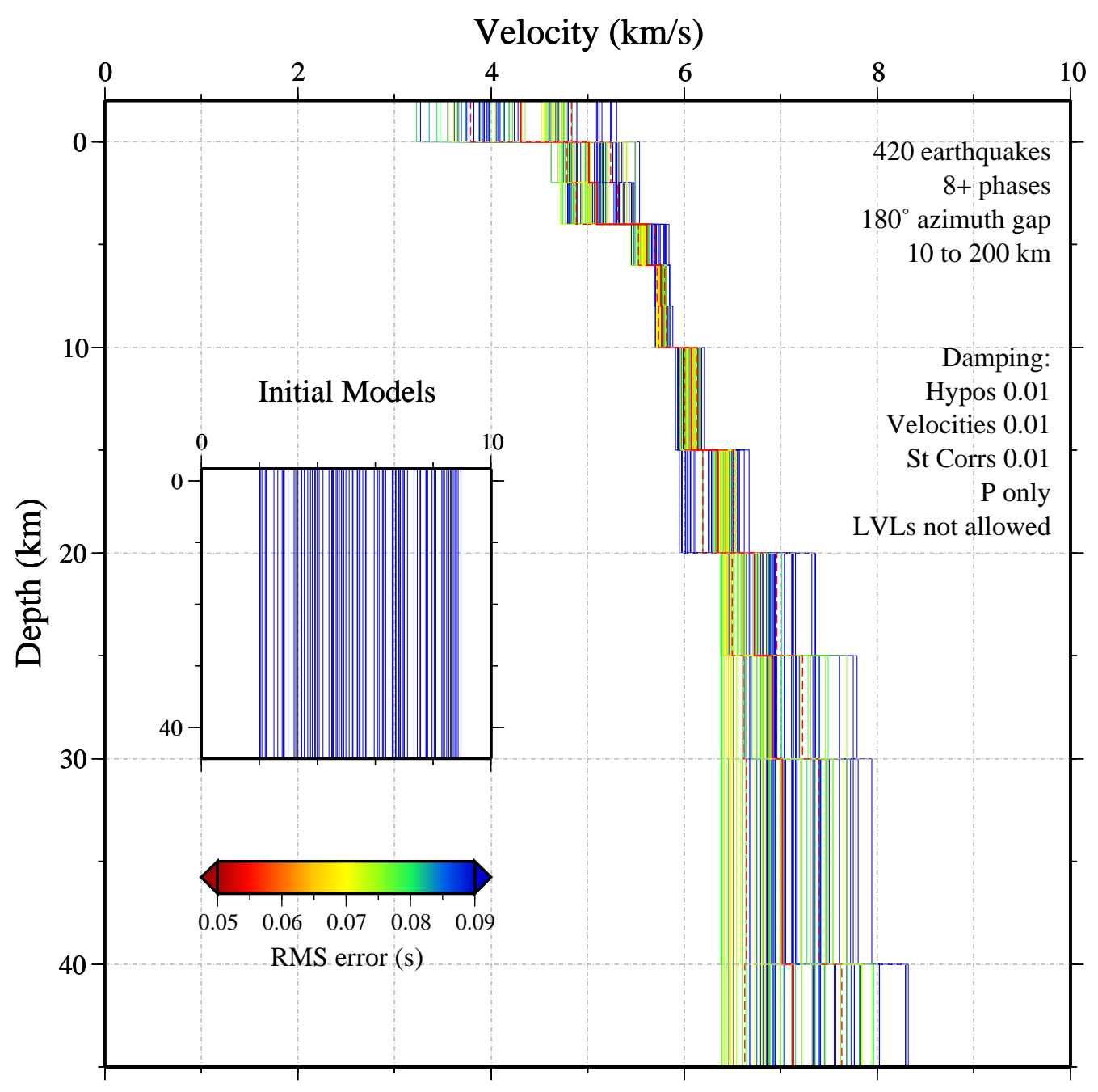

Figure A.7: 100 P-wave velocity models for Kawerau generated by Velest coloured according to the earthquake misfit they produce. Earthquake selection criteria and Velest control parameters are listed. The inset shows the distribution of constant input models. The solid red line shows the mean velocity for each layer, bound by one standard deviation (dashed red lines). 
Appendix B

\section{Double-difference relocation}




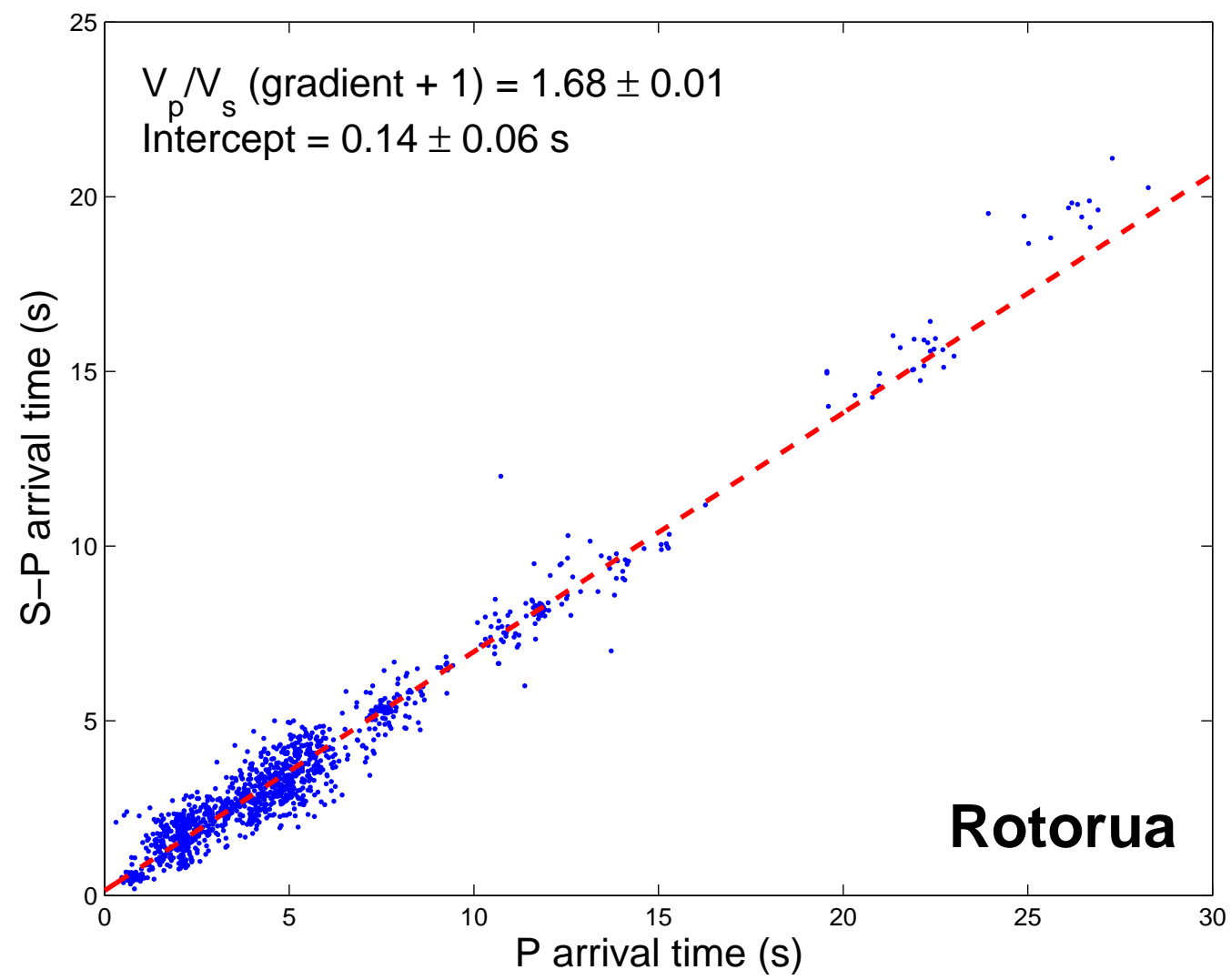

Figure B.1: A Wadati diagram constructed from all P- and S-wave arrival time pairs in the Rotorua arrival time catalogue. The gradient and intercept are listed along with $99 \%$ confidence ranges. 


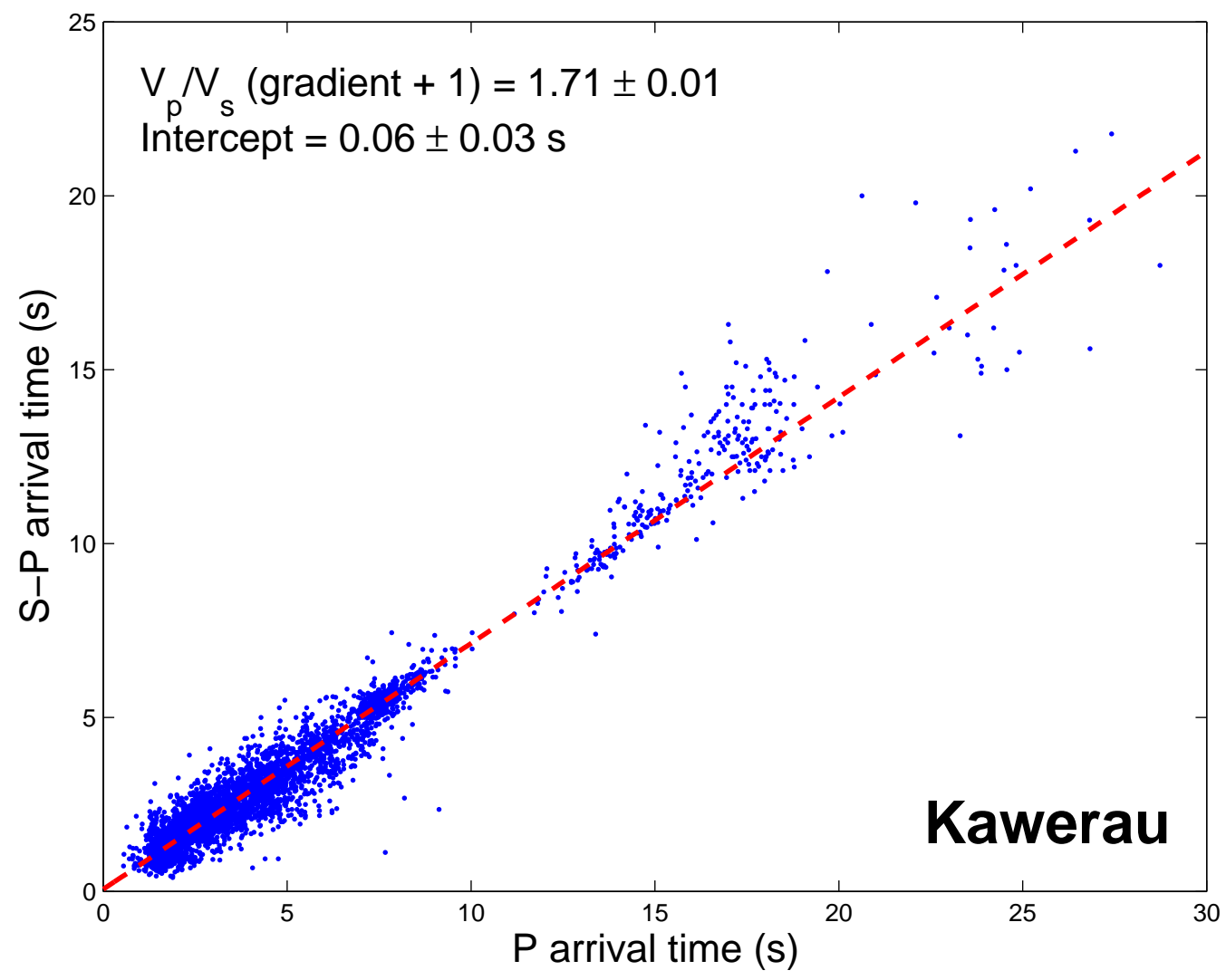

Figure B.2: A Wadati diagram constructed from all P- and S-wave pairs in the Kawerau arrival time catalogue. The gradient and intercept are listed along with $99 \%$ confidence ranges. 